\title{
Revisión taxonómica del género Meriania (Melastomataceae) en Colombia
}

\section{Taxonomic review of the genus Meriania (Melastomataceae) in Colombia}

\section{Acta Botanica Mexicana}

\author{
Humberto Mendoza-Cifuentes ${ }^{1,2}$ (1)
}

\section{Resumen:}

Antecedentes y Objetivos: El género Meriania cuenta con 120 especies neotropicales, 51 de ellas en Colombia. En este trabajo se aborda la revisión taxonómica del género para Colombia; se documentan especies, subespecies y sinónimos nuevos.

Métodos: Se revisaron y evaluaron 660 ejemplares de Meriania de 24 herbarios de Colombia, Ecuador, Estados Unidos de América e Inglaterra y se consultaron los protólogos e imágenes de ejemplares tipo en JSTOR Global Plants de las especies presentes en Colombia. Se establece una descripción detallada del género, una clave de identificación, descripciones, ilustraciones, mapas de distribución y categorías de amenaza para cada una de las especies presentes en Colombia.

Resultados clave: Meriania se caracteriza por presentar pétalos $\geq 9 \mathrm{~mm}$ de largo, estambres no geniculados, anteras en estambres opositipétalos con poros dorsalmente inclinados, frutos capsulares y semillas con embrión recto. Se describen dos especies nuevas ( $M$. neillii y $M$. ramosii) y tres subespecies nuevas de M. macrophylla (M. macrophylla subsp. antioquiensis, M. macrophylla subsp. franciscana y M. macrophylla subsp. peltata). Se establecen 18 sinónimos nuevos y se realizan 19 lectotipificaciones. Las especies en Colombia se distribuyen en la región Andina (34 spp.), en la Sierra Nevada de Santa Marta (2 spp.) y en el Escudo Guayanés-Orinoquia ( 2 spp.), entre 100 y 3700 m s.n.m. Se documenta la categoría de amenaza para 31 especies, mientras que seis no se categorizaron por su mayor distribución en otros países.

Conclusiones: Con la presente revisión, Meriania queda constituido por 102 especies, 37 de ellas presentes en Colombia. Las andinas (33 spp.) se pueden considerar dentro del grupo de Meriania s.s., mientras que cuatro de zonas bajas del Magdalena Medio y Escudo Guayanés-Orinoquia, podrían considerarse a futuro como géneros distintos con base en caracteres de las anteras, número de lóculos del ovario y disposición de los rudimentos seminales.

Palabras clave: Adelobotrys, Axinaea, Centronia, Merianieae, Neotrópico, nueva especie, taxonomía.

\section{Abstract:}

Background and Aims: The genus Meriania has 120 neotropical species, 51 of them in Colombia. This work deals with the taxonomic review of the genus for Colombia, documenting species, subspecies, and synonyms.

Methods: A total of 660 specimens of Meriania from 24 herbaria from Colombia, Ecuador, the United States of America, and England were reviewed and evaluated, and the protologues and images of type specimens in JSTOR Global Plants of the species present in Colombia were consulted. A detailed description of the genus, an identification key, as well as descriptions, illustrations, distribution maps and threat categories are established for each of the species present in Colombia.

Key results: Meriania is characterized by petals $\geq 9 \mathrm{~mm}$ long, nongeniculate stamens, anthers of antepetalous stamens with dorsally inclined pores, capsular fruits and seeds with a straight embryo. Two new species ( $M$. neilli and $M$. ramosii) and three new subspecies of $M$. macrophylla ( $M$. macrophylla subsp. antioquiensis, $M$. macrophylla subsp. franciscana and $M$. macrophylla subsp. peltata) are described. In addition, 18 new synonyms are established and 19 lectotypifications are carried out. The species in Colombia are distributed in the Andean region (34 spp.), Sierra Nevada de Santa Marta (2 spp.), and Guiana Shield-Orinoquia ( 2 spp.), between 100 and $3700 \mathrm{~m}$ a.s.l. Threat categories are documented for 31 species, while six species were not categorized because most of their distribution ranges are found in other countries.

Conclusions: With this revision, Meriania consists of 102 species, 37 of them present in Colombia. Andean species (33 spp.) can be considered within Meriania s.s., while four species found in lowland areas of the Magdalena Medio and Guiana Shield-Orinoquia could be considered as different genera in the future, based on anthers characters, ovary locule number, and seminal rudiment arrangement.

Key words: Adelobotrys, Axinaea, Centronia, Merianieae, Neotropics, new species, taxonomy.

1Jardín Botánico de Bogotá, Cl. 63 \#68-95, Bogotá DC., Colombia.

²Autor para la correspondencia: hmendoza@jbb.gov.co
Recibido: 21 de mayo de 2020.

Revisado: 25 de agosto de 2020.

Aceptado por Gilberto Ocampo: 10 de febrero de 2021.

Publicado Primero en línea: 20 de abril de 2021.

Publicado: Acta Botanica Mexicana 128(2021).

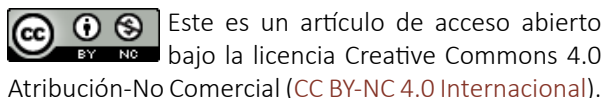

Citar como: Mendoza-Cifuentes, H. 2021. Revisión taxonómica del género Meriania (Melastomataceae) en Colombia. Acta Botanica Mexicana 128: e1734. DOI: https://doi.org/10.21829/abm128.2021.1734

e-ISSN: $2448-7589$ 


\section{Introducción}

Merianieae, establecida por Triana (1865), corresponde a una de las tribus neotropicales con más especies de Melastomataceae. Cuenta con 15 géneros y más de 280 especies (Mendoza-Cifuentes y Fernández-Alonso, 2010). Dentro de la tribu, Meriania Sw. es el género más grande con 120 especies aceptadas y distribuidas en Las Antillas y desde el sur de México hasta el sureste de Brasil; desde el nivel del mar hasta el subpáramo (Wurdack, 1973; Mendoza y Ramírez, 2006; Melastomataceae.Net., 2007-2018; Chiavegatto y Baumgratz, 2009; Mendoza-Cifuentes y Fernández-Alonso, 2010, 2011, 2012; Fernández-Fernández et al., 2020; Fernández-Hilario et al., 2020; Goldenberg et al., 2020).

Colombia es el país con más especies (51) de Meriania, seguido por Ecuador (28), Brasil (14) y Venezuela (12) (Renner, 1999; Calderón y Mendoza, 2000; Mendoza y Ramírez, 2006; Michelangeli y Cotton, 2008; Chiavegatto y Baumgratz, 2009; Baumgratz et al., 2010; Almeda et al., 2016; Fernández-Fernández et al., 2020; Goldenberg et al., 2020).

Meriania se caracteriza por tener plantas leñosas con flores diplostémonas grandes (pétalos $>9 \mathrm{~mm}$ de largo), estambres no geniculados, anteras de los estambres opositipétalos con poros dorsalmente inclinados, frutos capsulares y semillas con embrión recto. Este grupo tiene problemas de circunscripción con géneros cercanos como Adelobotrys DC., Axinaea Ruiz \& Pav. y Centronia Ruiz \& Pav., por lo que se ha sugerido que es un taxón no natural (Schulman y Hyvönen, 2003; Mendoza-Cifuentes y Fernández-Alonso, 2010, 2011, 2012).

Los trabajos de Triana (1872) y Cogniaux (1891) son los únicos que han abordado todas las especies de Meriania hasta el momento. El género ha sido objeto de estudios regionales en tratados como las floras de Mesoamérica (Almeda, 1993, 2009), las Guayanas (Wurdack, 1993), Guayana venezolana (Lukana y Berry, 2001), Brasil (Chiavegatto y Baumgratz, 2009), Ecuador (Wurdack, 1980), Perú (Macbride, 1941), Venezuela (Wurdack, 1973) y las Antillas Mayores (Michelangeli et al., 2015).

Para Colombia, los únicos trabajos publicados sobre Meriania son los de Uribe $(1962,1965,1969)$, Lozano y Alvear (2001) y Mendoza-Cifuentes et al. (2014), en los que se describen varias especies nuevas, y los de Mendoza-Cifuentes y Fernández-Alonso (2010, 2011, 2012), en los que se presenta un análisis filogenético preliminar y la revisión taxonómica de la sección Brachycera.

En este trabajo se presenta el tratado taxonómico para las especies de Meriania distribuidas en Colombia y se establecen propuestas nomenclaturales y taxonómicas nuevas que involucran taxones de países vecinos.

\section{Materiales y Métodos}

Se revisaron especímenes de herbario y se compilaron los protólogos e imágenes tipo de las especies de Meriania presentes en Colombia. Fueron examinados 660 ejemplares de herbarios de Colombia, Ecuador, Estados Unidos de América e Inglaterra. Colombia: CAUP (Universidad del Cauca), COAH (Instituto SINCHI), COL (Universidad Nacional de Colombia sede Bogotá), CUVC (Universidad del VaIle), FAUC (Universidad de Caldas), FMB (Instituto Alexander von Humboldt), HECASA (Universidad de Pamplona), HUA (Universidad de Antioquia), HUQ (Universidad del Quindío), JAUM (Jardín Botánico Joaquín Antonio Uribe), MEDEL (Universidad Nacional de Colombia sede de Medellín), PSO (Universidad de Nariño), SURCO (Universidad Surcolombiana), UDBC (Universidad Distrital de Bogotá), UPTC (Universidad Pedagógica y Tecnológica de Colombia), VALLE (Universidad Nacional de Colombia sede Palmira). Ecuador: QCA (Pontificia Universidad Católica del Ecuador), QCNE (Museo Ecuatoriano de Ciencias Naturales). Estados Unidos de América: CAS (California Academy of Sciences), $F$ (Field Museum of Natural History), MO (Missouri Botanical Garden), NY (New York Botanical Garden), US (Smithsonian Natural Museum of Natural History). Inglaterra: K (Royal Botanic Gardens, Kew).

Para realizar las descripciones se tomaron medidas a partir de material seco y rehidratado. Se capturaron microfotografías de tricomas, semillas y polen en un microscopio electrónico (SEM) (Hitachi S-50, Schaumburg, IL, EUA) en el Departamento de Botánica de la Academia de Ciencias de California, Estados Unidos de América. De cada una de las especies consideradas se establecieron descripciones, ilustraciones, mapas de distribución y, en la medida de las posibilidades, imágenes de campo. Se describieron los tipos de tricomas con base en el Atlas de 
Tricomas de Melastomataceae (Wurdack, 1986). En el caso de una especie (Meriania macrophylla (Benth.) Triana), donde se proponen nuevas subdivisiones infraespecíficas, se incluyen descripciones de algunas subespecies de otros países.

Se establecieron lectotipos - de aquellos taxones donde las publicaciones originales no hacen referencia del holotipo o solo presentan sintipos-, acorde con lo estipulado en el Código Internacional de Nomenclatura para Algas, Hongos y Plantas (Turland et al., 2018). Se indican con un (!) los ejemplares tipo revisados físicamente o las imágenes consultadas en Global Plants database de JSTOR (2018-presente). En el caso de herbarios que tienen varios tipos nomenclaturales que corresponden a un mismo taxón, y de los cuales no se tiene certeza sobre su estatus nomenclatural, se muestra además el número de catálogo de los ejemplares en cuestión.

Las especies se delimitaron con base en el concepto de Nixon y Wheeler (1990), que establece que una especie es un grupo de organismos con poblaciones que comparten un conjunto o combinación de caracteres únicos y constantes.

Se documenta el estado de conservación de las especies presentes en Colombia con base en la literatura y la Lista Roja de la Unión Internacional para la Conservación de la Naturaleza-IUCN (2020). Para aquellas especies aun no categorizadas, y con su mayor área de distribución en Colombia, se sugiere su estado de conservación con base en el Área de Ocupación (AOO) y/o Extensión de Ocurrencia (EOO), utilizando para ello la herramienta GeoCat (Bachman y Moat, 2012) y aplicando las directrices y criterios de la IUCN (2017).

\section{Resultados}

\section{Historia taxonómica}

Meriania fue descrito por Swartz (1798) y corresponde a un nombre conservado que prevalece a Meriana Trew propuesto en 1754 y asociado a la familia Iridaceae (ver Turland et al., 2018). El género fue dedicado a Ana María Sibylla Merian, artista y naturalista que trabajó en la Guayana Francesa. En esta obra, Swartz (1798) incluyó los nombres Meriania purpurea y M. leucantha (especie tipo) de Jamaica, que ya habían sido publicados por el mismo au- tor bajo el género Rhexia L. Este último, en su momento, incluía todas las especies de Melastomataceae con frutos capsulares.

Posteriormente, Don (1823) consideró como sinónimos de Meriania a Wrightia Soland y Melastomeae Sw. (p.p.) y describió las especies M. prunifolia y M. parviflora (actualmente consideradas bajo Trembleya parviflora Cogn.).

De Candolle $(1828 ; 1838)$ incluyó a Meriania en la tribu Lavoisiereae, transfirió algunas especies de Rhexia y describió cuatro bajo el nuevo género Davya DC., que actualmente se considera dentro de Meriania. De Candolle diferenció a Davya de Meriania por las anteras uniporadas, el cáliz truncado, las anteras oblongas y las flores blancas. Posteriormente, autores como Martius (1831), Don (1832), Spach (1835), Bentham (1840), Endlicher (1840) y Walpers (1846) establecieron sinonimias nuevas e hicieron pequeños aportes a la concepción del género.

Naudin (1852) reconoció a Davya y Meriania como géneros distintos dentro de una misma tribu (Miconieae, subtribu Davyeae). Además, describió dos especies nuevas de Meriania y cinco de Davya, sinonimizó dos taxones a Davya y estableció el género Notocentrum Naudin, actualmente considerado como sinónimo de Meriania.

Triana (1872) incluyó a Meriania en una tribu nueva (Merianieae) y consideró 28 especies (seis de ellas nuevas), 35 sinonimias y estableció como sinónimos del género a Adalbertia Meisn., Davya y Notocentrum. Adicionalmente, Triana fue el primero en proponer una clasificación infragenérica que contenía cinco secciones basadas en caracteres de la inflorescencia, el ápice del cáliz y las anteras.

Cogniaux (1891) retomó el trabajo de Triana y consideró 39 especies para el género con igual número de subdivisiones, constituyéndose en su momento como el trabajo más completo conocido para Meriania. Además, Cogniaux estableció la clasificación infragenérica que se utiliza hasta la actualidad, documentando siete especies nuevas y más de 43 sinonimias.

Posterior a estos trabajos se publicaron alrededor de 45 especies, aunque no se han realizado aportes nuevos a las divisiones infragenéricas propuestas por Triana (1872) y Cogniaux (1891). En el siglo pasado, H.A. Gleason y J.J. Wurdack fueron quienes más aportaron en la publicación 
de especies de Meriania; en particular Wurdack, quien publicó 33 actualmente vigentes.

En la historia de Meriania se han involucrado 65 taxónomos que han publicado 211 nombres de géneros y especies asociados a este taxón. De todos los nombres de especies asociados al género, se han sinonimizado 91 y actualmente se aceptan 120 (Melastomataceae.Net, 20072018). No obstante, con base en el presente trabajo y depuraciones futuras de nombres redundantes, el número de especies de Meriania podría corresponder a 102 (Mendoza-Cifuentes et al., 2014).

Por otra parte, existen algunos trabajos que toman en cuenta las relaciones filogenéticas de Meriania de forma tangencial. Schulman y Hyvönen (2003) estudiaron las relaciones filogenéticas de Adelobotrys, mientras que Mendoza-Cifuentes y Fernández-Alonso $(2011,2012)$ hicieron lo propio con Centronia D. Don, en donde transfirieron seis especies de este género a Meriania. Estos dos trabajos documentan que Meriania es un grupo parafilético con problemas de circunscripción y relacionado con Adelobotrys, Centronia y Graffenrieda DC.

\section{Circunscripción de Meriania}

Swartz (1798) describió a Meriania con base en la presencia de flores pentámeras, hipanto campanulado, cáliz persistente con lóbulos denticulados (dientes dorsales), pétalos patentes, estambres curvos (no geniculados) y cápsulas pentaloculares con semillas abundantes.

Don (1823) documentó como caracteres diagnósticos las inflorescencias axilares bibracteadas y sin profilos (brácteas), hipanto campanulado, cáliz con 5-6 lóbulos persistentes, 5-6 pétalos, anteras biporadas con ápice obtuso (subuladas) y calcaradas en la base (codo, según MendozaCifuentes y Fernández-Alonso, 2010) y frutos capsulares con 5-6 lóculos.

Triana (1872) circunscribió el género por la presencia de un cáliz no caliptriforme, anteras inapendiculadas o apendiculadas dorsalmente. Cogniaux (1891) reconoció al género porque sus especies son árboles con flores pentámeras, cáliz lobulado, conectivo dorsal subulado (codo) y apendiculado (con apéndices en el conectivo dorsal) y semillas rectas.
Wurdack $(1973,1980)$, en sus trabajos de Melastomataceae para Venezuela y Ecuador, estableció como caracteres nuevos para el género el cáliz truncado o lobado, no caliptrado, y las anteras con poros dorsales. En concordancia con esto, Almeda (1993) transfirió las especies centroamericanas de Centronia a Meriania.

Mendoza-Cifuentes y Fernández-Alonso (2011) argumentaron que Meriania no es un grupo natural y que para su circunscripción se deben considerar los siguientes caracteres: anteras de los estambres opositipétalos con poro dorsal, pétalos de $\geq 0.9 \mathrm{~cm}$ de largo, anteras con haz vascular del conectivo orientado hacia su base y placenta con rudimentos seminales en todas las superficies. Con este conjunto de caracteres, Meriania se separa de géneros cercanos como Adelobotrys, Centronia s.s. y Graffenrieda, aunque no de Axinaea (Mendoza-Cifuentes y FernándezAlonso, 2012). El único caracter que segrega a Meriania de Axinaea es la forma del conectivo dorsal de la antera, el cual es globoso y redondeado en este último, mientras que en Meriania tiende a ser espolonado y no globoso (Cotton et al., 2014). Varias especies de Meriania del Escudo Guayanés y del Magdalena Medio presentan rudimentos seminales solo en el dorso de las placentas, y posiblemente sea uno de los grupos que deba ser excluido de este género.

\section{Aspectos ecológicos}

Meriania nobilis Triana es visitada y, al parecer, polinizada por abejorros del género Bombus Latreille, 1802 (Restrepo, 1994). Las especies con corola cuculada producen néctar en los estambres (Varassin et al., 2008) y algunas de ellas, como Meriania tomentosa (Cogn.) Wurdack y M. phlomoides (Triana) Almeda, son polinizadas tanto por colibríes como por murciélagos (Vogel, 1997; Muchhala y Jarrin-V., 2002).

Las especies de Meriania con corolas patentes no producen néctar. En campo es común encontrar las anteras consumidas parcial o completamente, por lo que pareciera que los tejidos de estas estructuras fueran la recompensa obtenida por los polinizadores. Dellinger et al. (2014) documentan para Axinaea - género cercano a Meriania-, la polinización por aves paseriformes, cuya recompensa son 
los tejidos azucarados de las anteras que son extraídas parcial o completamente por estas.

Las especies de Meriania asociadas al grupo Brachycera presentan, con la edad, un cambio en la coloración de los pétalos. Se tornan de fucsia a violeta, lo que posiblemente sea causado por la polinización (MendozaCifuentes y Fernández-Alonso, 2012).

Dellinger et al. (2018, 2019a, b) estudiaron los síndromes de polinización en la tribu Merianieae. Se detectaron en Meriania tres tipos de síndromes asociados a polinización: por abejas, donde el polen solo puede liberarse aplicando fuertes vibraciones; por vertebrados, donde la recompensa es néctar secretado por estambres y las flores son cuculadas y regularmente péndulas; por aves, donde la recompensa principal son tejidos (ej. Meriania macrophylla). Se propone que en Meriania los síndromes evolucionaron desde la polinización de vibración por abejas hacia sistemas bimodales con vertebrados; es decir, que las especies generaron adaptaciones para varios tipos de polinizadores, ya sean colibríes-murciélagos, colibríes-roedores o perforadores de flores-roedores.

\section{Morfología de Meriania}

Hábito. La mayoría de las especies de Meriania son árboles pequeños, aunque también hay arbustos y árboles grandes que ocasionalmente alcanzan $30 \mathrm{~m}$ de altura. Meriania selvaflorensis Humberto Mend. crece como un arbusto de ramas péndulas en zonas abiertas, pero también puede crecer como liana en el interior del bosque.

Ramas. Pueden ser teretes, aplanadas, subcuadrangulares (con aristas redondeadas), cuadrangulares y fuertemente aristadas (como en Meriania nobilis). Algunas especies desarrollan líneas interpeciolares notorias (como $M$. nobilis, $M$. sanguinea Wurdack y $M$. splendens Triana). En $M$. acostae Wurdack la línea interpeciolar es densamente villosa.

Indumentos. Las especies de Meriania distribuidas en Colombia presentan 15 tipos diferentes de tricomas de acuerdo con el atlas de tricomas presentado para Melastomataceae (Wurdack, 1986) (Fig. 1, Cuadro 1). Predominan los tricomas filamentosos de base ensanchada y barbelada (tipo 21) y los alargados o adpresos amorfos de paredes rizadas (tipos 30 y 31). Meriania barbosae Humberto Mend., Alvear \& Almeda, M. ramosii (especie nueva descrita aquí; ver abajo), $M$. selvaflorensis y $M$. silverstonei Humberto Mend. \& Fern. Alonso presentan tricomas glandulares (tipo 6). El indumento varía de ralo a denso, mientras que en $M$. fantastica Alvear, Humberto Mend. \& Almeda, M. hernandi L. Uribe, M. neillii (especie nueva descrita aquí; ver abajo), M. mexiae Wurdack, M. nobilis y $M$. pastazana Wurdack son glabrescentes o glabras.

Hojas. Las hojas de Meriania son generalmente isofilas, simétricas y pecioladas, pero en $M$. hoyosii (Wurdack) Almeda \& Penneys, M. mexiae y $M$. selvaflorensis se puede presentar una leve anisofila hacia el ápice de las ramas. El pecíolo es terete excepto en $M$. nobilis que es aristado. En M. drakei (Cogn.) Wurdack, M. fantastica y M. hernandi se encuentra un engrosamiento hacia el ápice del pecíolo conocido como escutelo o escudo. La lámina regularmente es coriácea, de hasta $35 \mathrm{~cm}$ de largo. El margen puede ser entero, denticulado, aserrado o dentado (como en M. acostae y $M$. sanguinea); en $M$. fantastica y $M$. pastazana el margen de la base foliar es revoluto. Por otra parte, en M. neillii se presentan domacios por el envés hacia la base de las venas secundarias.

Nervadura. En todas las especies de Meriania es acródroma. No obstante, en algunas especies como M. neillii las venas secundarias se despliegan hacia el margen, lo que le confiere apariencia broquidódroma. La disposición de las venas secundarias varía entre basal y plinervia (suprabasal) (Fig. 2). La nervadura terciaria no presenta mayor variación, excepto en $M$. speciosa (Bonpl.) Naudin, donde las venas aledañas a la vena media se anastomosan en la mitad de su recorrido formando un retículo que se asemeja a la línea de prefoliación típica de Erythroxylum P. Browne, denominada como "nervadura eritroxiloide". La distancia que se encuentra entre la vena media, las venas secundarias próximas a la vena media y el margen, es una medida utilizada algunas veces como un carácter taxonómico, por lo que es importante medirla solo en la de la mitad de la lámina foliar (Fig. 2C).

Inflorescencias. Corresponden a panículas tirsoides, abiertas o con ramificaciones atrofiadas, terminales, con 

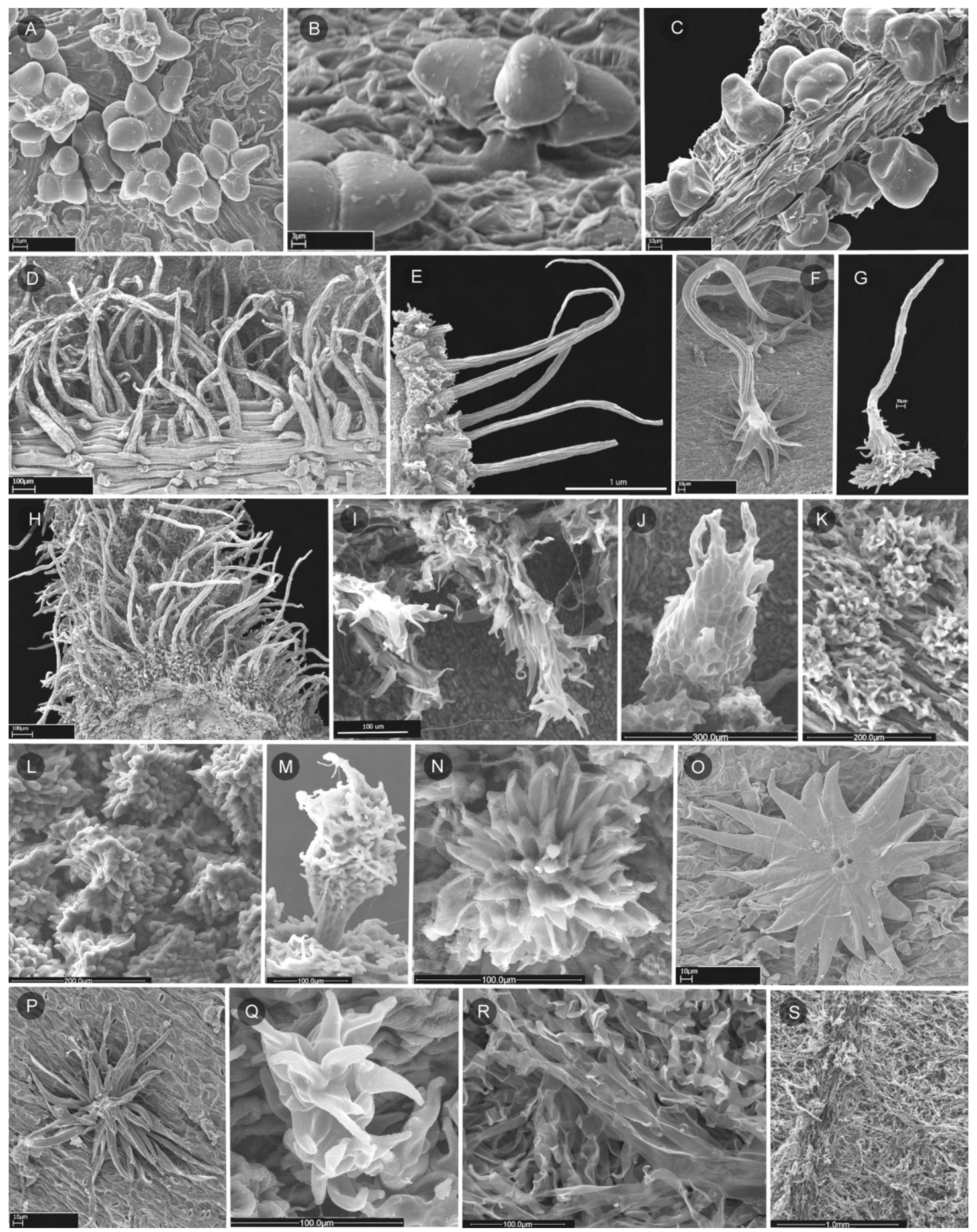

Figura 1: Microfotografías electrónicas de barrido de algunos tipos de tricomas en Meriania Sw. A-C. tricomas glandulares cortamente pedunculados tipo 6 en M. selvaflorensis Humberto Mend. (A, B: Barbosa 7876 (FMB)) y M. barbosae Humberto Mend., Alvear \& Almeda (C: Barbosa 14932 (FMB)); D. tricomas filiformes de superficie alveolada tipo 12 en M. speciosa (Bonpl.) Naudin (Mendoza 4097 (FMB)); E. tricomas filiformes y lisos tipo 11 en M. mutisii (Bonpl.) Humberto Mend. \& Fern. Alonso (Téllez 6232 (UDBC)); F, G, H. tricomas filiformes o subulados de base ensanchada y barbelada tipo 21 en M. acostae Wurdack (F: Herrera 9586 (FMB)), M. arborea (Naudin) Triana (G: Zuluaga 4506 (COL)) y M. dimorphanthera Wurdack (H: Mendoza 16675 (FMB)); I, K. tricomas esponjosos irregulares diminutos tipo 25 en M. yalconensis Humberto Mend. \& Fern. Alonso (I: Mendoza 16439 (FMB)) y M. aguaditensis Humberto Mend. \& Fern. Alonso (K: Mendoza 16662 (FMB)); J. tricomas esponjosos irregulares con ramas cortas tipo 30 en M. mutisii (Téllez 6232 (UDBC)); L, M. tricomas piramidales estipitados en M. haemantha subsp. orientalis Humberto Mend. \& Fern. Alonso (L: Mendoza 2249 (FMB)) y M. yalconensis (M: Mendoza 16439 (FMB)); N, Q. tricomas esponjosos irregulares con ramas delgadas tipo 31 en M. haemantha subsp. orientalis (N: Mendoza 2249 (FMB)) y M. brachycera (Naudin) Humberto Mend. \& Fern. Alonso (Q: Mendoza 17376 (FMB)); O, P. tricomas estrellado-adpresos o de ramas alargadas tipo 38 en M. albertiae Wurdack (O: Albert de Escobar 5306 (HUA)) y M. phlomoides (Triana) Almeda (P: Mendoza 8622 (FMB)); R, S. tricomas aracnoides adpresos tipo 34 en M. brachycera (Mendoza 17376 (FMB)). 
Cuadro 1: Tipos de tricomas según Wurdack (1986) para las especies de Meriania Sw. de Colombia. ND=No disponible.

Tricoma/Descripción

Glandular sésil

Glandular cortamente pedunculado

Filiforme de superficie alveolada

Filiforme y liso

Filiforme de superficie alveolada, algunas veces ramificado

Filiforme o subulado de base ensanchada y barbelada

Setoso-ampollado

Filiforme ligeramente rugoso

Filiforme o subulado de superficie rizada, barbelado

Esponjoso irregular diminuto, pinoide diminuto, excepcionalmente alargado

Esponjoso irregular con ramas cortas

Piramidal estipitado

Esponjoso irregular con ramas delgadas

Estrellado adpreso, estrellado de ramas alargadas

Aracnoideo adpreso
Número del tipo de tricoma según Wurdack (1986)

\begin{tabular}{cc}
4 & ND \\
6 & $1 \mathrm{~A}, \mathrm{~B}, \mathrm{C}$ \\
12 & $1 \mathrm{D}$ \\
11 & $1 \mathrm{E}$ \\
12 & $\mathrm{ND}$ \\
21 & $1 \mathrm{~F}, \mathrm{G}, \mathrm{H}$ \\
15 & $\mathrm{ND}$ \\
16 & $\mathrm{ND}$ \\
17 & $\mathrm{ND}$ \\
25 & $1 \mathrm{I}, \mathrm{K}$ \\
30 & $1 \mathrm{~J}$ \\
27 & $1 \mathrm{~L}, \mathrm{M}$ \\
31 & $1 \mathrm{~N}, \mathrm{Q}$ \\
38 & $1 \mathrm{O}, \mathrm{P}$ \\
34 & $1 \mathrm{R}, \mathrm{S}$ \\
\hline
\end{tabular}

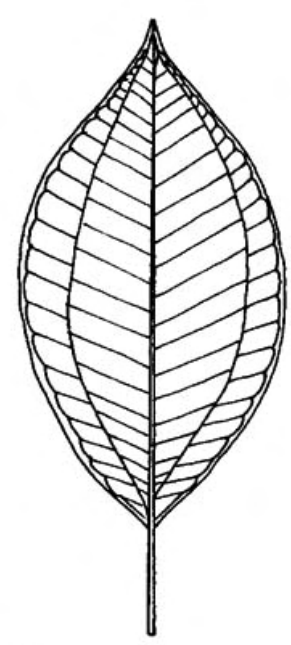

A

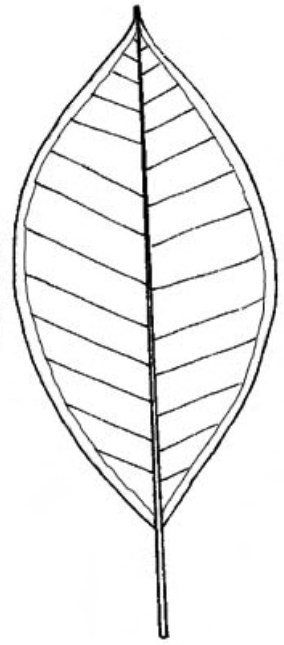

B
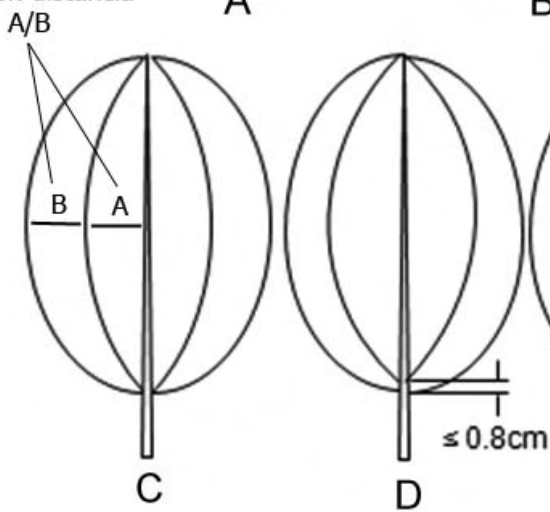

D

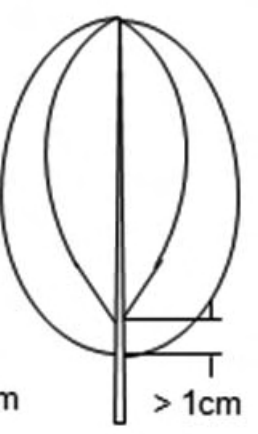

E

Figura 2: Características de la nervadura en Meriania Sw. A. nervadura acródroma; B. nervadura acródroma de apariencia broquidódroma; C. nervadura basal (se ilustra la relación de las distancias entre las venas principales); D. nervadura levemente plinervia; E. nervadura fuertemente plinervia. 
pocas a abundantes flores (Fig. 3). Se presentan variaciones inter e intraespecíficas dadas por la reducción de los ejes y los entrenudos. Meriania hoyosii y M. speciosa son las únicas especies en Colombia que no comparten esta arquitectura. La primera presenta inflorescencias umbeliformes, laterales o terminales, mientras que la segunda presenta inflorescencias unifloras o trifloras, laterales o terminales. En M. phlomoides hay brácteas foliáceas caducas que protegen la inflorescencia en sus primeras etapas de desarrollo. Todas las especies tienen inflorescencias erectas, excepto Meriania arizae, M. mexiae, $M$. sararensis y $M$. selvaflorensis que las tienen péndulas.

Flores. Son pediceladas, diplostémonas, 4-8-meras, grandes a gigantes para la familia (pétalos $>9 \mathrm{~mm}$ de largo) (Mendoza-Cifuentes y Fernández-Alonso, 2011).

Hipanto. Es ciatiforme a obcónico, cartáceo, excepto en Meriania albertiae Wurdack que es papiráceo en material seco. El torus regularmente es engrosado en el lugar de inserción de los estambres. En algunas especies del grupo Brachycera, hacia el interior del hipanto, se presentan ribetes gruesos frente a los pétalos.

Cáliz. Puede ser lobulado, truncado, subcaliptrado o caliptrado. Los dientes pueden ser conspicuos, levemente desarrollados o ausentes. En los cálices caliptrados o subcaliptrados, la apertura puede darse de forma regular (cuando hay rompimiento hacia el ápice y se generan lóbulos en igual número al de los pétalos), irregular o circuncísil (Fig. 4).

Corola. Puede ser patente (con los pétalos expandidos completamente) o cuculada (Fig. 5). Los pétalos pueden ser obovados y con ápice truncado y levemente emarginado, obovados y con ápice redondeado, u oblongos y con ápice redondeado o truncado. Su coloración varía entre blanca, rosada, fucsia y anaranjada. En las especies colombianas de Meriania los pétalos son glabros, excepto en Meriania drakei que presenta pétalos farinosos en la superficie adaxial.

Estambres. En Meriania se presentan estambres isomorfos o leve a fuertemente dimorfos (Mendoza-Cifuentes y Fernández-Alonso, 2010). Cuando los estambres son dimorfos, entonces los opositipétalos son los más grandes, excepto en Meriania selvaflorensis. En las flores abiertas, los estambres se disponen de forma zigomorfa respecto a la corola (Figs. 5A, C). El conectivo dorsal puede presentar un apéndice conspicuo o no. En caso de tener apéndice, este es abultado, tuberculado, dentiforme, subulado o cilíndrico con el ápice abultado. La antera es subulada y regularmente sigmoidea. En algunos casos, los estambres presentan pedoconectivo, que es una porción basal del conectivo libre de las tecas. El poro de la antera en los estambres opositipétalos siempre se orienta dorsalmente, mientras que en los estambres opositisépalos la orientación puede ser dorsal, ventral o apical.

Los estambres en Meriania no son geniculados y presentan una estructura denominada "codo" en el punto de conexión entre el filamento y la base de la antera, el cual puede ser triangular-subulado o de forma irregular (Mendoza-Cifuentes y Fernández-Alonso, 2010, Fig. 6). El concepto de estambre no geniculado ha generado discusión, pues algunos investigadores consideran que en la familia no se presenta este carácter o condición (Mendoza-Cifuentes y Fernández-Alonso, 2010). El concepto de geniculado surge de la palabra en latín "geniculātus", que literalmente se traduce como "presentar o tener una rodilla pequeña". El término implica la existencia de una estructura plegada con un punto de articulación, el cual permite la posibilidad de descontorsión (ver más adelante). El caracter geniculado es evidente en las especies de las tribus Miconieae y Melastomeae, donde se observa en la fase de botón floral filamentos plegados que durante la antesis floral se descontorsionan; esto es, existe una curvatura evidente del filamento que posteriormente desaparece, lo que implica la presencia de un punto o sección que funciona como una articulación. En los géneros Meriania, Graffenrieda, Axinaea y Adelobotrys, una vez efectuada la antesis floral, el filamento no se descontorsiona, pues no hay un plegamiento evidente de este en fase de botón floral. Este carácter de ausencia de descontorsión del filamento es el que se asume como "estambres no geniculados". En algunas especies de Graffenrieda este carácter no es tan evidente, pues presentan estambres rectos en flores abiertas, como si se decontorsionaran de la misma manera que ocurre en Miconieae. Esto es un factor secundario asociado a la elongación del filamento y alineación con la antera, pero que involucra todo el cuerpo del filamento y no una curvatura en el ápice en la 

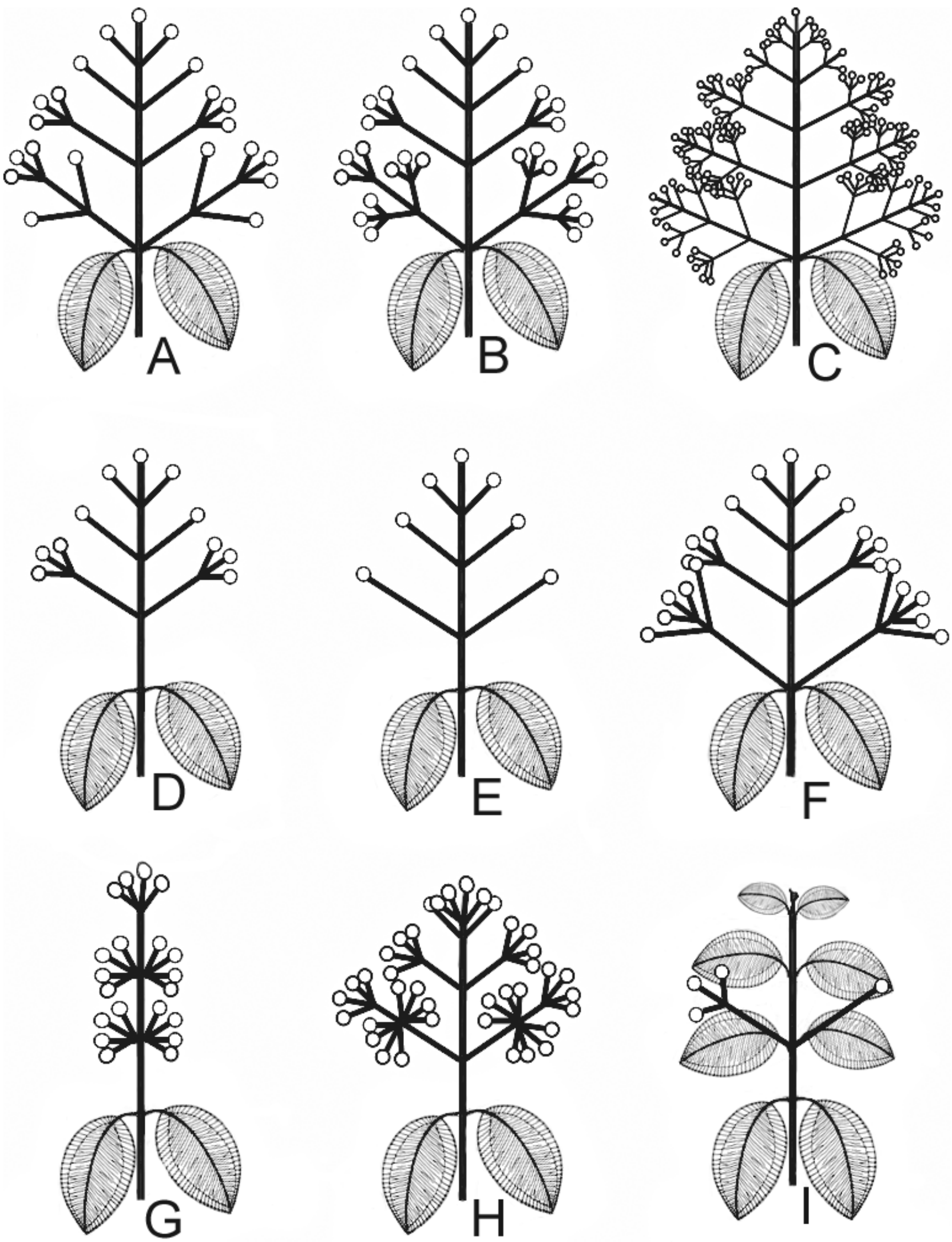

Figura 3: Tipos de inflorescencias en Meriania Sw. A, B, C. panículas con diferentes niveles de proliferación de ejes; D. panícula sin paracladios basales; E. panícula con paracladios no ramificados; F. panícula con entrenudos reducidos en los paracladios basales; G. panícula de apariencia glomerular debido a la reducción total de los ejes de las ramificaciones; H. panículas con reducción parcial de los ejes de las ramificaciones; I. inflorescencias solitarias o trifloras de apariencia axilar (con proliferación vegetativa). 


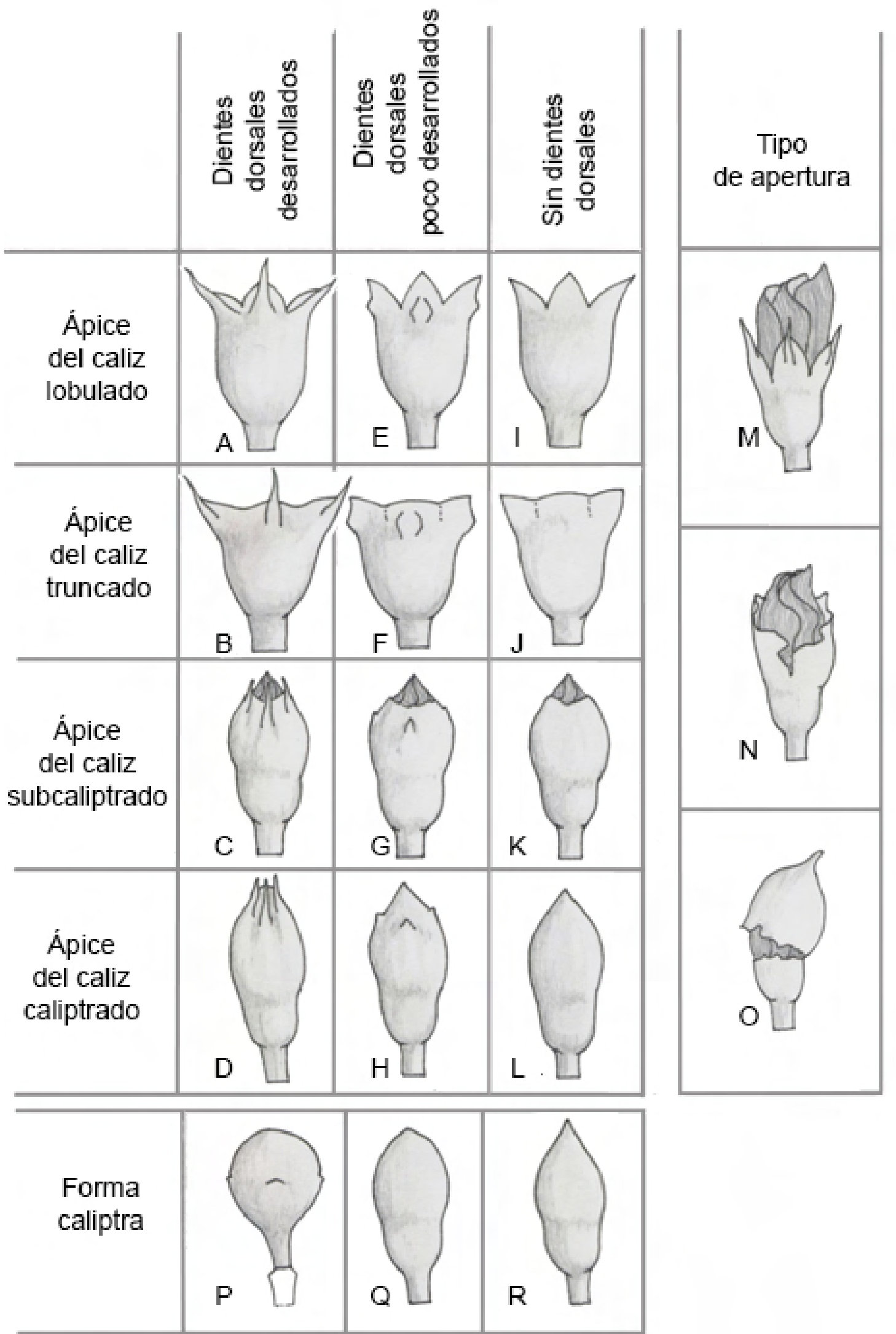

Figura 4: Características del cáliz en Meriania Sw. A-L. variantes de la forma del ápice del cáliz (izquierda) y el grado de desarrollo de los dientes dorsales (en la parte superior). M-N. tipos de aperturas cuando se presentan cálices caliptrados o subcaliptrados; M. apertura regular, generando igual número de lóbulos que pétalos; N. apertura irregular; O. apertura circuncísil; P-R. formas del ápice de cálices caliptrados; P. redondeado; Q. obtuso; R. agudo o apiculado. 

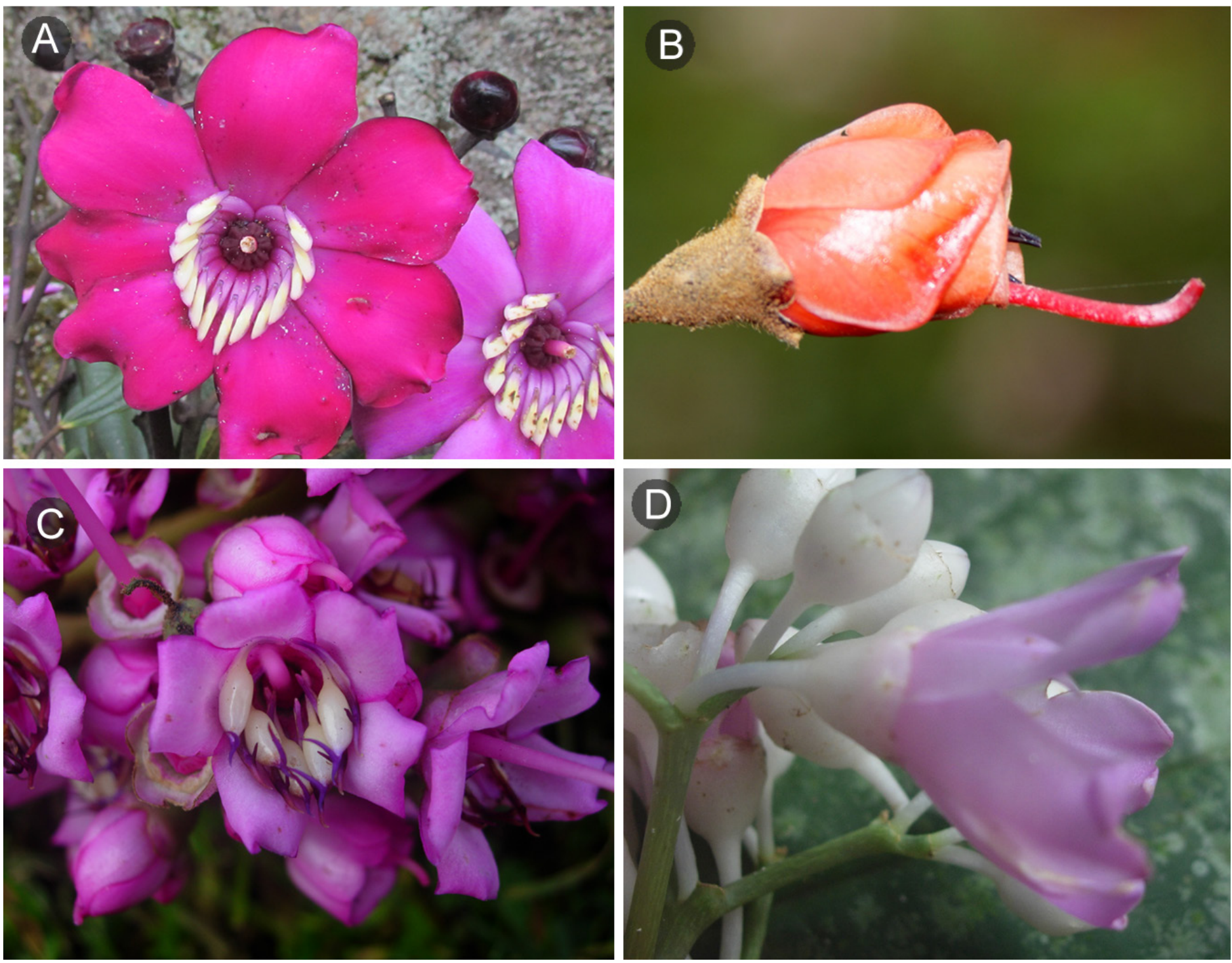

Figura 5: Ejemplos de tipos de corolas en Meriania Sw. A. corola patente en M. heptamera Lozano \& Alvear (Idárraga 4128 (HUA)); B. corola cuculada en M. dimorphanthera Wurdack (Mendoza 16675 (FMB)); C. corola cuculada en M. macrophylla subsp. peltata (L. Uribe) Humberto Mend. (Mendoza 16641 (FMB)); D. corola cuculada en M. hoyosii (Wurdack) Almeda \& Penneys (Mendoza 16981 (FMB)).

fase de botón floral. En algunas especies de este mismo género es posible apreciar una curvatura en el ápice del filamento en botón floral. No obstante, esta se presenta regularmente en especies que desarrollan un pedoconectivo; es decir, esto es un efecto de una parte del conectivo que no es homóloga a la parte curva que genera el estado geniculado en las especies de Miconieae.

La estructura o parte curva del filamento en botón floral de las especies de la tribu Miconieae es homóloga a la estructura subulada en el ápice del filamento en las especies de Meriania (Mendoza-Cifuentes y Fernández-Alonso, 2010). Esta última estructura se interpreta como un antiguo punto de articulación que perdió su capacidad de descontorsión por la fusión de tejidos del filamento y el conectivo, denominado "codo" por su forma subulada, más no implica descontorsión. El carácter de estambres no geniculados se ha utilizado en análisis filogenéticos y estudios taxonómicos de Adelobotrys (Schulman y Hyvönen, 2003), Axinaea (Cotton et al., 2014) y Blakea P. Browne (Penneys, 2007), pero se ha empleado de manera diferente a lo considerado en el presente trabajo.

Polen. Las especies colombianas de Meriania tienen granos esféricos en vista ecuatorial y triangular-convexos en vista polar, de 10.5-16.1 $\mu \mathrm{m}$ de diámetro, radiosimétri- 

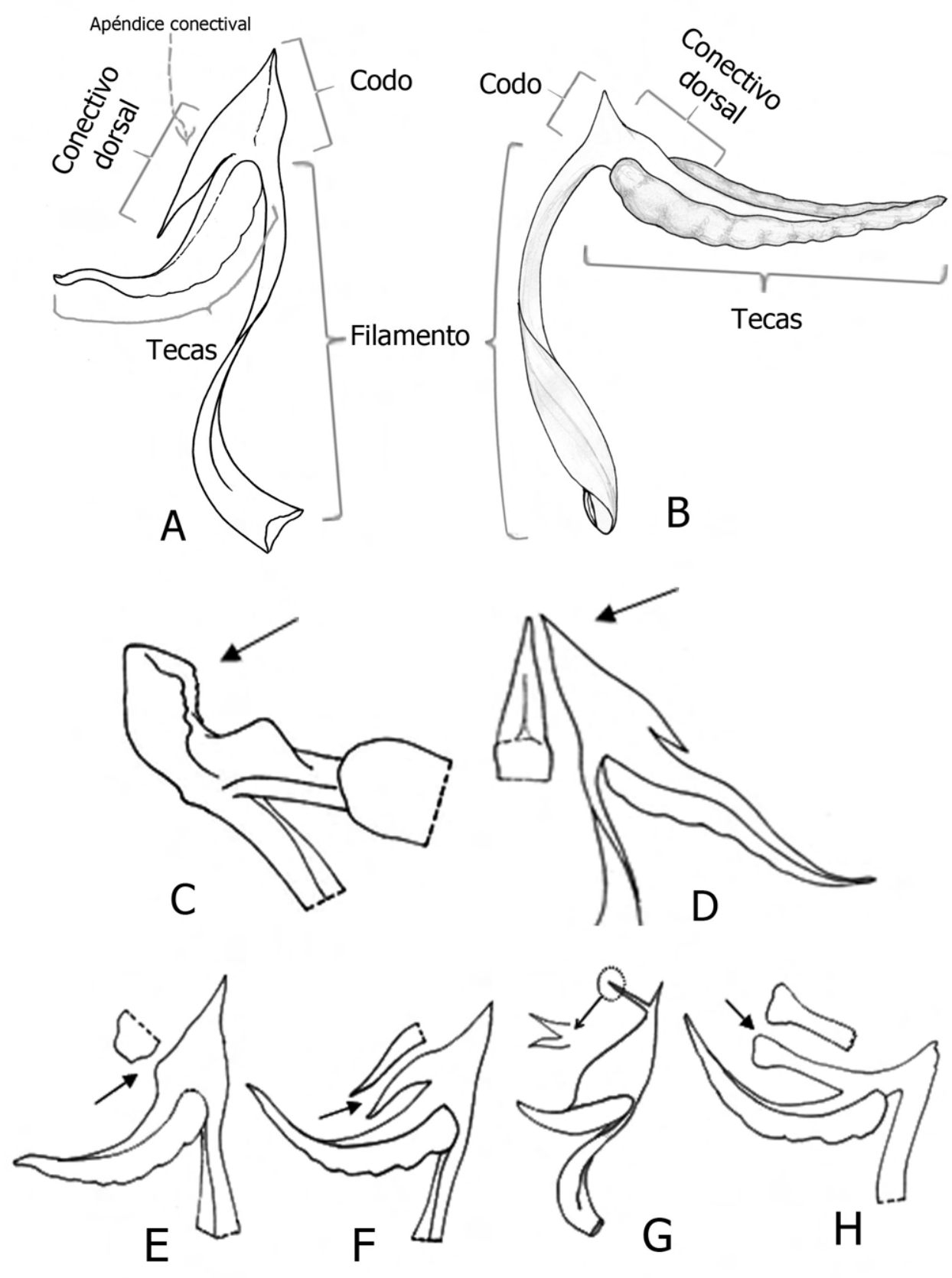

Figura 6: Partes del estambre en Meriania Sw. y algunas de sus características. A, B. partes del estambre; C, D. forma del codo; C. codo irregular; D. codo subulado; E, F, G, H. formas del apéndice conectival dorsal; E. apéndice dentiforme; $F$. apéndice subulado; G. apéndice subulado y bífido; G. apéndice cilíndrico y abultado hacia el ápice.

cos, isopolares, tricolporados, sincolpados y con exina rugulada (Fig. 7).

Ovario y estilo. En Meriania el ovario puede estar fusionado al hipanto en su parte basal o ser completamente libre. El número de lóculos varía entre 3 y 7 y, regularmente, puede variar dentro de la misma especie. Las placentas son ovoides y en corte horizontal tienen forma de "T" o "Y." Los rudimentos seminales se encuentran en toda la superficie de la placenta, excepto en M. albertiae, M. ornata y $M$. urceolata (Fig. 8). En las flores abiertas el estilo es curvo regularmente hacia el ápice; el estigma puede ser no expandido (puntiforme), levemente expandido (a manera de glande) o expandido a manera de disco (discoide). 

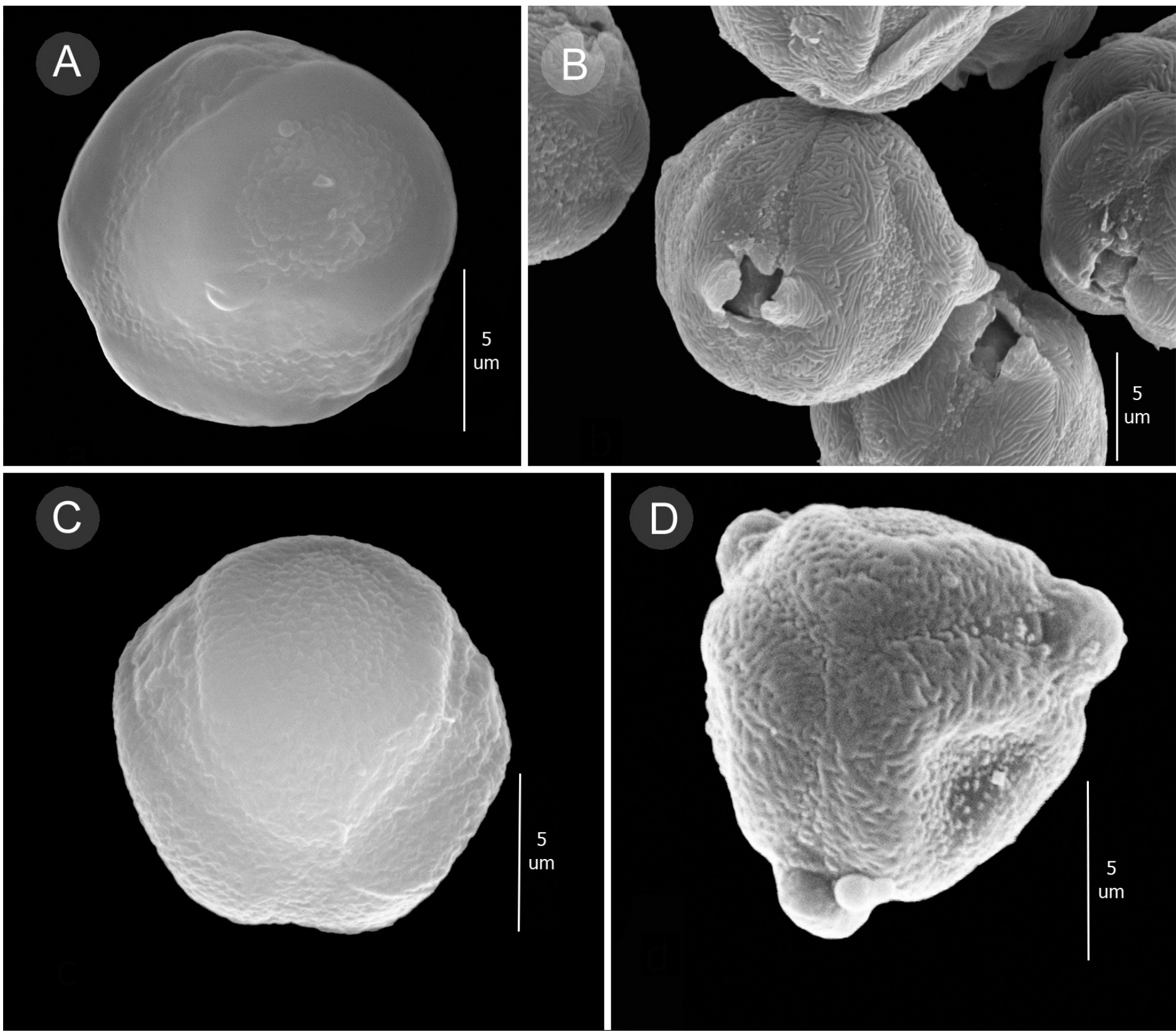

Figura 7: Microfotografías electrónicas de barrido de granos de polen en Meriania Sw. A. vista ecuatorial del polen en M. mutisii (Bonpl.) Humberto Mend. \& Fern. Alonso (Téllez 631 (UDBC)); B. vista ecuatorial del polen en M. heptamera Lozano \& Alvear (Barbosa 2900 (FMB)); C. vista polar de polen de M. brachycera (Naudin) Humberto Mend. \& Fern. Alonso (Mendoza 17376 (FMB)); D. vista polar de polen de M. hernandi L. Uribe (Mendoza $6010(\mathrm{FMB}))$.

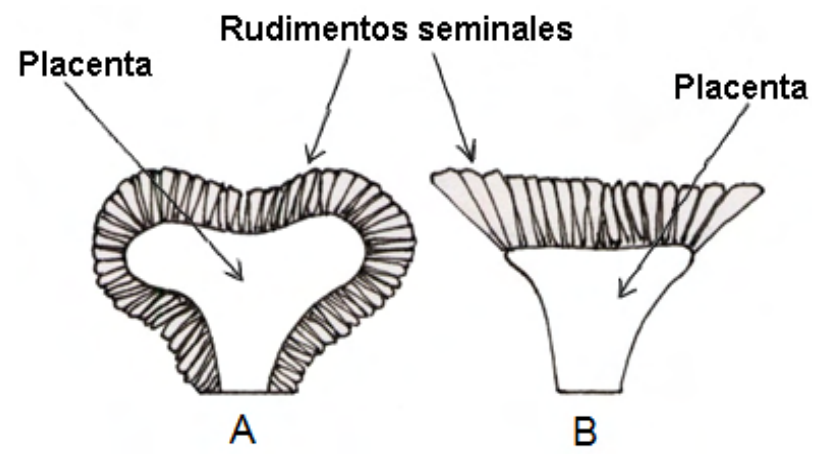

Figura 8: Cortes transversales de la placenta que muestran la distribución de los rudimentos seminales en toda la superficie (A) o solo en el dorso (B). 
Frutos. Son cápsulas loculicidas, con el hipanto relictual leñoso hemisférico o urceolado, el cual cubre parcial o completamente el ovario. El hipanto permanece intacto después de la liberación de las semillas, pero con el tiempo se desintegra y solo quedan los haces vasculares que regularmente se conectan hacia el ápice a través de un haz en forma de anillo. En este de tipo fruto el hipanto no participa en la dehiscencia de la cápsula y es equivalente al tipo de fruto seco llamado velatidio (Baumgratz, 1985).
Semillas. Son cuneiformes con los lados aristados, de 1-2.8 mm de largo; el ápice puede ser corto y recto o alargado (Fig. 9). El hilum es pequeño pero notorio y de color más oscuro que la testa. El rafe es regularmente notorio o no visible. La testa no presenta ornamentaciones; las paredes periclinales de las células son rectas o con bordes sinuosos y las de las paredes anticlinales son levemente convexas o aplanadas.
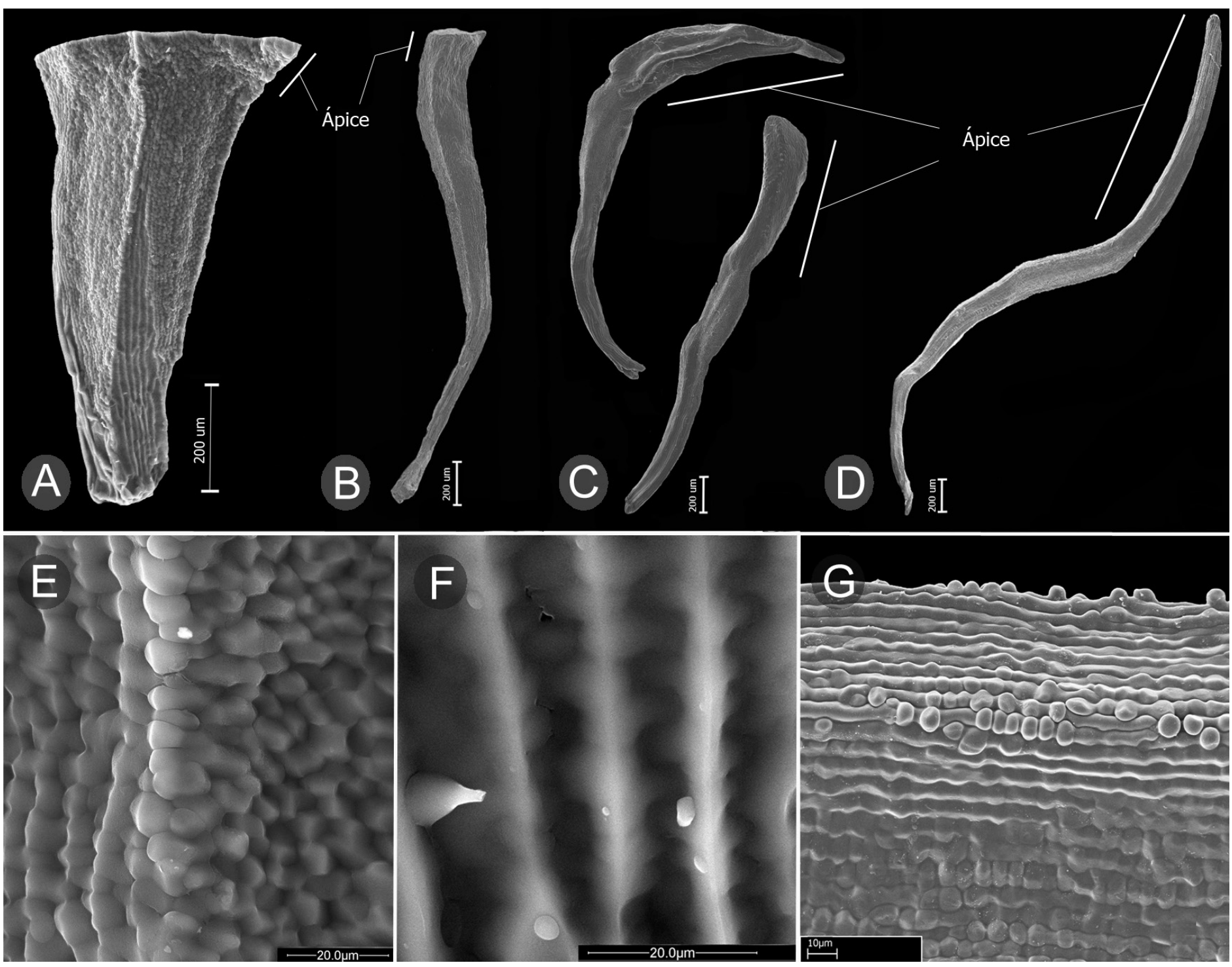

Figura 9: Características de las semillas en Meriania Sw. A, B. semillas con ápice corto y recto; A. M. albertiae Wurdack (Albert de Escobar 5306 (HUA)); B. M. neillii Humberto Mend. (Smith 8556 (MO)); C, D. semillas con ápice alargado; C. M. silverstonei Humberto Mend. \& Fern. Alonso (Mendoza 14937 (FMB)); D. M. selvaflorensis Humberto Mend. (Alvear 1465 (CAS)); E, G. paredes anticlinales levemente convexas; E. M. acostae Wurdack (Herrera 9586 (FMB)); G. M. selvaflorensis Humberto Mend. (Alvear 1465 (CAS)); F. paredes periclinales sinuosas, M. acostae Wurdack (Herrera 9586 (FMB)). 


\section{Tratado taxonómico}

Meriania Sw., nom. cons., Fl. Ind. Occ. 2: 823. t. 15. 1800. TIPO: Meriania leucantha Sw.

= Davya DC., Prodr. 3: 105. 1828; DC., p.p. TIPO: Davya paniculata DC.

= Adelbertia Meissn., Gen. PI. 114: 81. 1837. TIPO: Adelbertia calophylla Meissn.

= Pachymeria Benth., PI. Hartw 2: 130. 1844. TIPO: Pachymeria rigida Benth.

= Schwerinia Karst., Ausw. Neu. Gew. Venez. I: 12. 1848. TIPO: Schwerinia barbinervis Klotzsch ex H. Karst.

= Notocentrum Naudin, Ann. Sc. Nat. 18(2): 131. 1852. TIPO: Notocentrum arboreum Naudin

Árboles, arbustos o lianas; hojas opuestas, pecioladas o subsésiles, isofilas o con leve anisofilia hacia los nudos distales, nervadura acródroma; inflorescencias terminales, panículas tirsoides multifloras, ocasionalmente axilares uni o trifloras; flores pediceladas, diplostémonas, generalmente ebracteoladas; hipanto ciatiforme a obcónico, grueso cartáceo, raras veces delgado y papiráceo; cáliz lobulado, truncado, subcaliptrado o caliptrado; corola con 4-8 pétalos, obovados u oblongos, 9-55 mm de largo, glabros o excepcionalmente farinosos en la superficie adaxial; estambres no geniculados, isomorfos o dimorfos, anteras sigmoideas subuladas, con poro orientado dorsalmente en los estambres opositipétalos, codo agudo o de forma irregular; conectivo dorsal con o sin apéndices; polen tricolporado, exina rugulada; ovario completamente libre o parcialmente fusionado al hipanto hacia la base, 3-7-locular; ápice redondeado, truncado o con apéndices dentiformes a filiformes, placentas con rudimentos seminales en toda su superficie, excepto en las especies del Escudo Guayanés y el Magdalena Medio que los presentan solo hacia el dorso, estilo regularmente curvo hacia el ápice en antesis, estigma puntiforme a discoide; fruto cápsula loculicida con abundantes semillas, encerrado parcial o totalmente por el hipanto, el cual se desintegra con el tiempo; semillas diminutas, con el embrión recto, cuneiformes y con el ápice corto o alargado.
Clave para las especies de Meriania presentes en Colombia

1a. Plantas extra-andinas, creciendo en las formaciones del Escudo Guayanés sobre suelos arenosos o tepuyes (departamentos de Amazonas, Caquetá, Guainía, Guaviare, Meta, Vaupés y Vichada) 2

1b. Plantas de los Andes, Sierra Nevada de Santa Marta y Magdalena Medio 3

2a. Tricomas estrellados y adpresos en el envés de las hojas, ramas, inflorescencia e hipanto-cáliz; pecíolos $\leq 4.5 \mathrm{~cm}$ de largo M. urceolata Triana

2b. Tricomas barbelados en el envés de las hojas, ápice de las ramas, inflorescencia e hipanto-cáliz; pecíolos $\geq 7$ $\mathrm{cm}$ de largo M. ornata Wurdack

3a. Hojas sésiles o subsésiles, pecíolo $\leq 0.7 \mathrm{~cm}$ de largo ..... 4

3b. Hojas con pecíolo $>1 \mathrm{~cm}$ de largo 5

4a. Base de la lámina foliar cordada; pétalos fucsia oscuro; piedemonte de Putumayo ...... M. mexiae Wurdack

4b. Base de la lámina foliar aguda a obtusa; pétalos lila claro; Magdalena Medio y las vertientes colindantes de las cordilleras Central y Oriental

M. hoyosii (Wurdack) Almeda \& Penneys

5a. Lianas . M. selvaflorensis Humberto Mend.

5b. Árboles o arbustos erectos 6

6a. Nervadura intersecundaria aledaña a la vena media ramificada, produciendo un retículo profuso ("reticulación eritroxiloide", ver Fig. 59B)

M. speciosa (Bonpl.) Naudin

6b. Nervadura intersecundaria aledaña a la vena media, sin producir un retículo profuso ("no eritroxiloide")

7a. Entrenudos cuadrangulares aristado-alados; pecíolos ensanchados y alados basalmente ... M. nobilis Triana

7b. Entrenudos teretes o cuadrangulares, pero no aladoaristados; pecíolos teretes o cuadrangular-canaliculados, pero no alados basalmente 8

8a. Nudos de las ramas apicales con línea interpeciolar laminar estipuloide 9

8b. Nudos de las ramas sin línea interpeciolar laminar estipuloide 10

9a. Haz de la hoja con tricomas setosos de base ampollada M. sanguinea Wurdack 
9b. Haz de la hoja liso, glabro M. splendens Triana

10a. Ápice del pecíolo con un engrosamiento (escutelo) .....

10b. Ápice del pecíolo sin ningún tipo de engrosamiento 13

11a. Corola cuculada, pétalos rosado oscuro o magenta; centro de la Cordillera Oriental (Cundinamarca) M. macrophylla (Benth.) Triana

11b. Corolas patentes o levemente saliviformes, pétalos anaranjados; sur del Macizo Colombiano (Putumayo)

12a. Pecíolos canaliculados y envolviendo al tallo hacia la base; inflorescencias con más de 20 flores; pétalos menores de $3 \mathrm{~cm}$ de largo M. hernandi L. Uribe

12b. Pecíolos teretes no envolventes hacia la base; inflorescencias con menos de 15 flores; pétalos mayores de 5 $\mathrm{cm}$ de largo

....... M. fantastica Alvear, Humberto Mend. \& Almeda

13a. Flores caliptradas (cáliz completamente encerrando la flor en botón) 14

13b. Flores con cáliz lobulado, truncado o subcaliptrado 27

14a. Pétalos blancos, rojos o anaranjados; corola cuculada 15

14b. Pétalos fucsia oscuro o violeta oscuro; corola patente 16

15a. Pétalos anaranjados ... M. tomentosa (Cogn.) Wurdack 15b. Pétalos blancos M. phlomoides (Triana) Almeda

16a. Hojas conspicuamente plinervias, venas plinervias a 5-15 $\mathrm{mm}$ arriba de la base de la lámina 17

16b. Hojas basinervias o levemente plinervias menos de 5 $\mathrm{mm}$ arriba de la base 18

17a. Alvéolos y la nervadura por el envés cubiertos totalmente con indumento aracnoide

M. brachycera (Naudin) Humberto Mend. \& Fern. Alonso

17b. Alvéolos y la nervadura por el envés glabrescentes o completamente glabros

...... M. aguaditensis Humberto Mend. \& Fern. Alonso

18a. Ramas, pecíolo, hojas e inflorescencia con indumento homogéneo de pelos setosos filamentosos largos ....... 19

18b. Ramas sin indumento homogéneo de tricomas setosos filamentosos, si presente solo en algunas estructuras y no homogénea en todas las estructuras de ramas, hojas e inflorescencia 20

19a. Inflorescencia erecta; región del Sumapaz (Cundinamarca) y nororiente de Tolima

.. M. mutisii (Bonpl.) Humberto Mend. \& Fern. Alonso 19b. Inflorescencia péndula; Santander y Boyacá M. arizae Humberto Mend. \& Fern. Alonso

20a. Hojas desiguales en tamaño en el mismo nudo, de ápice con acumen de 1-3.5 cm de largo

M. selvaflorensis Humberto Mend.

20b. Hojas isofilas, corto acuminadas o no acuminadas ....... 21

21a. Envés con tricomas glandulares hialinos (con solo estos tricomas o intercalado con otros tricomas pinoides o esponjosos; Figs. 1A-C); semillas con ápice alargadofiliforme

21b. Sin tricomas glandulares hialinos por el envés, los únicos tricomas son piramidales o esponjosos de paredes rizadas; semillas de ápice corto y recto 24

22a. Ápice del ovario fuertemente prolongado (9-15.5 mm de largo), excediendo el torus y rematando en dientes triangulares M. ramosii Humberto Mend.

22b. Ápice del ovario redondeado o con leves dientes redondeados, al mismo nivel del torus 23

23a. Partes vegetativas, inflorescencia e hipanto-cáliz con indumento denso de tricomas alargados ramificados y de paredes irregulares; base de la lámina foliar levemente cordada o peltada; Cordillera Central vertiente del río Magdalena, Caldas

M. barbosae Humberto Mend., Alvear \& Almeda

23b. Partes vegetativas, inflorescencia e hipanto-cáliz con indumento de tricomas cortos pinoides harinosos no alargados ni ramificados; base de la lámina foliar obtusa o si redondeada no es peltada; Cordillera Occidental y norte de la Cordillera Central

M. silverstonei Humberto Mend. \& Fern. Alonso

24a. Hipanto y ramas con indumento denso de tricomas apicalmente deltoide-piramidales (Figs. 1L, M) ...........

24b. Hipanto y ramas con tricomas subtriangulares o irregulares esponjosos, no deltoide-piramidales (Figs. $1 \mathrm{H}$ K) 26 
25a. Caliptra con indumento similar al del hipanto, nervadura con 1-2 pares de venas acompañando a la vena media M. haemantha

(Planch. \& Linden) Humberto Mend. \& Fern. Alonso

25b. Caliptra con indumento de tricomas subulados de hasta $1 \mathrm{~mm}$ de largo (ausentes en el hipanto), nervadura con 3 pares de venas acompañando a la vena media . M. sararensis Humberto Mend. \& Fern. Alonso

26a. Pared interna del hipanto con ribetes gruesos frente a los pétalos, Macizo Colombiano

M. yalconensis Humberto Mend. \& Fern. Alonso

26b. Pared interna del hipanto lisa y sin ribetes, Cordillera Central ..

mutabilis (Gleason) Humberto Mend. \& Fern. Alonso

27a. Nervadura de apariencia broquidódroma o con la relación A/B >3 (Fig. 2C) .... 28

27b. Nervadura de apariencia no broquidódroma o relación $A / B<2.5$ 30

28a. Ramas y envés foliar con tricomas pinoides y de 0.1$0.5 \mathrm{~mm}$ de largo; corola cuculada; pétalos rosados; estambres fuertemente dimorfos

M. macrophylla (Benth.) Triana

28b. Ramas y envés foliar glabros y si se presentan tricomas, entonces son escasos y $<0.06 \mathrm{~mm}$ de largo; corola patente; pétalos fucsia oscuros; estambres isomorfos

29a. Ramas (en material seco) 2-4 mm de diámetro; pecíolo (en material seco) 1-1.6 mm de diámetro, lámina foliar regularmente con solo un par de venas secundarias cerca del margen ......... M. neillii Humberto Mend.

29b. Ramas (en material seco) 4-9 mm de diámetro; pecíolo (en material seco) 2-3.5 mm de diámetro, lámina foliar con dos pares de venas secundarias cerca del margen M. hexamera Sprague

30a. Cáliz truncado 31

30b. Cáliz lobulado o subcaliptrado 36

31a. Base de la lámina foliar revoluta; pétalos anaranjados M. pastazana Wurdack

31b. Base de la lámina foliar no revoluta; pétalos magenta, blanco o lila claro 32

32a. Pétalos lila claros o blancos; corolas cuculadas ........ 33

32b. Pétalos magentas; corolas patentes 34

33a. Lámina foliar obovada, 7-23 cm de ancho; inflorescen- cia umbeliforme; ovario 5-locular M. hoyosii (Wurdack) Almeda \& Penneys

33b. Lámina foliar elíptica, $2.5-4.7 \mathrm{~cm}$ de ancho; inflorescencia paniculada; ovario 3-locular ................................................. M. albertiae Wurdack

34a. Flor heptámera; estigma capitado M. heptamera Lozano \& Alvear

34b. Flor pentámera; estigma puntiforme (no expandido) .. 35

35a. Ramas, hojas, inflorescencia, hipanto y pétalos glabros; pétalos $50-60 \mathrm{~mm}$ de largo M. maxima Markgr.

35b. Ramas, venas por el envés, inflorescencia e hipanto pubérulos, con tricomas filiformes ligeramente rugosos diminutos; pétalos externamente furfuráceos, $<40$ $\mathrm{mm}$ de largo

M. drakei (Cogn.) Wurdack

36a. Hipanto con costillas grandes y dentadas; línea interpeciolar vilosa; corola patente; anteras tabicadas internamente y de apariencia ruminada externamente M. acostae Wurdack

36b. Hipanto liso o con costillas no evidentes; sin línea interpeciolar vilosa; corola cuculada; anteras lisas, no septadas 37

37a. Pétalos blancos o lila claros; ovario 3-locular; forma de la lámina foliar con relación largo/ancho entre 3 y 4 (angostamente elíptica) ............ M. albertiae Wurdack

37b. Pétalos magentas, rosado oscuros, rojos o anaranjados; ovario 4-6-locular; forma de la lámina foliar con relación largo/ancho entre 1.4 y 2.5 .... 38

38a. Pétalos rosado-oscuros o magentas; estambres con apéndice conectival dorsal subulado

M. macrophylla (Benth.) Triana

38b. Pétalos rojos o anaranjados; estambres sin apéndice conectival, o si presente, dentiforme (corto y romo) 39

39a. Plantas glabrescentes, o si tienen indumento, este es ralo y blancuzco; estilo de igual longitud a la de la corola cuando las flores están abiertas

M. quintuplinervis Naudin

39b. Plantas pubescentes y con indumento ferrugíneo denso; estilo excediendo la longitud de la corola de manera conspicua cuando las flores están abiertas 40 
40a. Estambres con apéndices conectivales dorsales conspicuos (dentiformes) en ambas series de estambres, con pedoconectivo $>1.5 \mathrm{~mm}$ de largo M. arborea (Naudin) Triana

40b. Estambres sin apéndices conectivales dorsales, sin pedoconectivo, o si presente $<1 \mathrm{~mm}$ de largo 41

41a. Estambres fuertemente dimorfos (las dos series diferentes en forma y tamaño); inflorescencias con más de 35 flores; dientes dorsales del cáliz excediendo los lóbulos calicinos menos de $4 \mathrm{~mm}$

\section{M. dimorphanthera Wurdack}

41b. Estambres similares en forma pero levemente disimiles en la longitud de la antera; inflorescencias con menos de 15 flores; dientes dorsales del cáliz excediendo los lóbulos calicinos 8-10 mm

M. colombiana Gleason

Meriania acostae Wurdack, Phytologia 35(1): 5. 1976. Fig. 10. TIPO: ECUADOR. Provincia Pichincha, Saloya, vertiente occidental de la Cordillera Occidental, $1800 \mathrm{~m}$, 9.IX.1943, fl, M. Acosta-Solís 5809 (holotipo: F!).

Árboles 7-15 m de altura; entrenudos cuadrangulares, línea interpeciolar desarrollada, vilosa; ramas, pecíolo e inflorescencia con indumento denso de tricomas filamentosos de base ensanchada, levemente barbelada (tipo 21), 1-3 mm de largo; hojas con pecíolo 7-10 cm de largo; lámina 25-35 × 18-30 cm, ovada, base cordada, ápice agudo o corto acuminado, margen irregularmente dentado, estos 2-4 $\mathrm{mm}$ de largo; haz rugosa, en hojas jóvenes con indumento similar al de los entrenudos; envés fuertemente reticulado, con indumento en la nervadura de tricomas filamentosos de base barbelada 0.2-0.5 mm de largo; nervadura con 3-4 pares de venas basales; inflorescencia $23-30 \mathrm{~cm}$ de largo, eje central con 3-4 nudos de ramificación, paracladios hasta $18 \mathrm{~cm}$ de largo, ramillas de ápices corimbiformes; flor pedicelada, 5-mera; pedicelo 15-25 mm de largo; hipanto 7-9.6 $\mathrm{mm}$ de largo, con 10 costillas, con indumento similar al de las ramas, tricomas 0.5-1 mm de largo; cáliz con lóbulos grandes, estrechamente triangulares; dientes dorsales 1017 mm de largo, mucho más largos que los lóbulos; corola patente; pétalos 21-33 × 18-25 mm, glabros, magentas; estambres dimorfos; filamento $11-13 \mathrm{~mm}$ de largo; anteras tabicadas internamente, de apariencia ruminada en su parte exterior; estambres opositisépalos con codo más corto, expandido hacia los lados, 2-2.5 mm de largo, superficie papilosa hacia el centro; conectivo dorsal con apéndice 0.3$0.4 \mathrm{~mm}$ de largo, tuberculado; antera 6.2-6.4 mm de largo, subulada, sigmoidea, poro apical; estambres opositipétalos más grandes por mayor desarrollo del conectivo, mayor longitud de la antera; codo 3.2-3.4 mm de largo, deltoide, superficie papilosa hacia el centro; conectivo dorsal con apéndice 0.7-0.8 $\mathrm{mm}$ de largo, dentiforme; antera 9.7-10 $\mathrm{mm}$ de largo, subulada, sigmoidea, poro dorsal; ovario 6.5$6.9 \mathrm{~mm}$ de largo, 5-locular, oblongo, parcialmente fusionado hacia la base al hipanto en aristas 2.3-2.5 mm; ápice con lóbulos redondeados cortos; placentas con rudimentos seminales en todas las superficies; estilo $1.7-2 \mathrm{~cm}$ de largo, obcónico, curvo hacia el ápice; estigma puntiforme; cápsula 11.5-15 mm de largo sin incluir el pedicelo, con el hipanto cartáceo, costillado; semillas 0.6-0.8 mm de largo, cuneiformes, con ápice corto; testa y rafe marrón claros.

Notas taxonómicas: Meriania acostae difiere de las demás especies del género por tener el indumento de las ramas y la inflorescencia con tricomas filamentosos de 1-3 $\mathrm{mm}$ de largo, hojas hasta de $30 \mathrm{~cm}$ de largo, haz rugoso y margen dentado. Por otra parte, junto con $M$. amischophylla Wurdack y M. weberbaueri J.F. Macbr. de Perú, son las únicas especies del género con el hipanto fuertemente costillado y con lóbulos calicinos.

Distribución y hábitat: se encuentra en Colombia y Ecuador (provincia Pichincha). Para Colombia la especie solo se conoce de una localidad en Nariño, Reserva Natural La Planada, entre 1700-1900 m de elevación (Fig. 11). Crece en zonas de bosque subandino y menos frecuentemente en bosque andino, en el interior y en el borde del bosque.

Etimología: en honor al botánico ecuatoriano Misael Acosta Solís (1910-1994).

Estado de conservación: Meriania acostae se encuentra categorizada como "Amenazada" (EN) en la Lista Roja de la IUCN (2020). En Colombia se conoce de una localidad en inmediaciones de la Reserva Natural La Planada, fuera del 


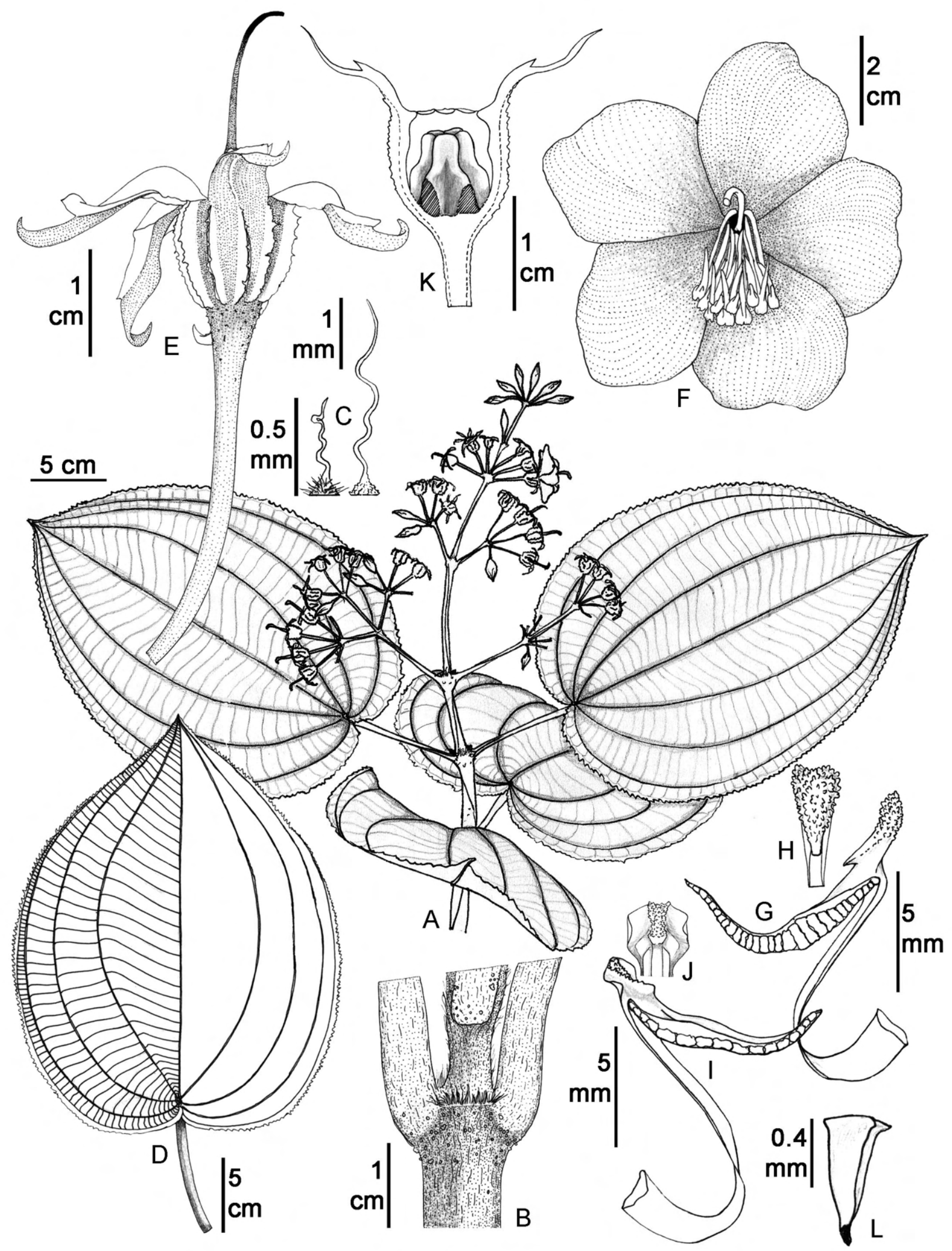

Figura 10: Meriania acostae Wurdack. A. rama florífera; B. vista lateral de un nudo; C. tricomas de envés foliar (izq) y pecíolo (der); D. hoja; E. vista lateral del hipanto-cáliz; F. vista superior de la corola; G. estambre opositipétalo; $\mathrm{H}$. vista superior del codo y apéndice conectival estambre opositipétalo; I. estambre opositisépalo; J. vista superior del codo y apéndice conectival estambre opositisépalo; K. corte longitudinal del hipantocáliz y vista lateral del ovario; L. semilla. A-L: Herrera 9586 (FMB). 

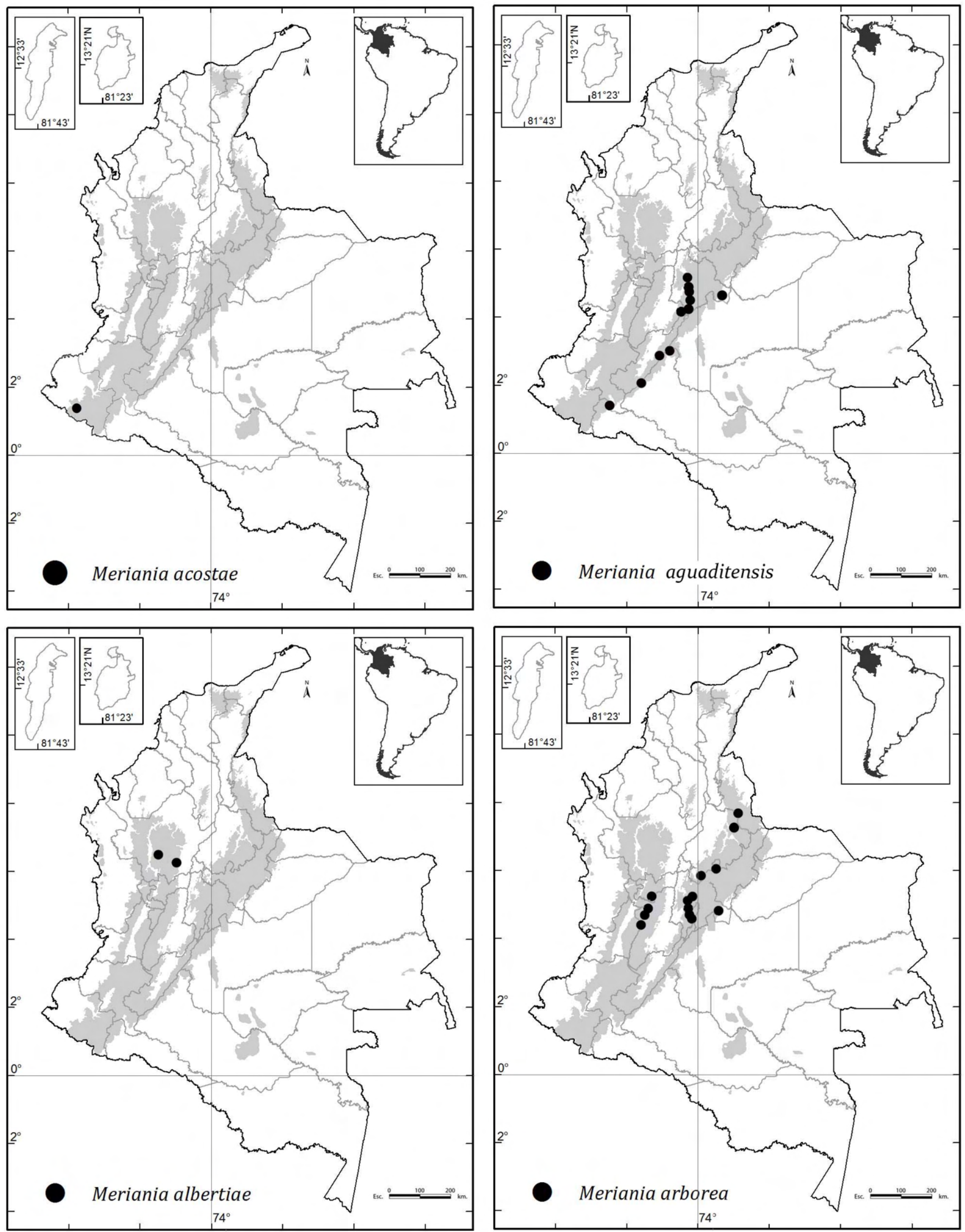

Figura 11: Distribución geográfica de Meriania acostae Wurdack, M. aguaditensis Humberto Mend. \& Fern. Alonso, M. albertiae Wurdack y M. arborea (Naudin) Triana. 
sitio protegido, en donde no hay áreas de conservación gubernamentales y la fragmentación del bosque subandino es evidente. Esta especie tiene gran potencial ornamental y sería importante implementar su propagación ex situ.

Material examinado: COLOMBIA. Departamento Nariño, municipio Ricaurte, Reserva Natural La Planada, 1950 m, 22.IV.1997, fl, fr, G. Herrera 9586 (FMB); loc. cit., 1900 m, 20.II.1995, fl, H. Mendoza 771 (FMB, PSO).

Meriania aguaditensis Humberto Mend. \& Fern. Alonso, Anales Jard. Bot. Madrid 69(2): 264-267. 2012. Figs. 12, 13A. TIPO: COLOMBIA. Departamento Cundinamarca, municipio Fusagasugá, inspección de policía La Aguadita, vereda Los Robles, finca La Carbonera, $2400 \mathrm{~m}$, $4^{\circ} 24^{\prime} 52.6^{\prime \prime} \mathrm{N}, 74^{\circ} 18^{\prime} 38.2^{\prime \prime} \mathrm{W}, 8 . \mathrm{VII} .2006, \mathrm{fl}$, H. Mendoza 16662 (holotipo: FMB!; isotipo: COL!).

Árboles 7-15 m de altura; entrenudos jóvenes aplanados o subcuadrangulares; ramas, pecíolos, inflorescencia y venas principales por el envés con indumento laxo de tricomas esponjosos irregulares cortos (tipo 25), 0.08-0.1 $\mathrm{mm}$ de largo, marrón claro, ocasionalmente los entrenudos y la axila de las venas principales por el envés con tricomas setosos, filiformes, rojizos 2-3 $\mathrm{mm}$ de largo (tipo 11); hojas con pecíolo 1.1-2.6 cm de largo; lámina 5.2-12.1 × 2.2$5.3 \mathrm{~cm}$, elíptica, angostamente elíptica, oblongo-elíptica u oblongo-obovada; ápice obtuso a redondeado; base obtusa; margen entero o denticulado hacia el ápice; haz glabro; envés con alvéolos glabros, regularmente con tricomas setosos hacia las axilas de las tres venas principales; nervadura con 2 pares de venas secundarias, plinervias; inflorescencia 6.5-16 cm de largo, con 2-3 nudos de ramificación principal, 6-34 flores; paracladios con 1-2 niveles de ramificación, 6.5-10.7 cm de largo, algunas veces ausentes; ramificaciones de ápices trifloros o con entrenudos muy cortos por lo que rematan en 5 flores; flor pedicelada, 5-7-mera; pedicelos 7-11 $\mathrm{mm}$ de largo; hipanto 5-6.8 $\mathrm{mm}$ de largo, ciatiforme, externamente con indumento laxo de tricomas esponjosos irregulares cortos, internamente con callosidades hacia la base de los estambres frente a los pétalos; cáliz caliptrado; caliptra $12-15 \mathrm{~mm}$ de largo, ápice agudo o con un apículo de hasta $5 \mathrm{~mm}$ de largo, externamente con indumento como el del hipanto; corola patente; pétalos $25-38 \times 15-28 \mathrm{~mm}$, obovados, ápice truncado emarginados, glabros, magentas; estambres isomorfos; filamento 8-10 mm de largo; codo 3.8-4.6 mm de largo, subulado, fucsia claro; conectivo dorsal con apéndice $0.3-1.5 \mathrm{~mm}$ de largo, subulado, blanco; antera 7.2-9.7 mm de largo, subulada, sigmoidea, fucsia oscuro, poro dorsal; polen 11.4-12 $\mu \mathrm{m}$ diámetro; ovario 5-5.5 mm de largo, 5-7-locular, ovado, ligeramente fusionado hacia la base al hipanto por 1.2-1.6 $\mathrm{mm}$, en corte transversal con 5-7 costillas levemente alzadas, con el lomo levemente aplanado; ápice con apéndices subulados coronando cada carpelo 0.4-1 mm de largo; placentas 1.9-2 mm de largo, ovoides, con rudimentos seminales en todas las superficies; estilo $11-13 \mathrm{~mm}$ de largo, levemente obcónico; estigma puntiforme; cápsula 7.2-8.5 $\mathrm{mm}$ de largo sin incluir el pedicelo, con hipanto leñoso hemisférico cubriendo la mitad del fruto; fruto propiamente oblongo; semillas $0.89-0.92 \mathrm{~mm}$ de largo, cuneiformes, con ápice corto.

Notas taxonómicas: esta especie se caracteriza por tener hojas pequeñas, elípticas o estrecho-elípticas, glabrescentes por el envés (a excepción de las bases de las venas secundarias y media que pueden ser setoso hirsutas) y flores caliptradas. Las especies afines son $M$. brachycera, de la que difiere por la ausencia del indumento marrón y denso de tricomas aracnoides por el envés; $M$. mutisii, de la que difiere por la forma y el tamaño de las hojas y la carencia de la pubescencia de pelos setosos largos rojizos; $M$. haemantha, de la que difiere por el tamaño y la forma de las hojas y de $M$. yalconensis, de la que difiere por la carencia del indumento ferrugíneo por el envés.

Distribución y hábitat: especie hasta ahora restringida a los Andes de Colombia y norte de Ecuador (Fig. 11). En Colombia se distribuye en la Cordillera Oriental y el Macizo Colombiano, departamentos Cundinamarca, Tolima, Huila, Caquetá y Putumayo, entre 1300 y 3150 m de elevación. En los departamentos de Caquetá y Putumayo crece en la vertiente amazónica de la Cordillera en bosques por debajo de $2000 \mathrm{~m}$ de elevación. Crece en el interior de bosques andinos $y$, menos frecuentemente, en bosques subandinos $y$ altoandinos. 


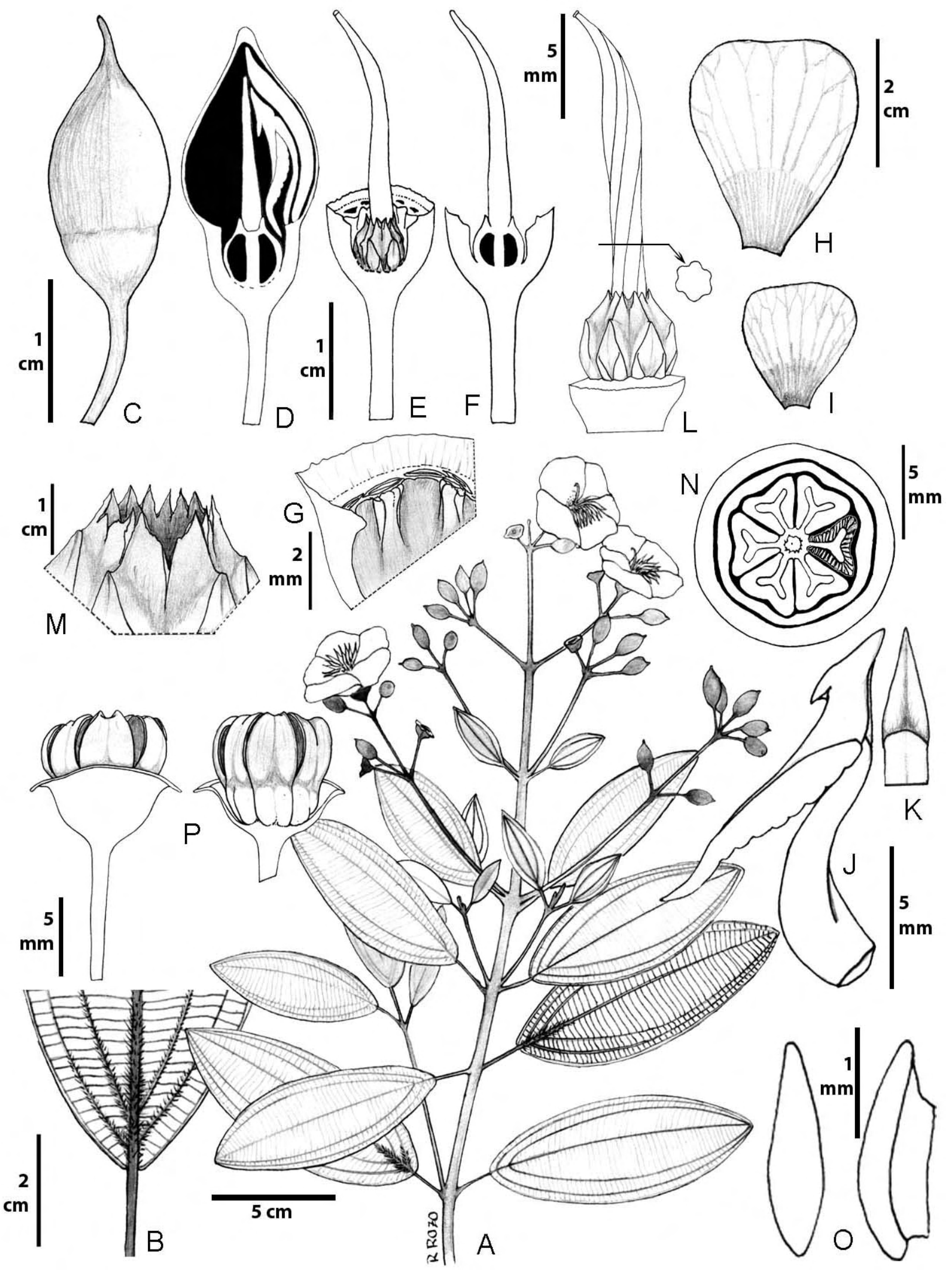

Figura 12: Meriania aguaditensis Humberto Mend. \& Fern. Alonso. A. rama florífera; B. parte basal del envés; C, D. botón floral en vista lateral y en corte longitudinal; E. corte longitudinal del hipanto; F. corte longitudinal de hipanto-ovario; G. callosidades del torus; H, I. pétalos; J. estambre; K. codo ápice del filamento; L. vista lateral del ovario y estilo; M. apéndices del ápice del ovario; N. corte horizontal del hipanto-ovario; O. vista frontal y lateral de la placenta; P. fruto con y sin hipanto. A-P: Mendoza 16662 (FMB); tomada de Mendoza-Cifuentes y Fernández-Alonso (2012). 


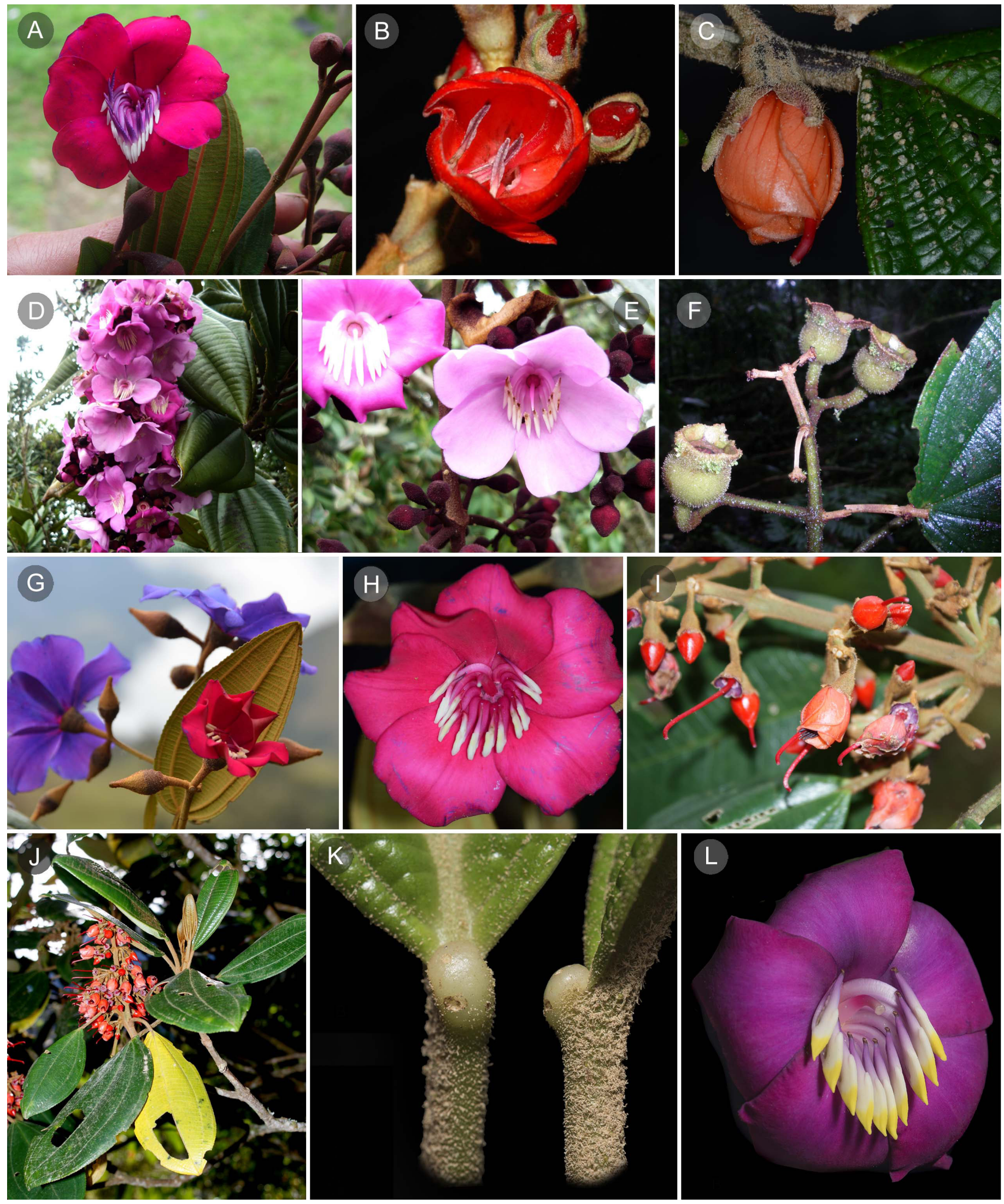

Figura 13: Fotografías de Meriania Sw. de Colombia. A. M. aguaditensis Humberto Mend. \& Fern. Alonso; B, C. M. arborea (Naudin) Triana; D, E. M. arizae Humberto Mend. \& Fern. Alonso; F. M. barbosae Humberto Mend., Alvear \& Almeda; G, H. M. brachycera (Naudin) Humberto Mend. \& Fern. Alonso; I, J. M. dimorphanthera Wurdack; K, L. M. drakei (Cogn.) Wurdack. Créditos: H. Mendoza (A, I, J); F. Michelangeli (B); M. Alvear (C, F); W. Ariza (D, E); F. Almeda (G, H); S. Moreno (K, L). 
Etimología: en alusión a la localidad tipo, La Aguadita.

Estado de conservación: categorizada como "Vulnerable" (VU) (Mendoza-Cifuentes y Fernández-Alonso, 2012).

Material examinado: COLOMBIA. Departamento Caquetá, municipio San Vicente del Caguán, $30 \mathrm{~km}$ SE of Guadalupe on road to Florencia, 2300 m, 9.I.1974, fl, A. Gentry 9041 (COL, MO); Parque Nacional Natural Los Picachos, cuenca alta del río Pato, 2000 m, 15.XI.1997, fr, H. Mendoza 4479 (FMB). Departamento Cundinamarca, Bogotá DC, Sumapaz, San Juan, vereda Capitolito, Paramillo y Chorrera Blanca, 3150-3200 m, 27.II.1999, fl, P. Franco 8185 (COL). Municipio Fusagasugá, La Aguadita, finca La Carbonera, 2470 m, 8.VI.2006, st, H. Mendoza 16631 (FMB), 16676 (FMB); municipio Facatativá - La Vega, bosque El Dintel, 2900-3000 m, 29.VIII.1999, fl, T. van der Hammen 7219 (COL). Municipio Pasca, vereda Las Mesas, 2700-2800 m, 6.IX.1967, fl, L. Uribe 5974 (COL, US). Municipio Sibaté, San Miguel, 2900 m, 7.VI.1948, fl, J.G. Hawkes 33 (COL, US); cerca de Altos San Miguel, 2800 m, 19.III.1969, fl, L. Uribe 6263 (COL, US). Departamento Huila, municipio Campoalegre, vereda Alto El Roble, 2200 m, 29.IX.2001, fl, fr, F. Llanos 3314 (COL). Departamento Putumayo, municipio Mocoa, carretera Mocoa - Sibundoy, El Mirador, 1300-2000 m, 2.V.1994, fl, J. Betancur 5504 (COAH, COL, HUA, MO, NY, US). Sin localidad precisa, 1760-1808, fl, fr, J. C. Mutis 1334 (US), 3414 (US).

Meriania albertiae Wurdack, Phytologia 64(4): 293. 1988.

Fig. 14. TIPO: COLOMBIA. Departamento Antioquia, municipio Guatapé, vereda Santa Rita, finca Montepinar, 1850 m, 8.XI.1985, fl, L. Albert de Escobar 6096 (holotipo: HUA!; isotipos: COL!, HUA!, US!).

Árboles 6-15 m de altura; entrenudos cuadrangulares, aristas redondeadas, canaliculados; ramas, inflorescencia e hipanto glabros o pubérulos, tricomas estrellados, escuamiformes, blanquecinos, adpresos (tipo 38); hojas con pecíolo 1-2 cm de largo; lámina 10-15.5 × 2.5-4.7 cm, angostamente elíptica; base aguda o atenuada; ápice acu- minado; margen entero; haz glabro; envés de apariencia glabra, pero con indumento denso de tricomas glandulares sésiles hialinos; nervadura con un par de venas secundarias plivervias 5-18 $\mathrm{mm}$ arriba de la base (sin considerar la vena submarginal), raras veces venas basales; inflorescencia 8-15 cm de largo, 4-6 nudos de ramificación, 40-60 flores, paracladios con 2-3 niveles de ramificación, ramillas apicales umbeliformes o dicasiales; brácteas foliáceas en los nudos basales, brácteas lineares caducas 2-3 mm de largo en los nudos distales; flor pedicelada, 5-mera; pedicelo 4-8 $\mathrm{mm}$ de largo; hipanto 3-4 mm de largo, ciatiforme, con paredes delgadas, papiráceo en seco; cáliz truncado (tubo 1 $\mathrm{mm}$ de largo) o con lóbulos anchamente triangulares 1.5$2 \times 2.5-3 \mathrm{~mm}$, internamente glabros o pruinosos; dientes dorsales ausentes; corola levemente campanulada; pétalos 9-11.5 × 5-6.5 mm, obovados, más largos que anchos, ápice truncado asimétrico, glabros, lila claro o blanco; estambres dimorfos por variación en la orientación del poro y tamaño de la antera; estambres opositipétalos de mayor tamaño, con la antera más larga que el filamento; filamento 6-6.3 $\mathrm{mm}$ de largo, codo 1-1.3 mm de largo, subulado; conectivo dorsal con apéndice 2.3-2.8 mm de largo, cilíndrico, de ápice abultado a levemente bilobado; antera 5.7-6.5 $\mathrm{mm}$ de largo, subulada, sigmoidea, poro dorsal; estambre opositisépalo de menor tamaño, la antera no excediendo la longitud del filamento; filamento 6-8 mm de largo; codo 0.9-1.2 $\mathrm{mm}$ de largo, subulado; conectivo dorsal con apéndice 1.2$1.8 \mathrm{~mm}$ de largo, cilíndrico; antera $4-5 \mathrm{~mm}$ de largo, fuertemente arqueada hacia el dorso, poro ventral; ovario 2.5-2.7 $\mathrm{mm}$ de largo, 3-locular, oblongo u oblongo-obovado, completamente libre del hipanto; ápice levemente lobulado, encerrando la base del estilo 0.4-0.6 mm, lóbulos redondeados; placentas $2 \mathrm{~mm}$ de largo, obovadas, con rudimentos seminales solo en el dorso; estilo 6-6.5 mm de largo, levemente obcónico; estigma puntiforme; cápsula 4-6 mm de largo sin incluir el pedicelo, ciatiforme, hipanto papiráceo; semillas 0.7-1.2 mm de largo, cuneiformes con ápice corto, marrón claras, con rafe más oscuro que la testa.

Notas taxonómicas: Wurdack (1988) asoció esta especie con Meriania urceolata, por el ovario trilocular a pesar de sus diferencias en la forma de la corola y coloración de los pétalos. Otra especie que se puede asociar a este 


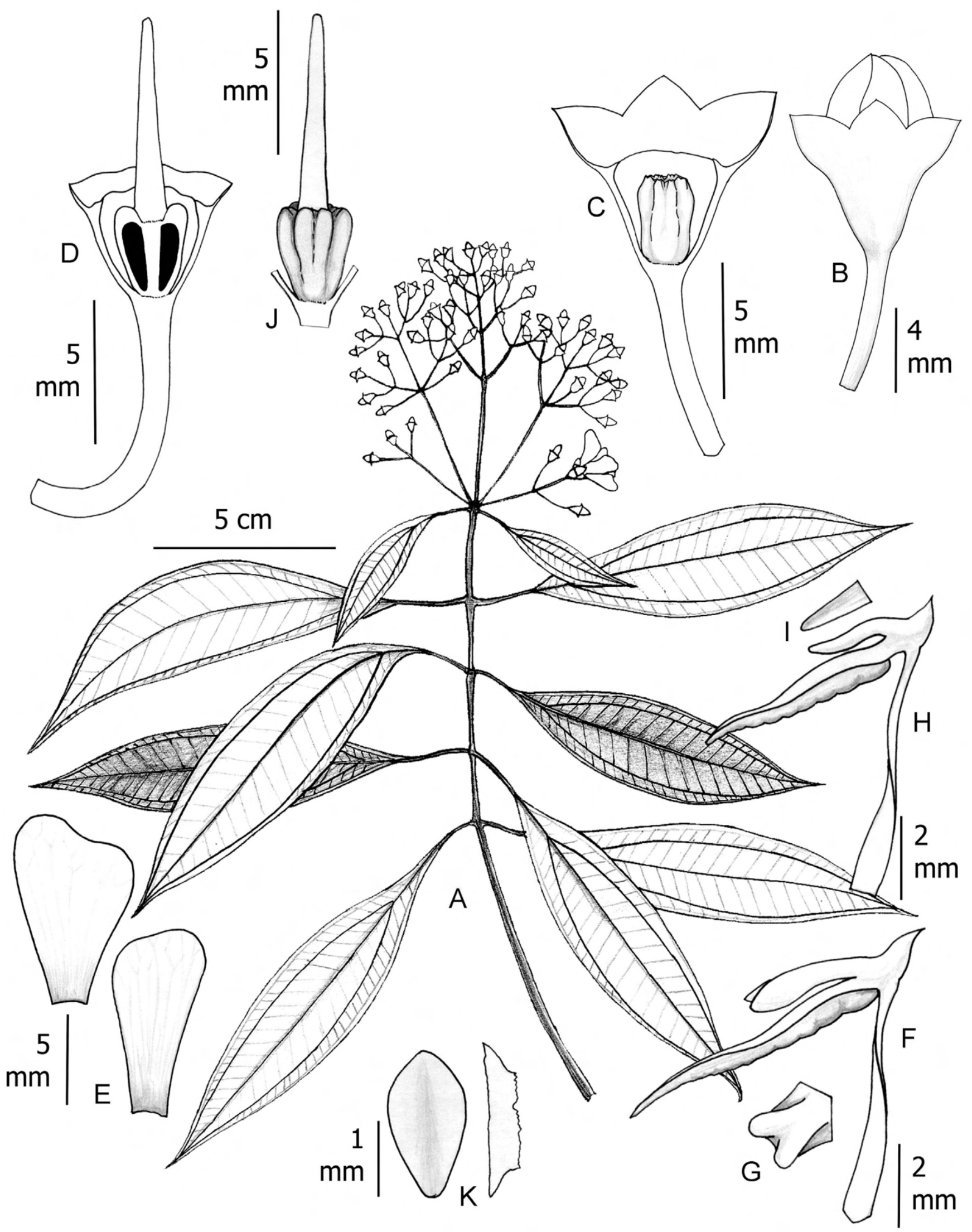

Figura 14: Meriania albertiae Wurdack. A. rama florífera; B. botón floral; C. corte longitudinal del hipanto-cáliz y vista lateral del ovario; D. corte longitudinal del hipanto-cáliz y ovario-estilo; E. pétalos; F. estambre opositipétalo; G. ápice apéndice conectival del estambre opositipétalo; H. estambre opositisépalo; I. ápice apéndice conectival del estambre opositisépalo; J. vista lateral del ovario y estilo; K. vista frontal y lateral de la placenta. A-K: Albert de Escobar 5346 (US). 
grupo es $M$. ornata, ya que comparten las placentas con rudimentos seminales solo en el dorso y la forma de los estambres con anteras esbeltas, haz vascular del conectivo orientado hacia el ápice de la antera y un apéndice dorsal cilíndrico y levemente bífido (ver figuras 14F, H; 45F, I). Este autor también anotó que a pesar de su apariencia $M$. albertiae no se asocia con M. hoyosii.

Distribución y hábitat: especie hasta ahora conocida solo para los departamentos de Antioquia y Caldas, Colombia, en zonas de bosque subandino entre 1300 y $2000 \mathrm{~m}$ de elevación (Fig. 11).

Etimología: especie nombrada en honor a Linda Katherine Albert de Escobar (1940-1993), profesora de la Universidad de Antioquia y especialista en la familia Passifloraceae.

Estado de conservación: esta especie es endémica de los departamentos Antioquia y Caldas, Colombia, y crece en zonas muy húmedas de bosques subandinos, áreas muy intervenidas por las actividades agrícolas y mineras. Según la Lista Roja de la IUCN (2020) está categorizada como "Vulnerable" (VU), ya que se registra en seis localidades, una en un área protegida. No obstante, se sugiere su reasignación a la categoría "En Peligro" (EN) considerado que tiene un EOO de ca. $250 \mathrm{~km}^{2}$ y las localidades de donde se conocen son cercanas y con activos procesos de deforestación. Cumple los criterios B1ab(i) ya que su área se encuentra fuertemente fragmentada (IUCN, 2017). Las áreas de conservación en la zona solo custodian una porción de las poblaciones de esta especie y hasta el momento no se conocen estrategias para establecerla como valor objeto de conservación y no hay garantía de su conservación efectiva.

Material examinado: COLOMBIA. Departamento Antioquia, municipio Anorí, vereda Los Sauces, cerca de las quebradas El Oso y Los Sauces, 1800-1950 m, 24.III.2007, fr, H. David 1718 (HUA). Municipio Carolina del Príncipe, carretera a la represa Miraflores, 2000-2200 m, 28.VII.2011, fl, H. David 3663 (HUA). Municipio Guatapé, vereda Santa Rita, 1850 m, 1.X.1982, fl, fr, L. Albert de Escobar 2413 (HUA, US); vereda Santa Rita, 1850 m, 12.XI.1987, fl, A. Uri- be 8010 (HUA). Municipio San Luis, Ecoparque El Castellón, 1300-1500 m, 9.XI.1995, fl, fr, R. Fonnegra 5711 (HUA, MO). Departamento Caldas, municipio Samaná, vereda La Abundancia, Selvas de Florencia, 12.IV.2001, fr, F. Arroyave 213 (FAUC).

Meriania arborea (Naudin) Triana, Trans. Linn. Soc. Bot. 28: 67. 1872. Figs. 13B-C, 15.

इ Notocentrum arboreum Naudin, Ann. Sc. Nat. Sér. 3, 18: 131. 1852. TIPO: COLOMBIA. Departamento Quindío, páramo, 1844, fl, M. Goudot s.n. (holotipo: P!).

= Meriania steyermarkii Gleason, Fieldiana Bot. 28: 430 . 1952. TIPO: VENEZUELA. Estado Mérida, between El Molino and ridge above San Isidro Alto, 2430-2895 m, 14.V.1944, fl, J. Steyermark 56513 (holotipo: F!; isotipos: NY!, VEN!), syn. nov.

Árboles o arbustos, 2-20 m de altura; entrenudos subcuadrangulares a oblongos, algunas veces canaliculados; ramas, pecíolos, envés, inflorescencia, hipanto y cáliz con indumento denso de tricomas subulados con base ensanchada, barbelada (tipo 21), marrón claro o rojizo, en algunos casos los de las ramas y pecíolos son irregulares adpresos como escamas (tipo 31), esponjosos irregulares cortos (tipo 25), los del hipanto también varían a esponjosos irregulares cortos; hojas con pecíolo de $1.5-2.2 \mathrm{~cm}$ largo; lámina 8.5-21.5 × 3.3-11 cm, elíptica, oblongo-elíptica u ovado-elíptica; haz liso o levemente bullado, glabro; envés con indumento en todas las superficies (alvéolos y nervadura); margen denticulado, dentículos 1-1.7 mm de largo; nervadura con 2 pares de venas acompañando a la vena principal, rara vez 3 pares sin incluir al par submarginal, basales o levemente plinervias, el par más cercano a la vena media 3-8 $\mathrm{mm}$ por encima de la base; inflorescencia $6.5-18.5 \mathrm{~cm}$ de largo, sésil o pedunculada, eje central con 1-4 nudos de ramificación, 8-22 flores; ramillas trifloras o menos frecuentes glomerulares (más de tres flores); paracladios 5.5-8 cm de largo; brácteas en los nudos basales a manera de hojas pequeñas, brácteas en los nudos distales, ramificaciones lineares, caducas desde botones; flor pedicelada, 5-mera; pedicelo 7-15 $\mathrm{mm}$ de largo; hipanto 6-10 $\mathrm{mm}$ de largo, ciatiforme, externamente costillado o tere- 


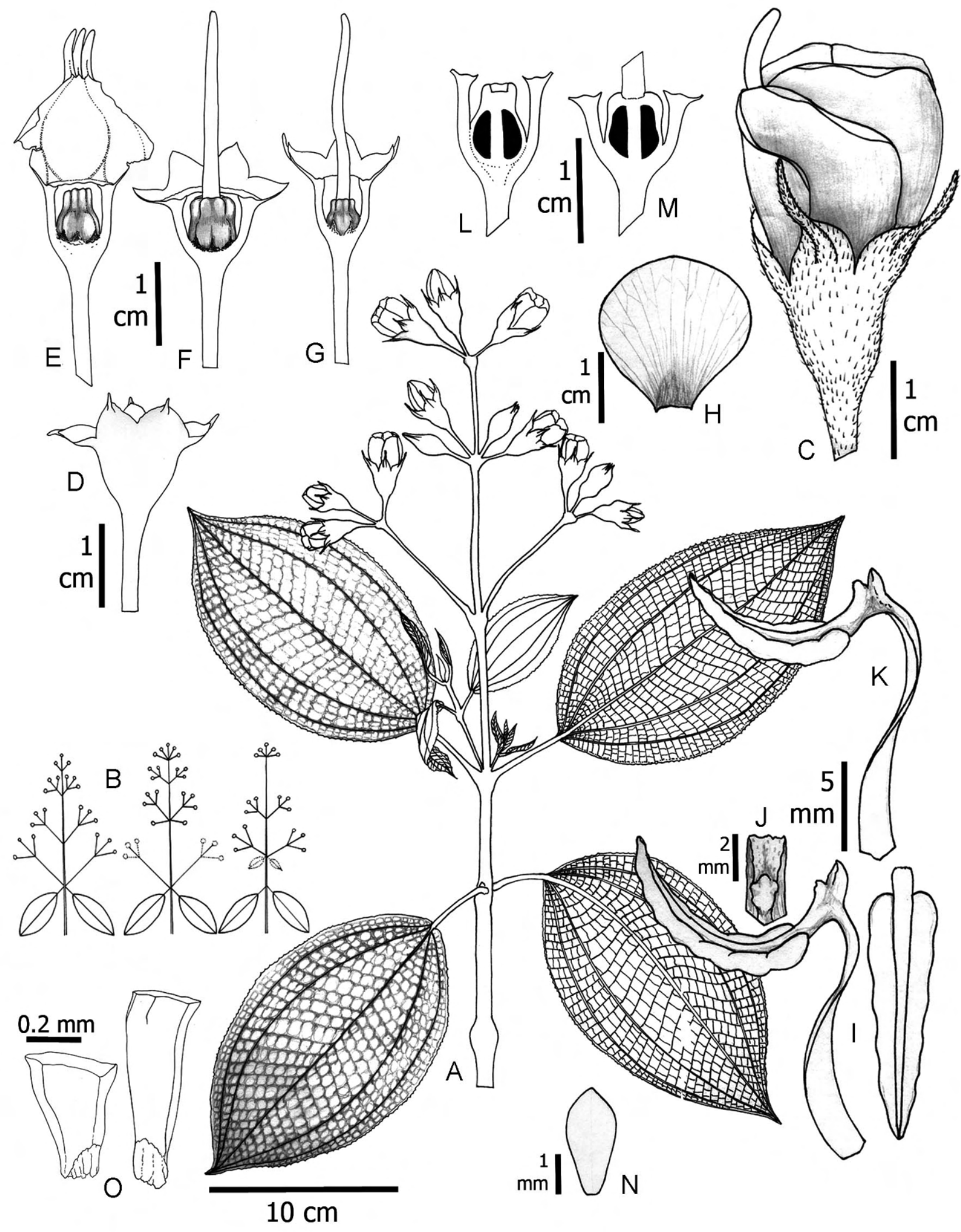

Figura 15: Meriania arborea (Naudin) Triana. A. rama florífera; B. esquema de las variaciones de la inflorescencia; C. flor; D. vista lateral del hipantocáliz; E, F, G. corte longitudinal del hipanto-cáliz y vista lateral del ovario; H. pétalo; I. estambres opositipétalos en vista lateral y dorsal; J. codo del estambre opositipétalo en vista dorsal; K. estambre opositisépalo; L, M. corte longitudinal del hipanto-cáliz y ovario; N. placenta en vista dorsal; O. semillas. A, E, L: Cuatrecasas 23313 (VALLE); C, D, F, H, I, J, K, M, O: Wurdack 2736 (US); G: Mendoza 2560 (FMB); N: Vélez 1737 derecha (COL) y Mendoza 14576 izquierda (FMB). 
te; cáliz subcaliptrado, abre en lóbulos regulares, internamente con líneas marrón oscuro a lo largo de las zonas de apertura; tubo 3-4 mm de largo, cae de forma circuncísil en frutos inmaduros; lóbulos 4-6 × 4-5 mm, internamente glabros o con ralos tricomas rizados aplanados; diente dorsal linear subulado, excediendo la longitud del lóbulo 3-6 mm; corola cuculada; pétalos 17-30 × 14-23 mm, obovados, ápice redondeado, rojo o anaranjados, glabros; estambres levemente dimorfos, los opositipétalos con la antera más robusta, color rojizo o morado claro, tecas de apariencia resupinada; estambres opositipétalos, filamento 7-13.5 $\mathrm{mm}$ de largo; codo 1.2-3 mm de largo, ápice truncado; conectivo dorsal con apéndice 0.5-1.3 mm de largo, a manera de diente o tuberculado; pedoconectivo $0.5-2 \mathrm{~mm}$ de largo; antera 7-12 mm de largo, oblongo subulada, arqueada hacia el dorso, poro apical o levemente dorsal; estambre opositisépalo, filamento 7-14 mm de largo; codo $2.5 \mathrm{~mm}$ de largo, ápice truncado; conectivo dorsal con apéndice 0.5-0.8 mm de largo, levemente tuberculado; pedoconectivo 0.5-1 mm de largo; antera 5-10 $\mathrm{mm}$ de largo, oblongo subulada, arqueada hacia el dorso, poro apical; ovario 4.2$10 \mathrm{~mm}$ de largo, 5-locular, oblongo-ovado, fusionado en la base al hipanto 1-2 mm en aristas; ápice con lóbulos redondeados, encerrando la base del estilo 0.4-0.5 mm; placentas 2.7-3.5 mm de largo, ovoides, rudimentos seminales en todas las superficies; estilo $18-25 \mathrm{~mm}$ de largo, cilíndrico, es más largo que la corola en flores abiertas, pero es inserto en botones; estigma puntiforme; cápsula 9-13 mm de largo sin incluir el pedicelo, acopada, inmersa completamente en el tálamo del hipanto; hipanto cartáceo, costillado; semillas 1-1.3 mm de largo, cuneiformes con ápice corto, recto, marrón oscuro; rafe no visible.

Notas taxonómicas: el nombre de esta especie cayó en desuso y prácticamente no fue utilizado desde de la publicación original de Naudin y posterior transferencia a Meriania por Triana en 1872; las colecciones de esta especie se asociaron principalmente a $M$. steyermarkii. Los caracteres con los que se le reconocen son las flores de corola tubulosa, cáliz subcaliptrado abriendo en lóbulos regulares, dientes dorsales del cáliz conspicuos (subulados y sobresaliendo de los lóbulos) y el indumento denso marrón claro en todas las superficies de tricomas subula- dos de base rizada, la inflorescencia laxa con menos de 25 flores, los estambres levemente dimorfos con apéndices conectivales dorsales conspicuos en ambas series y pedoconectivo (área basal del conectivo no cubierto por las tecas). Meriania steyermarkii comparte estos caracteres en su totalidad, por lo que se establece como una sinonimia ya que es el nombre más reciente. La especie más afín es $M$. dimorphanthera, la cual difiere en tener las flores más pequeñas, las inflorescencias con muchas flores (30 o más flores), los estambres sin apéndices conectivales dorsales en ambas series y regularmente sin pedoconectivo. Meriania costata Wurdack de Ecuador, caracterizada por la presencia de costillas externas en el hipanto, es también muy similar a $M$. arborea; no obstante, difiere en la coloración de los estambres, en la inflorescencia mucho más corta y menor número de flores.

En Meriania arborea el atrofiamiento de los ejes o ramas de la inflorescencia no es tan marcado como en otras especies asociadas a M. tomentosa (grupo Tomentosa). Se encuentran ramillas largamente pedunculadas que regularmente rematan en tres flores o un grupo de flores; también, presenta brácteas regularmente persistentes.

Distribución y hábitat: especie restringida a zonas andinas de Colombia y Venezuela, entre 1900 y 3300 m de elevación, en zonas de bosque andino y altoandino. En Colombia se encuentra en las cordilleras Central y Oriental, desde Quindío hasta Norte de Santander (Fig. 11).

Etimología: en alusión a su hábito de crecimiento.

Estado de conservación: categorizada como "Casi Amenazada" (NT) en la Lista Roja de la IUCN (2020).

Material examinado: COLOMBIA. Departamento Caldas, municipio Manizales, $9 \mathrm{~km}$ arriba de termales El Otoño, 2400 m, Ill.1990, fr, Orozco 004 (FAUC). Municipio Pereira, hoya del río Otún, arriba de Peñas Blancas, 3000 m, 27.XI.1946, fl, J. Cuatrecasas 23313 (US, VALLE). Departamento Norte de Santander, municipio Cucutilla, vereda Carrizal, Parque Natural Regional Sisavita, 2300 m, 28.II.2012, $\mathrm{fl}$, fr, F. Almeda 10564 (CAS, COL); vereda Sisavita, quebrada La Salina, arriba de la escuela, 2300-2500 m, 21.III.2002, fr, 
fl, H. Mendoza 14519 (FMB), 14576 (FMB); loc. cit., 2200 m, 8.XII.2001, fl, R. Sánchez 6057 (HECASA). Departamento Quindío, municipio Armenia, Navarco, 3000 m, XII-1943, fl, F. Zapata 522 (COL). Municipio Calarcá, estación Navarco, 2900 m, 10.IX.19990, fl, S. Zuluaga 4506 (COL). Municipio Génova, camino finca Las Nirlas-Servia, 1500-2700 m, 14.VII.1990, fr, M. C. Vélez 1737 (COL). Municipio Salento, Reserva Natura Alto Quindío, Acaime, 2680 m, 11.V.1991, fl, C. A. Agudelo 1533 (COL); Reserva Natura Alto Quindío, Acaime, estación La Picota, quebrada Monte-Loro, $2650 \mathrm{~m}$, 10.V.1990, fl, C. I. Orozco 2146 (NY). Departamento Santander, municipio Piedecuesta, vereda Cristales, estación experimental El Rasgón, 2200-2400 m, 19.IX.2004, fl, A. Dueñas 154 (FMB), 234 (FMB); loc cit., 19.IX.2004, st, H. Mendoza 16317 (FMB). VENEZUELA. Estados Lara - Trujillo, Páramo de Los Ñepes, 2570 m, 24.XII.1959, fl, H. G. Barclay 10315 (COL, MO, US). Estado Mérida, carretera Estanques - El Molino, $45 \mathrm{~km}$ de Estanques, 2750 m, 31.V.2008, fl, fr, F. Michelangeli 1266 (NY); municipio Arzobispo Chacón, Páramo Las Coloradas, $1 \mathrm{~km}$ después de El Portachuelos (El Ramal), entre las poblaciones de Santa Cruz de Mora y El Molino. Municipio Estanques, 2380 m, 7.IV.1966, fl, L. Ruiz-Terán 3018 (CAS, US); Cuesta de Rincón and Cuesta del Barro, between Canagua and La Quebrada, on road to El Molino, 1925-2175 m, 10.V.1944, fl, J. Steyermark 56463 (NY). Municipio Rivas Dávila, Sierra Tovar, road to Mesa de Bustamante to the $S$ of La Playita, 2700 m, 24.VIII.1973, fl, S. S. Tillett 738-392 (COL, US); between Santa Cruz and Canagua, 2780 m, 10.XI.1972, fl, J. J. Wurdack 2736 (NY, US). Estado Trujillo, municipio Boconó, Selvas de Guaramacal, $20 \mathrm{~km}$ al E de Boconó, 19002300 m, 7.II.1987, fl, G. Aymard 5206 (MO, NY).

Meriania arizae Humberto Mend. \& Fern. Alonso, Anales Jard. Bot. Madrid 69(2): 267-269. 2012. Figs. 13D-E, 16. TIPO: COLOMBIA. Departamento Santander, municipio Encino, Reserva Biológica Cachalú, 1900-2200 m, 18.VII.2002, fl, N. R. Salinas 130 (holotipo: COL!; isotipo: COL!).

Árboles 4-8 m de altura; entrenudos oblongo-aplanados; ramas, pecíolo, envés foliar e inflorescencia con indumento denso de tricomas filiformes rojizos perpendiculares a la superficie (tipo 11), 3.2-4.5 mm de largo; las estructuras anteriores, hojas jóvenes, cáliz, caliptra y venas por el envés adicionalmente con indumento denso de tricomas esponjosos irregulares rojizos en material fresco, marrón oscuro en muestras secas (tipo 30), 0.4-0.5 mm de largo; hojas con pecíolo 2.3-5 cm de largo; lámina 20-30 × 10-14 cm, ovalada u oblongo-ovalada; base levemente cordada; ápice agudo; margen espaciadamente denticulado; haz glabro, pero en hojas jóvenes con indumento de tricomas esponjosos irregulares diminutos (tipo 25), rojizos en material fresco; envés con indumento de tricomas esponjosos irregulares diminutos sobre la nervadura y tricomas filamentosos lisos (tipo 11), 0.7-0.9 mm de largo sobre la vena media; nervadura con 2 pares de venas basales; inflorescencia 40-55 cm de largo, péndula; eje central con 4-6 nudos de ramificación, 70 a 130 flores; paracladios $8-10 \mathrm{~cm}$ de largo, con 3 niveles de ramificación; ramificaciones de ápices con entrenudos cortos produciendo terminaciones con 4-5 flores; flor pedicelada, 5-mera; pedicelo 7-9.5 mm de largo; hipanto 4.8-6.3 mm de largo, ciatiforme, externamente pubescencia densa de tricomas harinosos marrón oscuro; torus sin callosidades, 1-1.2 mm grosor; cáliz caliptrado; caliptra 6-9 mm de largo, ápice agudo a obtuso, indumento similar al hipanto; parte basal del cáliz con un tubo relictual 2.8-3.8 mm de largo; corola patente; pétalos $16-23 \times 16-20 \mathrm{~mm}$, obovados de ápice truncado emarginado, fucsia oscuro; estambres isomorfos, filamento 8-11 $\mathrm{mm}$ de largo; codo 2.3-3 mm de largo, triangular; conectivo dorsal con apéndice $2.5-3 \mathrm{~mm}$ de largo, subulado; antera 7-9.2 $\mathrm{mm}$ de largo, subulada sigmoidea, poro dorsal; ovario 3-3.8 mm de largo, 5-locular, oblongo, completamente súpero; ápice con apéndices redondeado-truncados; placentas 1.9-2 mm de largo, obovadas a oblongas, rudimentos en todas las superficies; estilo 11-14 mm de largo, obcónico; estigma levemente glandiforme, 0.3-0.4 mm diámetro; cápsula 7.5-8.2 mm de largo, hipanto ciatiforme de paredes delgadas, levemente costillado en su parte externa; fruto completamente inmerso en el hipanto; semillas no vistas.

Notas taxonómicas: esta especie se caracteriza por la pubescencia densa y rojiza con tricomas filamentosos en los entrenudos y por la inflorescencia larga y péndula. Se puede confundir con M. mutisii de Cundinamarca, pero se diferencia por tener las flores más pequeñas, el ápice del ovario redondeado y el hipanto de paredes delgadas papiráceas. 


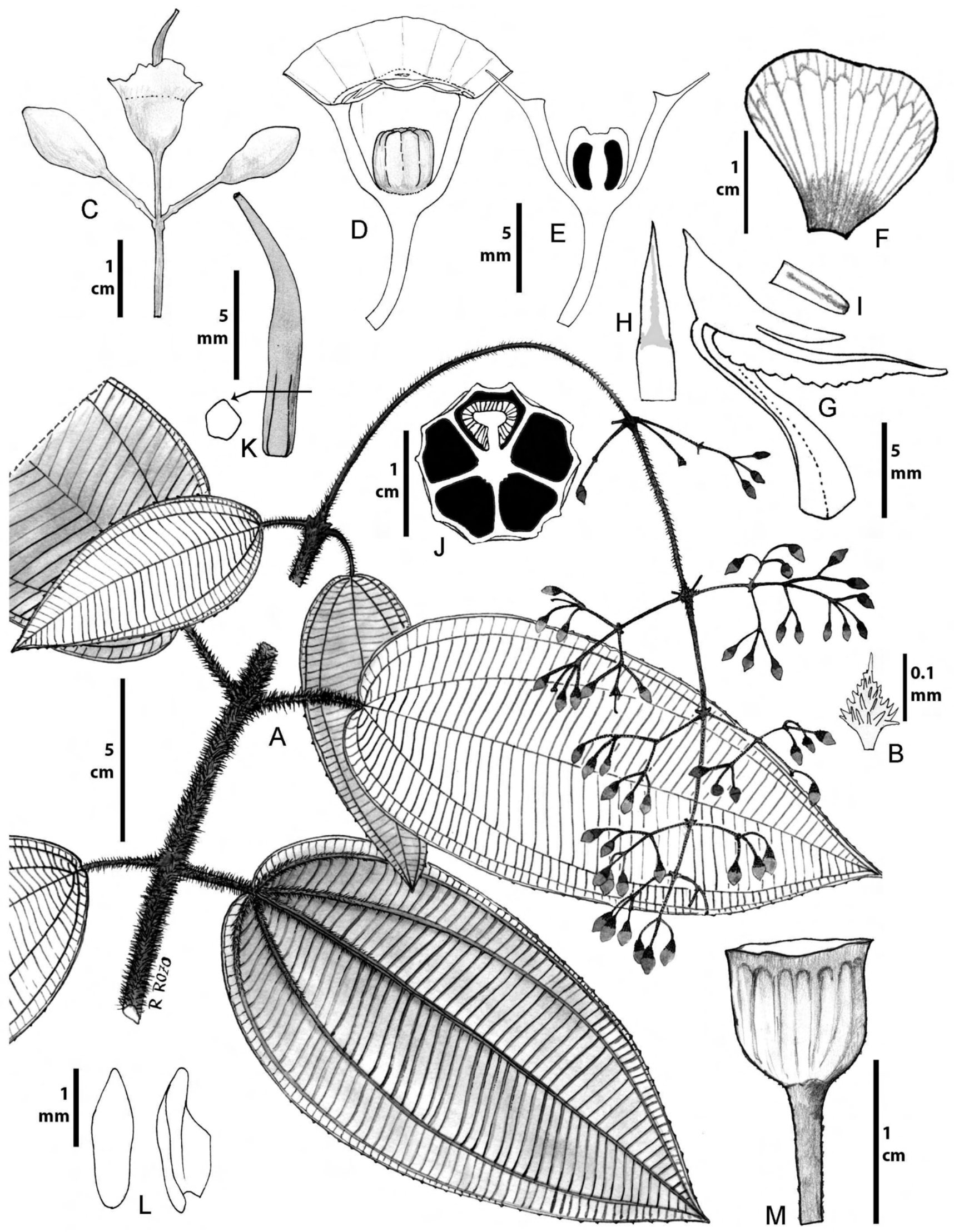

Figura 16: Meriania arizae Humberto Mend. \& Fern. Alonso. A. rama florífera; B. tricomas del hipanto; C. botones florales y flor sin pétalos; D. corte Iongitudinal del hipanto; E. corte longitudinal de hipanto-ovario; F. pétalo; G. estambre; H. codo ápice del filamento; I. vista dorsal del apéndice conectival; J. corte horizontal del ovario; K. estilo; L. vista frontal y lateral de la placenta; M. fruto. A-L: Salinas 130 (COL); M: Crespo 42 (UDBC); tomada de Mendoza-Cifuentes y Fernández-Alonso (2012). 
Distribución y hábitat: conocida hasta el momento solo de las localidades tipo en los departamentos Santander y Boyacá, Cordillera Oriental de Colombia, entre 1700 y 2000 $m$ de elevación en zonas de bosque subandino (Fig. 17). Puede crecer en interior de bosque, en bordes o zonas abiertas.

Nombre vernáculo y usos: en Boyacá estos árboles son conocidos como "churumbelitos" y se siembran en jardines como especie ornamental.

Etimología: en honor al ingeniero forestal William Ariza, profesor de la Universidad Distrital Francisco José de Caldas, Bogotá.

Estado de conservación: categorizada como Vulnerable (VU) (Mendoza-Cifuentes y Fernández-Alonso, 2012), y posteriormente como "Amenazada" (EN) en la Lista Roja de la IUCN (2020). Esta última categoría es más concordante con la realidad actual de conservación, ya que solo se conoce de dos localidades ubicadas hacia el centro de la Cordillera Oriental colombiana, área en proceso continuo de fragmentación de los bosques.

Material examinado: COLOMBIA. Departamento Boyacá, municipio Moniquirá, vereda el Ajizal, Bella Isla, 1700 m, 24.I.2008, fr, F. Crespo 42 (UDBC). Departamento Santander, municipio Encino, Reserva Biológica Cachalú, 2000 m, 29.VI.2008, fr, A. Jiménez 121 (UDBC).

Meriania barbosae Humberto Mend., Alvear \& Almeda, Phytotaxa 178(1): 24-26. 2014. Figs. 13F, 18. TIPO: COLOMBIA. Departamento Caldas, municipio Samaná, Florencia, de Ranchoquemado por la vía a Pensilvania (Parque Nacional Natural Selva de Florencia), 1800-2000 m, 523'13"N-759'48"W, 27.IX.1993, fl, C. Barbosa 14932-95 (holotipo: FMB!; isotipos: COL!, HUA!).

= Meriania juan-canoi Posada-Herrera, Idárraga \& Alzate, Phytotaxa 442(3): 226. 2020. TIPO: COLOMBIA. Departamento Antioquia, municipio La Unión, Mesopotamia, localidad El Cardal, 2450 m, 553'30"N-75¹8'35"W, 28.VI.2018, $\mathrm{fl}, \mathrm{fr}$, J. S. Murillo et al. 103 (holotipo: HUA; isotipos: COL, FMB!), syn. nov.
Árboles 4-6 m de altura; entrenudos cuadrangulares; ramas, pecíolo, inflorescencia e hipanto-cáliz con indumento denso marrón rojizo de tricomas alargados, ramificados, de paredes alveoladas (tipo 12 pero ramificados), 0.3-1.2 $\mathrm{mm}$ de largo, ralos tricomas glandulares hialinos cortamente pedunculados (tipo 6) ca. $0.1 \mathrm{~mm}$ de diámetro, algunos sobre las paredes de los tricomas alargados; hojas con pecíolo 2-5.2 cm de largo; lámina 16.5-20.5 × 9-11.5 $\mathrm{cm}$, ovada a elíptica; ápice agudo o levemente acuminado; base redondeada, peltada o levemente cordada; margen entero a levemente crenulado; haz glabro; envés con indumento sobre toda la nervadura de tricomas similares a los de las ramas pero más pequeños, adicionalmente con abundantes tricomas glandulares hialinos cortamente pedunculados; nervadura con 2-3 pares de venas secundarias acompañando a la vena media, solo 2 llegan al ápice, basales (de apariencia plinervia pero nacen donde se inserta el pecíolo); inflorescencia $10-25 \mathrm{~cm}$ de largo, pedunculada o sésil, con 6-13 flores; eje central con 2-3 nudos de ramificación, cuadrangular, pedúnculo $3-3.5 \mathrm{~cm}$ de largo, sin brácteas, bractéolas lineares deciduas; paracladios $6-8 \mathrm{~cm}$ de largo, no ramificados; ramillas trifloras, regularmente con huellas de flores abortadas en la base de las flores persistentes; flor pedicelada, 5-mera; pedicelo 7-17 mm de largo; hipanto 9-11 mm de largo, ciatiforme, externamente liso, con indumento denso como en la inflorescencia; torus engrosado 4-4.5 mm; cáliz caliptrado; caliptra apicalmente obtusa en botones, indumento similar al de la inflorescencia y ramas, abre por fisuras irregulares, parte del tálamo queda sujeto al hipanto posterior a la dehiscencia, en fruto permanece un tálamo de unos $5 \mathrm{~mm}$ de largo; dientes dorsales a manera de cayos rugosos; corola patente; pétalos 29-32 × 21-26 mm, obovados, de ápice truncado emarginado, fucsia, glabros tornándose rosado claro con la edad; estambres levemente dimorfos, los opositipétalos mayores por la longitud de la antera; estambre opositipétalo, filamento 1.6-2.3 mm de largo; codo 5.5-1.2 mm de largo, triangular; conectivo dorsal ca. 4-5 mm de largo, subulado; antera ca. 12-15 mm de largo, subulado sigmoidea, poro dorsal; pedoconectivo 1.3-2.6 mm de largo; estambre opositisépalo, filamento de 1.7-1.8 mm de largo; codo 3-3.2 $\mathrm{mm}$ de largo, anchamente triangular; conectivo dorsal con apéndice 2.1-3.5 mm de largo, subulado, apicalmente agu- 

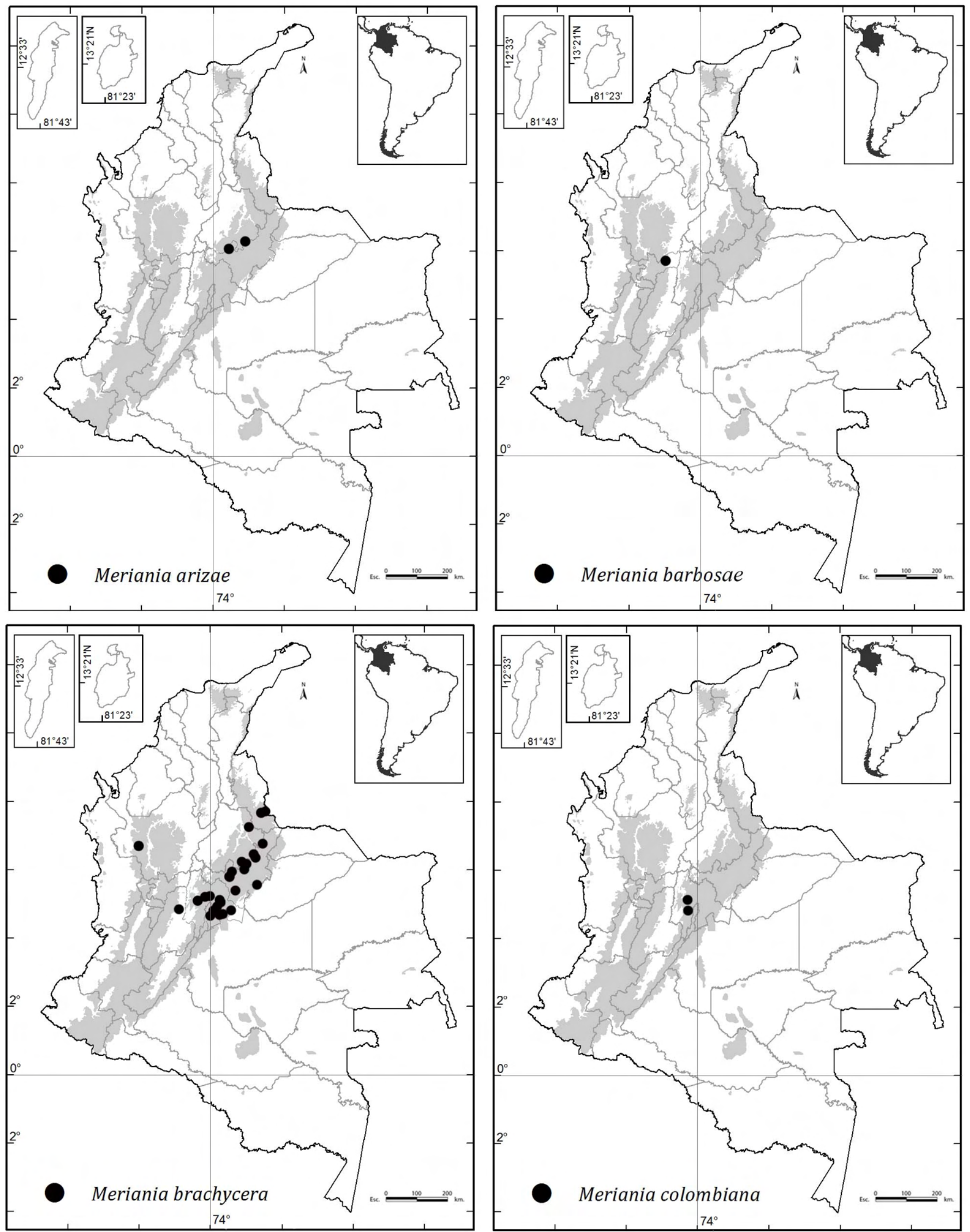

Figura 17: Distribución geográfica de Meriania arizae Humberto Mend. \& Fern. Alonso, M. barbosae Humberto Mend., Alvear \& Almeda, M. brachycera (Naudin) Humberto Mend. \& Fern. Alonso y M. colombiana Gleason. 


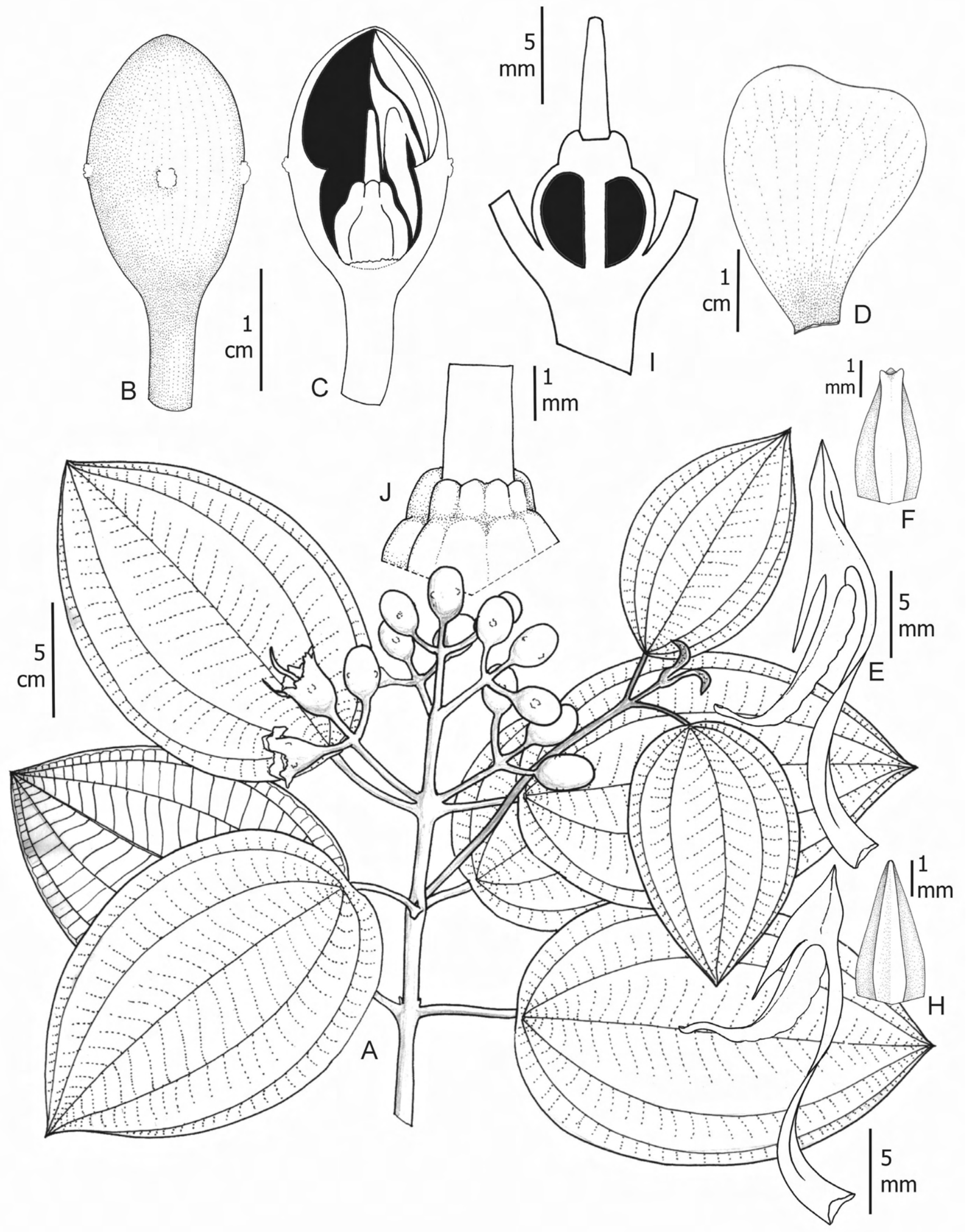

Figura 18: Meriania barbosae Humberto Mend., Alvear \& Almeda. A. rama florífera; B. botón floral; C. corte longitudinal del botón floral; D. pétalo; E. estambre opositipétalo; F. codo del estambre opositipétalo en vista dorsal; G. estambre opositisépalo; H. codo del estambre opositisépalo en vista dorsal; I. corte longitudinal de ovario-estilo; J. ápice del ovario. A-H: Barbosa 14923-95 (FMB); tomada de Mendoza-Cifuentes et al., 2014. 
do o levemente bífido; antera 10-11 mm de largo, subulada, fuertemente arqueada hacia el dorso, poro dorsal; sin pedoconectivo; ovario 6-7 mm de largo, 5-locular, ovoide, súpero, fusionado en la base al hipanto $1 \mathrm{~mm}$; ápice con escasos lóbulos dentiformes que no alcanzan a encerrar la base del estilo; placentas 2.1-2.3 mm de largo, obovadas, rudimentos seminales en todas las superficies; estilo 1.8 cm de largo, cilíndrico, curvo hacia el ápice en flores abiertas; estigma levemente expandido; cápsula 13-17 mm de largo, encerada completamente por el hipanto y parte del tubo del cáliz; semillas 2.5-2.7 mm de largo, cuneiformes con el ápice o lado chalazal alargado.

Notas taxonómicas: Meriania barbosae posee la siguiente combinación única de caracteres dentro del género: hojas levemente peltadas, con indumento de tricomas glandulares hialinos cortamente pedunculados por el envés, cáliz caliptrado, corola patente y estambres levemente dimorfos con apéndices conectivales dorsales subulados. La especie más afín es $M$. selvaflorensis, la cual es una liana y tiene grandes inflorescencias de ramillas delgadas y no presenta el indumento rufo denso. Meriania barbosae, junto con $M$. selvaflorensis y $M$. ramosii, conforman un grupo caracterizado por el cáliz caliptrado y los tricomas glandulares hialinos sésiles. Este conjunto de especies podría asociarse al grupo Brachycera (Mendoza-Cifuentes y Fernández-Alonso, 2012), pero difiere de él por los tricomas glandulares y los estambres levemente dimorfos.

Meriania juan-canoi, recientemente descrita (Posada-Herrera et al., 2020) comparte las características diagnósticas de $M$. barbosae y adicionalmente sus tipos provienen de localidades relativamente cercanas (separadas cerca de $65 \mathrm{~km}$ lineares). Sus diferencias radican en que $M$. juan-canoi presenta hojas con nerviación plinervia (vs. basal), base foliar no subpeltada (vs. subpeltada a levemente cordada), codo del estambre subulado y mucronado (vs. triangular), apéndice conectival en los estambres opositisépalos levemente bífido (no detectado en $M$. barbosae) y ovario completamente súpero (vs. fusionado en la base $1 \mathrm{~mm}$ ). Algunas de estas diferencias para M. juan-canoi se deben a una apreciación inexacta de los caracteres. La nerviación de $M$. juan-canoi es basal y no plinervia, ya que las venas secundarias nacen de donde se inserta el ápice del pecíolo, carácter que se aprecia en la ilustración y en las imágenes de su publicación. La base de la lámina foliar varía entre subpeltada y levemente cordada, la forma del codo del estambre es triangular y no subulada. La diferencia más notable entre estos dos taxones se encuentra en el ápice levemente bífido del apéndice conectival del estambre opositisépalo, carácter que pasó inadvertido en la publicación original de $M$. barbosae, posiblemente por describirse de material seco rehidratado o por variaciones poblacionales. Igualmente, el ovario completamente súpero puede deberse a una variación poblacional leve, ya que en $M$. barbosae $84-88 \%$ de la longitud del ovario es libre del hipanto. Otros caracteres variables entre estos dos taxones son el tamaño de la inflorescencia y su grado de ramificación, así como la forma de los dientes dorsales de la caliptra; no obstante, esto también se debe a una apreciación inexacta de donde empieza la inflorescencia y de la forma de los dientes dorsales, los cuales son a manera de cayos en los dos taxones.

Distribución y hábitat: hasta ahora conocida solo de tres localidades en los departamentos de Antioquia y Caldas, en el flanco oriental de la Cordillera Central, entre 1500 y 2500 m de elevación (Fig. 17).

Etimología: en honor al botánico César Barbosa, quien fue el primer colector de plantas en el Parque Nacional Natural Selvas de Florencia, de donde procede el tipo.

Estado de conservación: categorizada como "Peligro Crítico" (CR) (Mendoza-Cifuentes et al., 2014) y recategorizada como "Amenazada" (EN) en la Lista Roja de la IUCN (2020). Esta última recategorización es más acertada que la original, considerando que una de las localidades se encuentra en un área de conservación. Es importante implementar su propagación ex situ considerando su potencial ornamental y su reducida área de distribución donde los bosques se encuentran fuertemente fragmentados.

Material examinado: COLOMBIA. Departamento Antioquia, municipio Cocorná, El Viaho, antigua escuela, 2400 m, 27.X.1999, st, A. Gil 234 (HUA). Municipio Guatapé, vereda Santa Rita, 1850 m, 23.X.1986, fr, L. Albert de Escobar 
7219 (HUA). Departamento Caldas, municipio Samaná, corregimiento de Florencia, Parque Nacional Natural Selva de Florencia, sector de manejo Florencia, sendero Bocatomas, cerca de Río Claro, 1573 m, 2.III.2011, fr, M. Alvear 1459 (CAS, COL, NY).

Meriania brachycera (Naudin) Humberto Mend. \& Fern. Alonso, Anales Jard. Bot. Madrid 69(2): 269-274. 2012. Figs. 13G-H, 19.

三 Calyptraria brachycera Naudin, Ann. Sc. Nat. Sér. 3, 18: 134. 1852. TIPO: COLOMBIA. Prov. Pamplona (departamento Norte de Santander): La Baja, 3000 m, fl, fr, Funck \& Schlim 1310 (holotipo: P!; isotipos: BR!, G!, MPU!, P!, fragmento en $\mathrm{F}$ etiquetado como Lehmann 1310!).

= Calyptraria eximia Naudin, Ann. Sci. Nat. Ser. 3 Bot. 18: 133. t. 5. f. 3. 1858. TIPO: COLOMBIA. Crescit in monte Quindiu, alt. 770 hex", fl, A. Bonpland s.n. (holotipo: P!; isotipo: P!).

इCentronia brachycera (Naudin) Triana, Trans. Linn. Soc. Bot. 28: 72. 1872.

= Centronia eximia (Naudin) Triana, Trans. Linn. Soc. Bot. 28: 72.1872.

= Centronia pulchra Cogn., Monographiae Phanerogamarum 7. 1891. TIPO: Venezuela. Mérida, fl, Engels s.n. (holotipo: $\mathrm{P}$; isotipo: $\mathrm{BR}$ !).

= Centronia dichromantha L. Uribe, Caldasia 9: 324. 1965. TIPO: COLOMBIA. Boyacá, páramo de La Rusia, 3000 m, fl, fr, L. Uribe 4246 (holotipo: COL 99745!; isotipo: COL 99744!).

Árboles 5-18 m de altura; entrenudos aplanados a subcuadrangulares; ramas, pecíolos, envés foliar, inflorescencia, cáliz e hipanto con indumento denso de tricomas esponjosos irregulares ferrugíneos (tipo 31), algunas veces aplanados lateralmente; en estas superficies, excepto el envés, frecuentemente se presentan esparcidos tricomas setosos rojizos (tipo 11), 2-4.8 mm de largo, caedizos; hojas con pecíolo 1-6.5 cm de largo; lámina 4.5-15.5 × 2.1-7.2 cm, ovado-elíptica, ovada u elíptica, menos frecuente oblongoelíptica u oblongo-ovada; base redondeada a obtusa o muy raras veces levemente peltada, raras veces revoluta; ápice agudo u obtuso; margen espaciadamente denticulado; haz glabro o raras veces con tricomas esponjosos irregulares diminutos (tipo 25); envés cubierto totalmente con un indumento de tricomas aracnoideos (tipo 34), raras veces el indumento es parcial, regularmente con mechones de tricomas setosos (tipo 11) de 3-5.5 mm de largo en la axila de las primera venas secundarias; nervadura con dos pares de venas plinervias, muy raras veces tres pares de venas, el primer par más cercano a la vena media plinervio a 2-15 $\mathrm{mm}$ arriba de la base; inflorescencia 7-22 cm de largo; eje central con 2-4 nudos de ramificación, 5 a 35 flores; paracladios 3.5-15.5 cm de largo, 1-2 niveles de ramificación; ramificaciones de ápices trifloros, algunas veces los entrenudos se acortan produciendo terminaciones con 5 flores; ramificaciones basales algunas veces completamente atrofiadas; flor pedicelada, 5-7-mera; pedicelo 4-14 mm de largo; hipanto 4.3-7.5 mm de largo, hemisférico a obcónico, externamente con pubescencia densa de tricomas similares a los entrenudos, adicionalmente esparcidos cuerpos verrugosos; paredes 1-2.5 mm grosor; torus con engrosamientos callosos en la base de los estambres opositipétalos; cáliz caliptrado, caliptra 8-18 mm de largo, ápice agudo o apiculado; corola patente; pétalos 20-53 × 17-47 mm, obovados de ápice truncado-emarginado, fucsia oscuro; estambres isomorfos, filamento $6-20 \mathrm{~mm}$ de largo; codo 1.4-6.6 mm de largo, subulado; conectivo dorsal con apéndice 0.3-1.5 mm de largo, subulado a romo; antera 7.2-9.5 $\mathrm{mm}$ de largo, subulada, sigmoidea, poro dorsal; polen 12.5$13 \mu \mathrm{m}$ diámetro; ovario 4.5-10 mm de largo, 5-7-locular, oblongo a ovado, ligeramente fusionado en la base con el hipanto 0.5-1 mm, raras veces completamente súpero, en corte transversal en su parte media tiene 5 a 7 costillas levemente alzadas, de lomo aplanado; ápice con apéndices subulados 0.5-2.5 mm de largo coronando cada carpelo, raras veces ausentes o truncados; placentas 1.8-3.4 mm de largo, obovadas, rudimentos seminales en todas las superficies; estilo 10-15 mm de largo, columnar-cónico; estigma puntiforme; cápsula 9-17 mm de largo, con el hipanto leñoso ciatiforme, fruto propiamente oblongo, 8-10 mm diámetro, sobresaliendo su mitad superior del hipanto; semillas 1.5-1.7 mm de largo, cuneiformes con el ápice corto.

Notas taxonómicas: esta especie se reconoce por el indumento denso por el envés que cubre completamente la superficie, la nervadura plinervia y las flores caliptradas. 


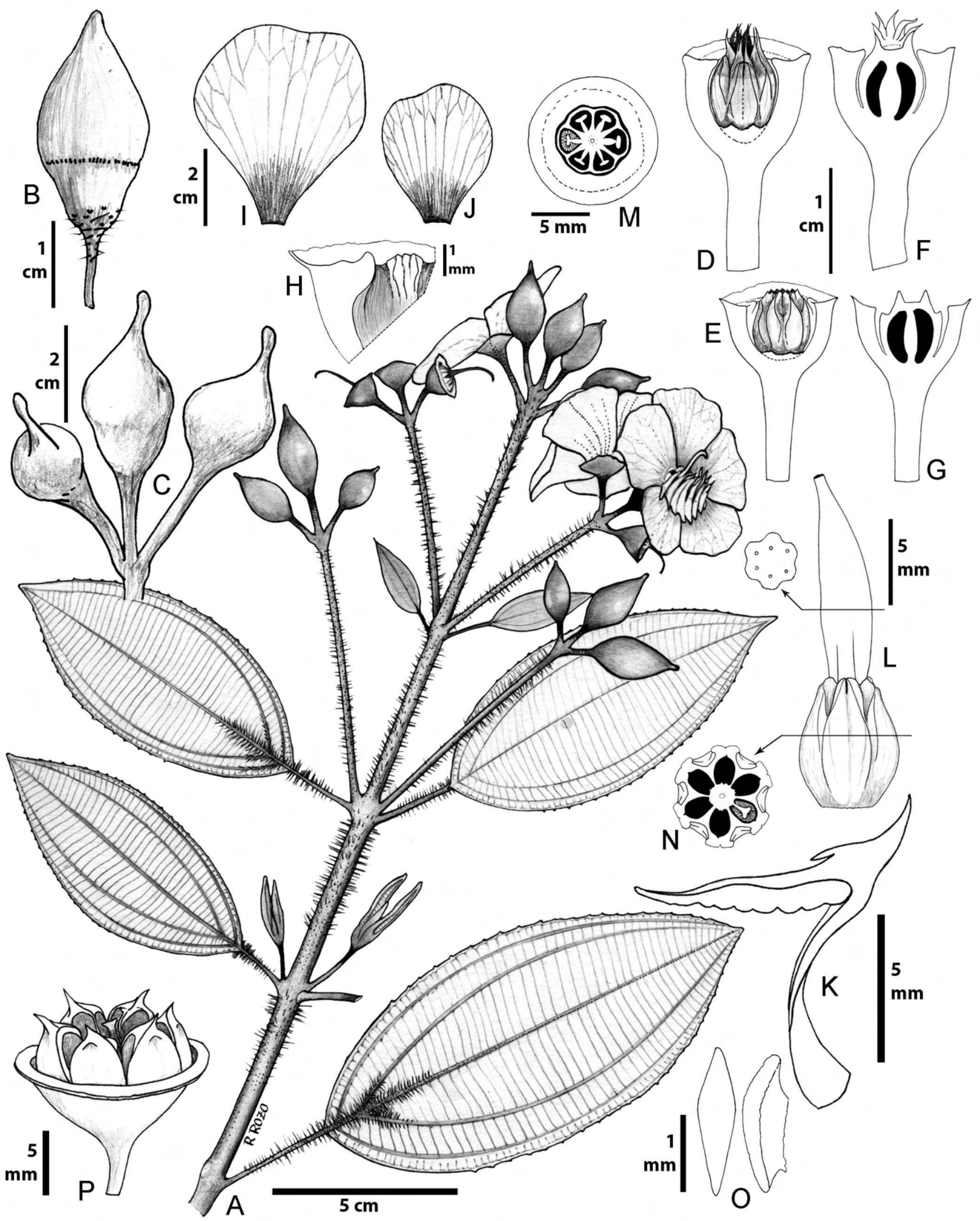

Figura 19: Meriania brachycera (Naudin) Humberto Mend. \& Fern. Alonso. A. rama florífera; B, C. botones florales; D, E. cortes longitudinales del hipanto y vista lateral del ovario; F, G. cortes longitudinales del hipanto y del ovario; $\mathrm{H}$. vista de parte del torus con rebordes frente a los pétalos; I, J. pétalos; K. estambre; L. ovario y estilo; M. corte transversal del hipanto-ovario en el botón floral; N. corte horizontal del ovario; O. vista frontal y lateral de la placenta; P. fruto. A: Prieto 1918 (FMB); B, P: Uribe 4246 (COL); C, H, L, N: Prieto 1768 (FMB); D, F, J, M: Mendoza 17376 (FMB); E, G, I, K: Duran s. n. (COL); O: Rodríguez 23 (COL); tomada de Mendoza-Cifuentes y Fernández-Alonso (2012). 
Se diferencia de especies afines como M. aguaditensis por el indumento del envés, de $M$. mutabilis por las venas plinervias y de $M$. haemantha por el menor número de venas secundarias de las hojas y el indumento de las hojas y del hipanto-caliptra.

Distribución y hábitat: esta especie habita en los Andes de Colombia y Venezuela (estados Mérida y Táchira). En Colombia está restringida a la Cordillera Oriental, entre 2000 y 3350 m de altitud, en los departamentos Boyacá, Cundinamarca, Huila, Meta, Norte de Santander y Santander (Fig. 17). La mayoría de los registros se concentran hacia el flanco occidental de la cordillera (vertiente del río Magdalena); son pocos los registros para flanco en los departamentos de Meta y Boyacá. Hay una población disyunta en el páramo de Frontino, departamento Antioquia, Cordillera Occidental. Predominante en zonas de vegetación de subpáramo y bosque altoandino; también se encuentra esporádicamente en zonas de bosque andino. Parte del área de distribución de esta especie coincide con zonas de robledales (bosques dominados por Quercus humboldtii Bonpl.).

Nombres vernáculos: en Colombia es conocida como "arracacho" o "morcato" en Norte de Santander (Triana, 1872), "tuno roso" en Huila y Cundinamarca en las localidades Fómeque y Chingaza, "sietecueros" o "liberal" en el Páramo de La Rusia en Boyacá.

Etimología: el epíteto específico significa "espolón corto" en alusión al codo que forman el ápice del filamento y la base de la antera.

Estado de conservación: categorizada como "Preocupación Menor" (LC) (Mendoza-Cifuentes y FernándezAlonso, 2012).

Material examinado: COLOMBIA. Departamento Antioquia, municipio Belmira, camino viejo entre Belmira y Santa Rosa de Osos, páramo, 2800-3000 m, 15.VII.1987, fl, O. Marulanda 432 (COL, HUA). Municipio Peque, vereda Las Toldas, Alto del Poal, D. Benítez 117 (JAUM). Municipio Sal- gar, vereda La Liboriana, camino al Cerro Plateado, $1800 \mathrm{~m}$, J. C. Marrugo 1098 (MEDEL). Municipio Urrao, Páramo de Frontino, 3070 m, 9.I.1984, fl, R. Londoño 181 (COL, US); Páramo de Frontino, 3200-3600 m, 19.XI.1988, fl, G. McPherson 13170 (HUA, JAUM, MO, US). Departamento Boyacá, municipio Arcabuco, Santuario de Flora y Fauna Iguaque, 2900-3000 m, 28.VI.2008, fl, H. Mendoza 17376 (FMB). Municipio Chinavita, cerro Mamapacha, 3250 m, 11.XII.1999, fl, S. Cortés 3077 (COL). Municipio Chiscas, vereda Duartes Arriba, Montaña de Duartes, 2962 m, 22.II.2012, fr, F. Almeda 10531 (CAS, COL). Municipio Duitama, carretera de Virolín, hacienda La Rusia, 2900 m, 12.X.1959, fr, L. Uribe 3400 (COL, NY); entre Duitama y Charalá, carretera de Virolín, vertiente occidental del Páramo de La Rusia, 3200 m, 19.IV.1965, fl, L. Uribe 5219 (COL, F, NY). Departamento Cundinamarca, municipio Choachí, carretera a Ubaté, 3100 m, 2.VI.1959, fl, fr, H. García Barriga 17162 (COL, NY, US); Fómeque-Guasca, Chingaza, 2900-2970 m, 21.XI.2003, fl, A. Prieto 1921 (FMB), 1928 (FMB), 1936 (FMB). Municipio Guasca, vereda Potreritos, Reserva Forestal Cárpatos, 2750 m, 21.IX.2003, fl, A. Avella 30 (FMB); páramo de Guasca, vertiente oriental, 2900-3000 m, 27.VIII.1941, fl, J. Cuatrecasas 11981 (COL, F, NY, US). Municipio La Vega, 2600-3000 m, 21.XII.1926, E. P. Killip 15879 (F, MO, NY, US). Bogotá, Páramo del Retiro, 3000-3100 m, 27.VII.1942, fl, fr, R. E. Schultes 3186a (COL, NY). Departamento Huila, divide at extreme N. end, Camp., La Tabanera, 2900 m, 7.I.1944, fr, E. L. Little, Jr. 7035 (COL, NY, US). Departamento Meta, municipio San Juanito, Parque Nacional Natural Chingaza, 2990 m, 22.XI.2003, st, H. Mendoza 15570 (FMB), 15574 (FMB). Departamento Norte de Santander, municipio Chinácota, vereda Iscalá, Alto de Mejué, 2600 m, 26.II.2012, fr, F. Almeda 10547 (CAS, COL). Municipio Toledo, vereda Quebradagrande, 2520 m, 3.III.2012, fl, F. Almeda 10593 (CAS, COL). Departamento Santander, municipio Encino, Vereda Río Negro, 2900 m, 12.XII.1999, fr, R. Galindo 181 (COL), 190 (COL); carretera del páramo de Guantiva a Onzaga, 2970-3100 m, 27.XI.1967, fr, fl, R. Jaramillo-Mejía 4430 (COL), 4422 (COL). Municipio Onzaga, páramo de Guantiva, 3400 m, 27.XI.1967, fr, R. Jaramillo-Mejía 4323 (COL); vereda Chaguacál, 3040-3190 m, 31.X.1987, fl, C. I. Orozco 1829 (COL). 
Meriania colombiana Gleason, Bull. Torrey Bot. Club 68: 245. 1941. Fig. 20. TIPO: COLOMBIA. Departamento Cundinamarca, Dintel (Facatativá-La Vega), 2300-2700 m, 4.VI.1939, fl, E. Pérez-Arbeláez 5285 (holotipo: NY!; isotipos: COL!, F!, US!).

Arbustos o árboles hasta $12 \mathrm{~m}$ de altura; entrenudos cuadrangulares de aristas redondeadas; ramas, ejes de la inflorescencia y pecíolos con indumento rufo denso de tricomas subulados de base barbelada (tipo 21), hasta $2 \mathrm{~mm}$ de largo; hojas con pecíolo $2-4 \mathrm{~cm}$ de largo; lámina $12-20 \times 5.5-9 \mathrm{~cm}$, elíptica; base y ápice obtusos; margen entero; haz liso, glabro; envés conspicuamente reticulado por la nervadura terciaria, con indumento denso similar al de las ramas y pecíolos; nervadura con 2 pares de venas secundarias acompañando a la vena media, plinervias 5-8 $\mathrm{mm}$ arriba de la base; inflorescencia $10-20 \mathrm{~cm}$ de largo, eje central con 2 a 4 nudos de ramificación, el nudo basal regularmente atrofiado, brácteas semejantes a hojas pequeñas, 3-15 flores; paracladios 4-6 cm de largo, algunas veces con 2 nudos de ramificación; ramillas apicales con ejes atrofiados por lo que rematan en puntos glomerulares con más de tres flores, ramillas basales trifloras; flor pedicelada, 5-mera; pedicelo 10-15 mm de largo; hipanto 6-8.5 mm de largo, ciatiforme, externamente con indumento denso similar al de las ramas; cáliz subcaliptrado, abriendo en lóbulos regulares, anchamente triangulares; dientes dorsales subulado-lineares, excediendo la longitud del lóbulo 8-10 mm; corola cuculada; pétalos 20-24 × 22-23 mm, obovados, de ápice redondeado o truncado asimétrico, rojo-anaranjado, glabros; estambres levemente dimorfos, los opositipétalos mayores principalmente por el tamaño de la antera; estambres opositipétalos, filamento $10-11 \mathrm{~mm}$ de largo; codo 1.8-2 mm de largo, dentiforme, liso; pedoconectivo ausente; conectivo dorsal liso, sin apéndices; antera 11-12 mm de largo, oblongo-subulada, recta, poro apical; estambres opositisépalos, filamento $8.4-9 \mathrm{~mm}$ de largo; codo $0.8 \mathrm{~mm}$ de largo, dentiforme, liso; conectivo dorsal sin apéndices; antera 9-10 $\mathrm{mm}$ de largo, oblongo-subulada, recta, poro apical; ovario $4 \mathrm{~mm}$ de largo, 5-locular, oblongo, fusionado en la base al hipanto 2-3 mm en aristas; ápice redondeado, con leves lóbulos que encierran la base del estilo 0.3-0.5 $\mathrm{mm}$; placentas 2-2.5 mm de largo, elípticas a ovoides, ru- dimentos seminales en todas las superficies; estilo 2.9-3.4 $\mathrm{mm}$ de largo, cilíndrico, exserto en botones florales, curvo en el ápice en flores abiertas; estigma puntiforme; cápsula no vista; semillas no vistas.

Notas taxonómicas: los caracteres de esta especie se comparten con $M$. arborea y $M$. dimorphanthera, por lo que posiblemente corresponda a un híbrido natural. Con M. dimorphanthera comparte todas las características vegetativas (como el indumento), estilo exserto y forma de los estambres, pero se diferencia en las inflorescencias con menos de 20 flores, cáliz con dientes dorsales desarrollados y excediendo la longitud de los lóbulos $8-10 \mathrm{~mm}$, pétalos 2.2-2.4 cm de largo y estambres levemente dimorfos. Con M. arborea comparte las flores grandes con pétalos 20-25 $\mathrm{mm}$ de largo, forma de la inflorescencia y los dientes dorsales de cáliz conspicuamente desarrollados, pero difiere en los estambres sin apéndices dorsales conectivales. Gleason (1941) describe la especie y establece su diferencia con $M$. steyermarkii $(=M$. arborea) en la longitud de los dientes dorsales del cáliz y el indumento denso en hojas. Posteriormente, Uribe (1972) la sinonimizó bajo M. quintuplinervis. De esta última difiere en el estilo exserto, los dientes dorsales del cáliz mucho más largos y los pétalos más grandes. Es necesario conocer y estudiar la(s) población(es) en campo para establecer su verdadero estatus taxonómico.

Distribución y hábitat: esta especie se conoce de pocos ejemplares provenientes de localidades cercanas en el departamento Cundinamarca: El Dintel, La Mesa y Soacha, sitios localizados al occidente de la Sabana de Bogotá donde empieza el descenso hacia la planicie del río Magdalena (Fig. 17).

Etimología: especie nombrada en alusión a Colombia.

Estado de conservación: categorizada como “En Peligro" (EN) en la Lista Roja de la IUCN (2020).

Material examinado: COLOMBIA. Departamento Cundinamarca, municipio Facatativá, de Faca a La Vega, bosque El Dintel, 2900-3000 m, 29.VIII.1999, fl, T. van der 


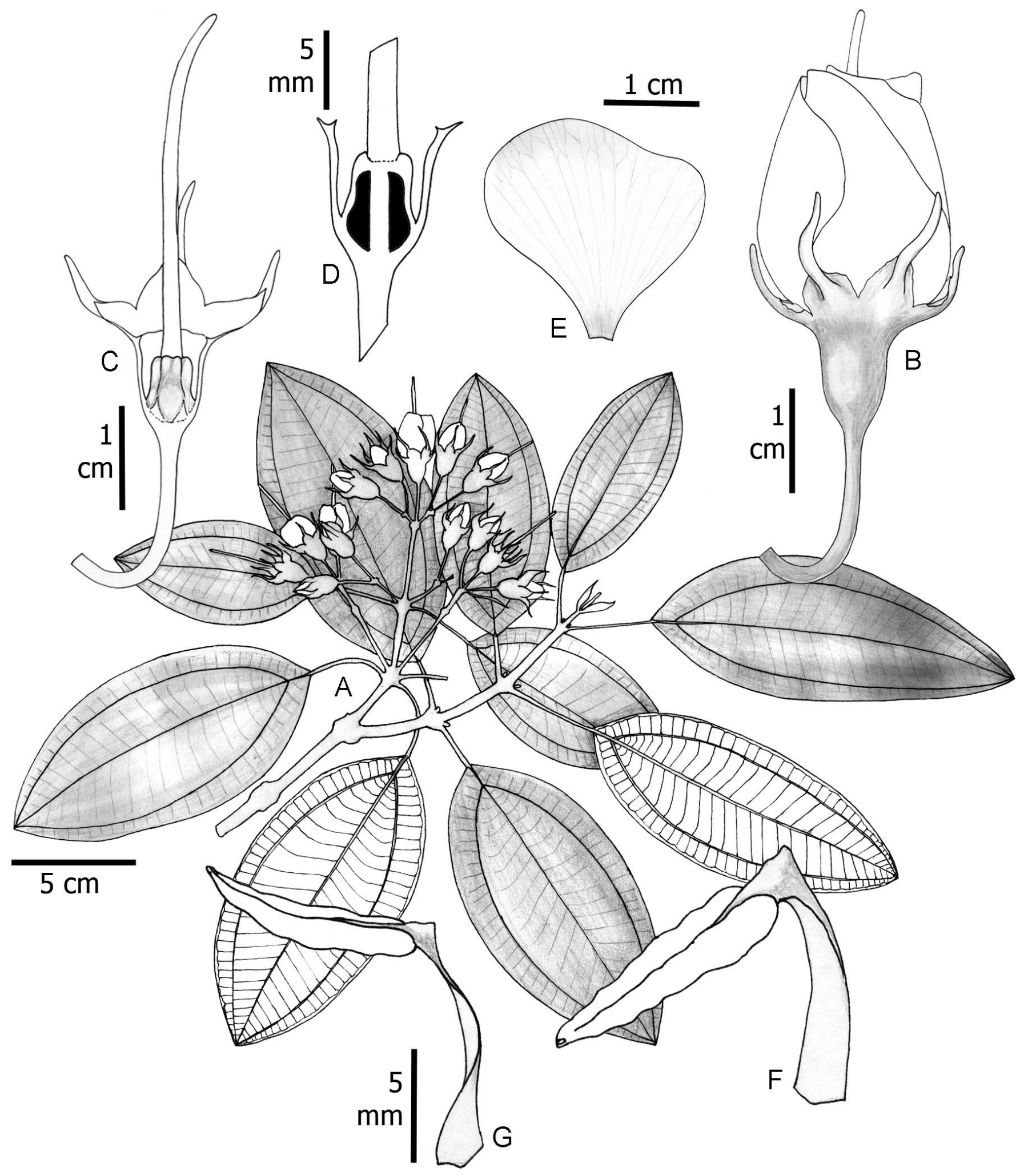

Figura 20: Meriania colombiana Gleason. A. rama florífera; B. flor; C. corte longitudinal del hipanto-cáliz y vista lateral del ovario y estilo; D. corte longitudinal del hipanto-cáliz y del ovario; E. pétalo; F. estambre opositipétalo; G. estambre opositisépalo. A-G: Uribe 4123 (COL). 
Hammen 7218 (COL). Municipio La Mesa, $16 \mathrm{~km}$ al sur de Mosquera sobre la carretera a La Mesa, 2650 m, 24.X.1962, fl, L. Uribe 4123 (COL, MO, NY, US). Municipio Soacha, vereda El Soche, junto a la carretera a Granada, 2700 m, 30.IV.1964, fr, L. Uribe 4773 (COL, NY). Municipio Subachoque, Cerro El Tablazo, camino real que lleva a Subachoque, 26.I.1986, fl, L. E. Gutiérrez 118 (FMB).

Meriania dimorphanthera Wurdack, Brittonia 9(2): 101109. 1957. Figs. 13I-J, 21. TIPO: COLOMBIA. Departamento Cundinamarca, municipio Gachetá, valle Munchidote, margen este de la quebrada Negra, $13 \mathrm{~km}$ noreste de Gachetá, 2675 m, 4.VII.1944, fl, M. L. Grant 9604 (holotipo: US!; isotipos: NY!, WIS!).

= Meriania versicolor L. Uribe, Caldasia 8(40): 534. 1962. TIPO: COLOMBIA. Departamento Cundinamarca, municipio San Antonio del Tequendama, al sur del Salto del Tequendama, en los alrededores del cerro El Ermitaño, 2200 m, 27.VI.1960, fl, L. Uribe 3483 (holotipo: COL!; isotipos: COL!, NY!, US!, VEN), syn. nov.

Arbusto o árboles 3-12 m de altura; entrenudos cuadrangulares de aristas redondeadas; ramas, ejes de la inflorescencia y pecíolos con indumento rufo denso de tricomas filiformes (subulados) de base barbelada (tipo 21), 0.3-1.2 $\mathrm{mm}$ de largo; hojas con pecíolo $2-9 \mathrm{~cm}$ de largo; lámina 7-24 × 3.2-14 cm, elíptica, ovado-elíptica u oblongo-elíptica; base obtusa a levemente redondeada; ápice obtuso a cortamente acuminado; margen entero o denticulado; haz liso, glabro; envés conspicuamente reticulado por la nervadura terciaria, con indumento denso similar al de las ramas y pecíolos; nervadura con 2 pares de venas secundarias acompañando a la vena media, basales o levemente plinervias 2-9 mm arriba de la base; inflorescencia 5-15 cm de largo, eje central con 3 a 6 nudos de ramificación, nudo basal regularmente con brácteas semejantes a hojas pequeñas, 35-90 flores; paracladios 2-5 cm de largo, algunas veces con 2 nudos de ramificación; ramillas con ejes atrofiados por lo que rematan en puntos glomerulares con más de tres flores; flor pedicelada, 4-5-mera; pedicelo 3-15 mm de largo; hipanto 3.5-6 mm de largo, ciatiforme, externamente con indumento denso similar al de las ramas; cáliz subcaliptra- do, abriendo en lóbulos regulares o irregulares, anchamente triangulares; dientes dorsales no visibles o excediendo la longitud del lóbulo 0.9-2.5 mm; corola cuculada; pétalos 12-16 × 7-11 mm, oblongos a obovados, ápice redondeado o truncado asimétrico, rojo-anaranjado, glabros; estambres dimorfos, los opositipétalos mayores principalmente por el tamaño de las tecas; el ápice de las anteras sobresale de la corola en flores abiertas; estambres opositipétalos, filamento 6.7-10 mm de largo; codo 0.5-1.2 mm de largo, dentiforme, regularmente liso; pedoconectivo ausente o de $0.9-1.0 \mathrm{~mm}$ de largo; conectivo dorsal liso, sin apéndices; antera 7-8 mm de largo, poro apical; estambres opositisépalos, filamento 6-9 mm de largo; codo 0.3-0.8 mm de largo, dentiforme, liso; conectivo dorsal sin apéndices; antera 4.8-7 mm de largo, poro apical; ovario 3-4 $\mathrm{mm}$ de largo, 4-5-locular, oblongo a oblongo-ovado, fusionado en la base al hipanto 1.4-2 mm en aristas; ápice redondeado, con leves lóbulos que encierran la base del estilo 0.3-0.5 $\mathrm{mm}$; placentas 1.5-1.8 mm de largo, elípticas a ovadas, con rudimentos seminales en todas las superficies; estilo 14-23 $\mathrm{mm}$ de largo, cilíndrico, exserto en botones florales, curvo en el ápice en flores abiertas; estigma puntiforme; cápsula 8-12 mm de largo, acopada; semillas no vistas.

Notas taxonómicas: esta especie se caracteriza por la inflorescencia con abundantes flores (35 a 90 flores por inflorescencia), dientes dorsales del cáliz inexistentes o cortos, la corola tubulosa, cáliz subcaliptrado, el estilo que sobrepasa conspicuamente la longitud del tubo de la corola, los estambres dimorfos, codo del ápice del filamento estaminal liso (sin rugosidades) y no presenta apéndices conectivales dorsales. El estilo es exserto en botones florales y en flores abiertas excede fuertemente la longitud de la corola. El ápice de los estambres también excede levemente la longitud de la corola en flores abiertas.

Las especies más cercanas son $M$. colombiana, $M$. arborea y M. quintuplinervis. Meriania arborea tiene dientes dorsales del cáliz desarrollados, pétalos 20-25 mm de largo, inflorescencias laxas con pocas flores (menos de 25), el codo del ápice del filamento es rugoso y presenta un apéndice conectival dorsal dentiforme. Difiere de $M$. quintuplinervis por el indumento mucho más denso marrón 

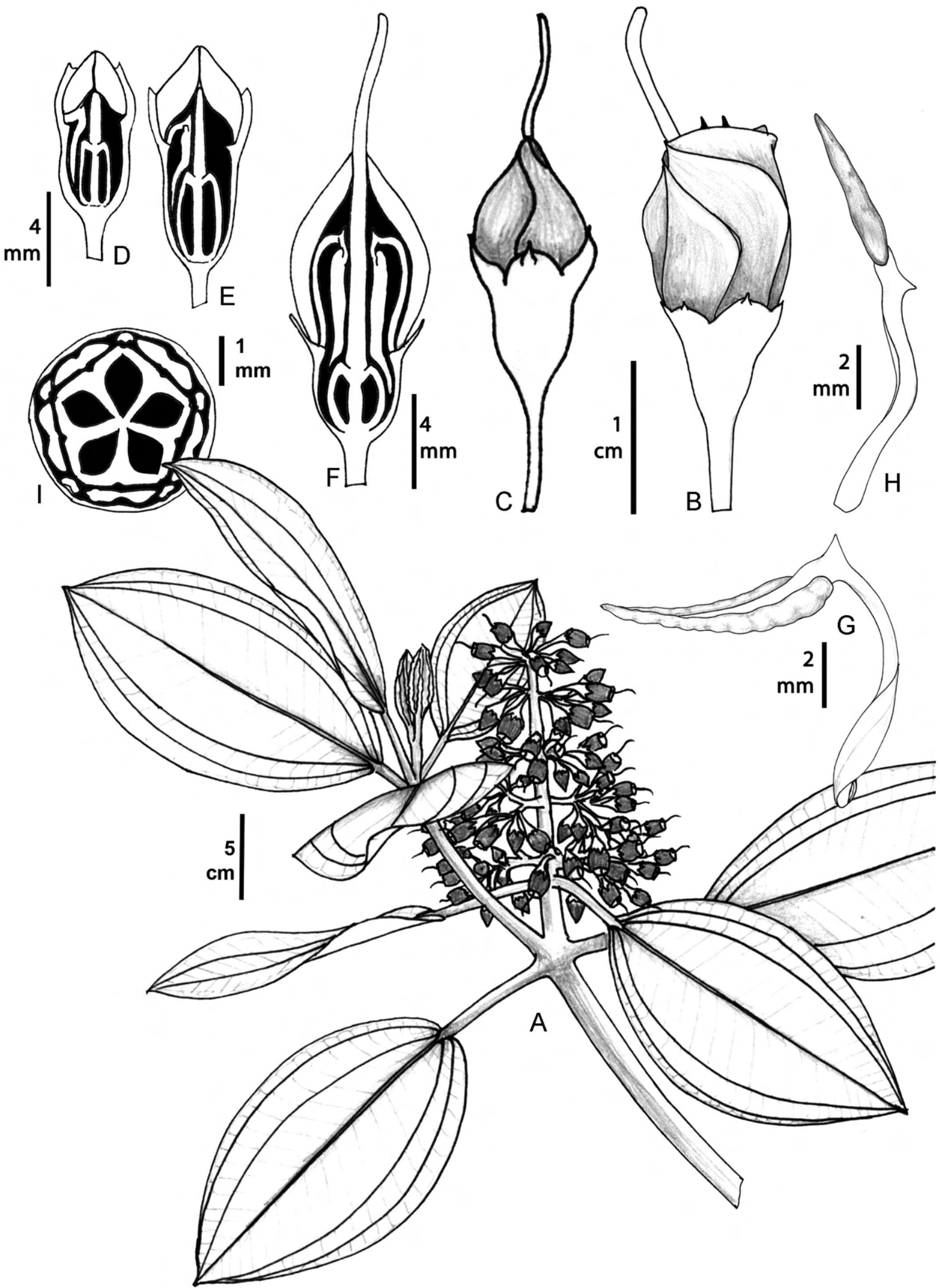

Figura 21: Meriania dimorphanthera Wurdack. A. rama florífera; B. flor; C. botón floral previo a la antesis; D, E, F. cortes longitudinales de botones florales en diferentes etapas de desarrollo; G. estambre opositipétalo; H. estambre opositisépalo; I. corte horizontal del hipanto-ovario. A-I: Mendoza 16675 (FMB). 
oscuro, el estilo exserto, las inflorescencias con más de 30 flores y los estambres fuertemente dimorfos y sin apéndices dorsales del conectivo ( $M$. quintuplinervis tiene apéndices dorsales en los estambres opositipétalos). Wurdack (1957) documenta que se diferencia de M. quintuplinervis en que esta última tiene hojas 5-plinervias, pocas flores en la inflorescencia, hipanto costillado de hasta $7 \mathrm{~mm}$ de largo y dientes externos del cáliz. La nervadura plinervia, el número de flores y el grado de desarrollo del diente dorsal calicino, son caracteres variables en ambas especies, por lo que no son muy útiles para separar estas dos especies. Las diferencias con M. colombiana se ilustran en la discusión de esta última especie.

Distribución y hábitat: especie restringida a la parte centro-norte de la Cordillera Oriental en Colombia y Cordillera de Mérida en Venezuela, entre 2100 y 2800 m de elevación (Fig. 22). En Colombia se encuentra en los departamentos Cundinamarca y Boyacá, en zonas de bosque andino y altoandino en buen estado de conservación.

Etimología: en alusión a los estambres dimorfos.

Estado de conservación: en Colombia su área de distribución es reducida a los departamentos Cundinamarca y Boyacá; siempre se encuentra en bosques en buen estado de conservación y hasta el momento no hay registros en áreas protegidas. Su EOO es de ca. $9000 \mathrm{~km}^{2}$, AOO de ca. 24 $\mathrm{km}^{2}$ y se conoce de $<10$ localidades. Según los lineamientos de la IUCN (2017), cumple los criterios B1ab(i)+2ab(ii), lo que permite categorizarla como "Amenazada" (EN). No obstante, esta especie llega hasta Venezuela, por lo que con mayor muestreo es posible que su área de ocupación y extensión de presencia aumenten; es importante indicar que en medio de su área de distribución hay cuatro grandes parques nacionales, donde es posible que se encuentre. Considerando esto se sugiere su categorización como "Vulnerable" (VU).

Material examinado: COLOMBIA. Departamento Boyacá, municipio Arcabuco, Cañón del Río Pómeca, 2400 m, 15.IV.1997, fl, H. Mendoza 3862 (FMB). Municipio Chichinquirá, cerca a Chiquinquirá, 19.VII.1936, fl, H. García-
Barriga 4898 (NY, US). Municipio Pauna, carretera Chiquinquirá - Pauna, San Antonio, 2400-2600 m, 18.III.1986, fr, J. L. Fernández-Alonso 5945 (COL). Departamento Cundinamarca, municipio Fusagasugá, Inspección de La Aguadita, vereda Los Robles, finca La Carbonera, 2470 m, 8.VII.2006, fl, $H$. Mendoza 16675 (FMB). Municipio Granada, vereda Los Amarillos, 2600-2800 m, 19.VI.1987, fl, fr, G. Morales 998 (COL). Municipio Medina, Farallones de Medina, 2000 m, 25.II.1997, fr, H. Mendoza 2560 (COL). Municipio San Antonio del Tequendama, Reserva Natural Los Tunos, 22.VII.2012, fl, J. Jaime 0068 (UDBC). Municipio Sibaté, San Miguel, $1 \mathrm{~km}$ abajo, quebradita al lado de la gruta del Niño Jesús, 2700-2800 m, X-1974, fl, st, L. Uribe 6884 (COL, MO, P). VENEZUELA. Estado Mérida, distrito Sucre, along the road from Estanques to Canaguá, 2200 m, 13.XII.1984, fl, A. L. Weitzman 169 (MO, NY, US). Estado Táchira, municipio Juaregui, Quebrada Blanca, $8 \mathrm{~km}$ al sur del pueblo El Cobre, 2700 m, 21.XII.1991, fl, M. Pietrangeli 1720 (US).

Meriania drakei (Cogn.) Wurdack, Mem. New York Bot. Gard. 16: 3. 1967. Figs. 13K-L, 23.

三 Axinaea drakei Cogn., DC. Mon. Phan. 7: 447-448. 1891. TIPO: ECUADOR. Provincia Loja, quebrada prope Loxa, $H$. Poortmann 149 (holotipo: P 228664!; isotipos: BR, P).

Árboles $\mathrm{o}$ arbustos 2-8 $\mathrm{m}$ de altura, raras veces arbustos trepadores; entrenudos oblongo-aplanados; línea interpeciolar apenas pronunciada; ramas en sus partes apicales, nervadura por el envés, inflorescencia, hipanto y cáliz con indumento esparcido de tricomas filiformes ligeramente rugosos (tipo 16), 0.1-0.7 mm de largo; este indumento es caduco, las ramas tienden ser glabrescentes; hojas con pecíolo 1-3 cm de largo, ápice levemente tuberculado; lámina 12-30 × 4.5-15 cm, elíptica, textura rígidocoriácea; base aguda a obtusa; ápice agudo a acuminado; margen entero; haz liso o levemente rugoso por el retículo de la nervadura terciaria; envés fuertemente reticulado, indumento sobre la nervadura similar al de las ramas; nervadura con 2 pares de venas secundarias acompañando a la vena media, basales o levemente plinervias a 3-15 mm arriba de la base; inflorescencia $10-15 \mathrm{~cm}$ de largo, sésil o con pedúnculo 2-5 cm de largo, 5-35 flores, eje central 

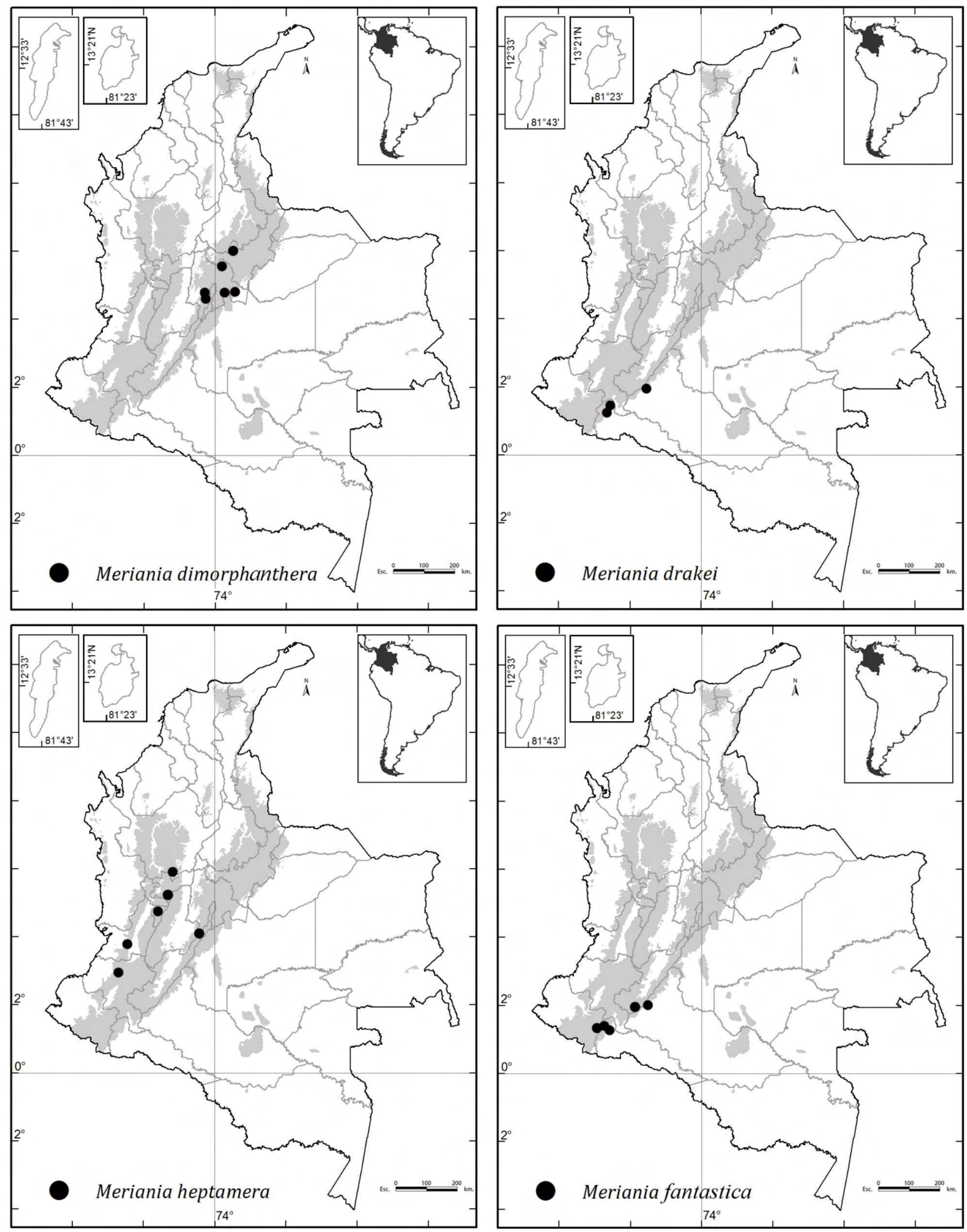

Figura 22: Distribución geográfica de Meriania dimorphanthera Wurdack, M. drakei (Cogn.) Wurdack, M. heptamera Lozano \& Alvear y M. fantastica Alvear, Humberto Mend. \& Almeda. 


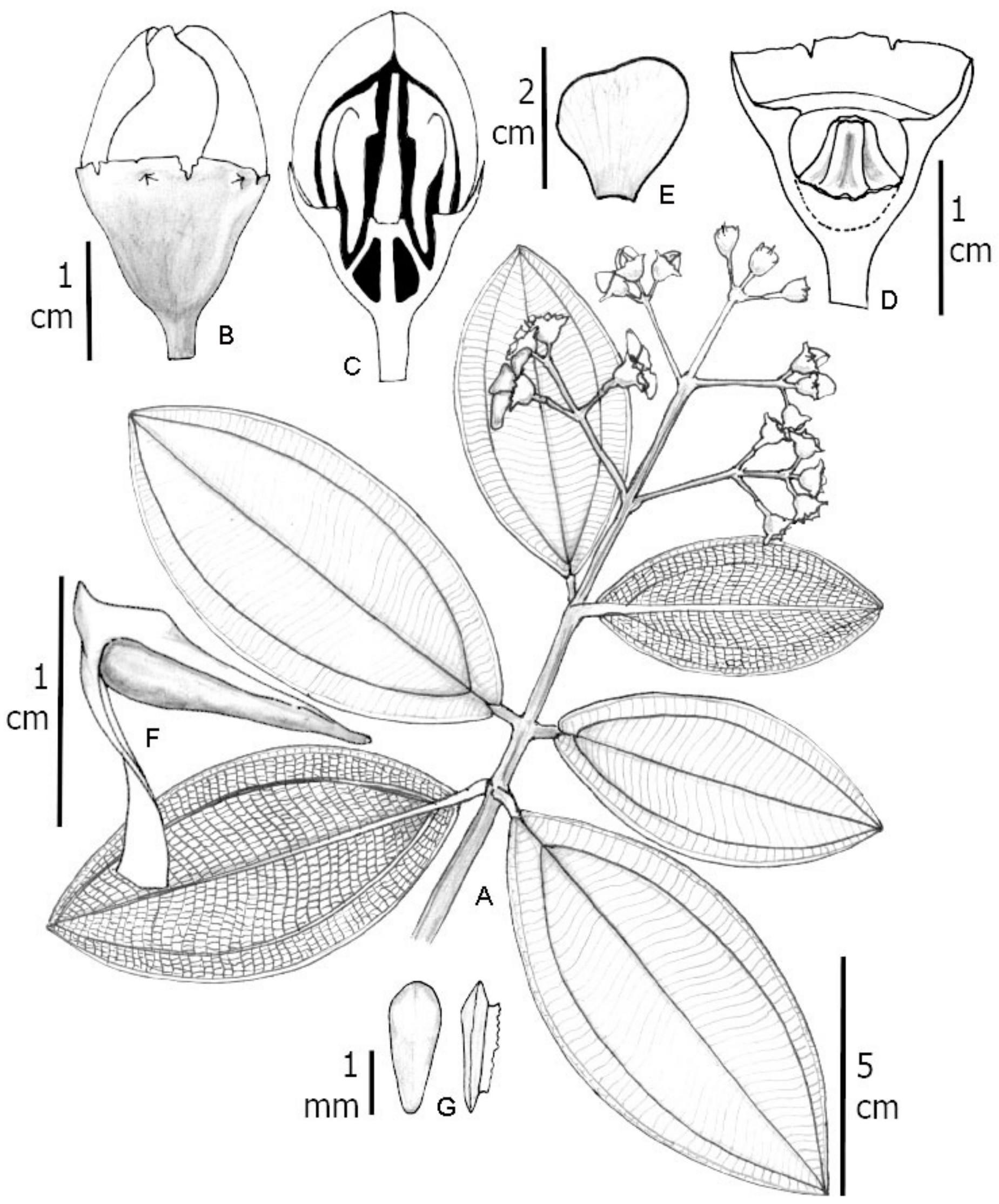

Figura 23: Meriania drakei (Cogn.) Wurdack. A. rama florífera; B. botón floral previo a la antesis; C. corte longitudinal del botón floral; D. corte longitudinal del hipanto-cáliz y vista lateral del ovario; E. pétalo; F. estambre; G. vista dorsal y lateral de la placenta. A-G: Camp 1576 (COL). 
con 3-5 nudos de ramificación, ramillas apicales con 2-3 flores; paracladios 5-9 cm de largo, con 1-3 niveles de ramificación; flor pedicelada, 5-mera; pedicelo 4-9 $\mathrm{mm}$ de largo; hipanto 6-10 mm de largo, ciatiforme, externamente con indumento similar al de las ramas; cáliz truncado, levemente lobulado o subcaliptrado, abriendo en lóbulos irregulares o regulares (en igual número de pétalos), tubo 4.5-8.5 mm de largo; lóbulos cuando existentes 5-5.5 mm de largo; dientes dorsales a manera de protuberancias o linear subulados, algunas veces sobresaliendo del tubo del cáliz 1-1.3 mm; corola patente; pétalos 17-38 × 15$22 \mathrm{~mm}$, obovados de ápice truncado emarginado, fucsia oscuro, densamente furfuráceos en su parte externa (con tricomas esponjosos irregulares diminutos); estambres isomorfos, filamento 9-13 mm de largo; codo 2.5-2.7 mm de largo, levemente subulado; conectivo dorsal sin apéndices, levemente abultado; antera 5.5-7 mm de largo, subulada sigmoidea, poro dorsal; ovario 6-8 $\mathrm{mm}$ de largo, 5-locular, ovoide; ápice con cortos lóbulos truncados que encierra la base del estilo $0.2 \mathrm{~mm}$; placentas no vistas; estilo 13-15 mm de largo, columnar, levemente curvo en el ápice; estigma puntiforme; cápsula no vista; semillas no vistas.

Notas taxonómicas: esta es la única especie de Meriania en Colombia con pétalos pubérulos (indumento harinoso en la superficie adaxial). Adicionalmente, se reconoce por sus hojas elípticas, coriáceas, plinervias, con el retículo de la nervadura muy notorio por el envés e impreso por el haz. Wurdack (1967) comenta que otro carácter de la especie es una leve protuberancia en el ápice del pecíolo, pero este carácter no es constante. Este mismo autor establece dos subespecies, la subespecie típica y $M$. drakei subsp. chontalensis Wurdack, con base en el desarrollo de los dientes dorsales del cáliz. La colección de D. Neill 14208, procedente de Cantón Archidona, en Ecuador, representa una subespecie aún no descrita con hábito lianescente y hojas angosto-elípticas.

Distribución y hábitat: se encuentra a lo largo de la vertiente oriental de los Andes, entre los departamentos Caquetá y Putumayo en Colombia y el sur de Ecuador (Zamora Chinchipe), entre 1800 y 2400 m de elevación. Crece en zonas de bosque andino (Fig. 22). No se conocen datos de su hábitat.

Etimología: al parecer en alusión a Sir Francis Drake (1545-1595).

Estado de conservación: en la Lista Roja de la IUCN (2020) está categorizada como "Preocupación Menor" (LC). En Colombia está restringida a pocas localidades $(<5)$, crece en una franja de vegetación fuertemente intervenida y tiene una EOO $<5000 \mathrm{~km}^{2}$. Según lineamientos de la IUCN (2017) cumple el criterio B1ab(ii); no obstante, no se sugiere su recategorización pues cerca de la mitad de su área de distribución se encuentra en Ecuador.

Material examinado: COLOMBIA. Departamento Caquetá, municipio Florencia, vía Florencia - Suaza entre el primer y el segundo túnel, corregimiento El Caraño, Puente de Cerro Negro, 1800-1900 m, 18.VIII.2019, fl, H. Mendoza 22657 (FMB). Departamento Putumayo, municipio desconocido, vertiente oriental de la Cordillera, carretera Sibundoy a Urcique, El Silencio y La Cabaña, 2200-2400 m, 31.XII.1940, fl, J. Cuatrecasas 11503 (COL, US); San Francisco-Mocoa, 2000 m, III.1978, fl, F. Sánchez s.n. (COL).

Meriania fantastica Alvear, Humberto Mend. \& Almeda, Phytotaxa 178(1): 26-31. 2014. Figs. 24, 25A-C. TIPO: COLOMBIA. Departamento Putumayo, municipio Mocoa, carretera desde San Francisco a Mocoa, alrededores del $\mathrm{km} \mathrm{88,} 2314 \mathrm{~m}, 1^{\circ} 6.802$ ' $\mathrm{N}, 76^{\circ} 50.060^{\prime} \mathrm{W}, 16.1 \mathrm{l} .2013$, $\mathrm{fl}$ fr, M. Alvear 1851 (holotipo: COL!; isotipos: CAS! (2) pliegos, CAUP, CUVC, FMB!, HUA, MO, NY, PSO, US).

Árboles 3-20 m de altura; entrenudos subcuadrangulares o cuadrangulares de aristas redondeadas, canaliculados; ramas, pecíolo y partes florales completamente glabras; hojas con pecíolo $2.7-8.4 \mathrm{~cm}$, aplanado abaxialmente, ápice con escutelo; lámina 15.5-31 × 10.4-20 cm, elíptica, oblonga a suborbicular o anchamente ovada; base truncada-redondeada, revoluta, formando bolsillo domaciales; ápice obtuso, corto acuminado; margen entero; haz glabro; envés glabro o con ralos tricomas glandulares sésiles (tipo 4) menores de $0.2 \mathrm{~mm}$ de largo; nervadura con 


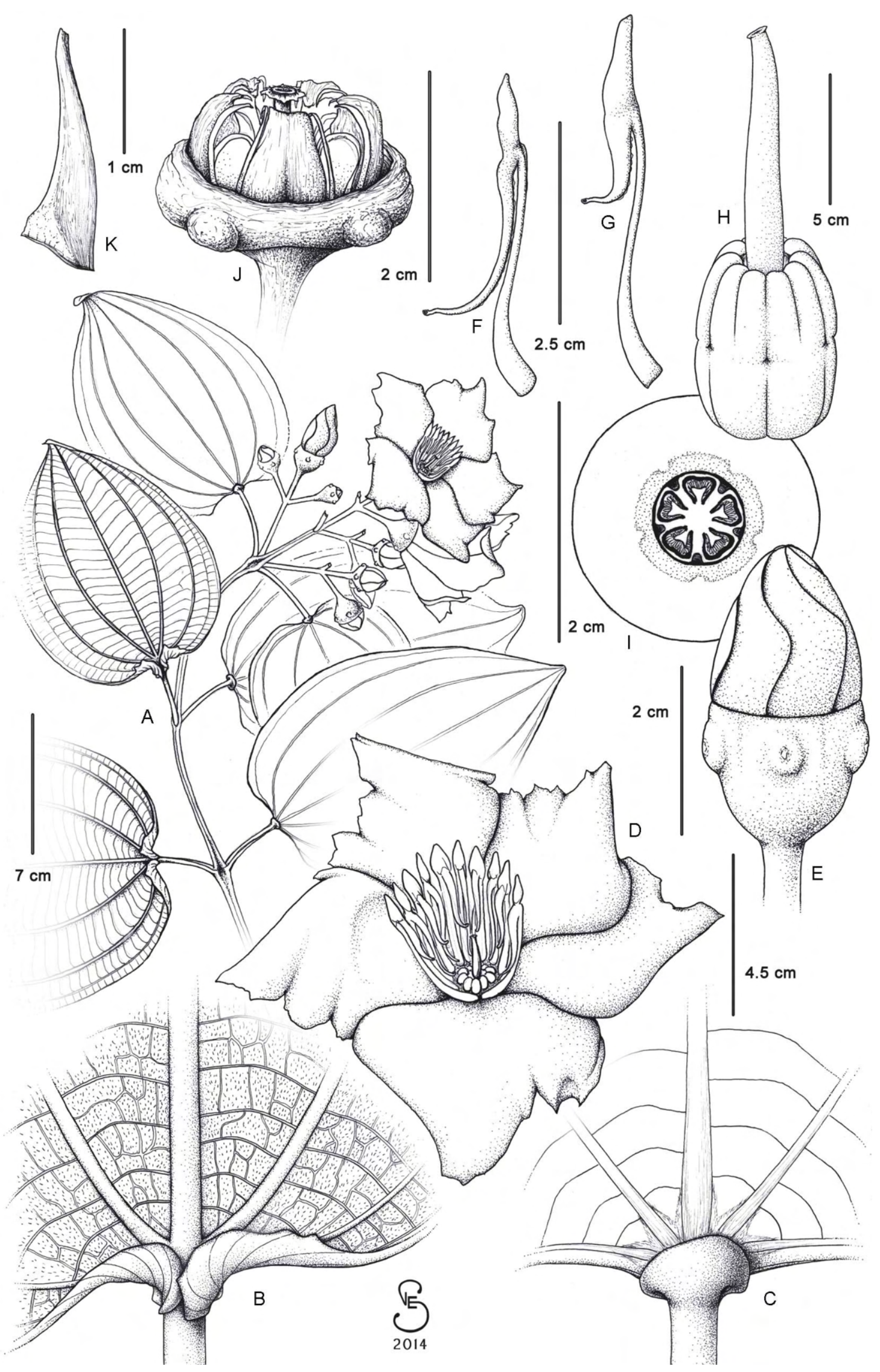

Figura 24: Meriania fantastica Alvear, Humberto Mend. \& Almeda. A. rama florífera; B. base de la lámina foliar por el envés; C. base de la lámina foliar por el haz; D. flor; E. botón floral; F. estambre opositipétalo; G. estambre opositisépalo; H. vista lateral del ovario y estilo; I. corte transversal del hipanto-ovario; I. fruto; J. semilla. A-J: Alvear 1851 (CAS); tomada de Mendoza-Cifuentes et al., 2014. 

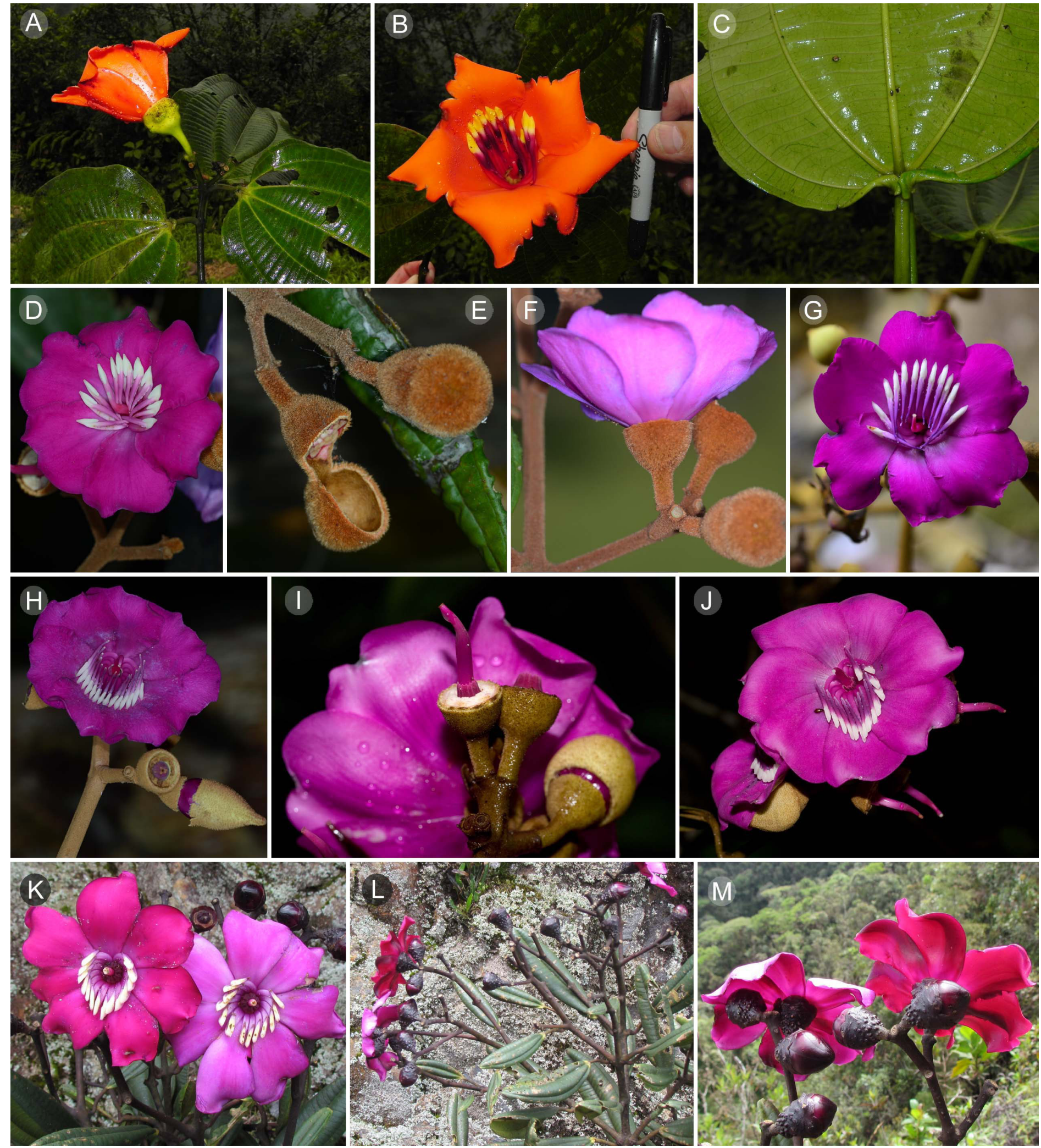

Figura 25: Fotografías de Meriania Sw. de Colombia. A, B, C. M. fantastica Alvear, Humberto Mend. \& Almeda; D, E, F. M. haemantha (Planch. \& Linden) subsp. haemantha; G, H. M. haemantha (Planch. \& Linden) subsp. orientalis Humberto Mend. \& Fern. Alonso; I, J. M. haemantha (Planch. \& Linden) subsp. virolinensis Humberto Mend. \& Fern. Alonso; K, L, M. M. heptamera Lozano \& Alvear. Créditos: M. Alvear (A, B, C); F. Almeda (D, E, F, H); A. Celis (G); F. Michelangeli (I, J); A. Idárraga (K, L, M). 
3 pares de venas secundarias basales, solo 2 llegan al ápice; inflorescencia 10-12 cm de largo, sésil o pedunculada, con 5-12 flores, eje central con 1-2 nudos de ramificación, ramillas de ápices trifloros, sin brácteas ni bractéolas; paracladios $7.5 \mathrm{~cm}$ de largo o ausentes, no ramificados; flor pedicelada, 5-mera, ca. $15 \mathrm{~cm}$ de diámetro; pedicelo 15-25 $\mathrm{mm}$ de largo; hipanto $14-18 \mathrm{~mm}$ de largo, campanulado, de paredes gruesas; torus 3.8-5 mm de grosor; cáliz truncado, con tubo 7-9 mm de largo, dientes dorsales abultados; corola patente; pétalos $65-85 \times 40-58 \mathrm{~mm}$, obovados, ápice fuertemente asimétrico truncado, glabros, anaranjados; estambres levemente dimorfos, opositipétalos con antera más larga, opositisépalos con filamento más largo; ambas series con filamento rojizo, codo amarillo, antera morado-rojiza; sin apéndices conectivales dorsales; estambres opositipétalos, filamento $33-35 \mathrm{~mm}$ de largo; codo ca. $10 \mathrm{~mm}$ de largo, triangular, expandido a los lados; antera 22-25 mm de largo, subulada, levemente sigmoidea, poro dorsal; estambre opositisépalo, filamento 35-40 $\mathrm{mm}$ de largo; codo 7.9-9.7 mm de largo, triangular; antera 14-18 mm de largo, subulada, sigmoidea, poro dorsal; ovario 10-13 mm de largo, 5-locular, ovoide; ápice con lóbulos redondeados, encerrando la base del estilo 0.2-1.3 mm; placentas 2.2-2.5 mm de largo, obovadas, ápice cordado, rudimentos seminales en todas las superficies; estilo 18-23 $\mathrm{mm}$ de largo, cónico, curvo en el ápice en flores abiertas, rojizo; estigma glandiforme; cápsula $18-20 \mathrm{~mm}$ de largo, parcialmente encerrada por el hipanto; semillas 1.5-2.2 $\mathrm{mm}$ de largo, cuneiformes con ápice corto; testa marrón claro.

Notas taxonómicas: el ápice del pecíolo con escutelo, las flores gigantes (hasta $15 \mathrm{~cm}$ de diámetro), los pétalos de color naranja y los estambres levemente dimorfos son un conjunto de caracteres únicos en Meriania. Es afín a $M$. maxima, pero difiere en la presencia de un escutelo en el ápice del pecíolo, base de la lámina fuertemente auriculada, estambres sin apéndices conectivales dorsales y los pétalos color naranja. También es afín a $M$. hernandi, pero difiere en los pecíolos no canaliculados ni envolventes en la base, en el tamaño de la flor (pétalos mucho más grandes) y el reducido número de flores de la inflorescencia. También se puede confundir con $M$. pastazana, pero difiere en la forma de la lámina, la presencia de escutelo del ápice del pecíolo. De M. splendens difiere en la ausencia de línea interpeciolar laminar, la presencia del escutelo del ápice del pecíolo y el color de los pétalos.

Distribución y hábitat: hasta ahora solo conocida para los departamentos Caquetá, Huila y Putumayo en el flanco que drena hacia la Amazonia del Macizo Colombiano (Andes), entre 1800 y 2400 m de elevación. Crece en la franja de bosque andino en interior de bosque en buen estado de conservación (Fig. 22).

Nombre vernáculo: en Putumayo la llaman "mayo".

Etimología: el nombre hace alusión a que sus flores son bastante llamativas y hermosas, dado su gran tamaño y color anaranjado.

Estado de conservación: categorizada como “En Peligro" (EN) (Mendoza-Cifuentes et al., 2014). En la Lista Roja de la IUCN (2020) fue recategorizada como "Preocupación Menor" (LC), posiblemente por un registro que se localiza en la Cordillera Central, departamento Caldas, que amplia significativamente su área de distribución. Sin embargo, este registro puede obedecer a un error de identificación taxonómica o a un ejemplar cultivado, ya que esta especie se restringe al flanco amazónico del Macizo Colombiano y Cordillera Oriental, con registros de herbario de los departamentos Caquetá, Huila y Putumayo. Hay un registro fotográfico del departamento Meta, pero no se conoce la localidad exacta ni los ejemplares de herbario. Por esto se sugiere mantener la propuesta origina "En Peligro" (EN). Es importante que se tomen medidas urgentes de conservación in situ y de propagación en jardines botánicos.

Material examinado: COLOMBIA. Departamento Caquetá, municipio Florencia, vía Florencia - Suaza entre el primer y el segundo túnel, corregimiento el Caraño, Puente de Cerro Negro, 1800-1900 m, 18.VIII.2019, fl, H. Mendoza 22653 (FMB). Departamento Huila, municipio Acevedo, Parque Nacional Natural Cueva de Los Guacharos, camino al filo del Churuco, 26.VIII.1973, fl, C. Barbosa 14521-104 
(FMB). Departamento Putumayo, municipio Mocoa, carretera entre San Francisco y Mocoa, 2700 m, 29.I.1973, fl, E. Hernández 351 (PSO); Río Blanco, 2400 m, III-1981, fl, G. Mahecha s.n. (COAH, COL); carretera entre Sibundoy y Mocoa, El Mirador, 2000 m, 7.IX.1998, fl, H. Mendoza 6056 (FMB), 7019 (FMB); carretera San Francisco - Mocoa, 21002300 m, 30.I.1973, fl, L. E. Mora-Osejo 6242 (COL). Municipio Sibundoy, entre San Francisco y Río Blanco, 2300-2800 m, 9.IV.1973, fl, B. Ramírez 392 (PSO); entre Río Blanco y la Cabaña, 2400 m, 6.III.1987, fl, B. Ramírez 937 (PSO); San Francisco - Mocoa, 2000 m, III.1978, fl, F. Sánchez s.n. (COL).

Meriania haemantha (Planch. \& Linden) Humberto Mend. \& Fern. Alonso, Anales Jard. Bot. Madrid 69(2): 274-280. 2012. Fig. 25D-J, 26.

三 Calyptraria haemantha Planch. \& Linden, Fl. des Serres, IX: 11. t. 924. 1853-1854. TIPO: COLOMBIA. Departamento Norte de Santander, municipio Ocaña, Jurisdicciones, fl, $L$. Schlim 23 (lectotipo: K! designado por Mendoza-Cifuentes y Fernández-Alonso (2012); isolectotipos: BR!, G!, K!, MPU!, $\mathrm{P} !)$.

इ Centronia haemantha (Planch. \& Linden) Triana, Trans. Linn. Soc. Bot. 28: 72. 1872.

Arbustos o árboles 3-15 m de altura; entrenudos rectangulares a fuertemente aplanados hacia el ápice; ramas, ejes de la inflorescencia y pecíolos con indumento de tricomas rufos piramidal-estipitados (tipo 27), algunas veces adpresos, semejantes a escamas; hojas con pecíolo 1.4-5.5 cm de largo; lámina 11-31 ×6.5-22 cm de largo, oblonga, suborbicular, oblongo-obovada, oblongo-elíptica, oblongo-ovada, ovada, predominante oblonga-suborbicular, raras veces elíptica; base obtusa, redondeada o levemente cordada, raras veces revoluta, muy raras veces levemente peltada a $0.6 \mathrm{~cm}$; ápice redondeado apiculado, agudo, obtuso; margen entero o denticulado; haz glabro; envés con indumento sobre las venas de tricomas piramidalesestipitados (tipo 27), filiformes o subulados de paredes rizadas (tipo 17) o esponjosos irregulares con ramas delgadas (tipo 31); raras veces tricomas setosos en las axilas de las venas secundarias; areolas notorias; nervadura con
2 pares de venas acompañantes de la vena media, básales o levemente plinervias; inflorescencia $10-30 \mathrm{~cm}$ de largo, 2-5 nudos de ramificación, primer internodo ausente (sésil) o hasta $11 \mathrm{~cm}$ de largo, los ejes son rectangulares o fuertemente aplanados, 11-120 flores; paracladios ausentes o 4-20 cm de largo, con 3-4 niveles de ramificación; ápices de las ramificaciones con 3-5 flores, entrenudos muy cortos; flor pedicelada, 5-7-mera, muy raras veces hasta 8-9-mera; pedicelo 2-8 $\mathrm{mm}$ de largo; hipanto $4.5-8.2 \mathrm{~mm}$ de largo, hemisférico, externamente con indumento denso de tricomas piramidales estipitados (tipo 27); torus engrosado a manera de un ribete de 1.7-3.5 mm grosor; cáliz caliptrado; caliptra 9-19 mm de largo, aguda, circuncísil, externamente con el mismo indumento del hipanto; corola patente; pétalos 18-40 × 14-38 mm, obovados de ápice truncado emarginado, fucsia oscuro, glabros; estambres isomorfos, filamento 6-15 mm de largo; codo 2.6-5.1 mm de largo, subulado, algunas veces con dientes diminutos en el ápice; conectivo dorsal con apéndice subulado 0.6-1.7 mm de largo; antera 8-10.1 mm de largo, subulada sigmoidea, poro dorsal; polen 10.5-11.5 $\mu \mathrm{m}$ diámetro; ovario 5.6-8 mm de largo, 5-6-locular, menos frecuente 7-8 locular, ovoide, su parte basal fusionada al hipanto $0.25-3.5 \mathrm{~mm}$, en su parte media tiene aristas aplanadas; ápice con lóbulos cortos truncados o si prolongado con dientes diminutos 0.3-0.7 $\mathrm{mm}$ de largo; placentas 3.4-3.7 mm de largo, ovoides, con rudimentos seminales en todas las superficies; estilo 11-15 $\mathrm{mm}$ de largo, cónico-columnar; estigma puntiforme o levemente ensanchado; cápsula 5.5-10 mm de largo sin incluir el pedicelo, hipanto hemisférico, el ovario sobresaliendo 0.5-6 mm; semillas $0.75-1.1 \mathrm{~mm}$ de largo, cuneiformes con el ápice corto; rafe notorio.

Notas taxonómicas: esta especie, dentro del grupo Brachycera, se caracteriza por el indumento denso del hipanto y la caliptra de tricomas piramidal-estipitados (tipo 27) y hojas con dos pares de venas basales o levemente plinervias acompañando a la vena media. Muy raras veces se presenta solo un par de venas acompañando a la vena media. También se caracteriza por la carencia de apéndices subulados en el ápice del ovario y la inflorescencia laxa y con abundantes flores; no obstante, este último caracter mostró variación entre las poblaciones estudiadas. Se pue- 


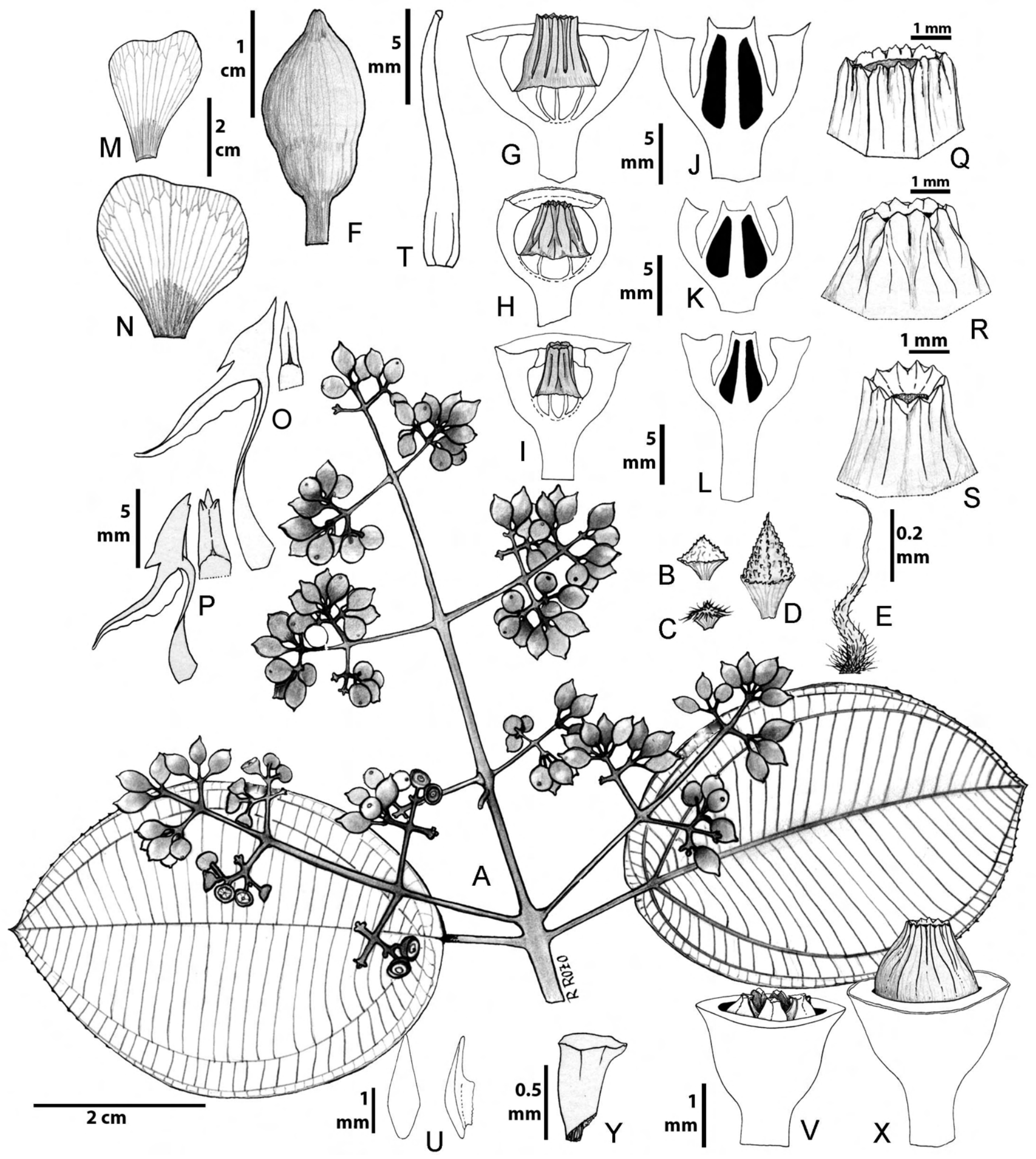

Figura 26: Meriania haemantha (PI. \& Lind.) Humberto Mend. \& Fern. Alonso. D, E, H, K, P, R, T: subsp. haemantha; A, B, C, I, L, O, S, U, Y: subsp. orientalis; F, G, J, M, N, Q, V, X: subsp. virolinensis. A. rama florífera; B, D. tricomas del hipanto; C, E. tricomas del envés foliar; F. botón floral; G, H, I. corte longitudinal del hipanto y vista lateral del ovario; J, K, L. corte longitudinal del hipanto-ovario; M, N. pétalos; O, P. codo apical del filamento y estambres; $Q, R, S$. variantes del ápice del ovario; T. estilo; U: vista frontal y lateral de la placenta; V, X. frutos; Y. Semilla. A, H, K, P, R, T: Mendoza 14677 (FMB); B, I, L, S, U: Mendoza 4089 (FMB); C: Mendoza 3212 (FMB); D, E: Mendoza 7207 (FMB); F, J, Q, V, X: Lozano 3004 (COL); G, M: Lozano 2539 (COL); N: Fernández-Alonso 12237 (COL); O: Mendoza 3205 (FMB); tomada de Mendoza-Cifuentes y Fernández-Alonso (2012); Y: Idrobo 2453 (COL). 
de confundir con $M$. brachycera, pues sus distribuciones se empalman; no obstante, difieren en el indumento del hipanto-caliptra y del envés.

Distribución y hábitat: crece en los Andes de Colombia y Venezuela. En Colombia se encuentra a lo largo de la Cordillera Oriental entre 1200 y 3700 m de elevación, en interior o bordes de bosque (Fig. 27).

Etimología: en alusión a los pétalos color rojo-sangre.

Clave para las subespecies de Meriania haemantha

1a. Hojas con solo un par de venas acompañando a la vena media; tricomas de la caliptra hasta $1.8 \mathrm{~mm}$ de largo

M. haemantha

(Planch. \& Linden) Humberto Mend. \& Fern. Alonso subsp. chaponensis Humberto Mend. \& Fern. Alonso

1b. Hojas con dos pares de venas acompañando a la vena media; tricomas de la caliptra $<1 \mathrm{~mm}$ de largo 2

2a. Nervadura por el envés densamente cubierta de tricomas filiformes de paredes rizadas (tipo 17); ramas y ejes de la inflorescencia con indumento denso de tricomas piramidal-estipitados (tipo 27) .. M. haemantha (Planch. \& Linden) Humberto Mend. \& Fern. Alonso subsp. haemantha

2b. Nervaduras por el envés laxa o densamente cubiertas de tricomas esponjosos irregulares con ramas delgadas (tipo 31); ejes de las ramas e inflorescencias con tricomas adpreso-escamosos 3

3a. Hojas elípticas; cápsulas con el ápice del ovario sobresaliendo del hipanto cerca de 4-6 $\mathrm{mm}$

M. haemantha

(Planch. \& Linden) Humberto Mend. \& Fern. Alonso subsp. virolinensis Humberto Mend. \& Fern. Alonso

3b. Hojas oblongas, oblongo-ovadas o suborbiculares; cápsulas con el ápice del ovario de igual longitud que el hipanto o sobresaliendo menos de $2 \mathrm{~mm}$

M. haemantha

(Planch. \& Linden) Humberto Mend. \& Fern. Alonso subsp. orientalis Humberto Mend. \& Fern. Alonso
Meriania haemantha (Planch. \& Linden) Humberto Mend. \& Fern. Alonso subsp. haemantha, Anales Jard. Bot. Madrid 69(2): 277. 2012. Figs. 25D-F, 26.

= Calyptraria insignis Naudin, Ann. Sci. Nat. Ser. 3 Bot. 18: 133. 1858. TIPO: VENEZUELA? In montibus provinciae Pamplona, Cachirí, 1847, fl, Funck et Schlim 1400 (holotipo: P!; isotipos: BR!, G!, MPU!, P!). Centronia insignis (Naudin) Triana, Trans. Linn. Soc. Bot. 28: 72. 1872.

Entrenudos y ejes de la inflorescencia rectangulares, algunas veces canaliculados; ramas, pecíolos, inflorescencia y flores (hipanto y caliptra) con indumento ferrugíneo de tricomas piramidal-estipitados, 0.3-0.6 mm de largo; lámina foliar oblonga, oblongo-elíptica a suborbicular, de base redondeada, levemente cordada u obtusa; envés con indumento denso sobre la nervadura de tricomas filiformes de paredes rizadas, regularmente se presentan pelos rígidos en la axila de las venas secundarias; inflorescencias laxas, más de 10 flores; cápsula con ovario sobresaliendo 1-2 $\mathrm{mm}$ arriba del torus.

Notas taxonómicas: se reconoce por el indumento denso de tricomas subulados de paredes ciliolado-rizadas por el envés.

Distribución y hábitat: conocida para los Andes de Colombia y Venezuela. En Colombia crece en los departamentos Boyacá, Cesar, Santander y Norte de Santander, entre 2200 y 3700 m s.n.m. (Fig. 27). Está asociada a zonas de bosque altoandino y subpáramo. Hay un registro en Farallones de Medina (departamento Cundinamarca) a 1500 m de elevación.

Nombres vernáculos: en los límites entre los departamentos Norte de Santander y Cesar, Colombia, es conocido como "margarito". Triana (1872) documenta el nombre "flor de toro" en el ejemplar tipo.

Estado de conservación: categorizada como "Casi Amenazado" (NT) (Mendoza-Cifuentes y Fernández-Alonso, 2012). 


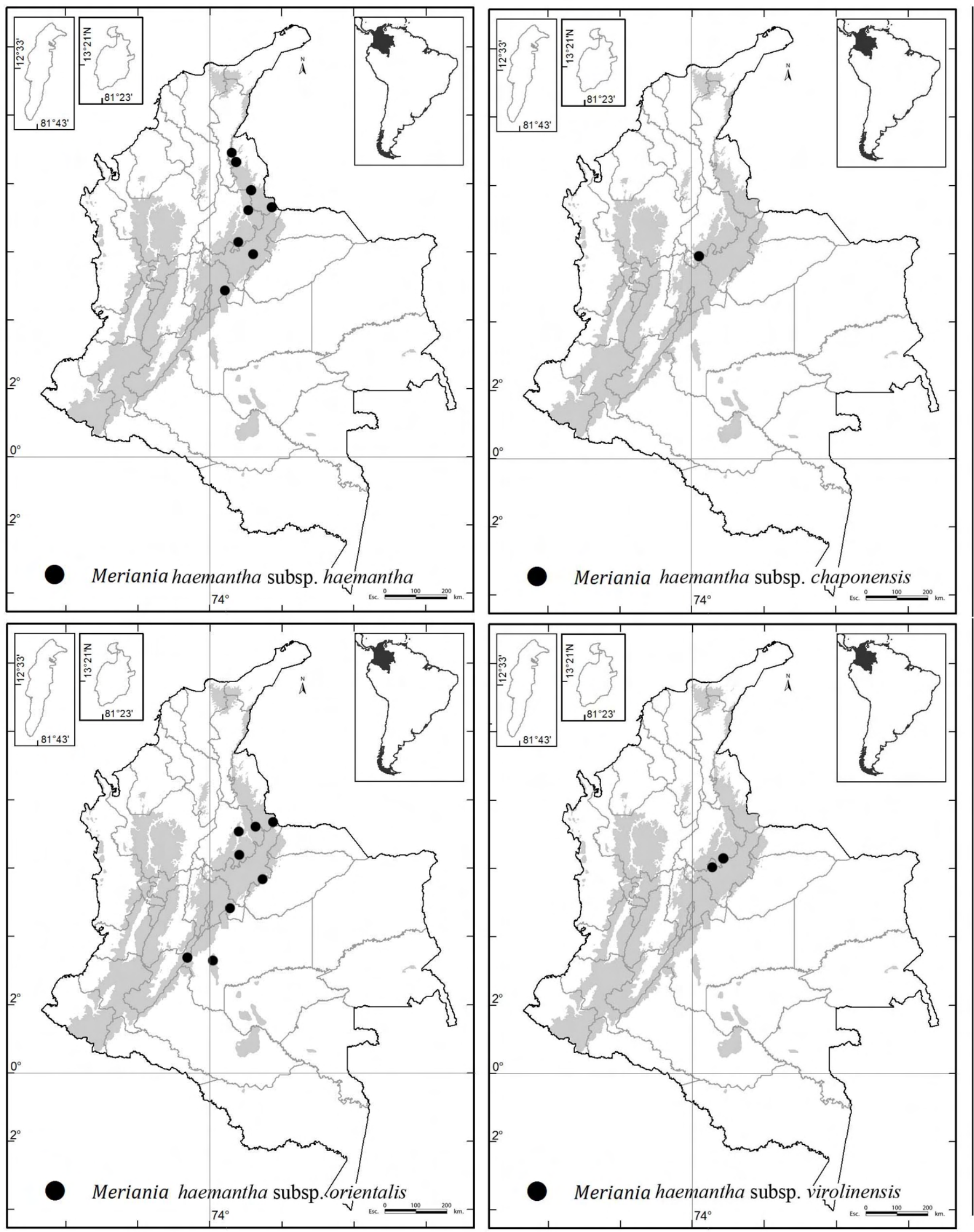

Figura 27: Distribución geográfica de las subespecies de Meriania haemantha (PI. \& Lind.) Humberto Mend. \& Fern. Alonso en Colombia. 
Material examinado: COLOMBIA. Departamento Boyacá, municipio Paipa, Vereda Peña Blanca, sector San Luís, fl, C. Camacho 4 (UPTC) loc. cit., N. Monroy 43 (UPTC). Departamento Cesar, La Gloria, vereda Agua Dulce, 2700 $\mathrm{m}$, 9.I.2011, fr, E. J. Castro 12 (FMB); entre Abrego y Las Jurisdicciones, Cerro de Orocué, 3400-3750 m, 22.V.1969, fl, H. García-Barriga 19875 (US); Jurisdicciones, Cerro Orocué, 3700-3900 m, 22.VII.1974, fl, fr, H. García-Barriga 20726 (COL, US). Departamento Cundinamarca, municipio Medina, Farallones de Medina, 1500 m, 25.II.1997, fr, H. Mendoza 2400 (FMB). Departamento Norte de Santander, municipio Chinácota, vereda Iscalá, Alto de Mejué, 2498 m, 26.II.2012, fr, F. Almeda 10546 (CAS, COL). Municipio Cucutilla, vereda Carrizal, Parque Natural Regional Sisavita, 2150 m, 29.II.2012, fl, F. Almeda 10569 (CAS, COL), 10572 (CAS, COL). Municipio Herrán, Parque Nacional Natural Tama, sector Orocué, 2400 m, 20.VI.1999, fl, H. Mendoza 7207 (FMB). Municipio Ocaña, Provincia de Ocaña, 2300 m, 1851, fl, J. J. Triana 6169 (COL). Municipio Toledo, Parque Nacional Natural Tamá, vertiente de Santamaría, 2600-2900 m, 29.X.1941, J. Cuatrecasas 12739 (US). Departamento Santander, municipio Piedecuesta, vereda Cristales, El Rasgón, 2200-2400 m, 19.IX.2004, st, H. Mendoza 16138 (FMB), 16181 (FMB); estación experimental El Rasgón, 3000 m, 16.XII.1997, fl, S. Oliveros 290 (COL). Municipio Suratá, páramo de Ramírez, 3000 m, 20.X.2009, fl, P. Ortíz-Valdivieso BVM29 (COL).

Meriania haemantha (Planch. \& Linden) Humberto Mend. \& Fern. Alonso subsp. chaponensis Humberto Mend. \& Fern. Alonso, Anales Jard. Bot. Madrid 69(2): 279-280. 2012. TIPO: COLOMBIA. Departamento Santander, municipio desconocido, Cerro Armas, 1200 m, VII.1936, fl, $O$. Haught 1951 (holotipo: NY!; isotipo: US!).

Entrenudos, pecíolos y ejes de la inflorescencia con indumento de pelos adpresos subescamosos; lámina foliar ovado-elíptica, con solo un par de venas secundarias acompañando a la vena media; base truncada; ápice agudo; envés glabrescente o con ralos tricomas filiformes de paredes rizadas sobre la nervadura; tricomas de la caliptra 0.3-1.8 $\mathrm{mm}$ de largo.
Distribución y hábitat: conocida solo para las localidades tipo en Colombia en el flanco occidental de la Cordillera Oriental en los departamentos Boyacá y Santander entre 1200 y 2250 m s.n.m. (Fig. 27). Crece en áreas de bosque subandino.

Etimología: en alusión a la localidad tipo, El Chapón.

Estado de conservación: categorizada como "Peligro Crítico" (CR) (Mendoza-Cifuentes y Fernández-Alonso, 2012).

Material examinado: COLOMBIA. Departamento Boyacá, region of Mt. Chapón, 2200 m, 3.VI.1932, fl, A. E. Lawrence 146 (US).

Meriania haemantha (Planch. \& Linden) Humberto Mend. \& Fern. Alonso subsp. orientalis Humberto Mend. \& Fern. Alonso, Anales Jard. Bot. Madrid 69(2): 279. 2012. Figs. 25G-H, 26. TIPO: COLOMBIA. Departamento Cundinamarca, municipio Medina, Farallones de Medina, 1500 m, 25.II.1997, fr, H. Mendoza 2249 (holotipo: FMB!; isotipos: COL!, FMB!).

Entrenudos y ejes de la inflorescencia fuertemente aplanados y no canaliculados; entrenudos y ejes de la inflorescencia con indumento de tricomas adpresos subescamosos; lámina foliar oblonga, oblongo-elíptica a suborbicular, base redondeada, peltada, levemente cordada u obtusa; las colecciones en el flanco interno de la Cordillera Oriental (Virolín, Tama, Yariguíes y Arcabuco) tienden a desarrollar hojas más pequeñas, elípticas, con el indumento más denso; envés con indumento laxo a denso sobre la nervadura de tricomas diminutos esponjosos irregulares con ramas delgadas (menores $0.3 \mathrm{~mm}$ de diámetro); hipanto con tricomas piramidales-estipitados 0.1-0.4 mm de largo; inflorescencia y cápsula con caracteres similares a la subespecie tipo.

Distribución y hábitat: conocida solo para Colombia en el flanco oriental de la Cordillera Oriental en los depar- 
tamentos Caquetá, Meta, Cundinamarca y Boyacá, entre 1200 y 2000 m de elevación. También se encuentra en el flanco interno de la Cordillera en los departamentos Boyacá y los Santanderes, entre 1400 y 2600 m s.n.m. (Fig. 27). Es predominante en zonas de bosque andino; no obstante, también se encuentra en zonas de bosque subandino y altoandino. Es un taxón poco frecuente y generalmente crece asociado a bosques en buen estado de conservación, aunque también se encuentra en bordes de bosque.

Nombre vernáculo: en Cundinamarca es conocida como "tuno esmeraldo".

Etimología: en alusión a que este taxón se encuentra principalmente en el flanco oriental de la Cordillera Oriental de Colombia.

Estado de conservación: categorizada como "Vulnerable" (VU) (Mendoza-Cifuentes y Fernández-Alonso, 2012).

Material examinado: COLOMBIA. Departamento Boyacá, municipio Arcabuco, La Cumbre, 2300 m, 8.X.1980, fl, G. Lozano 3710 (COL, HUA); Cañón del río Pómeca, 2500 m, 15.IV.1997, fr, H. Mendoza 2960 (FMB, COL); vía a Bucaramanga, La Cumbre, 2300 m, 3.III.1980, fl, J. E. Valencia 2 (COL); carretera Arcabuco - Moniquirá, km 43, 2600 m, 31.VIII.1968, fl, L. Uribe 6169 (COL, US). Municipio Pajarito, 2000 m, 5.VI.1997, fl, H. Mendoza 3205 (FMB), 3258 (FMB). Departamento Caquetá, municipio San Vicente del Caguán, Parque Nacional Natural Los Picachos, cuenca del río Pato, 1600 m, 2.XI.1997, st, H. Mendoza 4011 (FMB); Parque Nacional Natural Los Picachos, cuenca río Pato, 1700 m, 5.XI.1997, fl, H. Mendoza 4089 (FMB); Parque Nacional Natural Los Picachos, cuenca río Pato, 2000 m, 10.XI.1997, st, H. Mendoza 4492 (FMB); Parque Nacional Natural Los Picachos, cuenca río Pato, 1500 m, 15.XI.1997, st, H. Mendoza 4523 (FMB). Departamento Cundinamarca, municipio Medina, south side Guavio river, 20 km north Charalá, Las Mesitas, 1615 m, 31.X.1944, fl, M. L. Grant 10542 (COL, NY, US); Farallones de Medina, 1500 m, 25.II.1997, fr, H. Mendoza 2330 (FMB). Departamento Meta, municipio La Macarena, Sierra de La Macarena, Pico Rengifo, 1300 m, 23.III.1957, fl,
J. M. Idrobo 2453 (COL, US); Sierra de La Macarena, central mountains north ridge, 1500 m, 30.XII.1949, fr, W. Philipson 2010 (COL, NY, US). Municipio Mesetas, vereda Villa Lucía, resguardo indígena de Villa Lucía, $1200 \mathrm{~m}$, 2.X.2002, fr, $R$. López 7500 (COAH, COL, FMB). Departamento Norte de Santander, municipio Toledo, Parque Nacional Natural Tama, sector Alto de Herrera, 1400 m, 19.IX.1999, st, H. Mendoza 7349 (FMB); Parque Nacional Natural Tama, sector Alto de Herrera, 1400 m, 19.IX.1999, fr, H. Mendoza 7951 (FMB). Departamento Santander, municipio Charalá, Virolín, vereda el Reloj, 1600-1700 m, 4.XII.1978, fl, S. Díaz-Piedrahita 1494 (COL); Virolín, Costilla del Fara, 1750 m, 22.III.1999, st, H. Mendoza 7166 (FMB). Municipio El Carmen de Chucurí, vereda La Bodega, Parque Nacional Natural Yariguíes, sector Manchurrias, 1700 m, 11.III.2012, fl, F. Almeda 10651 (CAS, COL); Parque Nacional Natural Yariguíes, fl, $R$. Ardila 82 (FMB). Municipio San Vicente de Chucurí, vereda Centro, Finca El Talismán, 1900 m, 12.II.2006, fr, Z. Martínez 76 (FMB); vereda Guamales, Sector San Cayetano, finca Corrales, 1500-2500 m, 10.VI.2006, st, Z. Martínez 118 (FMB).

Meriania haemantha (Planch. \& Linden) Humberto Mend. \& Fern. Alonso subsp. virolinensis Humberto Mend. \& Fern. Alonso, Anales Jard. Bot. Madrid 69(2): 277-279. 2012. Figs. 25I-J, 26. TIPO: COLOMBIA. Departamento Santander, municipio Charalá, vereda Santa Helena, predio La Sierra, margen derecho aguas abajo del río La Rusia, Santuario de Flora y Fauna Guanentá Alto Río Fonce, 2700 m, 16.XII.1998, fl, J. Cadena 183 (holotipo: COL!).

Entrenudos y ejes de la inflorescencia con indumento de tricomas piramidales lateralmente aplanados; lámina foliar elíptica o anchamente elíptica, de base aguda u obtusa; envés con indumento sobre la nervadura de tricomas esponjoso-irregulares con ramas delgadas (diminutos); inflorescencia generalmente corta, con pocas flores, entre 5-20, 8-15 cm de largo, ejes laterales cortos, 3-4 cm de largo; ápice del ovario bastante desarrollado en comparación con las otras subespecies; cápsula con el ápice del ovario sobresaliendo 4-6 $\mathrm{mm}$ arriba del torus.

Notas taxonómicas: la forma de la hoja tiene una variación continua entre las subespecies. Esta subespecie 
en las zonas del departamento Boyacá puede tener hojas oblongas a suborbiculares; no obstante, las inflorescencias tienen ramificaciones cortas y no son tan laxas como la variedad orientalis.

Distribución y hábitat: subespecie conocida solo para Colombia en el flanco occidental de la Cordillera Oriental en los departamentos Boyacá y Santander entre 2350 y 2700 m s.n.m. (Fig. 27). Es muy frecuente en la zona conocida como Virolín en el Santuario de Fauna y Flora Guanentá - Alto Río Fonce, en áreas de bosque de roble (Quercus humboldtii).

Nombre vernáculo: conocida como "tuno" en la región de Virolín en el departamento de Santander.

Etimología: en alusión al antiguo y común nombre de la localidad del tipo, Virolín.

Estado de conservación: categorizada como "Casi Amenazado" (NT) (Mendoza-Cifuentes y Fernández-Alonso, 2012).

Material examinado: COLOMBIA. Departamento Boyacá, municipio Arcabuco, cabeceras del río Pómeca, 2400 m, 3.VII.1969, L. Uribe 6292 (COL, US). Municipio Duitama, vereda El Carmen, en la vía a Virolín, 2320 m, Nov-1994, fl, J. L. Fernández-Alonso 12237 (COL). Municipio Toguí, vereda Carare, arriba de la hacienda San Joaquín, 2350 m, 1.IX.1978, fl, fr, G. Lozano 3004 (COL, HUA). Departamento Santander, municipio Charalá, vereda Santa Helena, La Sierra, 2700 m, 14.XI.1997, fl, J. Cadena 60 (COL); vereda Santa Helena, La Sierra, 2500-2600 m, 12.V.1967, fl, G. Lozano 2385 (COL, HUA, MEDEL); loc. cit., fl, G. Lozano 2539 (COL). Municipio Gambita, vereda Poleo Alto, sector sur orienta de La Cuchilla del Fara, 2030 m, 25.III.2010, fr, R. Medina 552 (COL). Municipio San Joaquín, vereda San Ignacio, finca Panamá, 2465 m, 28.III.2008, fr, C. Vargas 916 (COL).

Meriania heptamera Lozano \& Alvear, Caldasia 23(1): 150151. 2001. Figs. 25K-M, 28. TIPO: COLOMBIA. Departamento Caldas, municipio Manizales, vereda La Esperanza, finca Torre Cuatro, parche cerca del río Chinchiná,
2700 m, 28.III.1999, fl, fr, M. Alvear 318 (holotipo: COL!; isotipos: COL!, HUA!, US!).

Árboles 7-30 m de altura; entrenudos apicales oblongo-aplanados; ramas, pecíolos e inflorescencia glabros o con ralos tricomas furfuráceos pinoides diminutos (tipo 25); hojas con pecíolo 2-4 cm de largo, 2.5-3 mm diámetro; lámina 10-27 × 6-14 cm, ovada a anchamente elíptica u oblonga, de textura coriácea; ápice obtuso; base obtusa a redondeada; margen entero, generalmente revoluto en la base; haz glabro; envés con indumento furfuráceo laxo de tricomas similares a los de las ramas; nervadura con 2 pares de venas basales acompañando a la vena media, raras veces solo un par de venas basales; inflorescencia $14-30 \mathrm{~cm}$ de largo, sésil o con el primer internodo $6-9 \mathrm{~cm}$ de largo, 3-5 nudos de ramificación, 20 a 40 flores, paracladios 10-19 cm de largo, 2-3 niveles de ramificación; flor pedicelada, 7-mera; pedicelo 3-10 mm de largo; hipanto $4.5-8 \mathrm{~mm}$ de largo, anchamente campanulado, externamente glabro o con ralos tricomas similares a los de las ramas; pared 1-1.3 $\mathrm{mm}$ de grosor; torus $2.1 \mathrm{~mm}$ de grosor; cáliz 2-4 mm de largo, truncado; dientes dorsales diminutos o ausentes; corola patente; pétalos 23-45 × 13-25 mm, obovados, ápice truncado emarginado a redondeado, fucsia oscuro, glabros; estambres isomorfos, filamentos $12-18 \mathrm{~mm}$ de largo; codo 1.6-1.9 mm de largo, apiculado; conectival dorsal con apéndice 0.3-3 mm de largo, dentiforme a subulado; antera 5.4$5.8 \mathrm{~mm}$ de largo, subulada, levemente arqueadas hacia el dorso, poro dorsal; ovario $6 \mathrm{~mm}$ de largo, 7-locular, oblongo, completamente supero; ápice redondeado-truncado, leves lóbulos que rodean la base del estilo de 0.5-0.8 mm; placentas $3.2 \mathrm{~mm}$ de largo, ovoides, rudimentos seminales en toda la superficie; estilo 7-10 mm de largo, columnar; estigma 2-2.2 mm diámetro, expandido, estriado-lobulado; cápsula $18 \mathrm{~mm}$ de largo; semillas $2 \mathrm{~mm}$ de largo, cuneiformes con el ápice corto.

Notas taxonómicas: el cáliz truncado no caliptrado, las flores heptámeras y las hojas anchamente elípticas con las venas secundarias basales son el conjunto de caracteres que circunscriben a esta especie. Meriania hexamera es la especie con mayor semejanza floral y vegetativa, no obstante se diferencia por las ramas y hojas glabrescentes 


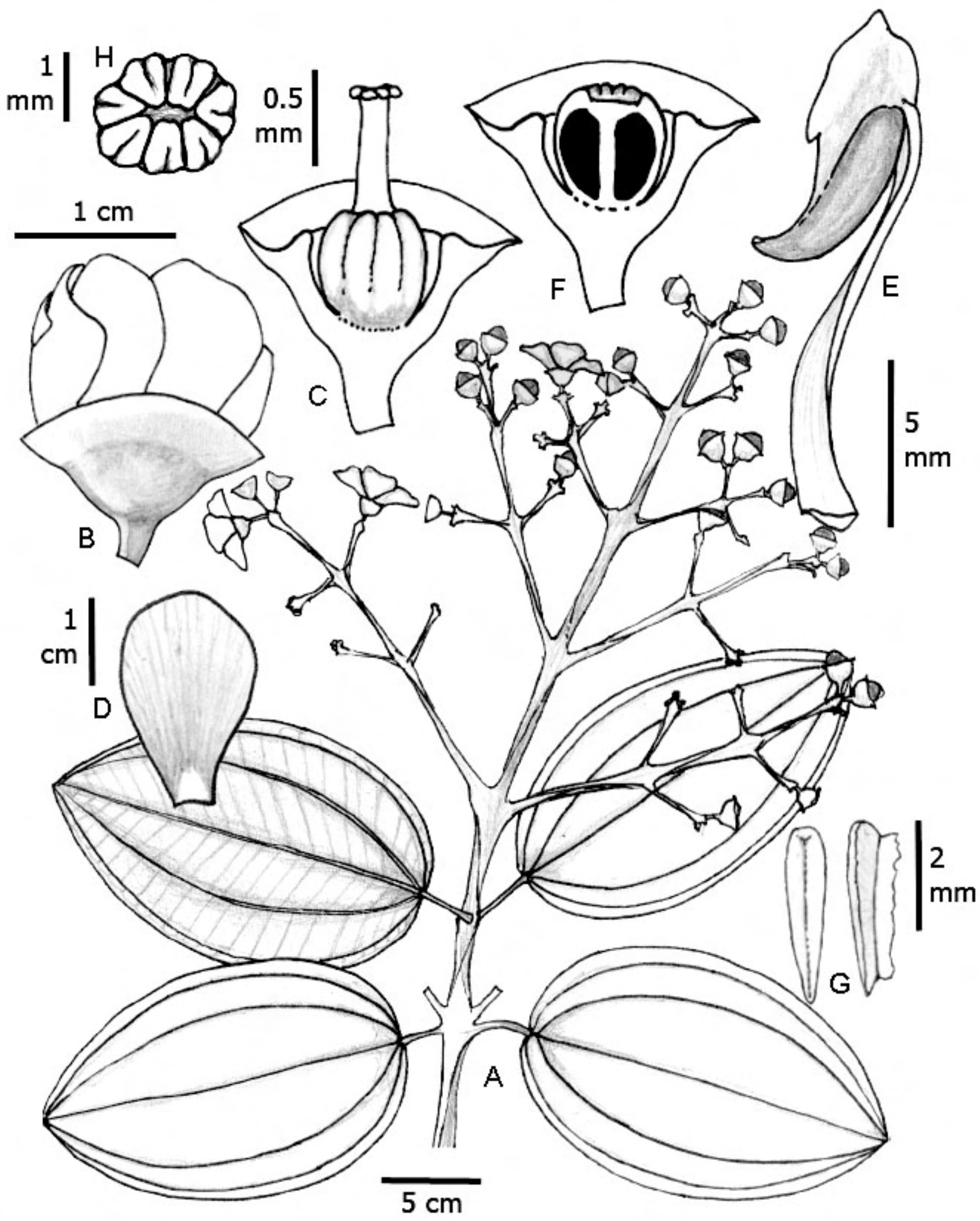

Figura 28: Meriania heptamera Lozano \& Alvear. A. rama florífera; B. botón floral previo a la antesis; C. corte longitudinal del hipanto y vista lateral del ovario; D. pétalo; E. estambre; F. corte longitudinal del hipanto-cáliz y ovario; G. vista dorsal y lateral de la placenta; H. estigma. A: Alvear 700 (COL); B-H: Barbosa 2900 (FMB). 
o con indumento laxo de tricomas pinoides diminutos, lámina foliar estrechamente elíptica de base aguda a obtusa, nervadura terciaria sobresaliente por el envés, relación A/B de la nervadura (Fig. 2C) entre 2.5 y 3.6, cáliz regularmente lobulado y con dientes dorsales conspicuos o a manera de líneas y ápice del ovario dentado; por otro lado, $M$. heptamera presenta indumento por el envés foliar harinoso marrón claro de tricomas pinoides diminutos, lámina foliar anchamente elíptica y con base predominantemente redondeada, nervadura terciaria plana o poco prominente por el envés, relación A/B de la nervadura entre 1.5 y 2.3, cáliz completamente truncado y sin dientes dorsales y ápice del ovario redondeado.

Distribución y hábitat: especie endémica a Colombia. Se registra para la Cordillera Central y parte de la Oriental (flanco occidental), en los departamentos Antioquia, Caldas, Quindío, Cauca, Cundinamarca y Valle del Cauca, entre 2400 y 2900 m de elevación, en zonas de bosque andino y altoandino (Fig. 22). Solo se encuentra en zonas bien conservadas en el interior de bosque.

Etimología: en alusión a las flores con siete pétalos.

Estado de conservación: categorizada en "Preocupación Menor" (LC) en la Lista Roja de la IUCN (2020), pero con algunos registros en Antioquia y Norte de Santander que demandan de evaluación. Tiene una EOO de ca. 37,000 $\mathrm{km}^{2}$, AOO de ca. $24 \mathrm{~km}^{2}$ y se conoce hasta ahora de nueve localidades. Según los lineamientos de la IUCN (2017), cumple los criterios B2ab(ii), por lo que se sugiere su recategorización como "Vulnerable" (VU).

Material examinado: COLOMBIA. Departamento Antioquia, municipio Jardín, Alto de Ventanas, $15 \mathrm{~km}$ SO de Jardín en la vía a Río Sucio, 2400-2800 m, 9.VI.1987, fl, $R$. Callejas 3954 (COL, HUA); sector Alto de Ventanas, 2800 m, 2.VII.2007, fl, H. David 2153 (HUA). Municipio Medellín, corregimiento San Cristobal, Cerro Padre Amaya, 3050 m, 4.VIII.2011, fl, A. Idárraga 4128 (HUA). Municipio Sonsón, km 11 of road Sonsón - Nariño, 2780 m, 1.IV.1987, fl, J. Zarucchi 5232 (CAS). Departamento Caldas, municipio Manizales, finca Torre Cuatro, 2600 m, 21.II.2000, fl, M. Alvear
700 (COL). Departamento Cauca, municipio Morales, vereda Chorrera Blanca, cerro Pico de Águila, 2800 m, 21.IX.1999, fr, G. Reina 367 (COL). Departamento Cundinamarca, municipio Cabrera, vereda Núñez, 2400 m, 27.VIII.1985, fl, G. Morales 505 (COL). Departamento Quindío, Parque Nacional Natural Los Nevados, salida al occidente de Rincón Santo, 13.XI.1984, fl, C. Barbosa 2900 (FMB). Municipio Salento, La Botánica, 2300 m, VI-1996, fl, W. Vargas 3164 (MO). Departamento Valle del Cauca, municipio La Cumbre, Corregimiento de Bitaco, vereda Chicoral, 2093 m, 22.VII.2003, st, H. Mendoza 14878 (FMB).

Meriania hernandi L. Uribe, Caldasia 10(48): 292-293. 1969. Figs. 29, 33A-C. TIPO: COLOMBIA. Departamento Putumayo, carretera de Sibundoy a Mocoa, Cordillera de Portachuelos, 2200 m, 8.X.1967, fl, H. García-Barriga 18630 (lectotipo: COL 3283!, aquí designado; isolectotipos: COL 3278, 3279!, 3280!, 3281!, 3282!, HUA!, US!).

Arbustos o árboles 2-15 m de altura; entrenudos cuadrangulares; ramas, hojas e inflorescencias glabras; hojas con pecíolo 7-11 cm de largo, alado o terete, caniculado, de base envolvente, ápice con un escutelo a manera de callo o disco; lámina $22-33 \times 19-27 \mathrm{~cm}$, suborbicular a anchamente ovada, textura delgado-coriácea; base cordada; ápice redondeado a obtuso; margen entero o espaciadamente denticulado; nervadura con 3 pares de venas secundarias basales, solo dos de ellas llegan al ápice; inflorescencia $30-70 \mathrm{~cm}$ de largo, abundantes flores, eje central con 5-6 nudos de ramificación; paracladios de hasta 40 cm de largo, con 2-3 niveles de ramificación; ápice de las ramillas tienen abundantes primordios florales atrofiados; flor pedicelada, 5-mera; pedicelos 7-23 mm de largo; hipanto 6.3-9 mm de largo, ciatiforme, textura carnosa; cáliz truncado, tubo 2-3.5 mm de largo, sin dientes dorsales o si presentes 1-2 mm de largo; corola patente; pétalos 19-30 $\times 15-32 \mathrm{~mm}$, obovados, apicalmente redondeados, carnosos, glabros, anaranjados; estambres isomorfos, filamento 13-15 mm de largo; codo 3.5-4 mm de largo, subulado, expandido hacia los lados; conectivo dorsal levemente abultado, sin apéndices; anteras 9-11 mm de largo, subuladas, levemente curvas hacia el dorso o sigmoidea, poro dorsal; ovario 6.8-7 mm de largo, 5-locular, oblongo, completa- 


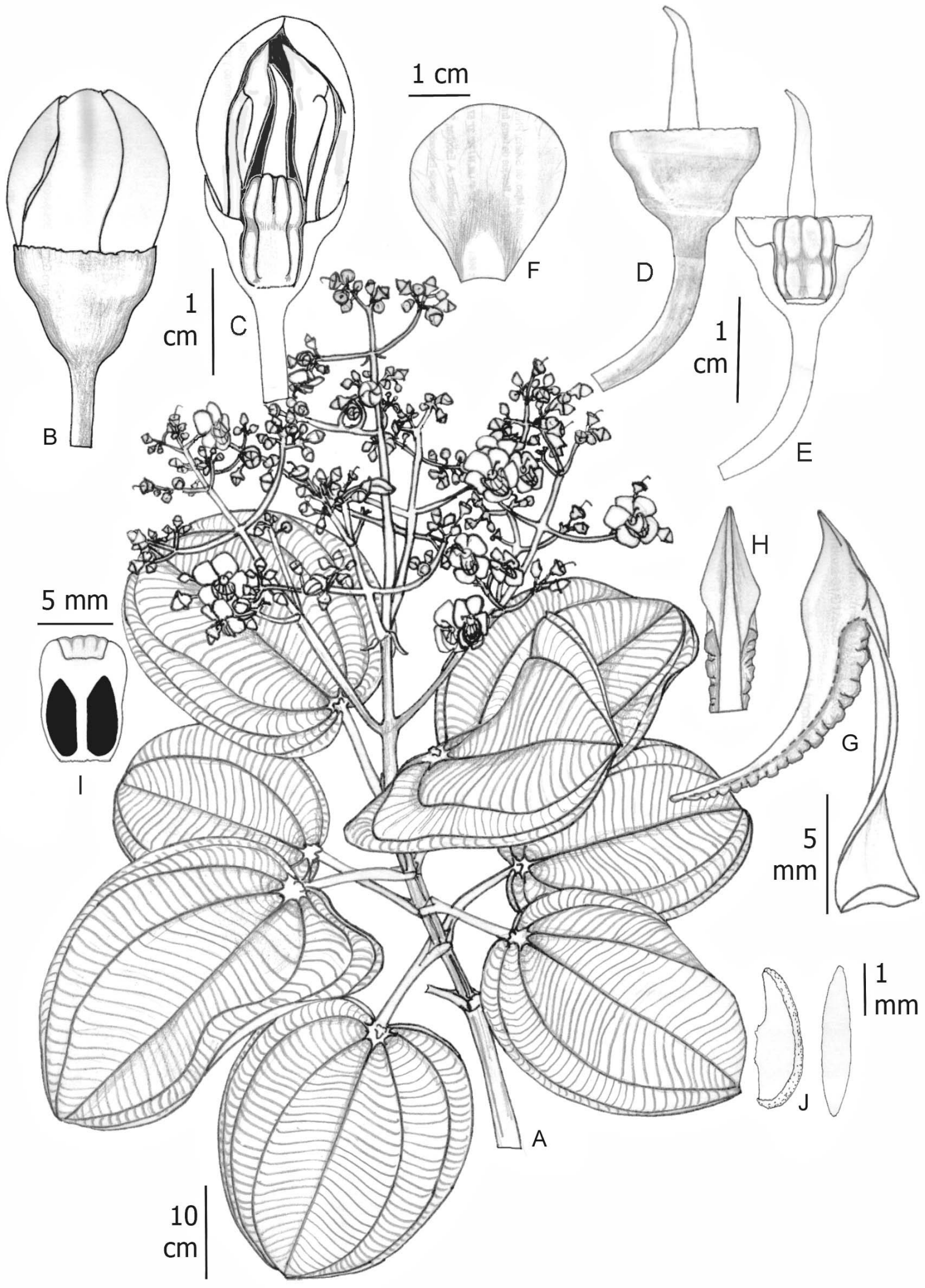

Figura 29: Meriania hernandi L. Uribe. A. rama florífera; B. botón floral previo a la antesis; C. corte longitudinal del botón floral; D. vista lateral del hipanto-cáliz y estilo; E. corte longitudinal del hipanto-cáliz y vista lateral del ovario; F. pétalo; G. estambre; H. codo en vista dorsal; I. corte longitudinal del ovario; J. vista lateral y dorsal de la placenta. Ilustración basada en colecciones vivas cultivadas en la Reserva Torremolinos, Valle del Cauca. 
mente supero o fusionado en la base al hipanto 0.7-1 mm; ápice con lóbulos muy cortos, redondeados, la parte que rodea la base del estilo de $1 \mathrm{~mm}$ de largo; placentas $3 \mathrm{~mm}$ de largo, estrechamente elípticas, rudimentos seminales en toda la superficie (una parte interna que no corresponde a placenta es desnuda); estilo 11-15 mm de largo, obcónico; estigma puntiforme; cápsula $12-15 \mathrm{~mm}$ de largo, la mitad superior del fruto sobresale por encima del hipanto en estado inmaduro, cuando maduro el hipanto es a manera de un disco en la base de la cápsula; semillas 3-4 mm de largo, de ápice alargado.

Notas taxonómicas: esta especie se reconoce por su amplia inflorescencia con abundantes flores de pétalos anaranjados. Vegetativamente se reconoce por sus grandes hojas redondeadas, de base cordada y ápice del pecíolo con escutelo.

Distribución y hábitat: especie restringida al sur de los Andes en Colombia y norte de Ecuador en la provincia Napo. En Colombia crece en el departamento Putumayo entre 1900 y 2200 m de elevación (Fig. 30). Crece en áreas de bosque andino en el interior del bosque en buen estado de conservación, aunque también se encuentra en borde de carreteras.

Etimología: especie nombrada en honor al botánico colombiano Hernando García-Barriga (1913-2005). Este epíteto fue corregido como "hernandoi" acorde con el artículo 60 C.2 del Código Internacional de Nomenclatura para Algas, Hongos y Plantas (Tropicos, 2016, 2020; Turland et al., 2018). No obstante, el epíteto hernandi se considera correcto ya que es derivado de Hernandus, forma latina de Hernando. El Padre Ortíz Valdivieso, taxónomo colombiano quien trabajo en orquídeas y experto en lenguas antiguas y árabes, refirió en comentarios personales que, si el nombre de este taxón se hubiera derivado directamente de "Hernando", la forma correcta sería "hernandoi", pero el autor, Lorenzo Uribe lo derivó de la forma latina (E. Calderón, com. per.). El Padre Valdivieso retoma tangencialmente el nombre correcto de esta especie en Ortíz Valdivieso y Medina (2012).
Estado de conservación: considerando algunos registros en la provincia Napo, Ecuador, esta especie tiene una EOO $<700 \mathrm{~km}^{2}$ y AOO $<16 \mathrm{~km}^{2}$. En Colombia se conoce de menos de cinco localidades (se conocen ocho colecciones de dos o tres localidades muy cercanas entre Mocoa y Sibundoy). Según los lineamientos de la IUCN (2017) cumple los criterios B1ab(i)+2ab(ii) por lo que se sugiere su categorización como "En Peligro" (EN). Ha sido propagada bajo condiciones de vivero y tiene gran potencial ornamental (Calderón, 2011).

Material examinado: COLOMBIA. Departamento Putumayo, municipio desconocido, entre El Encano y Mocoa, 2200 m, 3.X.1959, fl, H. G. Barclay 9664 (MO, US). Municipio Mocoa, carretera de Mocoa a Pasto, 1950 m, 13.X.1969, fr, B. Maguire 61833 (NY); El Mirador, 2000 m, 7.IX.1998, fl, H. Mendoza 6010 (FMB, PSO), 6070 (FMB, PSO). Municipio San Francisco, carretera San Francisco - Mocoa, 2800 m, 23.IX.1972, fl, L. E. Mora-Osejo 6156 (PSO); road from San Francisco to Mocoa, km 121 from Pasto, 5680 ft, 6.XI.1974, fl, T. Plowman 4425 (COL, PSO).

Meriania hexamera Sprague, Trans. Bot. Soc. Edinburgh 22: 431. 1905. Figs. 31, 33D-F. TIPO: COLOMBIA. Departamentos Huila-Putumayo, Eastern Cordillera, between Pitalito and Mocoa, 5.IV.1899, fl, R. Sprague 344 (lectotipo: K 329455!, aquí designado; isolectotipo: K 329456!).

= Meriania huilensis Wurdack, Brittonia 9 (2): 102, 1957. TIPO: COLOMBIA. Departamento Huila, municipio Gigante, finca Miravalles, on ridge between Río Blanco drainage, 21 km E of Gigante, 2800 m, 28.I.1943, fl, F. R. Fosberg 19853 (holotipo: US!; isotipo: NY!), syn. nov.

Árboles 5-15 m de altura; entrenudos subcuadrangulares u oblongo-aplanados, 4-9 mm de diámetro; ramas, hojas por el envés e inflorescencia con indumento laxo de tricomas esponjosos irregulares con ramas delgadas (tipo 31); hojas con pecíolo $0.90-2.7 \mathrm{~cm}$ de largo, 2-3.5 $\mathrm{mm}$ de diámetro; lámina $11-29 \times 4.5-14.5 \mathrm{~cm}$, elíptica a oblongoelíptica, textura delgado-coriácea; base obtusa a redondea- 

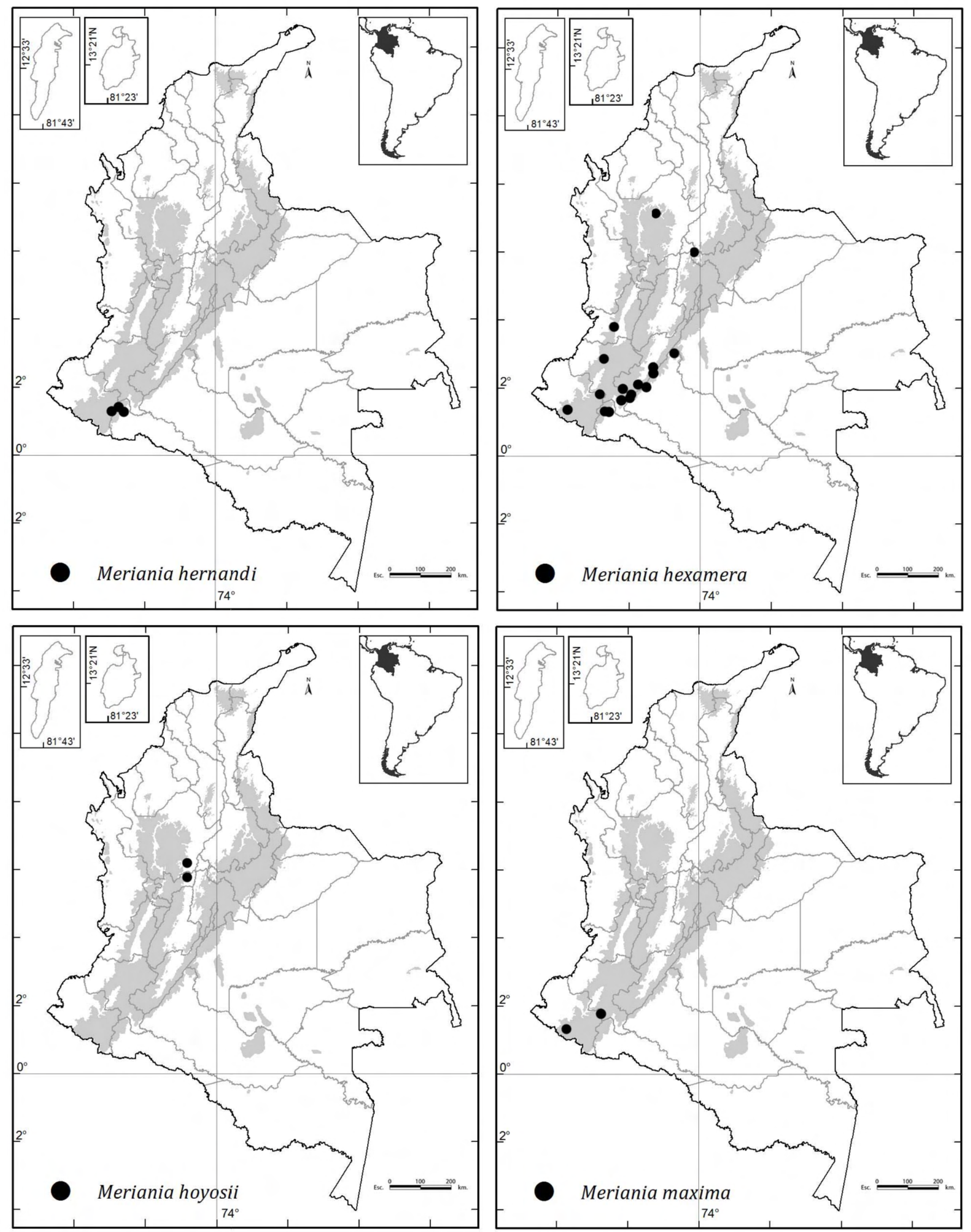

Figura 30: Distribución geográfica de Meriania hernandi L. Uribe, M. hexamera Sprague, M. hoyosii (Wurdack) Almeda \& Penneys y M. maxima Markgr. 


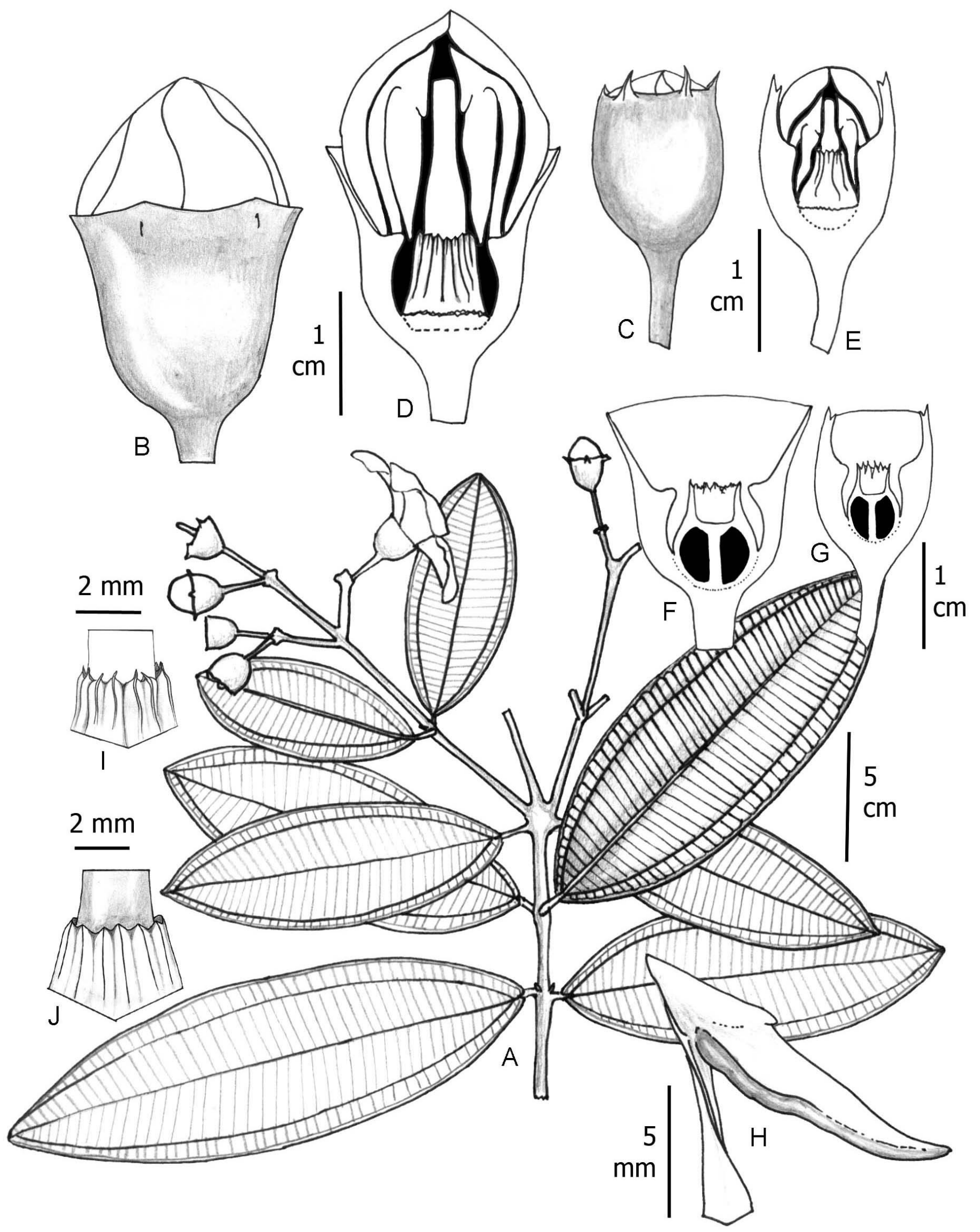

Figura 31: Meriania hexamera Sprague. A. rama florífera; B, C. botones florales; D, E. corte longitudinal de botones florales; $F$, G. corte longitudinal del hipanto-cáliz y del ovario; H. estambre; I, J. ápice del ovario. B-E: Mendoza 4752 (FMB); A, F, G, I, J: Mahecha s. n. (COL); H: Fosberg 19853 (NY). 
da, algunas veces revoluta; ápice agudo a corto acuminado; margen entero; nervadura con 2 pares de venas secundarias desplegándose cerca del margen, par interno plinervio a 3-6 $\mathrm{mm}$ arriba de la base; inflorescencia $10-15 \mathrm{~cm}$ de largo, 4 a 12 flores, eje central con 2-4 nudos de ramificación, ramillas de ápices dicasiales; flor pedicelada, 6-7mera; pedicelo 6.5-10 mm de largo; hipanto 8.4-13 mm de largo, cilíndrico o levemente campanulado, externamente glabrescente o con indumento laxo de tricomas como en los entrenudos; paredes 1.5-2.5 mm de grosor; torus 2.8$4.5 \mathrm{~mm}$ de grosor; cáliz truncado, tubo 2-8.4 mm de largo; dientes externos presentes o ausentes, cuando presente son filiformes, 2.5-12 mm de largo; corola patente; pétalos 25-38 × 15-27 mm, obovados, apicalmente truncados, magentas; estambres isomorfos, filamento $8.5-10 \mathrm{~mm}$ de largo; codo 3-4.7 mm de largo, triangular; conectivo dorsal con apéndice 0.2-0.5 mm de largo, dentiforme, algunas veces sin apéndices; antera 9.6-10 mm de largo, levemente sigmoidea o recta, oblongo subulada, poro dorsal; ovario 6-8 mm de largo, 6-locular, obcónico, en su mayor proporción libre, solo fusionado en la base al hipanto 2-3 mm; ápice con lóbulos dentiformes, la parte que rodea la base del estilo 2-4 mm de largo; placentas con rudimentos seminales en todas las superficies; estilo $10-14 \mathrm{~mm}$ de largo, 2.5-2.7 mm de diámetro, columnar, estriado hacia la base; estigma expandido, 3-3.5 mm de diámetro, con un hueco en el centro; cápsula no vista; semillas no vistas.

Notas taxonómicas: esta especie se reconoce por la nervadura con dos pares de venas secundarias cerca del margen (de apariencia broquidódroma), cáliz truncado o lobulado, corola patente, estambres isomorfos, estilo grueso columnar y estigma expandido. Las especies más afines son $M$. neillii y $M$. heptamera (ver diferencias en las descripciones de estas últimas). En la diagnosis de M. huilensis, Wurdack nombra la presencia de dientes dorsales del cáliz; no obstante, este caracter es variable ya que existen ejemplares con y sin dientes y formas intermedias, por lo que no es un carácter práctico para definir la especie. Por otro lado, Wurdack equívocamente asignó el nombre de $M$. huilensis a una variante robusta de $M$. hexamera (de ramas y pecíolos gruesos y pubérulos), mientras que asignó el nombre de $M$. hexamera a ejemplares glabros de ramas y pecíolos más delgados y que en este trabajo se establece como una especie nueva (M. neillii). La revisión de los tipos indica que la forma robusta en verdad corresponde a $M$. hexamera y la forma delgada corresponde a $M$. neillii.

Distribución hábitat: especie conocida para el centro-sur de la zona andina de Colombia y norte de Ecuador en la provincia Napo, entre 1350-2430 m de elevación. En Colombia se encuentre en los departamentos Boyacá, Caquetá, Cauca, Huila, Putumayo y Valle del Cauca (Fig. 30). Crece en áreas de bosque subandino y andino en interior de bosque en áreas en buen estado de conservación.

Nombre vernáculo: “árbol de mayo" en Putumayo.

Etimología: en alusión a las flores con seis pétalos.

Estado de conservación: considerando algunos registros en la provincia Napo, Ecuador, esta especie tienen una EOO de ca. 133,000 km², AOO de ca. $56 \mathrm{~km}^{2}$ y se conoce de más de 17 localidades. No cumple los criterios de la IUCN (2017) para las categorías de amenaza por lo que se sugiere su categorización como "Preocupación Menor" (LC).

Material examinado: COLOMBIA. Departamento Antioquia, municipio Yarumal, vereda Ventanitas, sector Ventanas, 2100-2300 m, 15.VII.2007, fl, H. David 2257 (HUA). Departamento Boyacá, municipio desconocido, Alto Chapón, NW of Bogotá, 7000 fl, 9.VIII.1932, fl, C. A. Lawrence 420 (MO, NY). Departamento Caquetá, municipio San Vicente del Caguán, Cordillera Oriental, vertiente oriental, entre Sucre y La Portada, 1200-130 m, 5.IV.1940, fl, J. Cuatrecasas 9139 (US); cuenca alta del río Pato, 1600 m, 15.XI.1997, st, $H$. Mendoza 4273 (FMB), 4276 (FMB); cuenca alta del río Pato, 1600 m, 15.XI.1997, fl, H. Mendoza 4752 (FMB). Municipio San José de Fragua, Serranía de Los Churumbelos, parte alta del río Yurayaco, 1450 m, 20.IX.2000, st, $H$. Mendoza 8833 (FMB). Departamento Cauca, municipio EI Tambo, Cerro Munchique, 2400 m, 6.X.1961, fl, R. Tryon 6000 (COL). Departamento Huila, municipio desconocido, Cordillera Oriental, vertiente occidental, abajo de Gabinete, 1900-2100 m, 24.III.1940, fl, J. Cuatrecasas 8614 (COL); Cordillera Oriental, 8200 ft, 29.X.1944, fl, E. L. Little Jr. 8872 
(Paratipo K). Municipio Palestina, Parque Nacional Natural Cueva de los Guacharos, 2020 m, 10.IX.1979, fl, J.E. Henao 223 (COL). Municipio San Agustín, vereda La Castellana, Reserva Natural Los Yalcones, 2320-2430 m, 9.VIII.2005, st, H. Mendoza 16374 (FMB); río Villalobos, region of the confluence of Ríos Villalobos and Cauchos, 1400 m, I.1943, fl, R. E. Schultes 5234 (COL). Departamento Putumayo, municipio Mocoa, corregimiento de San Antonio, Alto Campucana, finca La Mariposa, 1350 m, 20.IV.1994, fl, P. Franco 5312 (COL, COAH, HUA, US). Municipio Sibundoy, entre San Francisco y Río Blanco, 2300-2800 m, 9.IV.1973, fl, E. Hernández 408 (PSO); Río Blanco, 2400 m, II.1981, fl, G. Mahecha s.n. (COAH, FMB, UDBC). Departamento Valle del Cauca, municipio La Cumbre, corregimiento de Bitaco, vda. Chicoral, 2020-2093 m, 22.VII.2003, st, H. Mendoza 14932 (FMB), 15328 (FMB); loc cit., M. Ruiz 103 (FMB). ECUADOR. Provincia Napo, cantón Archidona, Parque Nacional Napo - Galeras, Cordillera Galeras, 1000-1650 m, 16.III.1997, fl, A. Álvarez 1639 (QCNE); Parque Nacional Napo - Galeras, Cordillera Galeras, 1550-1650 m, 20.III.1997, fl, A. Álvarez 1742 (QCNE); Parque Nacional Napo - Galeras, CordiIlera Galeras, 1700-1750 m, 26.III.1997, fl, A. Álvarez 1850 (QCNE); Parque Nacional Sumaco Napo - Galeras, 1650 m, 10.III.2003, fl, D. Neill 14205 (MO).

Meriania hoyosii (Wurdack) Almeda \& Penneys, Brittonia 66(2): 160-169. 2013. Figs. 32, 33G-I.

$\equiv$ Adelobotrys hoyosii Wurdack, Phytologia 55(3): 135-136. 1984. TIPO: COLOMBIA. Departamento Antioquia, municipio San Luís, autopista Medellín - Bogotá, sector Río Samaná - Río Claro, 752 m, 13.XII.1982, fl, J. J. Hernández 588 (holotipo: HUA!; isotipo: US!).

= Adelobotrys antioquiensis Wurdack, Phytologia 55(3): 134-135. 1984. TIPO: COLOMBIA. Departamento Antioquia, municipio San Luís, autopista Medellín - Bogotá, sector Río Samaná - Río Claro, 550 m, 5.XII.1981, fl, fr, J. J. Hernández 162 (holotipo: HUA!; isotipo: US!), syn. nov.

Arbustos o árboles pequeños 2-7 m de altura; plantas glabras; entrenudos oblongo-aplanados hacia las partes distales jóvenes, teretes en las partes basales; hojas similares en tamaño en el mismo nudo o con leve anisofilia; pecíolo 3-15 mm de largo; lámina $16-52 \times 7-23 \mathrm{~cm}$, obovada, delgado membranácea; ápice agudo a cortamente acuminado; base angostamente atenuada, algunas veces levemente cordada; margen entero; haz y envés glabros; nervadura con 2 pares de venas acompañando a la vena media, fuertemente plinervias; inflorescencia $9-18 \mathrm{~cm}$ de largo, umbeliforme, sencilla o con ramificaciones umbeliformes, sésil o pedunculada, con 10-50 flores por inflorescencias; pedúnculo aplanado, 2-4 cm de largo; flor pedicelada, 5-mera; pedicelo 10-15 mm de largo; hipanto 2.5-4 $\mathrm{mm}$ de largo, carnoso suculento en fresco, papiráceo en seco, anchamente campanulado, externamente glabro, blancuzco; cáliz truncado ondulado, tubo $1.8-3.8 \mathrm{~mm}$ de largo, externamente glabro; corola levemente cuculada; pétalos 13.5-17.2 × 6-9 mm, oblongo-obovados, de ápice truncado a redondeado, lila claro, glabros; estambres dimorfos, los opositipétalos con las anteras más largas mientras que los opositisépalos con el filamento más largo, los filamentos y las anteras son blancuzcos o lila claro, mientras que los apéndices dorsales del conectivo son amarillos; estambres opositipétalos, filamento 8.7-9.5 mm de largo; codo 1.5-1.7 mm de largo, triangular, tuberculado; conectivo dorsal con un apéndice 2.2-3.7 mm de largo, cilíndrico o levemente subulado; antera 7.4-10 mm de largo, subulada, sigmoidea, poro dorsal; estambres opositisépalos, filamento 10-13 mm de largo; codo $1.5-1.7 \mathrm{~mm}$ de largo, triangular, papilado; conectivo dorsal con un apéndice 1.8$3 \mathrm{~mm}$ de largo, cilíndrico o levemente subulado; antera 4.8$5.9 \mathrm{~mm}$ de largo, subulada, curvada hacia el dorso, poro dorsal o a veces inexistente; ovario 2.3-3.2 $\mathrm{mm}$ de largo, 5-locular, oblongo, súpero; ápice $1 \mathrm{~mm}$ de largo, lóbulos 5, truncados; placentas 2-2.7 $\mathrm{mm}$ de largo, estrechamente oblongo-ovadas, rudimentos seminales en todas las superficies; estilo 8-10 mm de largo, obcónico, glabro; estigma puntiforme; cápsula ca. 5-7 mm de largo sin considerar el pedicelo, hipanto papiráceo; solo sobresalen el ápice de los carpelos; con abundantes semillas; semillas $0.1-0.5 \mathrm{~mm}$ de largo, cuneiformes con ápice corto; área rafal más clara que la testa, hilum negro.

Notas taxonómicas: esta especie se asocia con Meriania compressicaulis Almeda \& Penneys de Panamá y con las especies de Meriania de la Mata Atlántica de Bra- 


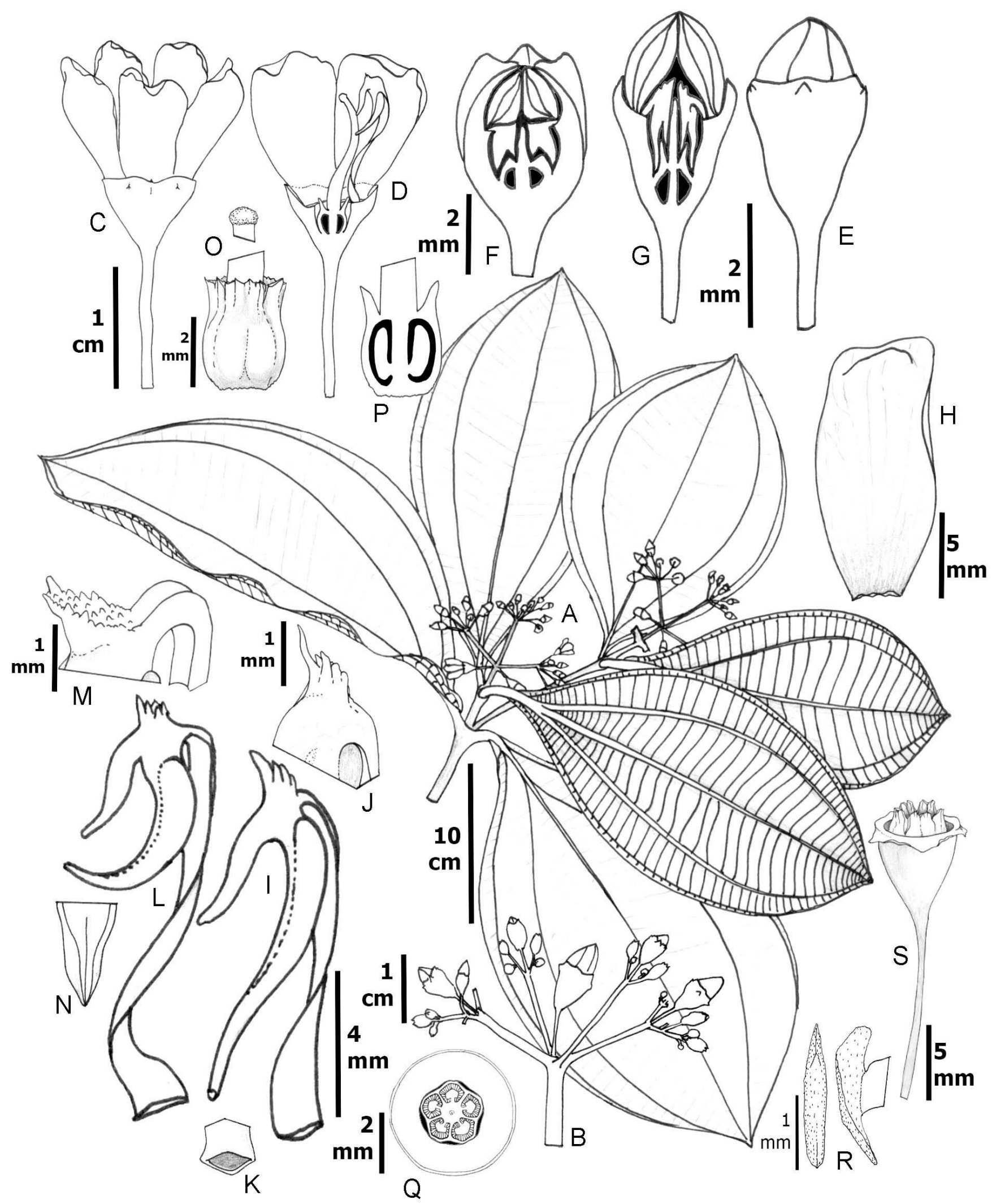

Figura 32: Meriania hoyosii (Wurdack) Almeda \& Penneys. A. rama florífera; B. parte de la inflorescencia; C. flor; D. corte longitudinal de una flor en antesis; E. botón floral previo a la antesis; F, G. corte longitudinal de botones florales en diferentes etapas de desarrollo; H. pétalo; I. estambre opositipétalo; J. vista lateral del codo en estambres opositipétalos; K. vista dorsal del ápice de la antera en estambres opositipétalos; L. estambre opositisépalo; M. vista lateral del codo en estambres opositisépalos; N. vista dorsal del ápice de la antera en estambres opositisépalos; O. vista lateral del ovario y estigma; P. corte longitudinal del ovario; Q. corte horizontal del hipanto-ovario; R. vista dorsal y lateral de la placenta; S. fruto. A-S: Mendoza 16884 (FMB), 16918 (FMB). 


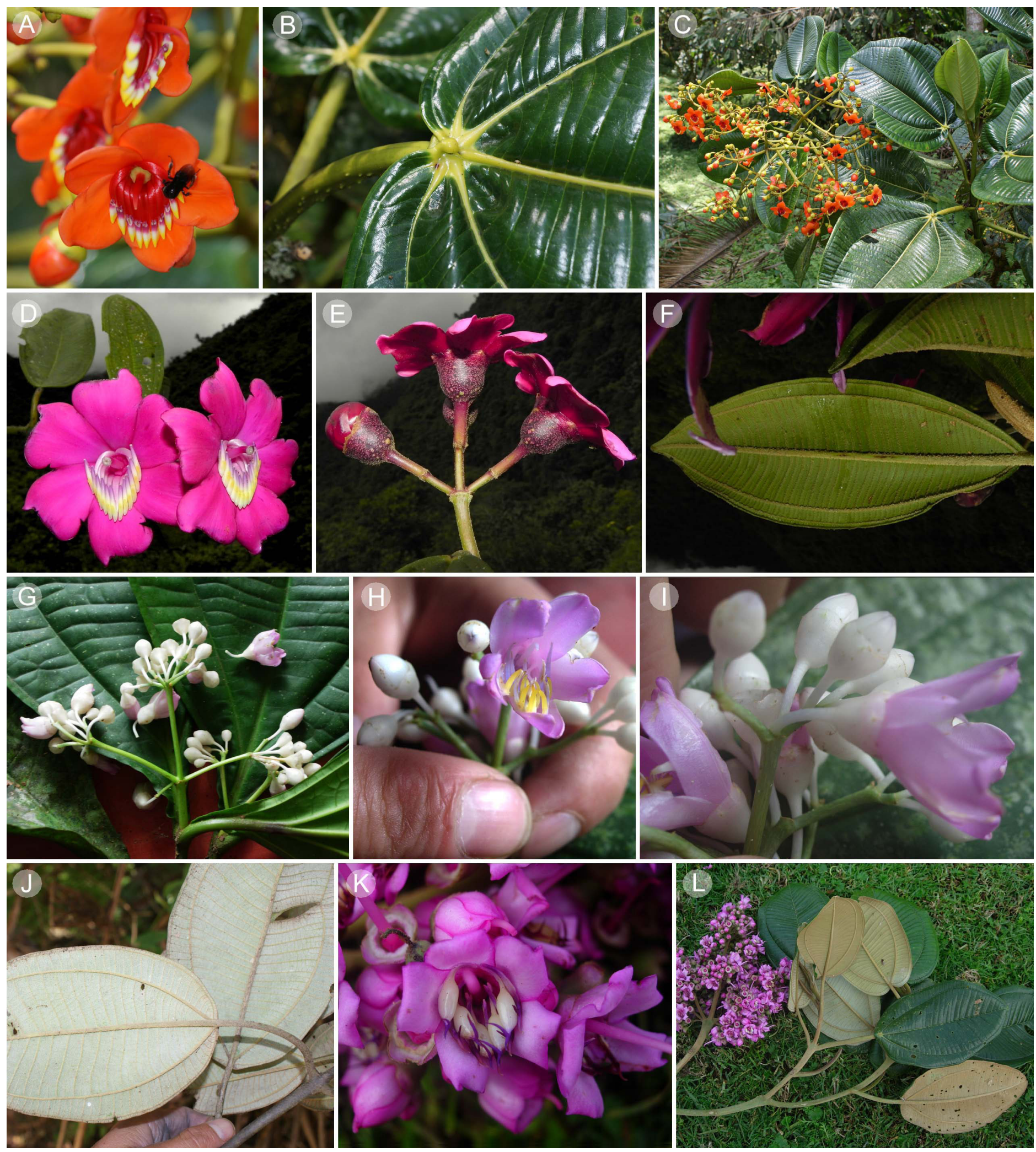

Figura 33: Fotografías de Meriania Sw. de Colombia. A, B, C. M. hernandi L. Uribe; D, E, F. M. hexamera Sprague; G, H, I. M. hoyosii (Wurdack) Almeda \& Penneys; J, K, L. M. macrophylla (Benth.) Triana. Créditos: H. Mendoza (A, B, C, G, H, I, J); M. Alvear (D, E, F), F. Forero (J, K. L). 
sil. Este grupo presenta corolas levemente cuculadas, estambres con una morfología similar al de las especies del género Adelobotrys (ver Mendoza-Cifuentes y FernándezAlonso, 2010), ovario 5-locular y placentas con rudimentos seminales en todas las superficies. Este grupo difiere de las merianias clásicas por la forma de los estambres y la corola; también difiere del grupo asociado a $M$. urceolata por el número de lóculos del ovario y la forma de las placentas. Perfectamente podría considerarse como un género aparte de Meriania.

Distribución y hábitat: especie endémica a Colombia y hasta el momento conocida solo de pocas localidades en los departamentos Antioquia y Caldas, en zonas húmedas y bajas (500-1000 m s.n.m.) del piedemonte oriental de la Cordillera Central colindante con el Magdalena Medio (Fig. 30). Posiblemente también se encuentre en el piedemonte de la cordillera Oriental que colinda con el Magdalena Medio en los departamentos Boyacá y Santander. Crece en zonas húmedas en el interior de bosque bien conservado.

Etimología: en alusión a Saúl E. Hoyos, investigador del departamento Antioquia.

Estado de conservación: esta especie tiene una EOO de ca. $40 \mathrm{~km}^{2}$, AOO de ca. $12 \mathrm{~km}^{2}$ y se conoce de seis localidades cercanas en el Magdalena Medio. Según lineamientos de la IUCN (2017) cumple los criterios B1ab(i)+2ab(ii), por lo que se sugiere su categoría como "En Peligro" (EN). Tiene gran potencial ornamental.

Material examinado: COLOMBIA. Departamento Antioquia, municipio Anorí, corregimiento de Providencia, carretera entre La Estación Biológica y Aljibes, 200-300 m, 20.IV.1977, fr, J. I. Santa 165 (HUA). Municipio Remedios, vereda El Totumal, occidente de la finca de Luis Carlos Restrepo, 600 m, entre 8.II.2000 y 10.II.2000, fr, A. Vasco 72 (HUA). Municipio San Luis, autopista Medellín - Bogotá, sector Río Samaná - Río Claro, 600-780 m, 24,26.XII.1982, fl, fr, J.J. Hernández 267 (COL), 402 (COL), 414 (COL), 493 (COL). Municipio Segovia, 500-600 m, 6.XII.2011, fl, fr, $C$. Sánchez 805 (HUA), 806 (HUA). Municipio Sonsón, juris- dicción de Cementos Argos, sector Los Limones, $400 \mathrm{~m}$, 18.II.2012, fr, H. David 3938 (COL, HUA). Departamento Caldas, municipio Norcasia, Río Moro, cerca del puente, 390 m, 15.VI.2001, fr, A. Duque 2519 (HUA), 2520 (HUA); balneario La Pava, debajo de Norcasia, 550 m, 3.IX.2006, fr, H. Mendoza 16884 (FMB); embalse Río La Miel 1, zona de Piñares, 650 m, 7.IX.2006, fl, H. Mendoza 16918 (FMB); embalse Río La Miel 1, zona de Piñares, 570 m, 28.X.2006, fr, fl, H. Mendoza 16929 (FMB). Municipio Victoria, sector La Pedrera, río La Miel, 800-815 m, 28.X.1997, fl, R. Sánchez 3529 (COL).

Meriania macrophylla (Benth.) Triana, Trans. Linn. Soc. Bot. 28: 66. 1872. Fig. 34.

E Davya macrophylla Benth., PI. Hartw. 75. 1841. TIPO: GUATEMALA. Rancho del Palo Hueco, Hartweg s.n. (lectotipo: K 329442!, aquí designado; isolectotipo: K 32943!).

Árboles 6-25 m de altura; entrenudos cuadrangulares $\mathrm{u}$ oblongo aplanados en los nudos apicales; ramas jóvenes, envés e inflorescencia con indumento ralo a denso de tricomas pinoides $0.1-0.5 \mathrm{~mm}$ largo, raras veces glabrescentes; hojas con pecíolo $2.2-11.5 \mathrm{~cm}$ de largo, con o sin escutelo en el ápice del pecíolo; lámina 10-33 × 4.5-28 $\mathrm{cm}$, ovado-elíptica a oblongo-elíptica, de textura delgado coriácea; ápice anchamente agudo a obtuso, algunas veces acuminado (acumen hasta $1 \mathrm{~cm}$ ); base obtusa, redondeada, cordada o peltada; margen entero o denticulado; haz glabro; envés glabrescente o con indumento laxo a denso de tricomas pinoides o aracnoideos (tipo 34); nervadura con 1-3 pares de venas acompañando a la vena media, solo 1 o 2 llegan al ápice, basales o levemente plinervias; venas intersecundarias prominentes; inflorescencia $8-25 \mathrm{~cm}$ de largo, abundantes flores (más de 50), eje con 3 a 6 puntos de ramificación, paracladios 5-15 cm de largo, ramillas con tendencia a la reducción de ejes por lo que las flores se agrupan en verticilos en los extremos de estas; flor pedicelada, 5-mera; pedicelo 5-15 mm de largo; hipanto 2.6-6.5 $\mathrm{mm}$ de largo, campanulado, externamente glabrescente o con indumento similar a las ramas; cáliz truncado a subcaliptrado, cuando presenta lóbulos estos son 5 o abriendo irregularmente en 2-4 lóbulos; tubo 1-2.2 mm de largo; 


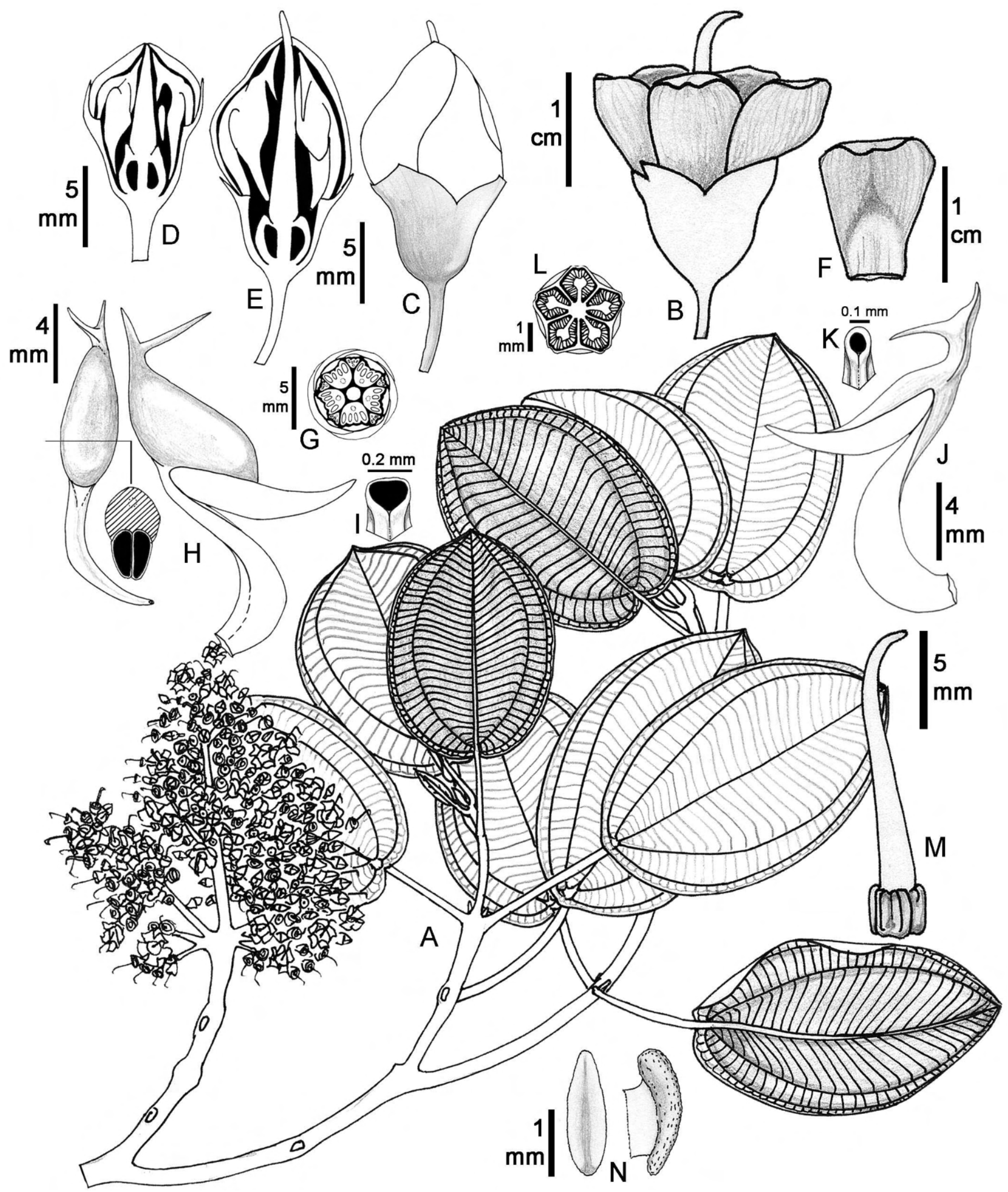

Figura 34: Meriania macrophylla subsp. peltata (L. Uribe) Humberto Mend. A. rama florífera; B. flor; C. botón floral previo a la antesis; D, E. corte longitudinal de botones florales en diferentes etapas de desarrollo; F. pétalo; G. corte horizontal del botón floral a la altura de los estambres; $\mathrm{H}$. vista dorsal y lateral del estambre opositipétalo y corte transversal de la antera en la base; I. ápice de la antera del estambre opositipétalo en vista dorsal; J. estambre opositisépalo; K. ápice de la antera del estambre opositisépalo en vista dorsal; L. corte horizontal del ovario; M. vista lateral del ovarioestilo; N. vista dorsal y lateral de la placenta. A-N: Mendoza 16641 (FMB). 
corola cuculada; pétalos 9.5-18 × 6.7-10 mm, oblongos, glabros, rosado oscuros o magenta claro; estambres fuertemente dimorfos, los opositipétalos más robustos por el tamaño del conectivo dorsal; estambres opositipétalos, filamento 4-8.2 mm de largo; codo 1.5-5.5 mm de largo, subulado; conectivo dorsal hinchado, un apéndice de 0.2$4.7 \mathrm{~mm}$ de largo, subulado, dentiforme o bífido, raras veces inexistente; antera 4.3-9 mm de largo, subulada, poro dorsal; estambres opositisépalos, filamento 4.3-10.2 $\mathrm{mm}$ de largo; codo 1.5-4.3 mm de largo, subulado; conectivo dorsal no hinchado, un apéndice $0.2-2.9 \mathrm{~mm}$ de largo, subulado o dentiforme; antera 3.9-9 mm de largo, subulada, poro dorsal; ovario 2.6-3.4 mm de largo, 4-5-locular, oblongo, súpero o fusionado al hipanto en la base 0.2-0.4 mm; ápice truncado-redondeado, levemente 5-lobado encerrando la base del estilo 0.2-0.8 mm; placentas 1.2-2.2 mm de largo, ovadas, rudimentos seminales en todas las superficies; estilo 8.3-22 mm de largo, cónico; estigma puntiforme; cápsula 5-8.8 $\mathrm{mm}$ de largo sin incluir el pedicelo, hipanto delgado encerrando la mitad del ovario; semillas $0.7-2 \mathrm{~mm}$ de largo, cuneiformes, ápice corto.

Notas taxonómicas: el conjunto de caracteres que circunscriben a $M$. macrophylla comprende inflorescencias multifloras con tendencia a la reducción de ejes de las ramillas, ocasionando inflorescencias con ramificaciones glomerulares, corola cuculada, pétalos oblongos 10-18 mm de largo, de color rosado a magenta, estambres fuertemente dimorfos, los opositipétalos con el conectivo dorsal globoso y ambas series con apéndice dorsal subulado o dentiforme.

Las especies Meriania pallida, M. antioquiensis, $M$. peltata y $M$. franciscana son muy similares a $M$. macrophylla y se pueden considerar variantes, pues sus diferencias se basan en caracteres que son plásticos. Meriania pallida del departamento Valle del Cauca, Colombia, por ejemplo, se caracteriza por indumento aracnoideo por el envés y el apéndice dorsal de estambres opositipétalos levemente bífido. El apéndice bífido varía en una misma inflorescencia (estambres con apéndices bífidos o no) y se presenta también en $M$. antioquiensis del norte de la Cordillera Central de Colombia; las poblaciones de M. macrophylla de Guatemala y Costa Rica presentan indumento seríceo y las hojas tienden a ser muy grandes y de ramas robustas similar a M. pallida.
Meriania antioquiensis, del departamento Antioquia, Colombia, se caracteriza por las hojas pequeñas glabrescentes y el apéndice dorsal del estambre opositipétalo bífido. El tamaño de las hojas es muy variable en todo el grupo de $M$. macrophylla considerado en este tratado, encontrándose variantes con láminas entre 12 y $33 \mathrm{~cm}$ de largo. Las poblaciones de Venezuela de M. macrophylla tienen hojas más bien glabrescentes y pequeñas, similar a $M$. antioquiensis. El apéndice dorsal bífido en los estambres opositipétalos es variable dentro de las colecciones de $M$. antioquiensis, lo que indica que este carácter es muy plástico y presenta diferentes grados de desarrollo desde apéndices subulados hasta subulados bífidos.

Meriania peltata, de la Cordillera Oriental de Colombia y norte de Ecuador, se caracteriza por las hojas de base peltada, indumento denso de tricomas pinoides sobre la nervadura por el envés y el cáliz subcaliptrado abriendo en lóbulos irregulares. El primer carácter de la base de la lámina foliar se presenta en las poblaciones de $M$. macrophylla en Centroamérica y de M. pallida en la Cordillera Occidental de Colombia. Dentro de las poblaciones de M. peltata en el departamento Cundinamarca (Páramo de Sumapaz), se encuentran variantes de hojas de base cordada, lo que indica que este carácter es plástico dentro de este complejo. La densidad del indumento del envés igualmente es variable en esta especie. Referente al cáliz, el desarrollo de lóbulos es variable, pues en $M$. macrophylla de Centroamérica y Venezuela se encuentran leves lóbulos o es subcaliptrado; en $M$. antioquiensis es subcaliptrado abriendo en lóbulos irregulares, mientras que en M. pallida es truncado.

Meriania franciscana, del sur de Ecuador y norte de Bolivia, corresponde a una variación poblacional glabrescente y con el apéndice conectival poco desarrollado; las colecciones de Bolivia muestran apéndices dorsales muy pequeños, casi inexistentes. La glabrescencia y el apéndice conectival dorsal dentiforme poco desarrollado también se presenta en poblaciones costeras de Venezuela asignadas a M. macrophylla subsp. costanensis por Wurdack (1978).

En síntesis, el complejo de especies documentado se basa en caracteres plásticos y ampliamente variables en $M$. macrophylla, como son la densidad de los indumentos y el grado de desarrollo del apéndice conectival dorsal. Considerando lo anterior y tomando en cuenta que ya han sido 
descritas varias subespecies y que hay poblaciones con coherencia geográfica y algunas características distintivas, se establece solo una especie con cinco variantes subespecíficas. No obstante, todas estas subespecies comparten los caracteres diagnósticos de la especie.

Distribución y hábitat: especie de amplia distribución desde el sur de México hasta Venezuela y norte de Bolivia, en zonas montañosas entre 1200 y 2800 m de elevación. En Colombia se encuentra en Sierra Nevada de Santa Marta, en las tres cordilleras y el Macizo Colombiano (Fig. 35). Su hábitat es el interior y borde de bosque en zonas de bosque subandino y andino.

Etimología: en alusión al gran tamaño de las hojas en comparación con otras especies congéneres.

\section{Clave para las subespecies de Meriania macrophylla}

1a. Envés glabro o glabrescente; nervadura terciaria visible 2

1b. Envés cubierto completo o parcialmente por tricomas pinoides o aracnoideos, blancuzco o ferrugíneo; nervadura terciaria no visible

2a. Apéndice conectival dorsal en estambres opositipétalos 3.1-4.5 $\mathrm{mm}$ largo, subulado o bífido, centro-norte de la Cordillera Central de Colombia M. macrophylla (Benth.) Triana subsp. antioquiensis (L. Uribe) Humberto Mend.

2b. Apéndice conectival dorsal en estambres opositipétalos inexistente o $0.2-2 \mathrm{~mm}$ de largo, subulado o dentiforme, no bífido; centro-norte de las tres cordilleras colombianas y Sierra Nevada de Santa Marta. 3

3a. Andes y Sierra Nevada de Santa Marta en Colombia, Cordillera de Mérida en Venezuela

... M. macrophylla (Benth.) Triana subsp. macrophylla

3b. Cordillera de la Costa en Venezuela o sur de Ecuador hasta norte de Bolivia 4

4a. Relación largo/ancho de la lámina foliar <1.8; pecíolos $>8 \mathrm{~cm}$ de largo; Cordillera de la Costa en Venezuela ..... M. macrophylla (Benth.) Triana subsp. costanensis Wurdack 4b. Relación largo/ancho de la lámina foliar $\geq 2$; pecíolos $<7 \mathrm{~cm}$ de largo; sur de Ecuador, norte de Bolivia M. macrophylla (Benth.) Triana subsp. franciscana (C. Ulloa \& Homeier) Humberto Mend.

5a. Base de la lámina foliar peltada; cáliz subcaliptrado; centro de la Cordillera Oriental de Colombia hasta el norte de Ecuador (vertiente oriental)

M. macrophylla (Benth.)

Triana subsp. peltata (L. Uribe) Humberto Mend.

5b. Base de la lámina foliar no peltada (cordada, redondeada); cáliz truncado; sur de México hasta Panamá, en Colombia en la Cordillera Occidental, el centro de la Cordillera Central, el norte de la Cordillera Oriental y la Sierra Nevada de Santa Marta y en Venezuela en la Cordillera de Mérida M. macrophylla (Benth.) Triana Triana subsp. macrophylla

Meriania macrophylla (Benth.) Triana subsp. macrophylla. Figs. 33J.

= Meriania pallida Gleason, Phytologia 2(6): 299-300. 1947. TIPO: COLOMBIA. Departamento Valle del Cauca, municipio Bolívar, Cordillera Occidental, vertiente occidental, hoya del río Sanquininí, lado izquierdo, La Laguna, 12501400 m, 16-20.XII.1943, fl, J. Cuatrecasas 15567 (holotipo: NY 228969!; isotipos: BC!, COL!, F!, NY 228970!/228971!, P!, US!), syn. nov.

= Meriania macrophylla (Benth.) Triana subsp. meridense Wurdack, Acta Bot. Venez. 13(1-4): 133-134. 1978. TIPO: VENEZUELA. Estado Mérida, between Guaraque and Tovar, 2000 m, 12.XI.1972, fl, J. J. Wurdack 2756 (holotipo: US!; isotipos: F!, MICH!, NY!, P!, US!), syn. nov.

Lámina foliar de base redondeada-cordada u obtusa; envés con indumento denso blancuzco; nervadura con 1-2 pares de venas secundarias basales, solo una llega al ápice; hipanto glabrescente o pubescente, pero con tricomas adpresos blancuzcos; cáliz truncado; ambas series de estambres con apéndices dorsales conspicuos, el de los estambres opositipétalos es subulado, 1.3-4.7 mm de largo, el de los estambres opositisépalos subulado o dentiforme, 0.5-2.9 mm de largo. 


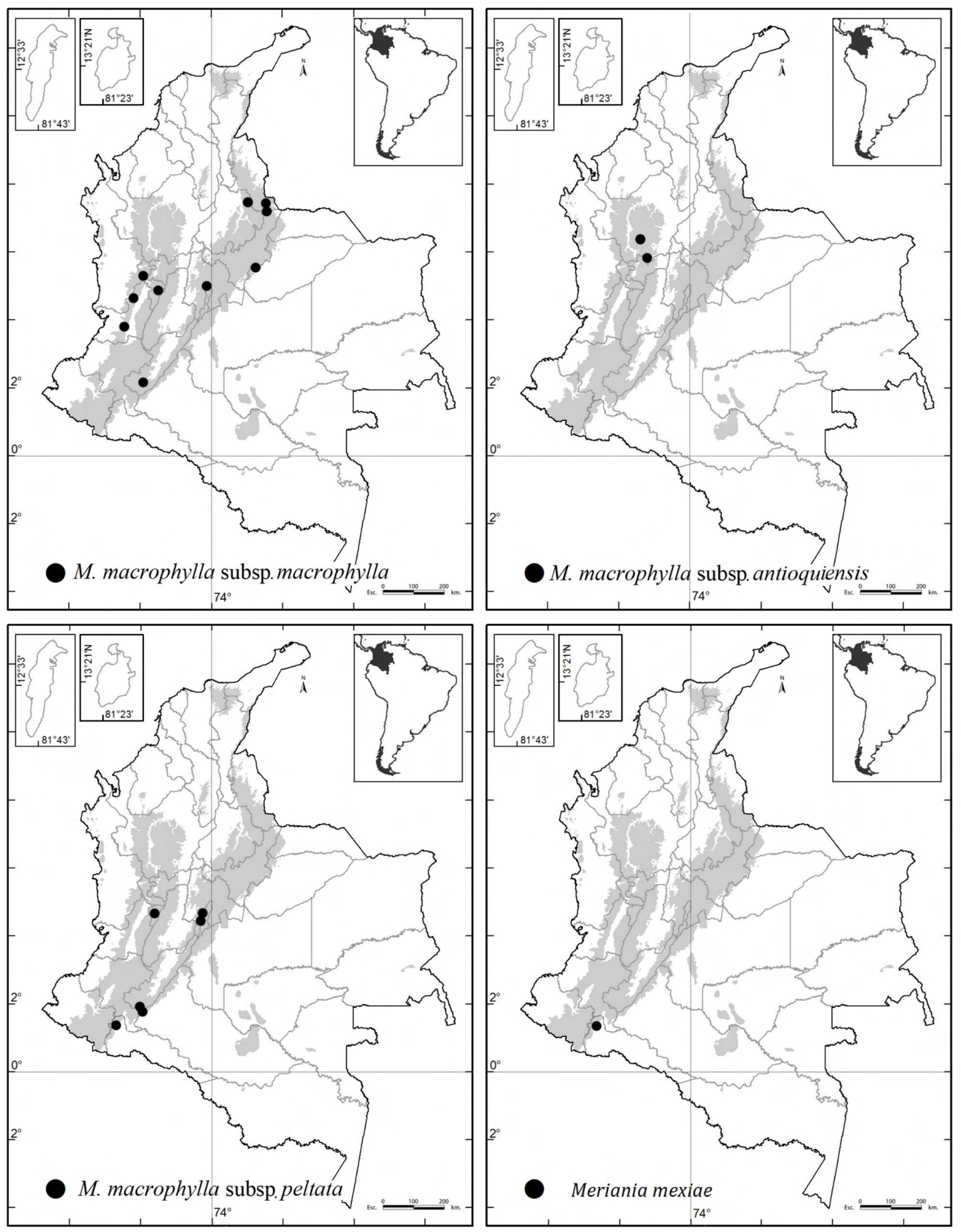

Figura 35: Distribución geográfica de Meriania macrophylla (Benth.) Triana subsp. macrophylla, M. macrophylla (Benth.) Triana subsp. antioquiensis (L. Uribe) Humberto Mend., M. macrophylla (Benth.) Triana subsp. peltata (L. Uribe) Humberto Mend. y M. mexiae Wurdack. 
Notas taxonómicas: se reconoce por el indumento blancuzco por el envés cubriendo la totalidad de la superficie, cáliz truncado y estambres con apéndices dorsales conspicuos (mayores de $1 \mathrm{~mm}$ de largo en estambres opositipétalos). La subespecie M. macrophylla subsp. meridense, establecida por Wurdack (1978), solo difiere levemente en la longitud de los apéndices conectivales dorsales (un poco más cortos que las poblaciones de Centroamérica y Colombia). En Cundinamarca (Albán) se encuentra una población que tiende a tener hojas glabrescentes por el envés y un escutelo en el ápice del pecíolo; no obstante, tiene los caracteres de la base de la lámina foliar, del cáliz y del apéndice conectival.

Distribución y hábitat: se distribuye desde Centroamérica (sur de México) hasta el norte de Suramérica en Venezuela (Cordillera de Mérida). En Colombia en las tres Cordilleras y Sierra Nevada de Santa Marta, en los departamentos Cundinamarca, Magdalena, Norte de Santander, Quindío y Valle del Cauca (Fig. 35). Su rango altitudinal comprende entre 1250 y $2800 \mathrm{~m}$. Siempre crece en zonas boscosas en buen estado de conservación.

Estado de conservación: no se sugiere la categorización ya que está ampliamente distribuida en Centroamérica y norte de los Andes, por lo que su categoría con solo la distribución en Colombia no es muy útil.

Material examinado: COLOMBIA. Departamento Cundinamarca, municipio Albán, Granja del Padre Luna, 1973, fr, G. Mahecha s.n. (COL); vereda Las Marías, Granja del Padre Luna, reserva El Gran Ciudadano, 1800-2100 m, 18.II.2002, fl, A. Plazas 8 (COL); cerca de la estación La Frontera, 1700 m, fl, L. Uribe 6601 (COL). Departamento Huila, municipio Palestina, Parque Nacional Cueva de Los Guacharos, 1830 m, 16.VII.1979, fl, J. E. Henao 187 (COL). Departamento Magdalena, municipio Santa Marta, Sierra Nevada de Santa Marta, cerro San Lorenzo, 2100 m, 11.IX.1965, fl, L. S. Espinal 1796 (COL); SW of Finca Los Arroyitos, 17001900 m, 5.X.1972, fl, J. H. Kirkbride Jr. 2390 (COL, NY); Santa Marta, Cerro Kenedy, Reserva Natural El Dorado, 1760 m, 2.II.2011, fr, H. Mendoza 17600 (FMB). Departamento Norte de Santander, municipio Cucutilla, vereda Carrizal, sector
Sisavita, 2800 m, 5.IV.2002, st, H. Mendoza 14744 (FMB). Municipio Toledo, Vereda Toledito, on the way to Los Ramos, 1930-2050 m, 1.III.2012, fr, F. Almeda 10577 (CAS, COL); Región del Sarare, entre el Alto del Loro y el Alto de Santa Inés, 1800-2200 m, 21.X.1941, fr, J. Cuatrecasas 12554 (COL). Municipio Villa Caro, vereda Peña de la Virgen, 2750 m, 3.IV.2012, fl, L. López 650 (COL). Departamento Quindío, municipio Salento, Reserva Natural Acaime, 2800 m, VI.1993, fl, W. Vargas 1554 (MO). Departamento, Risaralda, municipio Apia, 2200-2360 m, 26.VIII.2004, st, A. Prieto 2486, 2571 (FMB). Municipio Mistrató, corregimiento de San Antonio del Chamí, río San Juan, 24.IV.1992, fl, G. Lozano 6315 (COL). Municipio Pereira, vereda La Suiza, finca El Tesorito, 2060 m, 27.IX.2002, st, J. Mendoza 2363 (FMB). Municipio Pueblo Rico, vereda Providencia a Pavero, 2620 m, 21.VIII.2004, st, A. Prieto 2378 (FMB). Departamento Santander, municipio Suratá, Hoya del río Suratá, La Baja, 2500 m, 8.IV.1973, fl, J. Cuatrecasas 28745 (COL). Departamento Valle del Cauca, municipio La Cumbre, corregimiento de Bitaco, vereda Chicoral, 2020 m, 21.VII.2003, st, H. Mendoza 15329 (FMB); corregimiento de Bitaco, vereda Chicoral, 2093 m, 21.VII.2003, st, M. Ruiz 132 (FMB). COSTA RICA. Provincia Heredia, cantón Heredia, distrito San Rafael, Río San Rafael, NW slope of Bárbara Veleano, 1800 m, 17.IX.1967, fl, R. L. Lent 1291 (MO, F). Distrito San José, Z. P. Cerros de Escazú, falda norte del Cerro Rabo de Mico, 1600-2300 m, 9.X.1991, fl, J. F. Morales 174 (CAS). GUATEMALA. Departamento San Marcos, municipio San Marcos, Near Aldea Fraternidad, between San Rafael Pie de la Cuesta and Palo Gordo, west facing slope of the Sierra Madre Mountains, 1800-2400 m, 10.XII.1963, fl, fr, $L$. O. Williams 26200 (F). PANAMÁ. Provincia Chiriquí, distrito Barú, Above Boquete, near PN Volcán Barú, in a finca along Río Caldera in Alto Chiquero, 1500-1800 m, 8.II.2005, fl, fr, D. Penneys 1741 (CAS). VENEZUELA. Estado Mérida, municipio Sucre, distrito desconocido, La Trampa, carretera San Juan - La Azulita, 2500 m, 2.II.1987, fl, H. van der Werff 8776 (MO, NY); vertiente del Río Capaz, arriba de La Azulita, 2100-2400m, 1.IX.1966, J. Steyermark 97094 (NY). Estado Trujillo, distrito Boconó, Páramo de Guaramacal, SE of Boconó, 1500-2600 m, 18.VII.1990, L. J. Dorr 7350 (CAS, NY); PN Guaramacal, 2100 m, 17.VI.1995, fr, N. Cuello 988 (CAS). 
Meriania macrophylla (Benth.) Triana subsp. antioquiensis

(L. Uribe) Humberto Mend., comb. et stat. nov.

= Meriania antioquiensis L. Uribe, Sertulae Florae Colombiae XI, Caldasia 10(48): 293-295. 1969. TIPO: COLOMBIA. Departamento Antioquia, municipio Medellín, Alto de Las Palmas, camino de penetración hacia el sur, $2500 \mathrm{~m}$, 3.I.1969, fl, L. Uribe 6221 (lectotipo: COL 3269!, aquí designado; isolectotipos: COL 3271!, 3272!, US!), syn. nov.

Lámina foliar de base redondeada a obtusa; envés glabrescente (con solo ralos tricomas sobre la vena media); nervadura con solo un par de venas secundarias en la base; hipanto glabrescente; cáliz subcaliptrado; estambres en ambas series con apéndices dorsales conspicuos, estambres opositipétalos con apéndice subulado o bífido, de 3.1$4.5 \mathrm{~mm}$ de largo, estambres opositisépalos con apéndice subulado, 2-2.5 $\mathrm{mm}$ de largo.

Distribución y hábitat: subespecie restringida hasta el momento para el departamento de Antioquia, Cordillera Central, entre 2400-2500 m de elevación, en zonas de bosque andino (Fig. 35).

Estado de conservación: en la Lista Roja de la IUCN (2020), este taxón está categorizado como "Vulnerable" (VU).

Material examinado: COLOMBIA. Departamento Antioquia, municipio Caldas, La Corrala, 2440 m, 21.X.1985, fl, L. Albert de Escobar 5994 (COL); loc cit., 22.VI.1987, fl, L. Albert de Escobar 7745 (HUA); loc cit., 14.IV.1988, fl, L. Albert de Escobar 8408 (HUA). Municipio Envigado, finca La Miranda, La Catedral, nacimiento de la Miel, Cerro Higuerón, 2600 m, 11.XII.1996, fl, M. Correa 1601 (HUA). Municipio Medellín, corregimiento de Santa Helena, vereda El Cerro, cabecera quebradas El Cerro y Santa Helena, 9.IX.1996, fl, Giraldo 1338 (HUA).

Meriania macrophylla (Benth.) Triana subsp. costanensis Wurdack, Acta Bot. Venez. 13(1-4): 134. 1978. TIPO: VENEZUELA. Distrito Federal, entre El Junquito y la Colonia Tovar a $20 \mathrm{~km}$ al oeste del Junquito, $2200 \mathrm{~m}$,
17.X.1963, fl, J. Steyermark 91707 (holotipo: US!; isotipo: VEN!).

Ramas, pecíolos e inflorescencias glabrescentes; hojas con pecíolo, 9-11 cm de largo; lámina 20-22 × 15-17 cm (relación largo/ancho=1.4); base redondeada, cordulada; envés glabrescente (con solo ralos tricomas sobre la vena media); nervadura con 2 pares de venas secundarias en la base, solo una llega al ápice; hipanto glabrescente; cáliz truncado; estambres en ambas series con apéndices dorsales dentiformes, en estambres opositipétalos con apéndice 0.2-1 mm de largo, en estambres opositisépalos $0.3-1 \mathrm{~mm}$ de largo.

Distribución y hábitat: taxón restringido a la Cordillera de La Costa, en Venezuela; entre $1300-2200$ m s.n.m.

Estado de conservación: no se categoriza por ser un taxón fuera de Colombia.

Material examinado: VENEZUELA. Estado Aragua, distrito Colonia Tovar, Monumento Natural Codazzi, carretera a lo largo de la tubería entre sector La Flecha y El Acueducto, $2000 \mathrm{~m}, 9.1 .2002$, fr, F. Michelangeli 829 (NY); sin localidad, 2000 m, 30.X.1972, fl, J. J. Wurdack 2689 (NY); sin localidad, fl, W. Sonder 1780 (NY); sin localidad, $\mathrm{fl}, \mathrm{fr}, \mathrm{A}$. Heudler 40 (NY). Distrito Federal, alrededores de Las Aguaditas, a lo largo de una quebrada con manantiales, 2 km norte de Colonia Tovar, 1970-2000 m, 6.X.1980, fl, J. Steyermark 123513 (MO); Cordillera de La Costa, Cerro El Ávila, Pico El Ávila, lado sur, 2000 m, 20.VIII.1991, fl, W. Meier 327 (CAS). Distrito Sucre, northeast facing quebrada tributary to Río Manzanares, between Trinidad and ridge connecting Cerro del Diablo, western extension of southern peak of Cerro Turumuquire, 1300-1900 m, 12.V.1945, fl, fr, J. Steyermark 62757 (NY).

Meriania macrophylla (Benth.) Triana subsp. franciscana (C. Ulloa \& Homeier) Humberto Mend., comb. et stat. nov.

= Meriania franciscana C. Ulloa \& Homeier, Anales Jard. Bot. Madrid 65(2): 383-387. 2008. TIPO: ECUADOR. Zamora- 
Chinchipe, reserva San Francisco, road Loja-Zamora, near $35 \mathrm{~km}$ from Loja, montane tropical forest, $1890 \mathrm{~m}, 03^{\circ} 58^{\prime} \mathrm{S}$, 7904'W, 28.VII.2007, J. Homeier 2625 (holotipo: QCNE!; isotipos: CAS!, GOET!, LOJA!, M!, MO!, NY!, QCA!), syn. nov.

Ramas, pecíolo y lámina foliar por el envés glabrescentes; hojas con pecíolo $2.2-5 \mathrm{~cm}$ de largo; lámina de base redondeada, cordulada; nervadura con 2 pares de venas secundarias en la base, solo una llega al ápice; hipanto glabrescente; cáliz truncado o con leves lóbulos anchamente redondeados; estambres en ambas series con apéndices dorsales dentiformes, en estambres opositipétalos $0.2-0.3 \mathrm{~mm}$ de largo, en estambres opositisépalos $0.2-0.5 \mathrm{~mm}$ de largo.

Distribución y hábitat: desde el sur de Ecuador (Zamora-Chinchipe) hasta el norte de Bolivia, entre 1800 y $2020 \mathrm{~m}$, en el flanco oriental de Los Andes (Ulloa Ulloa y Homeier, 2008).

Estado de conservación: no se considera por ser un taxón que no está presente en Colombia.

Material examinado: ECUADOR. Provincia ZamoraChinchipe, estación científica San Francisco, Road Loja - Zamora, ca. 35 km, 1830 m, ca. 358'18''S 7904'44'W, 4.III.2000, J. Homeier 295 (QCNE). BOLIVIA. Departamento La Paz, Yungas, 6000 ft, 1885, fl, H. H. Rusby 2329 (NY).

Meriania macrophylla (Benth.) Triana subsp. peltata (L. Uribe) Humberto Mend., comb. et stat. nov. Figs. 33K-L, 34.

= Meriania peltata L. Uribe, Caldasia 8(40): 532. 1962. TIPO: COLOMBIA. Departamento Cundinamarca, bosques abajo del Salto del Tequendama, cerca de El Ermitaño, 2200 m, 18.V.1959, fl, L. Uribe 3285 (holotipo: COL 3288!; isotipos: AAU, COL! (5) pliegos, ENCB!, F!, GH!, MO!, NY, US!, VEN!), syn. nov.

Ramas, pecíolos, inflorescencias y envés foliar con indumento denso marrón claro de tricomas pinoides; lámina foliar de base redondeada, peltada; nervadura con 2-3 pares de venas secundaria basales, solo una llega al ápice; hipanto con indumento denso similar a las ramas; cáliz subcaliptrado, abriendo irregularmente o truncado; estambres en ambas series con apéndices dorsales conspicuos, subulados, en estambres opositipétalos 1.5-3 mm de largo, en estambres opositisépalos 1.3-2 mm de largo.

Distribución y hábitat: se encuentra desde el centro de Colombia hasta el norte de Ecuador (Napo), entre 1650 y 2800 m de elevación. En Colombia se encuentra en la Cordillera Oriental (Boyacá, Cundinamarca, Huila, Putumayo) y en la Cordillera Central en el norte del Valle del Cauca y sur de Quindío (Fig. 35).

Estado de conservación: categorizada en la Lista Roja de la IUCN (2020) como "Amenazada" (EN) bajo los criterios B1+2c. Considerando su EOO de ca. $52,000 \mathrm{~km}^{2}$, y que es conocida de más de 15 localidades, se sugiere su recategorización en "Preocupación Menor" (LC).

Material examinado: COLOMBIA. Departamento Cundinamarca, municipio Fusagasugá, La Aguadita, vereda Los Robles, finca La Carbonera, 2470 m, 8.VII.2006, fl, H. Mendoza 16641 (FMB), 16663 (FMB). Municipio Granada, vereda Los Amarillos, 2600-2800 m, 19.Vl.1987, fl, G. Morales 1001 (COL); Santandercito, hondonada detrás del Pico El Ermitaño, finca La Palma, 2400 m, 24.II.1968, fl, S. Restrepo 5 (COL); abajo del Salto del Tequendama, cerca al cerro El Ermitaño, 2100-2200 m, 27.VI.1960, fl, L. Uribe 3482 (COL). Municipio San Francisco, vereda Sabaneta, delante de Subachoque, 2600-2700 m, 14.VI.1964, fl, L. Uribe 4818 (COL). Departamento Huila, municipio Acevedo, El Diviso, sitio Villa Fátima, 1950 m, 9.VIII.2005, st, A. Prieto 3806 (FMB). Municipio Palestina, Parque Nacional Natural Cueva de Los Guacharos, El Pesebre, 2100 m, 28.XI.2001, st, $H$. Mendoza 14214 (FMB); vereda La Guajira, Reserva Natural La Rivera, 1970 m, 23.VIII.2005, st, A. Prieto 4043 (FMB), 4111 (FMB). Municipio San Agustín, vereda La Castellana, Reserva Natural Los Yalcones, alrededores de la Reserva, 2320-2430 m, 9.VIII.2005, st, H. Mendoza 16394 (FMB), 16410 (FMB); vereda La Castellana, Reserva Natural Los Yalcones, El Palmar, 2400-2600 m, 20.VIII.2005, st, H. 
Mendoza 16464 (FMB). Departamento Putumayo, municipio Mocoa, El Mirador, 2000 m, 7.IX.1998, st, H. Mendoza 7029 (FMB). Departamento Quindío, municipio Calarcá, quebrada Negra, vereda Vista Hermosa, finca La Floresta, 1650-2150 m, 2.III.1991, fl, C. A. Agudelo 894 (COL). Municipio Salento, Cocora, La Iberia, 2000 m, 22.II.1998, fr, W. Vargas 4479 (COL). Departamento Valle del Cauca, municipio Tuluá, V.1973, fl, A. Roa s.n. (COL). ECUADOR. Provincia Napo, cantón Cosanga, carretera Cosanga - El Aliso, 2240 m, 19.VIII.1990, fl, J. Jaramillo 11971 (COL, QCA). Provincia Quijos, cantón Quijos, Valle del río Consaga, 1 km arriba de la unión de los ríos Cosanga y Aliso, 2280 m, 19.X.1990, fr, W. Palacios 6432 (QCA, QCNE).

Meriania maxima Markgr., Notizblatt Bot. Gart. Berlin 13: 461-462. 1938. Figs. 36, 37A-D. TIPO: ECUADOR. Westkordilere westlich Quito, Campamento del río, zona del Pilatón, Río Toache, 900 m, 18.XII.1933, fl, E. Heinrichs 590 (holotipo: B, destruido; lectotipo: M!, aquí designado; isolectotipo: NY!).

Árboles 7-20 m de altura; entrenudos cuadrangulares sulcados, aristas anguladas en ramas jóvenes, redondeadas en las partes viejas; nudos con línea interpeciolar notoria pero no laminar; ramas, pecíolos, inflorescencia e hipanto-cáliz glabrescentes; hojas con pecíolo $3.1-6.6 \mathrm{~cm}$ de largo; lámina 15-28.5 × 8-14 cm, elíptica, anchamente elíptica, ovado-elíptica o suborbicular; ápice agudo, acuminado o redondeado; base obtusa, redondeada o cordulada, algunas veces revoluta; margen entero; haz glabro; envés glabro o pubérulo furfuráceo sobre la nervadura, tricomas esponjosos ramas delgadas (tipo 31); nervadura con 2-3 pares de venas que acompañan a la vena media más el par submarginal que no llega al ápice, basales o plinervias hasta $15 \mathrm{~mm}$ arriba de la base; inflorescencia $11-30 \mathrm{~cm}$ de largo, paniculada abierta o algunas veces con proliferación vegetativa con brácteas en los nudos semejantes a hojas en tamaño y forma, eje central con 3-4 nudos de ramificación, entre 13 a 35 flores, paracladios 9-29 cm de largo, 1-2 niveles de ramificación, ramillas apicales trifloras o más de tres flores por atrofiamiento de ejes; flor pedicelada, 5-mera; pedicelo $12-20 \mathrm{~mm}$ de largo; hipanto $8.5-11 \mathrm{~mm}$ de largo, campanulado; torus 4.5-4.6 mm de grosor; cáliz truncado, tubo 3.6-6.9 mm de largo; dientes externos inexistente o a manera de protuberancias; corola patente; pétalos 50 $60 \times 37-50 \mathrm{~mm}$, obovados, ápice truncado emarginado, fucsia oscuro, glabros; estambres levemente dimorfos; estambres opositipétalos mayores, filamento 19-24 mm; codo 4.4-5.2 mm de largo, 2.5-3.4 mm de ancho, triangular alado; conectivo dorsal con apéndice 1.3-1.7 mm de largo, lingüiforme - subulado; antera 10-11.5 mm de largo, subulada, sigmoidea, poro dorsal; estambres opositisépalos, filamentos 15.4-18 cm de largo; codo 2.9-4.3 mm de largo, 0.9-1.3 mm de ancho, estrechamente triangular; conectivo dorsal con apéndice 3.3-5.4 mm de largo, subulado; antera 11.2-13.3 mm de largo, subulada, sigmoidea, poro dorsal; ovario 7.5-8 mm de largo, 5-6-locular, ovoide, fusionado al hipanto en la base 2-2.5 mm; ápice con leves lóbulos dentiformes rodeando la base del estilo 0.3-0.4 mm; placentas 4-4.5 $\mathrm{mm}$ de largo, ovoides, rudimentos seminales en todas las superficies; estilo 19.8-20 mm de largo, columnar; estigma puntiforme; cápsula $17-20 \mathrm{~cm}$ de largo, urceolada; semillas no vistas.

Notas taxonómicas: esta especie se reconoce por ser árboles grandes, tener inflorescencias paniculadas con tendencia a la racemización (producción de hojas en los nudos de las inflorescencias), cáliz truncado sin dientes dorsales, pétalos 5-6 cm de largo, estambres dimorfos y apéndices conectivales dorsales conspicuos. La especie más afín es M. splendens; no obstante, M. maxima se diferencia de ella por la línea interpeciolar no laminar (vs. laminar), base foliar obtusa a redondeada (vs. cordada), envés y ramas glabrescentes (vs. indumento de tricomas farinosos), inflorescencia con 10 a 35 flores (vs. 30 a 70 flores), brácteas semejantes a hojas en los nudos (vs. inflorescencia sin brácteas), estambres dimorfos (vs. isomorfos), filamentos de los estambres opositipétalos regularmente 19-24 mm de largo (vs. $10-15 \mathrm{~mm}$ ), creciendo entre 1600 y $2600 \mathrm{~m}$ de elevación (vs. 2400 y 3300 m de elevación). Meriania pastazana es otra especie afín, la cual difiere de M. maxima por tener los estambres isomorfos y sin apéndices conectivales dorsales.

Distribución y hábitat: se distribuye entre el sur de Colombia y centro norte de Ecuador en zonas de bosque 


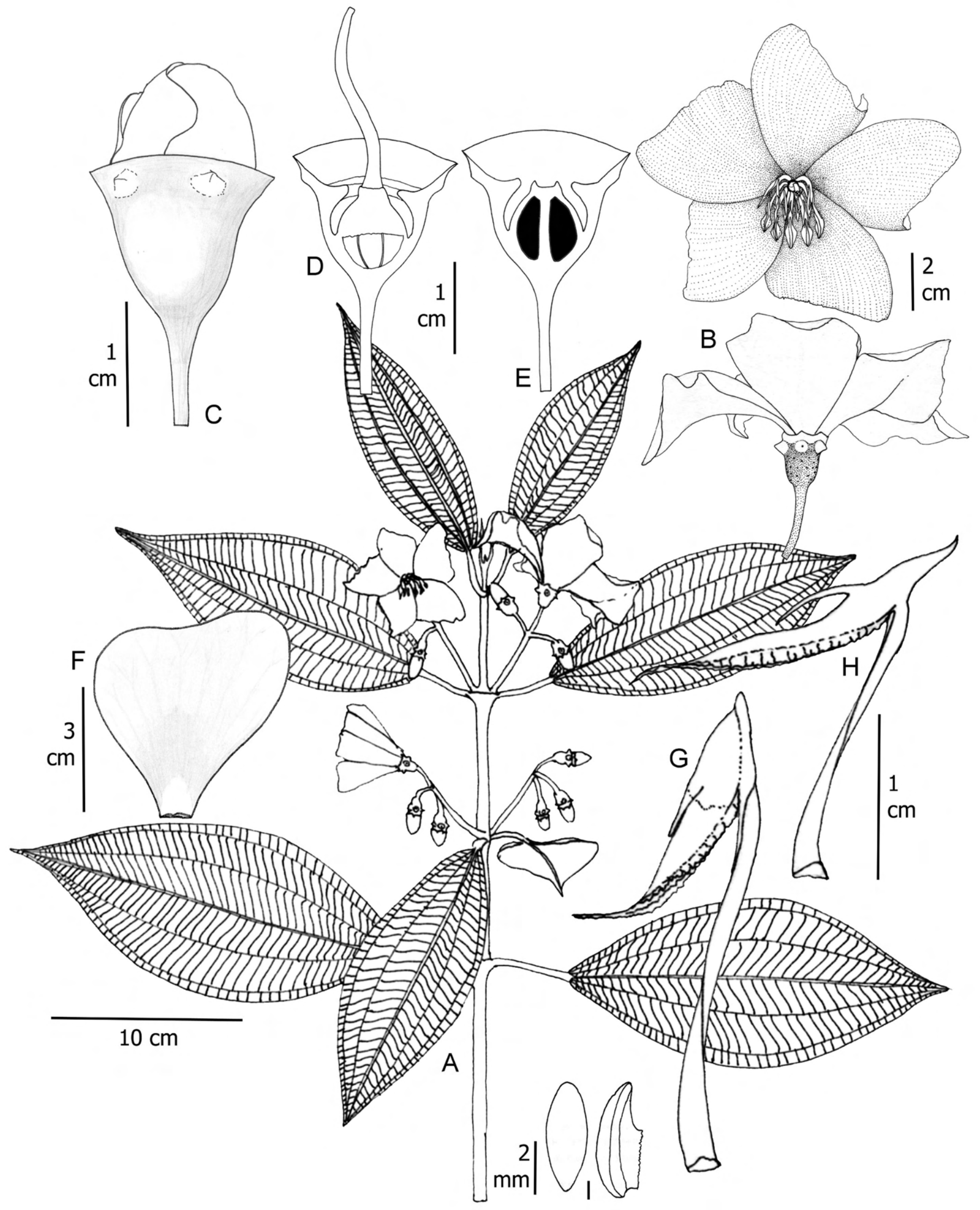

Figura 36: Meriania maxima Markgr. A. rama florífera; B. vista frontal y lateral de la flor; C. botón floral; D. corte longitudinal del hipanto-cáliz y vista lateral del ovario y estilo; E. corte longitudinal del hipanto y ovario; F. pétalo; G. estambre opositipétalo; H. estambre opositisépalo; I. vista dorsal y lateral de la placenta. A, B, G, H: Mendoza 746 (FMB); C, D, E, F, I: Gil 789 (FMB). 

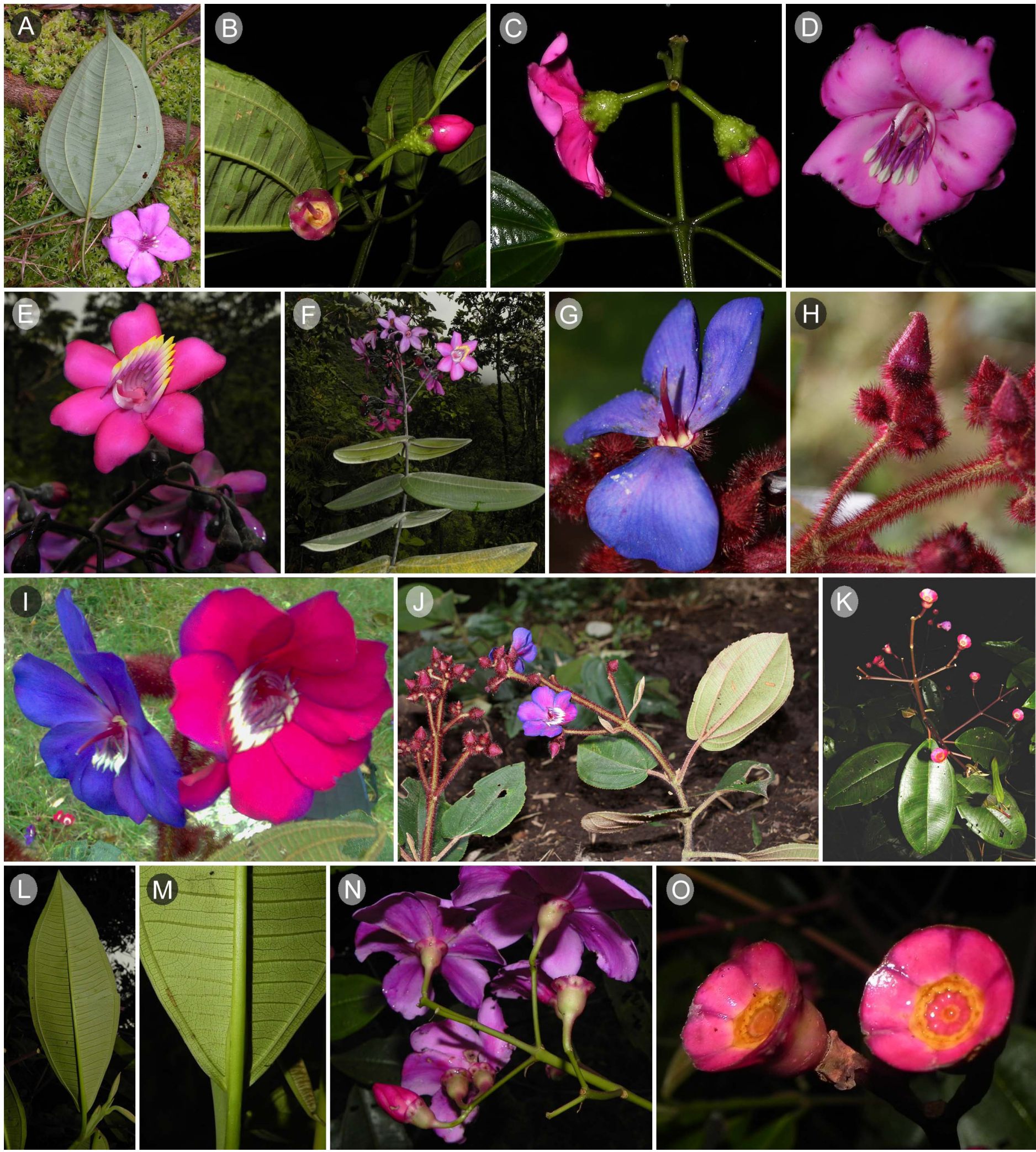

()

Figura 37: Fotografías de Meriania Sw. de Colombia. A-D. M. maxima Markgr.; E, F. M. mexiae Wurdack; G, H, I, J. M. mutisii (Bonpl.) Humberto Mend. \& Fern. Alonso; K, L, M, N, O. M. neillii Humberto Mend. Créditos: M. Vallejo (A); M. Alvear (B, C, D, E, F, K, L, M, N, O); G, Téllez (G, I); H. Mendoza $(\mathrm{H}, \mathrm{J})$. 
subandino con precipitación mayores a $3000 \mathrm{~mm}$ año, entre 1600 y 2200 m de elevación; excepcionalmente puede subir hasta $2600 \mathrm{~m}$. En Colombia solo se conoce para el departamento Nariño, en el flanco occidental de los Andes (Fig. 30). Crece en interior de bosque donde alcanza el dosel.

Nombres vernáculos: en Ricaurte, Nariño, en Colombia, la conocen como "sietecueros" o "mayo".

Etimología: posiblemente hace mención al gran tamaño de los individuos, aunque Markgraf no especifica exactamente el por qué del nombre. Esta es la especie de mayor porte dentro del género.

Estado de conservación: esta especie en Colombia se conoce de dos localidades en el departamento Nariño y su mayor área de distribución se encuentra en Ecuador. Por esto no se sugiere su categorización.

Material examinado: COLOMBIA. Departamento Nariño, municipio La Cruz, carretera Pasto - La Cruz, entre Plazuelas y La Cruz, 2500 m, 28.X.1962, fr, L.E. Mora-Ocejo 2419A (US). Municipio Ricaurte, Reserva Natural La Planada, 1750 m, 26.XI.1981, fl, A. Gentry 34981 (COL, MO, US); Reserva Natural La Planada, 1750-1850 m, 5.XII.1994, fl, H. Mendoza 746 (FMB, PSO); Reserva Natural La Planada, 1800 m, 10.X.2004, fl, N. Rodríguez 15 (COL); Reserva Natural La Planada, 1850 m, 26.XI.1981, fl, O. Salazar de Benavides 3325 (PSO); Reserva Natural La Planada, $1800 \mathrm{~m}$, 26.IX.1989, fr, O. Salazar de Benavides 10849 (PSO).

Meriania mexiae Wurdack, Phytologia 11(6): 383-384. 1965. Figs. 37E-F, 38. TIPO: ECUADOR. Napo-Pastaza, between Baños and Mera, 400-500 m, 23.II.1935, fl, Y. Mexia 6826 (holotipo: US!; isotipo: NY!).

Arbustos de ramas péndulas en barrancos; entrenudos oblongo-aplanados; ramas, hojas e inflorescencias glabros; hojas iguales o con tendencia a la anisofilia en las partes más apicales; pecíolo 3-7 mm de largo; lámina 5-20 $\times$ 2-8 cm, ovada, oblongo-ovada, ovado lanceolada, de textura delgado-coriácea; ápice agudo; base redondeada a cordada; margen entero; haz glabro; envés glabro; nervadura con 2 pares de venas basales, uno de ellos muy tenue, cerca del margen; inflorescencia $22-40 \mathrm{~cm}$ de largo, péndula, brácteas semejantes a hojas pequeñas en los primeros nudos, eje con 4-7 nudos de ramificación; primer internodo 6-7 cm de largo; paracladios basales 9-15 cm de largo; 2050 flores; ramillas apicales con 1-3 flores; flor pedicelada, 6-7-mera; pedicelo 1-2.5 cm de largo; hipanto 3-5.2 mm de largo, ciatiforme, glabro; cáliz truncado, sin dientes dorsales; tubo 2.2-2.5 mm de largo; corola patente; pétalos 16$25 \times 9-16 \mathrm{~mm}$, obovados, ápice truncado emarginado, glabros, fucsia oscuro; estambres isomorfos, filamento 8-10.7 $\mathrm{mm}$ de largo; codo 1.9-3 mm de largo, subulado; conectivo dorsal con una leve protuberancia; antera 7.4-8.4 mm de largo, subulada, sigmoidea, poro dorsal; ovario 5-5.2 mm de largo, 6-7-locular, oblongo, completamente supero o levemente fusionado en la base al hipanto 0.6-0.8 mm; ápice redondeado, con lóbulos redondeados muy cortos, encerrando la base del estilo 0.2-0.4 mm; placentas $1.6 \mathrm{~mm}$ de largo, obovadas, rudimentos seminales en todas las superficies; estilo 13-16 mm de largo, cónico, curvo en el ápice en flores abiertas; estigma puntiforme, papiloso; cápsula no vista; semillas no vistas.

Notas taxonómicas: esta especie se reconoce por ser completamente glabra, el hábito de crecimiento arbustivo con ramas péndulas, las hojas subsésiles y las inflorescencias péndulas largas.

Distribución y hábitat: especie restringida al sur de Colombia y a las provincias Sucumbíos, Napo y Tungurahua en Ecuador. En Colombia, los únicos registros provienen del piedemonte oriental de los Andes del departamento Putumayo, entre 1800 y 2300 m de elevación (Fig. 35). Posiblemente también presente en el departamento Nariño, municipio Ipiales, Colombia. Crece en taludes expuesto al borde de caminos.

Etimología: en honor a la botánica Ynes Mexia (18701938).

Estado de conservación: esta especie tiene su mayor área de distribución en Ecuador y solo se conocen menos 


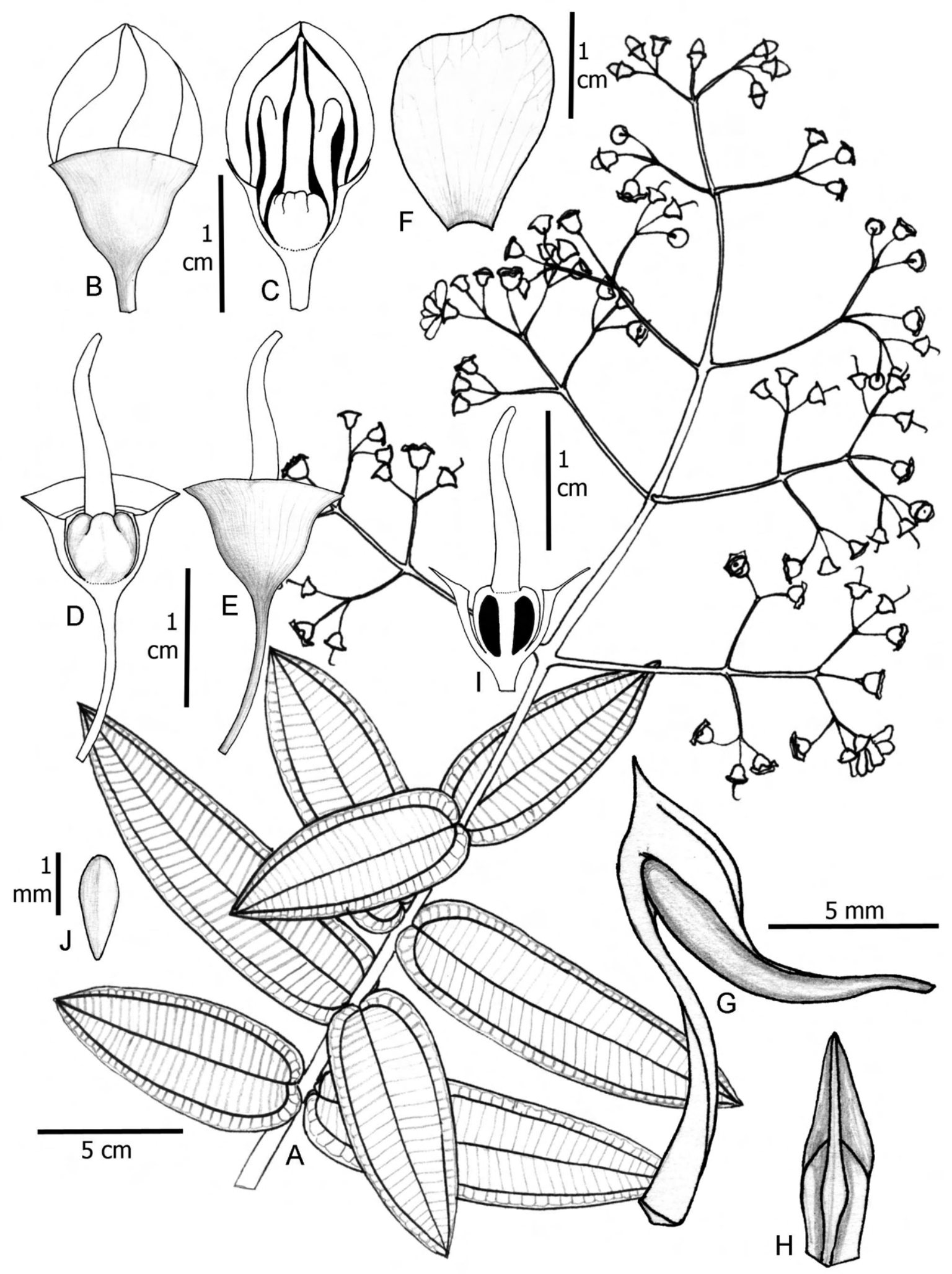

Figura 38: Meriania mexiae Wurdack. A. rama florífera; B. botón floral; C. corte longitudinal de botón floral; D. corte longitudinal del hipanto-cáliz y vista lateral del ovario y estilo; E. vista lateral el hipanto y estilo; F. pétalo; G. estambre; H. vista dorsal del codo; I. corte longitudinal del hipanto-cáliz y ovario-estilo; J. placenta en vista dorsal. A-I: Mendoza 6000 (FMB); J: Mora-Ocejo 6243 (COL). 
de cinco registros en Colombia en localidades muy cercanas. Por esto no se sugiere su categorización en este trabajo.

Material examinado: COLOMBIA. Departamento Putumayo, municipio desconocido, carretera entre San Francisco y Mocoa, 2700 m, 29.I.1972, fl, E. Hernández 352 (PSO); carretera entre San Francisco y Mocoa, 2100-2300 m, 30.I.1973, fl, L. E. Mora-Osejo 6243 (COL). Municipio Mocoa, El Mirador, 1900-2000 m, 7.IX.1998, fl, H. Mendoza 6000 (FMB). Municipio San Francisco, carretera entre San Francisco y Mocoa, 2100-2300 m, 23.IX.1972, fl, L. E. MoraOsejo 6155 (COL).

Meriania mutabilis (Gleason) Humberto Mend. \& Fern. Alonso, Anales Jard. Bot. Madrid 69(2): 280. 2012. Fig. 39.

三 Centronia mutabilis Gleason, Torrey Bot. Club 52: 340 . 1925. TIPO: COLOMBIA. Departamento Quindío, muncipio Salento, Alaska, arriba de Salento, Cordillera Central, 3100 3400 m, 7.VIII.1922, fl, F. W. Pennell 9385 (holotipo: NY!; isotipos: $\mathrm{GH}$ !, $\mathrm{K}$ !, $\mathrm{PH}$ !, $\mathrm{S}$ !, US!).

Árboles 0 arbustos 3-5 m de altura; entrenudos apicales aplanados; ramas, ejes de la inflorescencia y pecíolo con indumento de tricomas rufos esponjosos irregulares con ramas cortas (tipo 30), 0.2-0.3 mm de largo; hojas con pecíolo 1-2.6 cm de largo; lámina 5.5-14.7 × 2.8-9.7 cm, oblongo-ovada, oblongo-obovada u ovado-elíptica; base redondeada a levemente cordada; ápice obtuso; margen espaciadamente denticulado; haz glabro; envés con alveolos glabros, indumento laxo sobre la nervadura similar a la de los entrenudos y pecíolo; nervadura con 2 pares de venas acompañantes de la vena media, levemente plinervias; inflorescencia 3.7-12 cm de largo, con 1-2 nudos de ramificación; primer internodo ausente o $0.7-5 \mathrm{~cm}$ de largo; ejes fuertemente aplanados; paracladios basales ausentes o 3.8-6.5 cm de largo, con 1 (raras veces 2 ) niveles de ramificación; ápice de los ejes trifloros o 5 flores por reducción de entrenudos; inflorescencia con 7-21 flores; flor pedicelada, 5-7-mera; pedicelo 1.1-7.8 $\mathrm{mm}$ de largo; hipanto 4-5.7 mm de largo, hemisférico o ciatiforme, ex- ternamente con indumento denso de tricomas similares al de las ramas 0.4-0.5 mm de largo, algunas veces con ralos pelos rígidos setosos hasta $2 \mathrm{~mm}$ de largo; torus con ribetes en el punto de inserción de los estambres; cáliz caliptrado; caliptra 9.5-14.5 mm de largo, apicalmente aguda, no o escasamente apiculada, circuncísil, con indumento laxo de tricomas similares al hipanto; corola patente; pétalos 19-27 × 17-20 mm, obovados, ápice truncado emarginado, glabros, fucsia oscuro; estambres isomorfos, filamento 7.4-9.3 mm de largo; codo 2.4-4 mm de largo, subulado; conectivo dorsal con apéndice $0.5-0.8 \mathrm{~mm}$ de largo, subulado, rojizo; antera 6.4-8.1 mm de largo, subulada, sigmoidea, amarilla, poro dorsal; ovario 4.2-7.1 mm de largo, 5-6-locular, menos frecuente 7-locular, oblongo a suborbicular, parte basal fusionada al hipanto 0.6-1.5 mm, en corte transversal se aprecian costillas en su parte media; ápice con dientes subulados bífidos 1-3 mm de largo; placentas 2-2.1 mm de largo, ovoides, con rudimentos seminales en todas las superficies; estilo $11-13 \mathrm{~mm}$ de largo, levemente cónico; estigma puntiforme; cápsula no vista; semillas no vistas.

Notas taxonómicas: esta especie tiene caracteres como la forma de los tricomas del hipanto, el ovario casi súpero y la forma globosa del ovario que la diferencia de las otras especies del grupo Brachycera. La especie más afín es $M$. yalconensis, de la cual difiere en la ausencia de ribetes frente a los pétalos en el interior del hipanto y el reducido número de flores. También puede ser confundida con $M$. brachycera por el tamaño y forma de las hojas; no obstante, se diferencia de esta última por la ausencia del indumento aracnoideo por el envés y la nervadura basal de las hojas.

Distribución y hábitat: especie endémica a Colombia y restringida a la Cordillera Central en los departamentos Caldas, Quindío y Valle del Cauca (zona norte de este departamento) entre 2400 y 3200 m s.n.m. (Fig. 40). Se encuentra en áreas de bosque andino y altoandino. Puede crecer en interior de bosque, en bordes y esporádicamente en zonas abiertas. Meriania mutabilis es una especie poco colectada y al parecer es poco abundante en su área de distribución. 


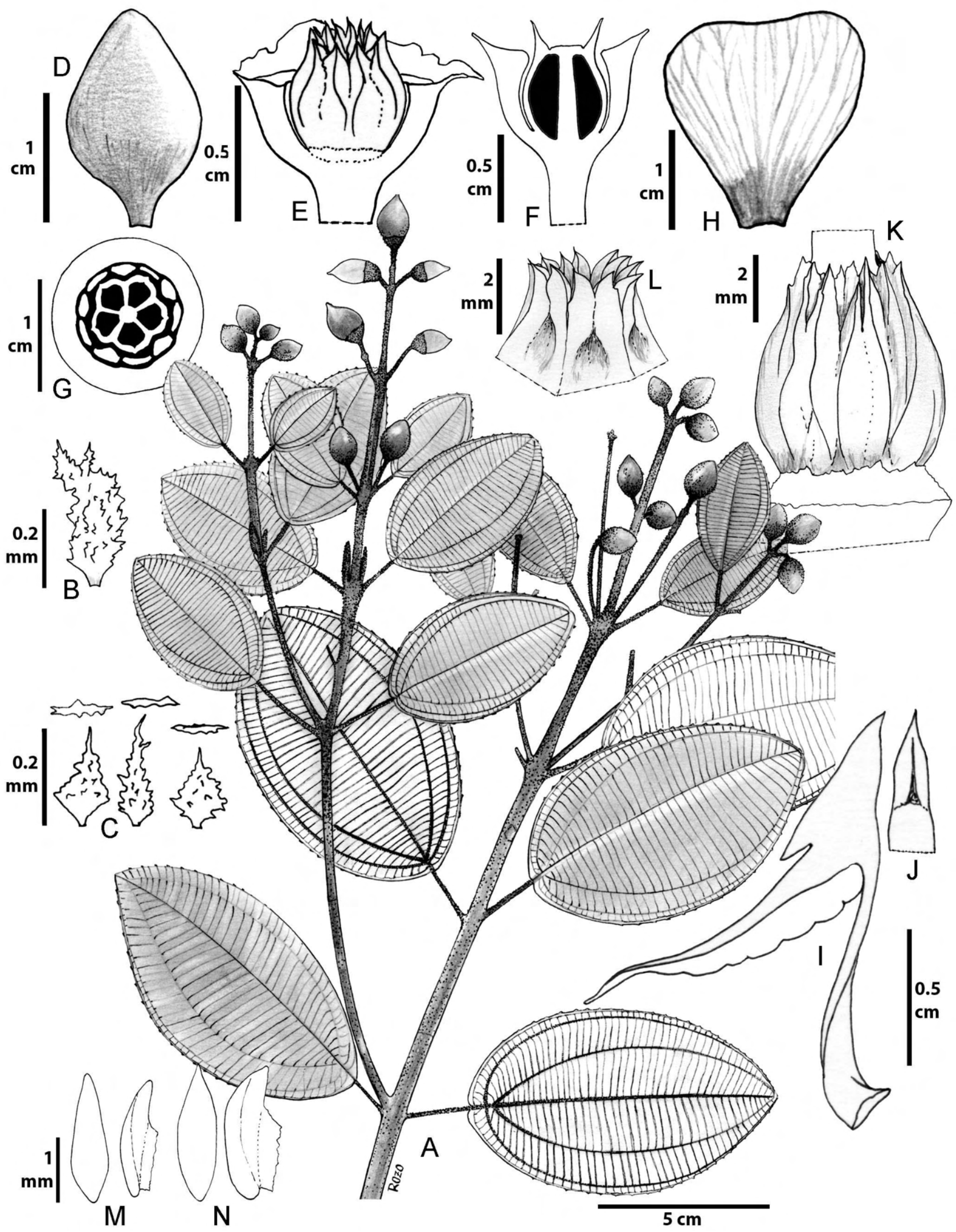

Figura 39: Meriania mutabilis (Gleason) Humberto Mend. \& Fern. Alonso. A. rama florífera; B. tricoma del hipanto; C. tricomas del pedicelo y ejes de la inflorescencia; D. botón floral; E. corte longitudinal del hipanto y vista lateral del ovario; F. corte longitudinal del hipanto-ovario; G. corte horizontal del hipanto-ovario en botón floral; H. pétalo; I. estambre; J. codo en vista ventral; K. ovario; L. ápice del ovario; M, N. vista frontal y lateral de las placentas. A, D, E, G, H, L, M, N: Rincón s. n. (HUQ); B, C: Agudelo 1540 (HUQ); F, I, J, K: Fernández 15 (HUQ); tomada de Mendoza-Cifuentes y Fernández-Alonso (2012). 

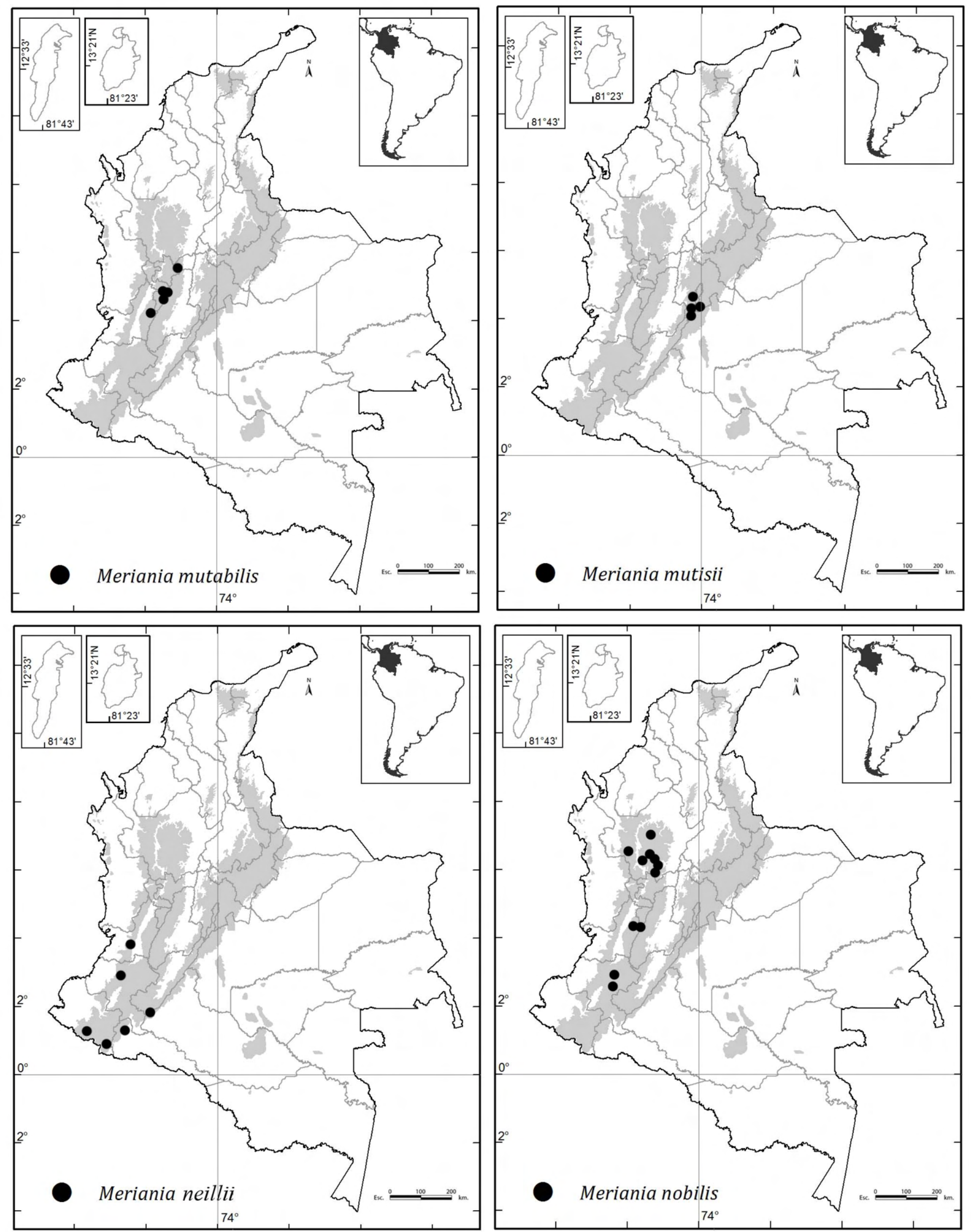

Figura 40: Distribución geográfica de Meriania mutabilis (Gleason) Humberto Mend. \& Fern.Alonso, M. mutisii (Bonpl.) Humberto Mend. \& Fern. Alonso, M. neillii Humberto Mend. y M. nobilis Triana. 
Etimología: el nombre del epíteto específico alude, al parecer, a la variación en el color de los pétalos que se presenta con la edad.

Estado de conservación: categorizada como "En Peligro" (EN) (Mendoza-Cifuentes y Fernández-Alonso, 2012) y posteriormente como "Vulnerable" (VU) en la Lista Roja de la IUCN (2020). Sin embargo, esta última recategorización se basa en registros erróneos para la especie de la Cordillera Oriental, por lo que sobrestiman el área de distribución. Se sugiere mantener la categoría "En Peligro".

Material examinado: COLOMBIA. Departamento Caldas, municipio desconocido, Cucarronera, New Quindío trail, 8.VIII.1922, fl, T. E. Hanzen 9689 (NY). Municipio Neira, vereda La Cristalina, cuchilla El Guayabo, cuenca alta río Tapias, 3640 m, 19.II.2002, st, S. Medina 9 (FMB). Municipio Pensilvania, Berlín, 2750 m, 23.VII.2004, st, A. Robles 6 (FMB), 26 (FMB); La Cabaña, 2600 m, 29.VII.2004, st, A. Robles 65 (FMB). Departamento Quindío, municipio Calarcá, La Niebla, 3200 m, 20.V.1977, Rincón s.n. (HUQ). Municipio Salento, Reserva Natural Alto Quindío, Acaime, 2680 m, 11.V.1991, fl, C. A. Agudelo 1540 (COL, HUQ); Reserva Forestal de Navarco, 3110 m, 25.VII.1983, fl, C. R. Fernández 15 (HUQ); vereda Cocora, La Marina, 2830 m, 1.VII.1992, fr, W. Vargas 578 (HUQ). Departamento Valle del Cauca, municipio Tuluá, Barragán, Monte Aurora, 2400 m, 25.VI.1983, fl, W. Devia 212 (COL, MO, US). Sin localidad precisa, 17601808, fl, J. C. Mutis 1238 (US).

Meriania mutisii (Bonpl.) Humberto Mend. \& Fern. Alonso, Anales Jard. Bot. Madrid 69(2): 280-285. 2012. Figs. 37G-J, 41.

इ Melastoma mutisii Bonpl., Melast., p. 136, tab. 38. 1823. TIPO: COLOMBIA. Montes de Quindío, fr, A. Bonpland s.n. (lectotipo: P 136486!; isolectotipo: P 136485!; designados por Mendoza-Cifuentes y Fernández-Alonso, 2012). 三 Conostegia mutisii Ser. ex DC., Prodr. 3: 174. 1828. 三 Calyptraria mutisii Naudin, Ann. Sci. Nat., Bot., ser. 3, 18: 132. 1854.
= Stephanogastra purpurea $\mathrm{H}$. Karst. \& Triana, Melastomataceae Endl. Linnaea xxviii. 425. 1857. TIPO: COLOMBIA. Departamento Cundinamarca, crescit locis montuosis asperis inter Bogotá et oppidum Fusagasugá, 2200 m, fr, J. J. Triana s.n. (lectotipo: K 329478!, designado por Mendoza-Cifuentes y Fernández-Alonso, 2012).

三 Centronia mutisii (Bonpl.) Triana, Les Mélastomatacées, Trans. Linn. Soc. Bot. 28: 72. 1871, 1872.

Árboles 3-22 m de altura; entrenudos subcuadrangulares; ramas, pecíolo, venas por el envés, inflorescencia y flores (hipanto y cáliz) cubiertos densamente por tricomas esponjoso-irregulares con ramas cortas, levemente alargados (tipo 30), 0.2-0.4 mm de largo, tricomas filamentosos lisos rojos erectos (tipo 11), 1.5-4.5 mm de largo (estos últimos son suaves en material fresco, pero se tornan levemente rígidos en material seco); hojas con pecíolo 2-10.5 $\mathrm{cm}$ de largo; lámina 7-27.5 × 5.1-19.6 cm, ovada; base redondeada a cordada, levemente peltada hasta $15 \mathrm{~mm}$ arriba de la base; ápice obtuso; margen espaciadamente denticulado (3-5 mm distanciados); haz glabro o con ralos tricomas subulados lisos, gruesos en hojas jóvenes, las venas son levemente marcadas; envés pubescente sobre las venas, areolas glabras; nervadura con 2-3 pares de venas principales acompañando a la vena media, basales; inflorescencia 14-22 cm de largo, erecta, eje central con 2-3 nudos de ramificación; paracladios basales con 2 niveles de ramificación; ramas apicalmente dicasiales o esciadoides; 15 a 33 flores; bractéolas $4 \times 0.8 \mathrm{~mm}$, caducas, estrechamente triangulares, abaxialmente glabras, adaxialmente con ralos tricomas largos, abundantes tricomas esponjosos irregulares; flor pedicelada, 6-8-mera; pedicelo 7-19 mm de largo; hipanto 6.2-7 mm de largo, ciatiforme, internamente liso; pared 1-1.7 mm grosor; torus 1.9-2.5 mm grosor, sin engrosamientos frente a los pétalos; cáliz caliptrado; caliptra apicalmente aguda, muy delgada, de apariencia membranácea, indumento caduco similar al del hipanto, abre irregularmente cerca del torus; corola patente; pétalos 26-39 × 20-31 mm, obovados, ápice truncado emarginado, glabros, fucsia oscuro; estambres isomorfos, filamento 9.8-11.6 mm de largo; codo 4.1-5 mm de largo, subulado; conectivo dorsal con apéndice dentiforme 0.1-0.5 mm de 


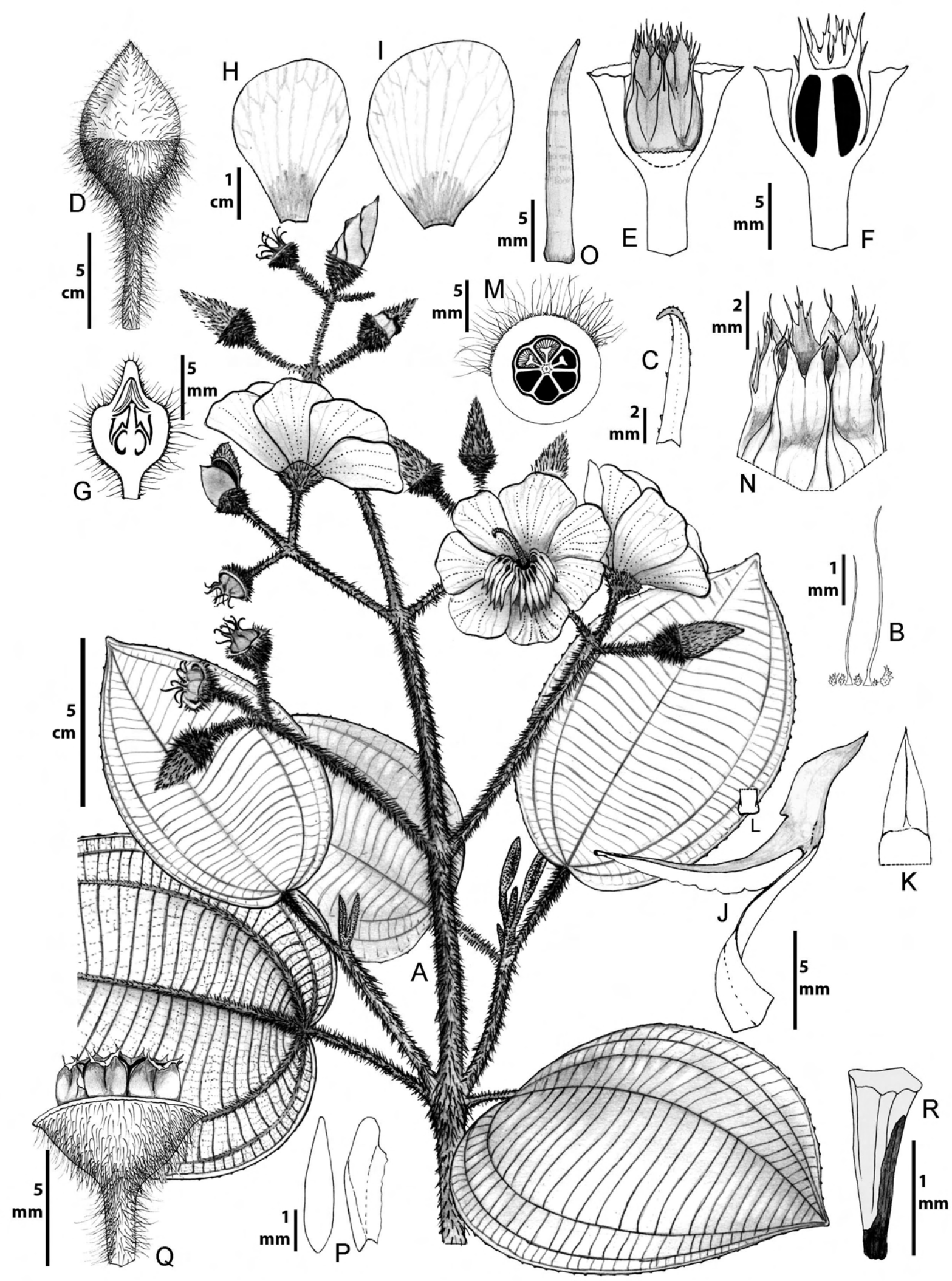

Figura 41: Meriania mutisii (Bonpl.) Humberto Mend. \& Fern. Alonso. A. rama florífera; B. tricomas de la caliptra; C. bráctea de la base de las ramificaciones de la inflorescencia; D. botón floral; E. corte longitudinal del hipanto y vista lateral del ovario; F. corte longitudinal del hipanto-ovario; G. corte longitudinal del botón floral; $\mathrm{H}$, I. pétalos; J. estambre; K. codo-ápice del filamento; L. vista superior del apéndice conectival dorsal; M. corte transversal del hipanto-ovario; N. apéndices del ápice del ovario; O. estilo; P. vista frontal y lateral de la placenta; Q. fruto; R. semilla. C, G, Q, R: Mendoza 16974 (FMB); A, B, D-F, H-P: Téllez 632 (UDBC); tomada de Mendoza-Cifuentes y Fernández-Alonso (2012). 
largo, blanco; antera 0.9-1.1 cm de largo, subulada, sigmoidea, morada, poro dorsal; polen 12-12.3 um de diámetro; ovario 9.1-9.5 mm de largo, 6-7-locular, oblongo, su parte basal fusionada al hipanto 0.8-1 $\mathrm{mm}$, en corte transversal en su parte media con aristas rectas; ápice con dientes subulados bífido-fimbriados, 3.8-5 $\mathrm{mm}$ de largo; placentas 3.2-3.4 $\mathrm{mm}$ de largo, ovoides, rudimentos seminales en todas las superficies; estilo $17-19 \mathrm{~mm}$ de largo, levemente cónico; estigma puntiforme; cápsula 10-12 mm de largo sin incluir el pedicelo, el hipanto en forma de copa grueso, no adherido a las paredes del fruto propiamente, carpelos cartáceos que sobresalen su mitad superior del hipanto, no se desintegran; semillas 1.4-1.6 mm de largo, rafe más oscuro que la testa.

Notas taxonómicas: es inconfundible por el indumento de largos tricomas vináceos en la mayoría de las estructuras, combinado con la base cordada de las hojas. Los ejemplares se reconocen, en campo, por la pubescencia rojiza de las ramas terminales y que es notoria a la distancia. Bonpland (1823) cita erróneamente el tipo proveniente de Montes del Quindío y que la especie presenta flores blancas. El espécimen tipo se asigna a Alexander von Humboldt; no obstante, si este geógrafo la hubiera colectado difícilmente habría asignado una localidad errónea a esta especie endémica a los alrededores de Bogotá, al igual que mal interpretar la coloración de los pétalos. El hecho de que la especie fuera dedicada a José Celestino Mutis indica que esta planta fue colectada por este último y no por Humboldt. Mutis donó varias muestras de plantas a Humboldt en su encuentro en Bogotá y posiblemente una de ellas correspondía al tipo de esta especie. Estos investigadores deciden describirla y dedicársela a Mutis, pero sin conocer directamente la especie ni su procedencia.

Distribución y hábitat: especie endémica de Colombia y restringida a la Cordillera Oriental, departamento Cundinamarca; posiblemente se encuentra en el nororiente del departamento Tolima. Las colecciones provienen de pocas localidades cercanas al páramo de Sumapaz, entre Sibaté y Cabrera, entre 2700 y 2900 m de elevación (Fig. 40). Es una especie muy rara (escasa) según las notas de campo de L. Uribe tomadas en la década de 1970 . Hoy en día solo se conoce una población de pocos individuos en una localidad llamada Santana, en la vía que conduce de Sibaté a Cabrera. En el departamento Antioquia, cerca de Medellín, se encuentra una población de una especie muy parecida a $M$. mutisii, pues presenta tricomas vináceos en la inflorescencia. No obstante, no tenemos la certeza de asignar esta población a la presente especie por lo que un análisis más detallado queda pendiente para estudios futuros. Crece en el interior de bosque maduro, aunque también se encuentra en bordes de bosque y de quebradas. En Santana, Cundinamarca, se encuentra en el interior de bosque maduro y en buen estado de conservación asociado a Podocarpus oleifolius D. Don ex Lamb. Los individuos de esta población muestran rebrotes vegetativos subterráneos que producen nuevos individuos.

Nombre vernáculo: una colección de J. M. Idrobo de 1968 documenta el nombre "tuno roso" para la zona de Altos de San Miguel, Sibaté, Cundinamarca.

Etimología: en honor a José Celestino Mutis.

Estado de conservación: categorizada como "En Peligro Crítico" (CR) (Mendoza-Cifuentes y Fernández-Alonso, 2012). En la Lista Roja de la IUCN (2020) está categorizada como "Casi Amenazada" (NT), no obstante, se basa en registros en Cordillera Central, Cordillera Occidental y norte de Bogotá, que posiblemente sean errores de identificación taxonómica. Hasta ahora solo hay certeza de su presencia en Cordillera Oriental, en la región de Sumapaz, por lo que se sugiere considerar su categoría como "En Peligro Crítico".

Material examinado: COLOMBIA. Departamento Cundinamarca, Bogotá DC, distrito de Sumapaz, inspección de Santana, Finca de Don Gustavo González, 2800 m, 11.I.2007, fl, G. Téllez 631 (COL, FMB, UDBC), 632 (COL, FMB, UDBC); loc. cit., 2900 m, 26.V.2007, fr, H. Mendoza 16794 (COL, FMB, UDBC); Provincia Santa Fé de Bogotá, San Fortunato, 2300 m, 1.IX.1853, fr, J. J. Triana 3886 (609 en la etiqueta) (COL). Municipio Cabrera, camino al páramo, 2700-2800 m, 27.XI.1968, fl, L. Uribe 6192 (COL). Municipio Sibaté, Altos de San Miguel, 2850 m, 23.IX.1968, fl, J. 
M. Idrobo 6276 (COL); loc. cit., 28.IX.1968, fl, L. Uribe 6175 (COL, MO, NY, US).

Meriania neillii Humberto Mend., sp. nov. Figs. 37K-O, 42.

TIPO: ECUADOR. Provincia Napo, southern slopes of Volcan Sumaco, Hollin - Loreto road, km 40, 1200 m, 11.II.1989, fl, D. Neill 8887 (holotipo: CAS!; isotipos: MO!, NY).

Brochidodromous venation and only with one pair of secondary veins, truncate calyx, the dorsal anther connective appendage toothlike, and magenta petals; related to $M$. hexamera but differs by the branches 2.2-4 $\mathrm{mm}$ in diameter, petiole 1-1.6 $\mathrm{mm}$ in diameter, leaf blade smaller than 22 $\mathrm{cm}$ long, ovary apex rounded (0.2-1.5 $\mathrm{mm}$ long) and with lobes rounded, style conic and apically curved, and stigma not expanded.

Árboles 5-20 m de altura; entrenudos oblongoaplanados, 2.2-4 mm de diámetro; ramas, hojas e inflorescencias glabras excepto en las partes juveniles en donde algunas veces se presenta un indumento laxo de tricomas esponjosos amorfos, adpresos (tipo 30); hojas con pecíolo 0.94-2.8 cm de largo, 1-1.6 mm de diámetro, terete, glabro; lámina 8-16 × 3.1-6.2 cm, elíptica u obovada, de textura delgado coriácea; base aguda a obtusa, algunas veces revoluta; ápice acuminado, acumen 0.4-1.3 cm; margen entero; algunas veces con domacios laminares en la base de la lámina formado por expansión de la vena media; nervadura con un par de venas secundarias desplegándose cerca del margen (de apariencia broquidódroma), basales o levemente plivervias a 2-4 $\mathrm{mm}$ arriba de la base; inflorescencia 8-15 cm de largo, paniculada, eje central con 3-4 nudos de ramificación, ápice de las ramillas dicasiales, con 10-30 flores; flor pedicelada, 6-mera; pedicelo 8-15 mm de largo; hipanto 4.1-6 mm de largo, campanulado, externamente glabro; paredes $1 \mathrm{~mm}$ de grosor; cáliz truncado, tubo 3.5-3.8 mm de largo; dientes externos levemente protuberantes o a manera de huellas lineares; corola patente; pétalos 22-32 × 15-25 mm, obovados, de ápice truncado, glabros, magenta; estambres isomorfos, filamentos 1.1-1.7 $\mathrm{mm}$ de largo; codo 2-3 mm de largo, subulado; conectivo dorsal con apéndice 0.5-1.2 mm de largo, dentiforme o levemente abultado, amarillo, raras veces no se presenta (en algunas poblaciones de Perú); antera 9-1.2 cm de largo, subulada, sigmoidea, ventralmente rugosas, morada, poro dorsal; ovario 4-4.5 mm de largo, 6-locular, completamente súpero, oblongo, glabro; ápice con lóbulos redondeados o dentiformes $0.3-1 \mathrm{~mm}$ de largo; placentas $2.5-2.8 \mathrm{~mm}$ de largo, ovoides, rudimentos seminales en todas las superficies; estilo 10-16 mm de largo, cónico a cilíndrico, curvo en el ápice en flores abiertas; estigma puntiforme o ligeramente expandido; cápsula 14-16 mm de largo sin incluir el pedicelo, ovario sobresaliendo del hipanto cerca de la mitad de su longitud; semillas 2.5-4 mm de largo, de ápice alargado; rafe no visible.

Notas taxonómicas: esta especie se caracteriza por ser predominantemente glabra, la nervadura con un solo par de venas secundarias cerca del margen (de apariencia broquidódroma), presentar regularmente domacios laminares en la base del envés, cáliz truncado, sin dientes dorsales y anteras con un apéndice conectival dorsal subulado. Es muy semejante a $M$. hexamera, pero esta última tiene dos pares de venas cerca del margen, no presenta domacios laminares por el envés, las ramas y pecíolos son más robustos, regularmente tiene indumento laxo de tricomas esponjosos amorfos, la base de la lámina foliar es obtusa a redondeada, el ápice del ovario tiene lóbulos dentiformes más largos (vs. escasos 0.3-0.5 mm de largo en $M$. neillii), el estilo es robusto y cilíndrico, y el estigma es conspicuamente expandido. Wurdack erróneamente asignó a ejemplares de $M$. neillii el nombre de $M$. hexamera (como J. Cuatrecasas 9139), por lo que pasó inadvertida hasta el momento.

Distribución y hábitat: esta especie crece desde el sur de los Andes de Colombia hasta Cusco en Perú, entre 1200-2500 m de elevación. En Colombia se encuentra al sur de la zona andina en las Cordillera Oriental y Occidental, en los departamentos Caquetá, Cauca, Nariño, Putumayo y Valle del Cauca (Fig. 40). En este último departamento se conoce de fotografías mas no de ejemplares colectados ( $E$. Calderón com. pers.). Crece en áreas de bosque subandino y menos frecuente en bosque andino; siempre se encuen- 


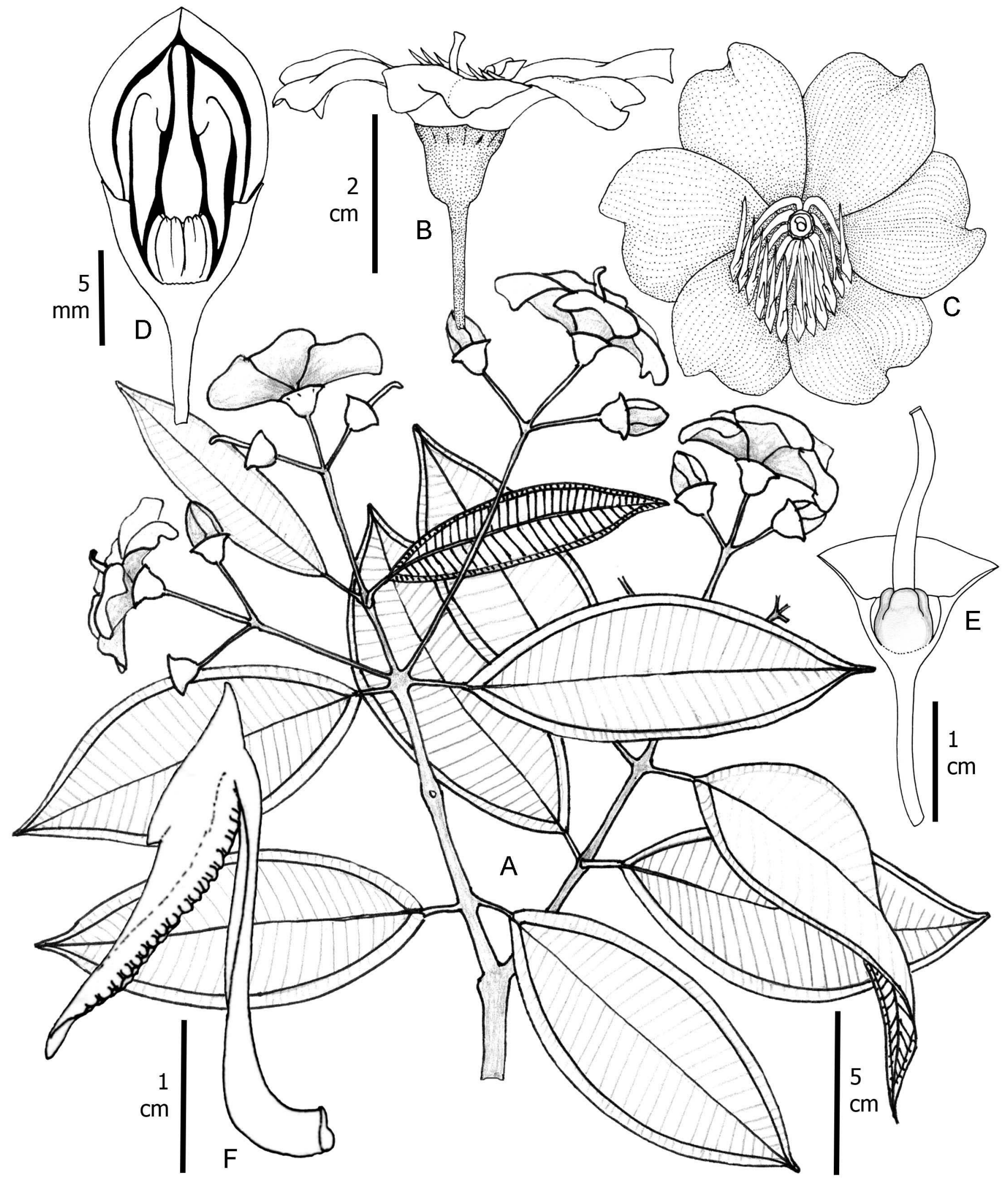

Figura 42: Meriania neillii Humberto Mend. A. rama florífera B, C. vista lateral y frontal de la flor; D. corte longitudinal del botón floral; E. corte longitudinal del hipanto y vista lateral del ovario y estilo; F. estambre. A, B, C, D, F: Mendoza 765 (FMB); E: Vargas 16995 (US). 
tra en interior de bosque en áreas en buen estado de conservación.

Etimología: en honor a David Neill, botánico norteamericano quien ha realizado abundantes colecciones en Ecuador.

Estado de conservación: esta especie tiene una EOO mayor de $450,000 \mathrm{~km}^{2}$ y considerando su amplio rango a lo largo de tres países no cumple ninguno de los criterios que definen las categorías de En Peligro Crítico, En Peligro, Vulnerable o Casi Amenazado. Por esto se categoriza como "Preocupación Menor" (LC).

Parátipos: COLOMBIA. Departamento Caquetá, municipio desconocido, Cordillera Oriental, entre Sucre y La Portada, 1200-1350 m, 15.IV.1940, fl, J. Cuatrecasas 9139 (COL, US). Departamento Cauca, municipio El Tambo, La Romelia, 2100-2500 m, 10.X.1995, fl, N. Ruiz 517 (COL). Departamento Nariño, municipio Puerres, Gran Jardín de La Sierra, ladera Cerro El Oso, 2314 m, 12.III.2014, fl, $M$. Montoya 1245 (COAH). Municipio Ricaurte, Reserva Natural La Planada, 1800-1900 m, 15.I.2003, st, I. Gil 837 (FMB); loc cit., 24.I.1995, fl, H. Mendoza 765 (FMB, PSO); loc. cit., 5.IX.1999, st, H. Mendoza 8620 (FMB). Departamento Putumayo, municipio Mocoa, El Mirador, $2000 \mathrm{~m}$, 7.IX.1998, st, H. Mendoza 6792 (FMB). Municipio Sibundoy, cuenca alta del río Putumayo, Valle de Sibundoy, $2800 \mathrm{~m}$, 2.I.1941, fl, J. Cuatrecasas 11627 (COL). ECUADOR. Provincia Napo, cantón Archidona, faldas al sur del Volcán Sumaco, 1200 m, 8.I.1989, fl, A. Alvarado 214 (F, NY); carretera entre Tena y Baeza, km 32, 1500 m, 4.II.1988, fl, D. Neill 8377 (NY, QCNE). Provincia Pastaza, cantón Mera, Hacienda San Antonio del Barón von Humboldt, 2 km al NE de Mera, 1300 m, 27.II.1985, fl, W. Palacios 96 (NY, QCNE). Provincia Zamora, cantón Zamora, Zamora-Chinchipe, eastern border of Podocarpus National Park, 1550 m, 6.XI.1996, fl, J. L. Clark 3299 (NY, QCNE). PERÚ. Departamento Amazonas, provincia Bongará, Shillac, 2260 m, 12.IX.1983, fr, M. Leo 334 (MO); Buenos Aires, km 53.6 across R. Chiriaco from Yambrasbamba, and $40 \mathrm{k}$ S of Jumbillo, 1860-2000 m, 2.III.1967, fl, S. S. Tillet 673-310 (US); along Yambrasbamba - Pomacocha trail between Yambrasbamba and Yanayacu,
2200-2300 m, 26.VI.1962, fl, J. J. Wurdack 1050 (NY, US); distrito Sipabamba, Shillac, 1850-1900 m, 6.V.1981, fl, fr, $K$. Young 381 (MO, NY). Departamento Cusco, provincia Paucartambo, Kosnipata Valley, road from Pillawata to Patria, 3900 ft, 5.II.1975, fl, T. Plowman 4995 (US); Santa Isabel, San Pedro, 1250 m, 25.XI.1965, fl, C. Vargas 16995 (US). Departamento Pasco, provincia Oxapampa, Palmazú, 2100 m, 28.IX.1984, fr, D. N. Smith 8556 (MO, US).

Meriania nobilis Triana, Trans. Linn. Soc. London 28: 66-67. 1872. Figs. 43, 44A-C. TIPO: COLOMBIA. Departamento Antioquia, municipio Rionegro, 2400 m, 1851-1857, fl, J. J. Triana 3857 (lectotipo: P!, aquí designado; isolectotipos: COL!, G!, K!, US!).

= Meriania kraenzlinii Cogn. Bot. Jahrb. 19-20. 1887. TIPO: COLOMBIA. Departamento Antioquia, municipio La Ceja, 2300 m, fl, C. Lehmann 911 (lectotipo: BR!, aquí designado; otro sintipo citado es: in silvis umbrosis prope Popayán, 1800-2600 m, fl, C. Lehmann 3194 (BR)).

Árboles, 3-12 m altura; entrenudos cuadrangulares aristado-alados línea interpeciolar laminar, tálamo 5.5-11 $\mathrm{mm}$ de ancho, todas las estructuras glabras; hojas con pecíolo 3.8-8.4 cm de largo, levemente alado, ápice con escutelo o liso, base envolvente (por la continuidad con la línea interpeciolar membranosa); lámina 19-36 ×9-20 cm, oblonga, ovada o suborbicular; base redondeada o subcordada, regularmente con aurículas revolutas; ápice redondeadoacuminado u obtuso; margen entero o raras veces dentado; haz y envés glabros; nervadura con 2-3 pares de venas basales, solo dos llegan al ápice; inflorescencia 19-35 cm de largo, sésil o pedicelada, ejes y ramas cuadrangular aristadas, 3-6 nudos de ramificación; nudos con línea membranosa igual a los nudos de las hojas; paracladios $10-21 \mathrm{~cm}$ de largo, con 2-3 niveles de ramificación; ramillas apicales con 1-4 flores por reducción de ejes; 20 a 50 flores; brácteas 3.8 $\times 0.7 \mathrm{~cm}$, en la base de las ramificaciones, obovadas, caducas; flor pedicelada, 5-mera; pedicelo 11-24 mm de largo; hipanto 9-12 $\mathrm{mm}$ de largo, campanulado; cáliz truncado, levemente ondulado; tubo 4-8.5 mm de largo; dientes dorsales a manera de protuberancias; corola levemente cuculada; pétalos 39-65 × 31-39 mm, obovados, apicalmente 


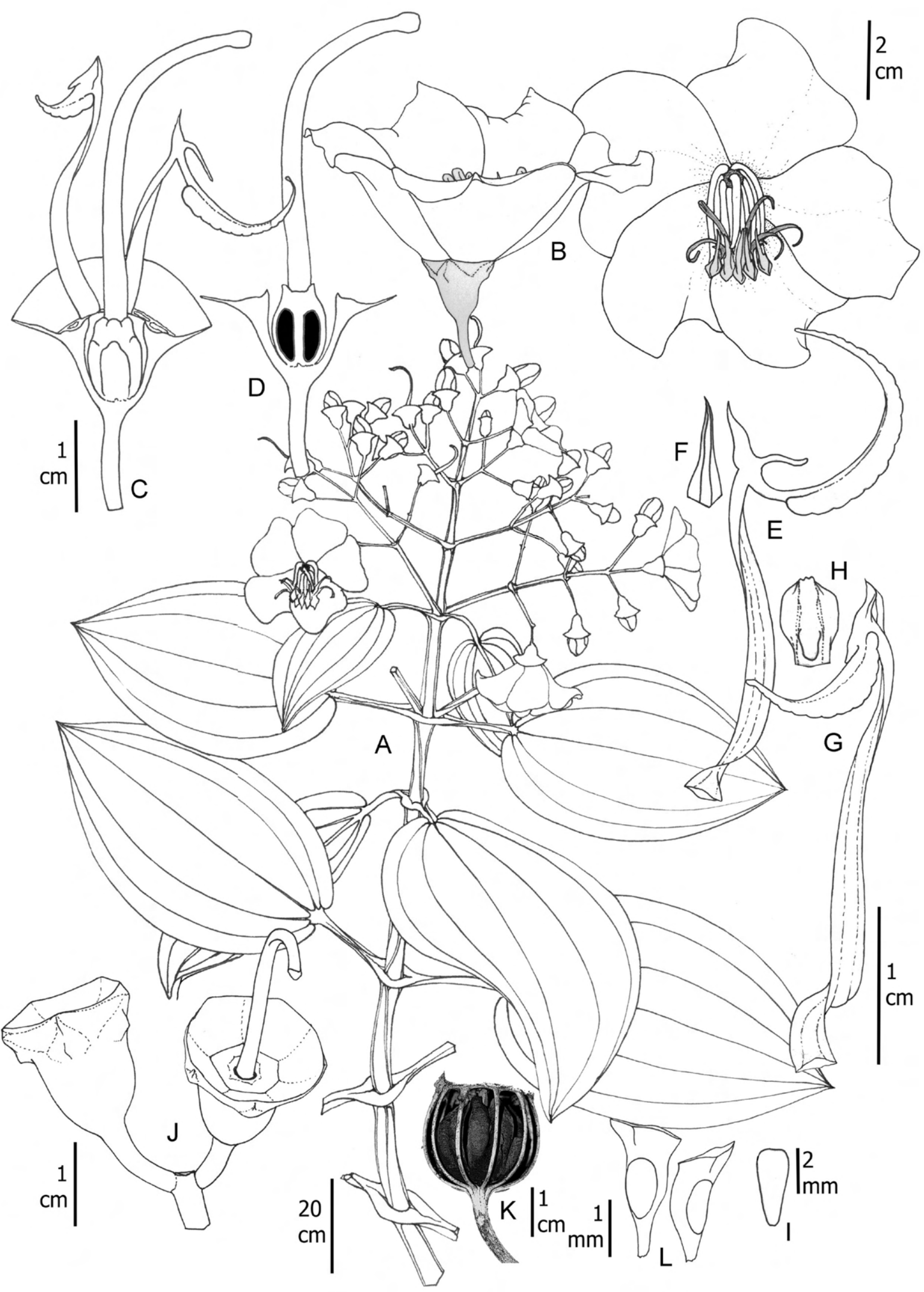

Figura 43: Meriania nobilis Triana. A. rama florífera; B. flor en vista lateral y superior; C. corte longitudinal del hipanto y vista lateral del ovario, estilo y estambres; D. corte longitudinal de hipanto y ovario; E. estambre opositipétalo; F. vista dorsal del codo del estambre opositipétalo; G. estambre opositisépalo; H. vista dorsal del codo del estambre opositisépalo; I. placenta en vita dorsal; J. frutos inmaduros; K. fruto viejo; L. semillas. A, B, K: a partir de fotos de campo; C, D, E, F, G, H, J: Uribe 50 (COL); I, L: Roa 1 (COL). 

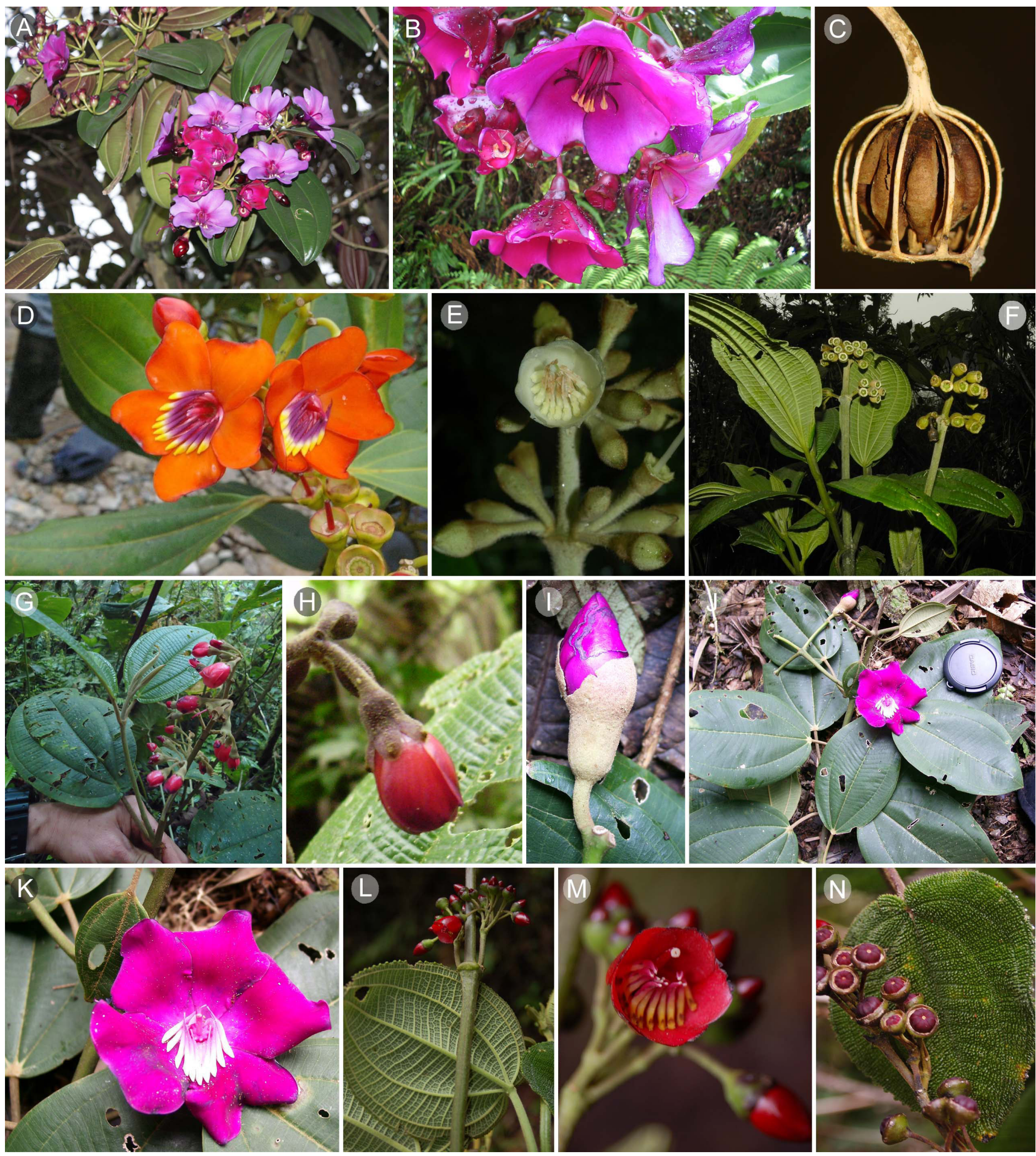

Figura 44: Fotografías de Meriania Sw. de Colombia. A, B, C. M. nobilis Triana; D. M. pastazana Wurdack; E, F. M. phlomoides (Triana) Almeda; G, H. M. quintuplinervis Naudin; I, J, K. M. ramosii Humberto Mend.; L, M, N. M. sanguinea Wurdack. Créditos: H. Mendoza (A, B, C, I, J, K); D. Neill (D); M. Alvear (E, F, J); M. Posada (G), A. Cogollo (H); R. Foster (L, M, N). 
truncado asimétrico, fucsia o rojos; estambres fuertemente dimorfos, estambres opositipétalos, filamento más corto, pero la antera más larga que los opositisépalos, filamento 16.5-23.2 mm de largo; pedoconectivo 2-3.6 mm de largo; codo 2-4.6 mm largo, subulado; conectivo dorsal con apéndice 3.5-5.5 mm de largo, filiforme, dorsalmente acanalado; antera 14-19 mm de largo, subulada, fuertemente arqueada hacia el dorso, poro dorsal; estambre opositisépalo, filamento de $22-29 \mathrm{~mm}$ de largo, sin pedoconectivo; codo $2.2-4 \mathrm{~mm}$ de largo, triangular, lados expandidos; conectivo dorsal con apéndice dentiforme 0.8-2.6 $\mathrm{mm}$ de largo; antera 7-12.3 mm largo, subulada, sigmoidea, poro dorsal; ovario 7-11 mm largo, 5-locular, oblongo a oblongo-ovoide, completamente supero; ápice redondeado, con leves lóbulos encerrando 0.5-0.7 mm la base del estilo; placentas $4 \mathrm{~mm}$ de largo, ovoides, rudimentos seminales en todas las superficies; estilo $34-38 \mathrm{~mm}$ de largo, cilíndrico o levemente cónico, curvo en el ápice; estigma puntiforme o levemente expandido; cápsula 18-25 mm de largo sin incluir el pedicelo, levemente urceolada por la presencia del cáliz; semillas 1.5-2.5 mm de largo, cuneiformes con ápice corto, marrón claro, la parte del embrión más oscura; ápice corto o levemente alargado.

Notas taxonómicas: el conjunto de caracteres que delimita esta especie es la ausencia de todo tipo de tricomas (plantas completamente glabras), los tallos aristados, pecíolos alados, línea interpeciolar lamiar, pétalos gigantes de color fucsia oscuro y estambres fuertemente dimorfos. La especie más afín es $M$. splendens, pero esta última tiene regularmente indumento de tricomas pinoides, los tallos no son cuadrangular-aristados y los estambres son isomorfos.

Distribución y hábitat: especie endémica de Colombia. Crece en la Cordillera Central vertiente occidental y la Cordillera Occidental vertiente oriental, en los departamentos Cauca, Valle del Cauca, Quindío y Antioquia, entre 1800 y 2630 m de elevación (Fig. 40). En Cundinamarca es cultivada, más no nativa. Puede encontrarse en interior de bosque o zonas abiertas.

Nombres vernáculos: en Antioquia es llamado "amarraboyo" y en Valle del Cauca "mayo" y "flor de mayo".
Etimología: el epíteto "nobilis" significa noble en latín, y posiblemente alude a la gran belleza de los individuos de esta especie.

Estado de conservación: categorizada como "Preocupación Menor" (LC) en la Lista Roja de la IUCN (2020), pero algunos de los registros en los que se basa corresponden a registros de plantas cultivadas. Está muy menguada en estado silvestre por la transformación del hábitat (bosque subandino) y además se ha colectado poco en las últimas dos décadas. Según lineamientos de la IUCN (2017), se clasifica en el criterio A1c, que permite recategorizarla como "Amenazada" (EN). Prevalecen individuos cultivados en las mismas regiones de donde procede en Antioquia y adicionalmente en ciudades de clima frio como Bogotá.

Material examinado: COLOMBIA. Departamento Antioquia, municipio Angosturas, río Pajarito, road to Hacienda Guácimo, 2596 m, 20.V.2012, fl, J. L. Clark 13051 (COL, HUA). Municipio Guarne, Piedras Blancas, 1800-2100 m, IV-1969, fl, D. D. Soejarto 2242 (COL). Municipio La Unión, corregimiento San Miguel, cerca al Río Piedras, 2630 m, 5.VII.1987, fl, O. Marulanda 306 (COL). Municipio Medellín, Santa Elena, bosque frente al Silletero, 2549 m, 26.III.2011, fl, A. Idárraga 3675 (HUA). Municipio Sonsón, Boquerón de Sonsón, 7800 ft, 31.VII.1968, fl, R. Barneby 380561 (COL). Municipio Urrao, vereda La Ano, 1900 m, 7.X.1977, fl, G. Lozano 2969 (COL). Departamento Cauca, municipio Caldono, vereda Oriente, microcuenca río Cabuyal, 2105, 29.III.1995, fl, N. Diago 36 (COL). Municipio El Tambo, cerca al cerro Munchique, 2300-2500 m, 5.XI.1968, fr, L. S. Espinal 3220 (CUVC). Municipio Piendamó, 2200 m, 14.X.1968, fl, L. S. Espinal 3037 (CUVC). Municipio Popayán, estribaciones del Puracé, 2000-2100 m, 9.IX.1961, fl, L. Uribe 3879 (COL). Departamento Cundinamarca, Bogotá DC, múltiples ejemplares en $\mathrm{COL}$, todos son registros de plantas cultivadas en Bogotá y sus alrededores. Departamento Quindío, municipio Génova, cuenca de la quebrada San Juan, finca Providencia, 2600 m, 19.IV.1999, fl, W. Vargas 5752 (COL). Departamento Valle del Cauca, municipio Palmira, cuenca superior del río Nima, nacimiento de la quebrada Las Mirlas, 11.IV.1969, fr, A. Roa 223 (CUVC). Municipio Sevilla, Cuenca de la Sara, quebrada La Tardanza, 2200 m, 22.VI.1983, fl, W. Devia 164 (COL). 
Meriania ornata Wurdack, Acta Bot. Venez. 13(1-4): 135136. 1978. Fig. 45. TIPO: VENEZUELA. Estado Amazonas, rain forest ESE of Puerto Ayacucho $10-30 \mathrm{~km}$ on road to Gavilán, 120 m, 11.VI.1977, fl, J. Steyermark 113912 (holotipo: US 2781961!, 2781962!; isotipo: VEN!).

Árboles 5-10 m de altura; entrenudos apicales aplanados; ramas, base del pecíolo e inflorescencia con indumento denso, ferrugíneo de tricomas filiformes, ligeramente rugoso $0.5-1 \mathrm{~mm}$ de largo (tipo 16 ), tricomas subulados de base ensanchada, barbelada 0.1-0.2 mm de largo (tipo 21); ápice de los ramas con tricomas filiformes levemente barbelados 4-6 mm de largo; hojas con pecíolo 7-11 cm de largo, acanalado en la superficie abaxial; lámina 13-30 × 6-21 cm, anchamente ovada; base cordada a redondeada; ápice agudo o corto acuminado; margen entero; haz glabro; envés con indumento laxo de tricomas subulado de base ensanchada, barbelada 0.1-0.3 $\mathrm{mm}$ de largo; nervadura con 2 pares de venas principales acompañando a la vena media, basales; inflorescencia 15-25 cm de largo, eje central con 3-4 nudos de ramificación; paracladios 9-10 cm de largo, con tres niveles de ramificación; ápices de la ramillas trifloros, con pequeñas bractéolas lineares en la base de las flores; cerca de 30 flores; flor pedicelada, 5-mera; pedicelo 3-5 mm de largo; hipanto $8-9 \mathrm{~mm}$ de largo, campanulado, externamente con indumento denso de tricomas similar al envés; paredes de 1.5-1.7 mm de grosor; cáliz truncado o con lóbulos poco desarrollados, ondulados; tubo 5-6 mm de largo; dientes dorsales levemente desarrollados, 2-3 mm de largo, lineares; corola patente; pétalos 31-35 × 21-25 mm, obovados, de ápice truncado emarginado, glabros, rosado oscuro; estambres fuertemente dimorfos, los opositisépalos más robustos; estambres opositipétalos, filamento $15-16 \mathrm{~mm}$ de largo; codo 0.8-1.2 mm de largo, subulado; conectivo dorsal con apéndice 4.8-5 mm de largo, cilíndrico; antera 12-15 mm de largo, subulada, sigmoidea, poro dorsal; estambres opositisépalos, filamento $18-19 \mathrm{~mm}$ de largo; codo 0.8-1 $\mathrm{mm}$ de largo, subulado; conectivo dorsal con apéndice 1.8-2.2 mm de largo, cilíndrico; antera 10-12 mm de largo, subulada, fuertemente arqueada hacia el dorso, poro ventral $1.1 \times 0.9 \mathrm{~mm}$; ovario $4-5 \mathrm{~mm}$ de largo, 3-locu- lar, oblongo, parcialmente fusionado en la base al hipanto 1-1.2 $\mathrm{mm}$; ápice redondeado, sin encerrar la base del estilo (sin lóbulos); placentas $3 \mathrm{~mm}$ de largo, obovadas, rudimentos seminales solo en el dorso; estilo $22-24 \mathrm{~mm}$ de largo, cónico; estigma puntiforme; cápsula no vista; semillas no vistas.

Notas taxonómicas: las hojas grandes hasta de 30 $\mathrm{cm}$, con largos pecíolos y el indumento denso de largos tricomas ferrugíneos en el ápice de las ramas, son caracteres únicos que diferencian a esta especie de todas sus congéneres. Comparte caracteres de los estambres y del ovario con M. urceolata, con la que difiere fuertemente en los caracteres mencionados arriba.

Distribución y hábitat: especie conocida de dos localidades en Colombia y Venezuela. En Colombia solo se conoce de una localidad en el departamento Vichada, en la cuenca baja del río Matavén (Fig. 46). Es posible que también se encuentre a lo largo de las riberas del río Orinoco en el departamento Vichada. No se conoce para el Parque Nacional Natural El Tuparro. Crece en zonas de relieve ondulado con sabanas con vegetación arbustiva y de suelos de arenas blancas.

Etimología: ornatus significa adornado, elegante, provisto de adornos; no obstante, no se sabe por qué Wurdack asignó este epíteto.

Estado de conservación: solo conocida de la localidad tipo en Venezuela y una segunda localidad cercana en Colombia, en áreas en buen estado de conservación. Al parecer tiene gran especificidad de hábitat pues crece en sabanas arboladas de arenas blancas sobre un relieve ondulado. De acuerdo con esto, y a pesar de no registrarse la especie en áreas de conservación, se sugiere su categoría como "Vulnerable" (VU) bajo los criterios D2.

Material examinado: COLOMBIA. Departamento Vichada, municipio Cuadrivio, selvas de Matavén, río Matavén, caño Carajo, resguardo unificado Selvas de Matavén, 240 m, 16.III.2007, st, A. Prieto 5453 (FMB). 


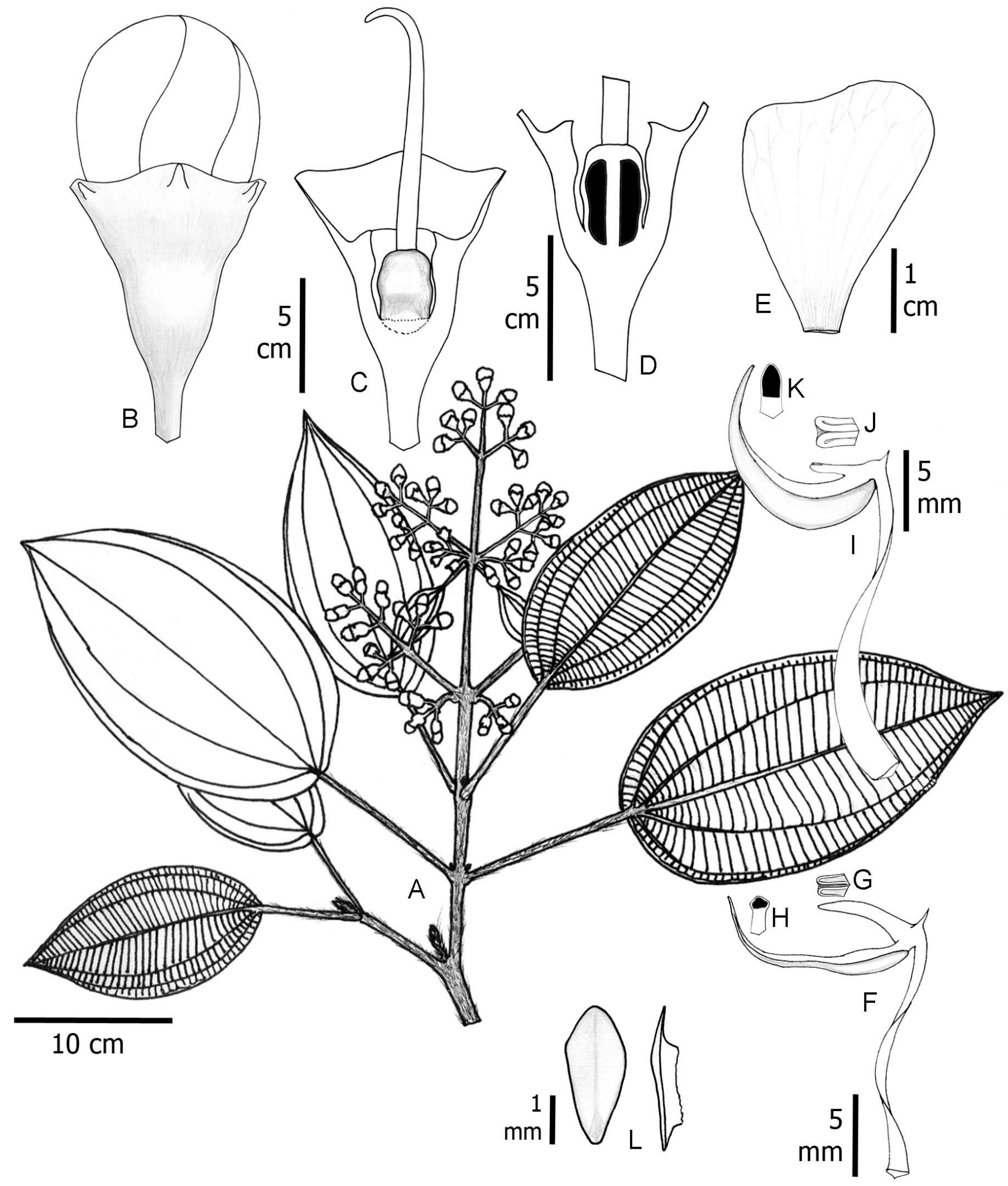

Figura 45: Meriania ornata Wurdack. A. rama florífera; B. botón floral; C. corte longitudinal del hipanto y vista lateral del ovario y estilo; D. corte longitudinal de hipanto y ovario; E. pétalo; F. estambre opositipétalo y detalle del poro de la antera y ápice del apéndice conectival; G. vista dorsal del ápice del apéndice conectival; $\mathrm{H}$. vista dorsal del ápice de la antera; I. estambre opositisépalo; J. vista dorsal del ápice del apéndice conectival; $\mathrm{K}$. vista ventral del ápice de la antera; L. vista frontal y lateral de la placenta. A-L: Steyermark 113912 (US). 

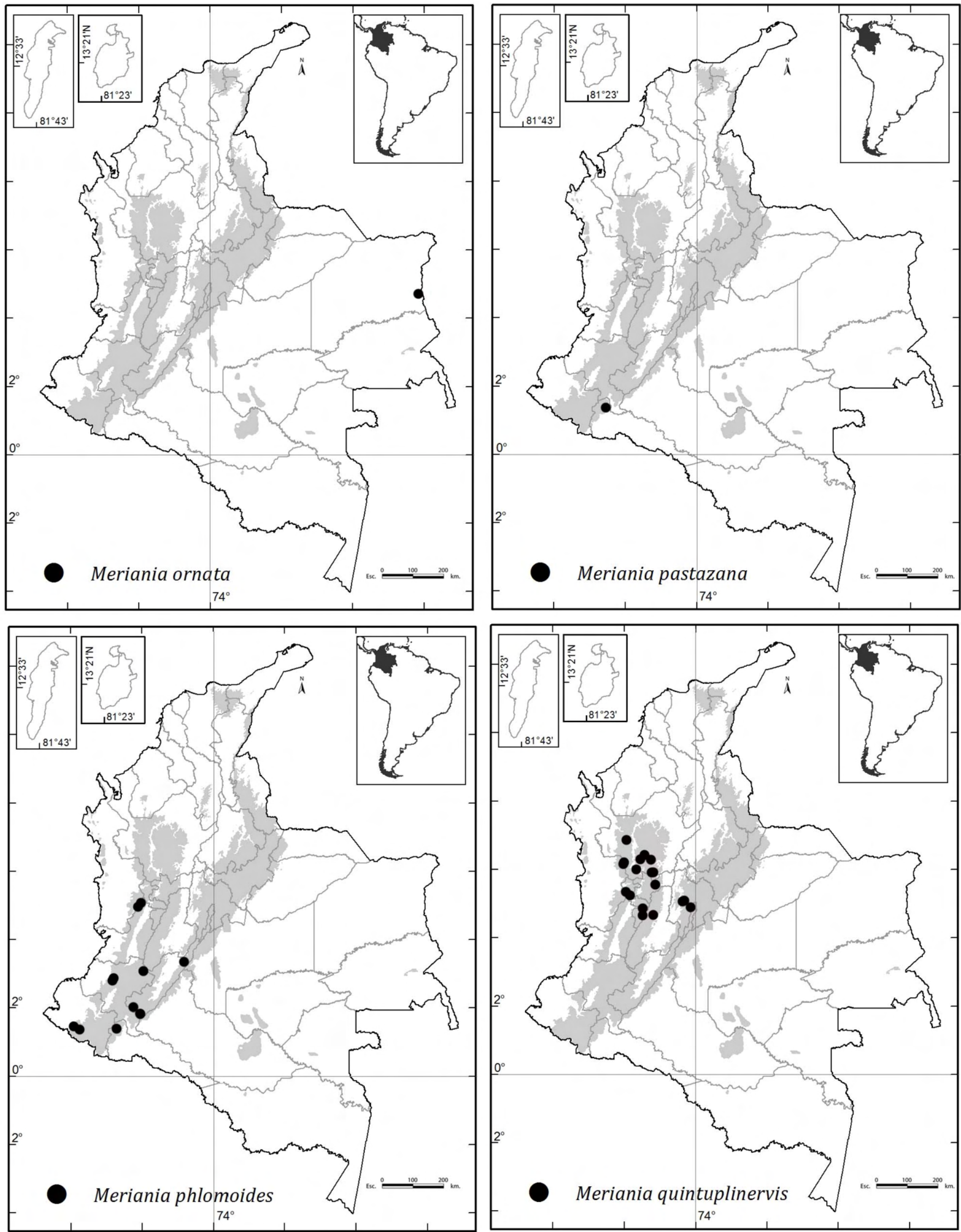

Figura 46: Distribución geográfica de Meriania ornata Wurdack, M. pastazana Wurdack, M. phlomoides (Triana) Almeda y M. quintuplinervis Naudin. 
Meriania pastazana Wurdack, Phytologia 29(2): 142-143. 1974. Figs. 44D, 47. TIPO: ECUADOR. Provincia Pastaza, cantón Mera, 25.V.1969, fl, G. Harling 10198 (holotipo: US!; isotipos: AAU, F!, GB!, MO!, NY!, S!).

Árboles 6-10 m de altura; entrenudos oblongos o cuadrangulares de aristas redondeadas, teretes en partes viejas, todas las partes de la planta son glabras incluyendo el hipanto; hojas con pecíolo 0.8-3 cm de largo; lámina 11$19 \times 5-9.7 \mathrm{~cm}$, elíptica a obovado-elíptica; base decurrente o redondeada, revoluta; ápice obtuso a agudo; margen entero; haz y envés glabros; nervadura con 1-2 pares de venas secundarias acompañando a la vena media, regularmente una sola llega al ápice, plinervio hasta $18 \mathrm{~mm}$ arriba de la base de la porción decurrente de la lámina; inflorescencia 12-25 cm de largo, 22 o menos flores; eje central con 3 nudos de ramificación, brácteas semejantes a hojas pequeñas en la mayoría de los nudos; paracladios $5.5-8.5 \mathrm{~cm}$, con un nivel de ramificación; ramillas apicalmente trifloras; flor pedicelada, 5-mera; pedicelo 6-12 mm de largo; hipanto 5-6 $\mathrm{mm}$ de largo, campanulado; cáliz truncado, tubo $4-4.5 \mathrm{~mm}$ de largo; sin dientes dorsales o a manera de protuberancias; corola patente; pétalos 25-35 × 13-23 mm, obovados, ápice truncado, anaranjados, glabros; estambres isomorfos, filamento $12-13 \mathrm{~mm}$ de largo; codo 3.5-4 mm de largo, triangular; conectivo dorsal sin apéndice o levemente abultado; antera 10-12 mm de largo, recta, poro dorsal; ovario 5-6 mm de largo, 5-locular, oblongo, fusionado en la base al hipanto cerca de $1 \mathrm{~mm}$; ápice encerrando la base del estilo 0.3-0.5 mm, lóbulos truncados a levemente dentiformes; placentas 2.8-3 mm de largo, levemente ovoides, rudimentos seminales en todas las superficies; estilo cerca de 15 $\mathrm{mm}$ de largo, levemente cónico; estigma glandiforme; cápsula no vista; semillas no vistas.

Notas taxonómicas: esta especie se reconoce por ser glabra en todas sus estructuras, la base de las hojas regularmente decurrente y revoluta, el cáliz truncado sin dientes dorsales, los estambres isomorfos, sin apéndices conectivales dorsales, los pétalos anaranjados. En ejemplares de herbario se puede confundir con $M$. rigida, pero se diferencia en que tiene hojas más grandes, de diferente forma (relación largo/ancho en $M$. rigida es 1.2-1.6 y en M. pastazana
1.8-2.2); la longitud del tubo del cáliz en $M$. rigida es 2-2.5 $\mathrm{mm}$ y en $M$. pastazana 4-4.5 mm; el ápice del ovario en $M$. rigida es redondeado y en $M$. pastazana tiene dientes que encierran el estilo 0.3-0.5 mm (Wurdack, 1980). Adicionalmente, $M$. rigida tiene un apéndice conectival dorsal conspicuo y flores de pétalos fucsia, mientras que $M$. pastazana no tiene apéndices y los pétalos son anaranjados. Con las especies de pétalos anaranjados de corola patente, como son $M$. fantastica y $M$. hernandi, difiere ampliamente en la forma de las hojas y ápice del pecio sin escutelo.

Distribución y hábitat: crece desde el sur de Colombia hasta el sur de Ecuador, entre 1400 y 2300 m de elevación, en zonas de bosque en buen estado de conservación. En Colombia se conoce para los departamentos Cauca y Putumayo, en la vertiente oriental del Macizo Colombiano (Fig. 46).

Etimología: el nombre del epíteto específico alude a la provincia Pastaza, Ecuador, lugar de procedencia del especimen tipo.

Estado de conservación: categorizada como "Vulnerable" (VU) en la Lista Roja de la IUCN (2020). Esta especie se conoce de pocos registros en Colombia y se restringe a una estrecha franja de vegetación actualmente muy impactada. Su mayor área de distribución se encuentra en Ecuador por lo que no se sugiere ningún cambio de categoría.

Material examinado: COLOMBIA. Departamento Cauca, municipio Santa Rosa, Bota Caucana, Serranía de Los Churumbelos, 1500 m, 16.VIII.1998, fl, C. González 961 (COL). Departamento Putumayo, municipio Buenos Aires, Cerro Portachuelo, 2800 m, 26.VII.1964, fl, D. D. Soejarto 1098 (COL).

Meriania phlomoides (Triana) Almeda, Proc. Calif. Acad. Sci. ser. 4, 48(7): 150-151. 1993. Figs. 44E-F, 48.

इCentronia phlomoides Triana, Trans. Linn. Soc. London 28: 72. 1872. TIPO: COSTA RICA. Sin localidad exacta, fl, fr, $A$. S. Oersted 55 (sintipo: B-destruido; fotografía en CAS!, F!, 

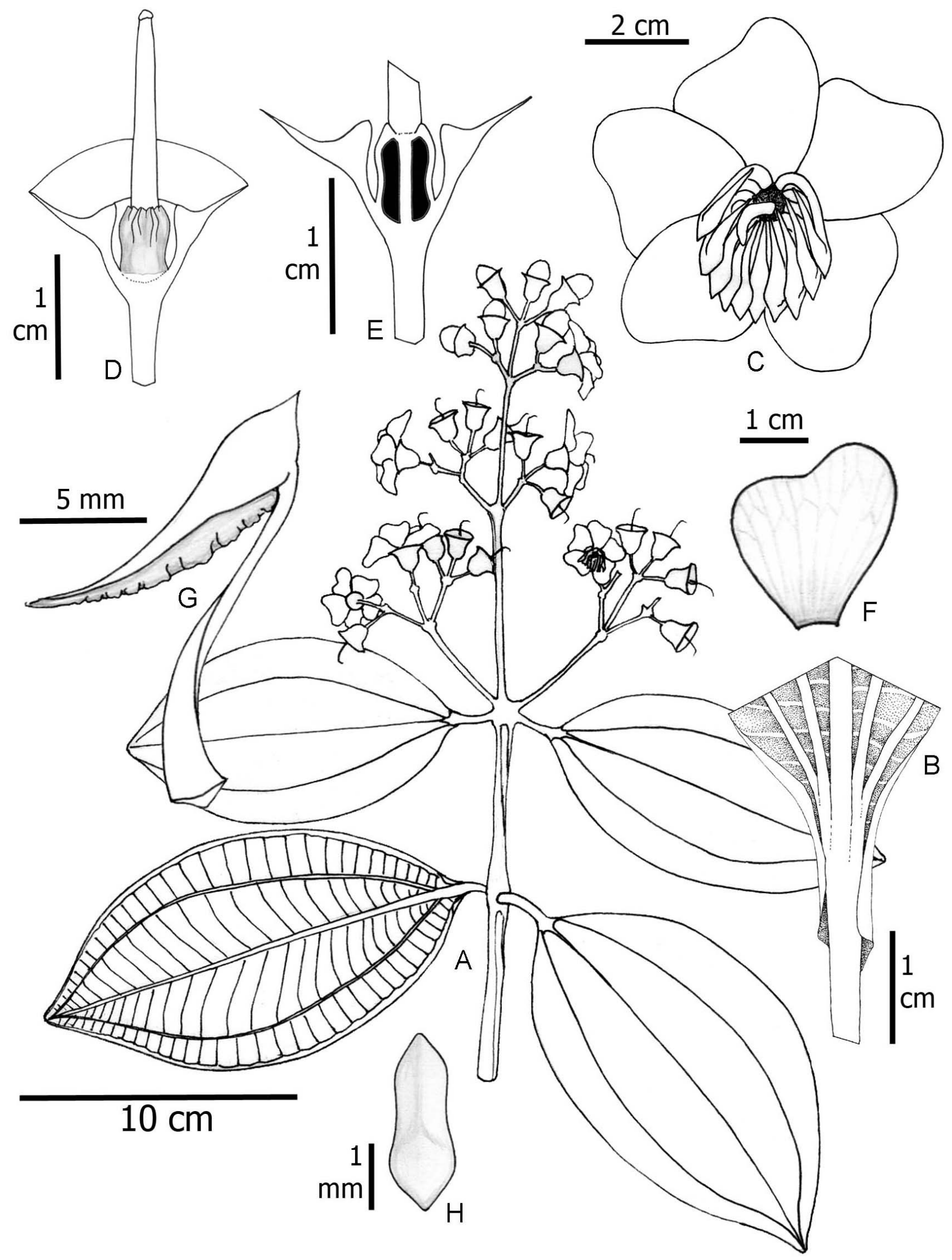

Figura 47: Meriania pastazana Wurdack. A. rama florífera; B. base lámina foliar por el envés; C. flor; D. corte longitudinal del hipanto y vista lateral del ovario y estilo; E. corte longitudinal de hipanto y ovario; F. pétalo; G. estambre; H. vista frontal de la placenta. A, C: a partir de fotografía de campo; B, D, E, F, G, H: Neill 16289 (CAS). 


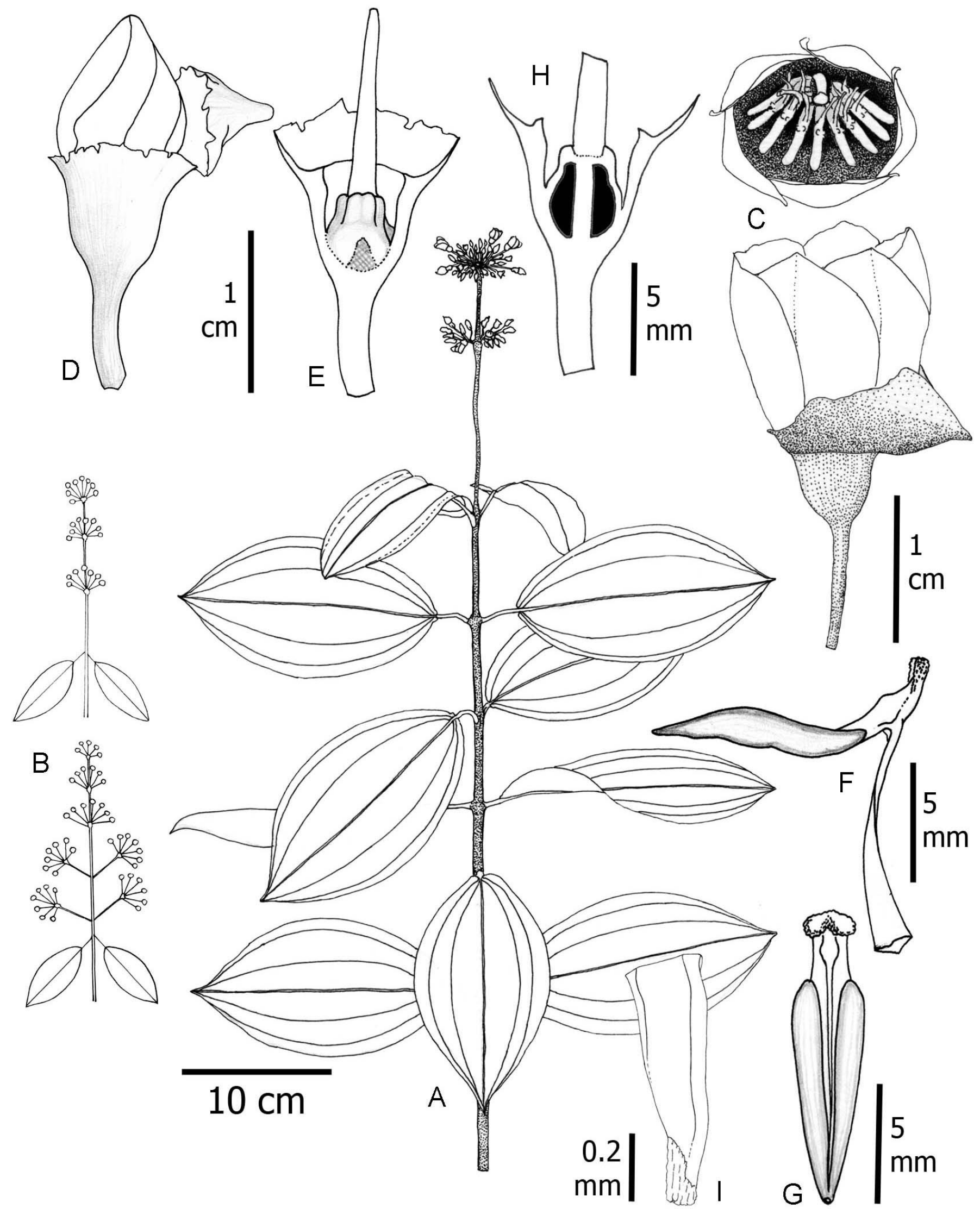

Figura 48: Meriania phlomoides (Triana) Almeda. A. rama florífera; B. representación de la variación de la inflorescencia; C. flor en vista superior y lateral; D. botón floral en antesis; E. corte longitudinal del hipanto-cáliz y vista lateral del ovario y estilo; F, G. estambre en vista lateral y superior; H. corte longitudinal del hipanto y ovario; I. semilla. A, C: Gil 861 (FMB); D, E, H: Luteyn 2575 (MO); F, G: Weling 361 (MO); I: Lozano 6596 (FMB). 
US!). Para notas de neotipificación ver Almeda (1993). = Meriania finicola Wurdack, Phytologia 55(3): 132. 1984. TIPO: ECUADOR. Provincia Napo, carretera Santa Bárbara - La Bonita, km 2, 2750 m, 17.V.1982, fl, H. Balslev 2575 (holotipo: US!; isotipos: AAU, MO!, QCA!, QCNE!), syn. nov.

Arbustos o árboles 2-12 m de altura; entrenudos cuadrangulares a subcuadrangulares; ramas, pecíolos e inflorescencia, con indumento laxo de tricomas subulados de base ensanchada, barbelada (tipo 21), marrón rojizo; hojas con pecíolo 1.5-6.4 cm de largo; lámina 10-26 × 7-16 $\mathrm{cm}$, ovado-elíptica, obovado elíptica o elíptica, textura rígido delgada; base redondeada a obtusa, algunas veces levemente cordada; ápice acuminado; margen entero a espaciadamente denticulado; haz glabro, liso o levemente bullado; envés con indumento sobre las venas similar al de las ramas, menos frecuente, tricomas estrellados de ramas largas (tipo 38); nervadura con 2 pares de venas secundarias que acompañan a la vena media además de un par submarginal que no llega hasta el ápice, raras veces 3 pares de venas, basales o más frecuente plinervias hasta $15 \mathrm{~mm}$ arriba de la base; inflorescencia $10-25 \mathrm{~cm}$ de largo, eje con 2 a 5 nudos de ramificación, pedúnculo $6-22 \mathrm{~cm}$ de largo; paracladios $2.5-10 \mathrm{~cm}$ de largo, algunas veces ausente; nudos superiores del eje y ápice de los paracladios con puntos glomerulares donde se encuentran múltiples flores (por atrofiamiento de ejes); brácteas foliosas involucrales (que encierran la inflorescencia) laminares pero caducas tempranamente; 20 a 40 flores; flor pedicelada, 5-mera; pedicelo 3-15 mm de largo; hipanto 4.5-6 mm de largo, ciatiforme, externamente liso o costillado, indumento denso de tricomas subulados de base ensanchada, barbelada 0.2-1.5 mm de largo; cáliz caliptrado, abriendo irregularmente, posteriormente se desprende completamente; externamente con indumento similar al del hipanto; corola cuculada; pétalos 10.5-16 × 7-12.5 mm, obovados, apicalmente redondeados, blancos, glabros; estambres levemente dimorfos, filamento 5-9 mm de largo; codo 1-2 mm de largo, a manera de cojín, de superficie rugosa; conectivo dorsal con apéndice dentiforme de 0.2 $0.5 \mathrm{~mm}$ de largo; antera 5.2-6.5 mm de largo, oblongo subulada, tecas conspicuamente separadas por el conectivo, este muy ancho, se nota por la parte abaxial, poro apical o levemente orientado hacia el dorso; ovario 4-5 mm de largo, 5-locular, ovoide, parciamente fusionado en la base al hipanto en aristas 1.5-2 mm; ápice con lóbulos redondeados, encerrando la base del estilo $0.7 \mathrm{~mm}$; placentas 2.1-2.3 $\mathrm{mm}$ de largo, rudimentos seminales en todas las superficies; estilo 10-17 mm de largo, cilíndrico; estigma puntiforme; cápsula $5-8 \mathrm{~mm}$ de largo sin incluir el pedicelo; semillas $0.4-10 \mathrm{~mm}$ de largo, cuneiformes con ápice corto; rafe no visible.

Notas taxonómicas: esta especie se reconoce por las brácteas involucrales laminares que encierran la inflorescencia en etapas tempranas y luego caen, las inflorescencias con tendencia a la reducción de los ejes por lo que presentan nudos glomerulares, los botones florales caliptrados, la corola cuculada y los pétalos blancos. Dentro del grupo Tomentosa es muy cercana a $M$. tomentosa, pero esta última tiene pétalos naranja y regularmente es más pubescente. Wurdack (1984) estableció a Meriania finicola documentando que solo difiere de esta especie en la densidad del indumento y el tamaño de las flores. Al observar la gradación de ejemplares desde Costa Rica hasta Ecuador, se encuentra que $M$. finicola es prácticamente una forma de zonas altas de esta especie y no hay caracteres reconocibles que puedan diferenciarla.

Distribución y hábitat: crece desde Costa Rica hasta el norte de Ecuador entre 1000 y 2800 m de elevación, en zonas muy húmedas de bosque subandino y andino. En Colombia se encuentra a lo largo de la Cordillera Occidental y en el Macizo Colombiano, en los departamentos Cauca, Chocó, Huila, Nariño, Putumayo y Valle del Cauca (Fig. 46).

Etimología: al parecer en alusión al indumento de las ramas y las flores.

Estado de conservación: tiene un rango amplio de distribución en el norte de Suramérica y parte de Centroamérica. En Colombia tiene una EOO de ca. 73,000 km² y se conoce de unas 14 localidades. No cumple los criterios para los grados de amenaza, pero su hábitat se encuentra fragmentado. Por esto sugiere su categoría como "Preocupación Menor" (LC). 
Material examinado: COLOMBIA. Departamento Cauca, municipio Almaguer, vereda Jordán, quebrada Agua del Oro, 2500 m, 27.XI.2003, fr, D. Macías 3525 (COL). Municipio El Tambo, cerca al Parque Nacional Natural Munchique, 2300-2500 m, 5.XI.1968, fl, L. S. Espinal 3218 (COL, CUVC); Parque Nacional Natural Munchique, La Romelia, 1555 m, 24.VII.1993, fr, F. González 2804 (COL, FMB); Parque Nacional Natural Munchique, Trompepuerco, 2590 m, 9.III.1979, fl, Lobo 55 (COL, FMB); Parque Nacional Natural Munchique, km 50-55 along road above Uribe, 1875-2256 m, 25.III.1979, fl, J. Luteyn 7479 (COL). Departamento Chocó, municipio San José del Palmar, vereda El Corcovado, finca La Esperanza, 1900 m, 19.I.1983, fr, P. Franco-Rosselli 1570 (MO). Departamento Huila, municipio desconocido, margen río Páez, 2480 m, 7.XII.1993, fl, C. Barbosa 9508(218) (FMB); Hacienda Pensilvania, $15 \mathrm{~km}$ E of Baraya, 7900 ft, 23.Vl.1944, fl, E. L. Litte Jr. 8126 (COL). Municipio Palestina, vereda La Guajira, Reserva Natural La Rivera, 1970 m, 23.VIII.2005, st, Prieto 4108 (FMB). Municipio San Agustín, vereda La Castellana, RN Los Yalcones, 2320-2430 m, 9.VIII.2005, fr, H. Mendoza 16372 (FMB). Departamento Nariño, municipio Barbacoas, Altaquer, vereda El Barro, Reserva Río Ñambí, 1325 m, 7.XII.1993, fl, J. Betancur 4363 (COL), 4601 (COL), 4706 (COL); loc cit., 9.XII.1993, fl, P. Franco-Rosselli 4734 (COL), 5062 (COL), 5073 (COL). Municipio Cumbal, Cerro Portachuelo, Buenos Aires Point, 2800 m, 25.VII.1964, fl, D. D. Soejarto 1069 (COL, US). Municipio Ricaurte, Reserva Natural La Planada, 1850 m, 21.I.1997, fl, G. Herrera 9177 (FMB); loc cit., 1900 m, 5.IX.1999, fr, H. Mendoza 8622 (FMB); loc cit., 1800 m, 15.XI.1987, fl, O. Salazar de Benavidez 8951 (MO, PSO). Departamento Valle del Cauca, municipio Tuluá, cuenca río Frazadas, finca El Porvenir, 2.II.1973, fl, fr, A. Roa-T. 376 (COL). ECUADOR. Provincia Carchi, cantón Tulcan, carretera Tulcán - Tufiño - Maldonado, sector Pradera, 2360-2640 m, 12.X.1986, fl, J. Jaramillo 9136 (QCA); cantón Espejo, El Gualtal, 2450 m, 21.VIII.1994, fl, W. Palacios 12697 (MO, QCNE); carretera Tulcán - Tufiño - Maldonado, sector Pradera, 12.X.1987, fl, C. Ulloa 259 (QCA); Maldonado - Tulcán road ca. km 20, 2400-2600 m, 7.X.1981, fl, L. Werling 361 (MO, QCA). Provincia Imbabura, cantón Otavalo, Otavalo - Selva Alegre, occidentales del Cotopaxi, 2300 m, 23.IV.1992, fl, W. Palacios 9997 (QCA). COSTA RICA. Provincia Cartago, cantón Cartago, ca. 4-5 km N of Trinidad on the south facing slope of Volcán Turrialba, 1700-1800 m,
4.VI.1977, fr, F. Almeda 2872 (CAS); upper reaches of the Río Grande de Orosi about $3 \mathrm{~km} \mathrm{~W}$ and down stream of the presa Tapantí, 1600 m, 11.VIII.1980, fl, J. M. MacDougal 1277 (CAS). Provincia Heredia, canton Heredia, Reserva Cerro Chompipe, 2000 m, 27.V.1994, fr, G. Umaña 559 (CAS). PANAMÁ. Provincia Chiriquí, camino de Los Pozos a Cotito y Nueva Zelandia, 6706-6743 ft, 13.III.1990, fr, J. E. Aranda 1103 (CAS); de Cotito siguiendo el camino a Jurutungo, hasta la cima del cerro que está enfrente, luego que se pasa el río, 6743-7060 ft, 15.III.1990, fl, J. E. Aranda 1180 (CAS).

Meriania quintuplinervis Naudin, Ann. Sci. Nat., Bot., ser. 3, 18(2): 129. 1852. Figs. 44G-H, 49. TIPO: COLOMBIA. In monte de Quindiu prope Popayán, $\mathrm{fl}, A$. Bonpland s. $n$. (holotipo: P 2274658!; isotipo: P 2274659!).

= Meriania tuberculata Triana, Trans. Linn. Soc. London 28(1): 67, 1872. TIPO: COLOMBIA. Departamento Antioquia, in nemoribus Andium Antioquensium ad Río Paz, fl, J. J. Triana s.n. (lectotipo: P!, aquí designado; isolectótipo: $\mathrm{K} !)$, syn. nov.

= Meriania tolimana Cuatrecasas, Trab. del Mus. Nac. de Cienc. Nat. de Madrid, Serie Botánica 26: 25. 1933. TIPO: COLOMBIA. Departamento Tolima, Cordillera Central, La Suiza, 1600 m, 12.V.1932, fl, J. Cuatrecasas 2787 (holotipo: MA!), syn. nov.

Arbustos o árboles 2-8 m de altura; entrenudos apicales subcuadrangulares; ramas y pecíolos glabros o con indumento laxo de tricomas adpresos barbelados (tipo 17), blancuzcos; ejes de la inflorescencia glabros o con ralos tricomas pinoides diminutos (tipo 25) o subulados de base ensanchada, barbelada (tipo 21), blancuzcos; hojas con pecíolo 1.2-4.6 cm de largo, terete; lámina 9.5-26 × 3.5-9.6 $\mathrm{cm}$, elíptica, oblongo-elíptica, ovado-elíptica u obovada; base obtusa a redondeada; ápice obtuso a corto acuminado; margen denticulado o entero; haz glabra, superficie lisa o levemente bullada; envés glabrescente o con indumento laxo sobre la nervadura de tricomas blancuzcos subulados de base ensanchada, barbelada, 0.5-10 mm de largo; nervadura con 2 pares de venas principales acompañando a la vena media (hay un tercer par submarginal, pero solo dos pares alcanzan el ápice), basales o plinervias hasta $12 \mathrm{~mm}$ 


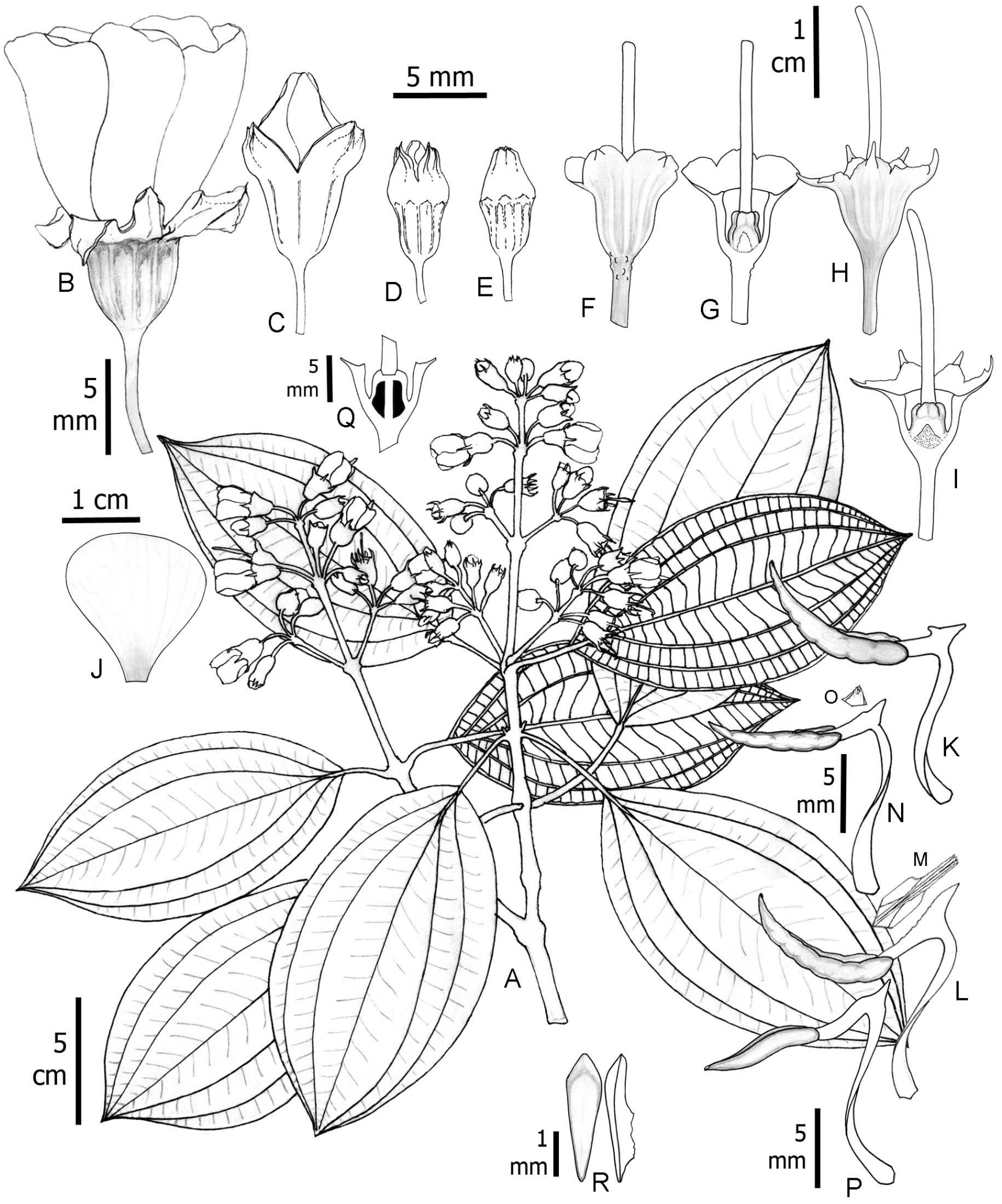

Figura 49: Meriania quintuplinervis Naudin. A. rama florífera; B. flor; C, D, E. botones florales en diferentes etapas de desarrollo; F, H. vista lateral del hipanto-cáliz; G, I. corte longitudinal del hipanto-cáliz y vista lateral del ovario y estilo; J. pétalo; K, L. estambre opositipétalo; M. vista dorsal del codo en estambres opositipétalos; N, P. estambres opositisépalos; O. vista dorsal del codo en estambres opositisépalos; Q. corte longitudinal del hipanto y ovario; R. placenta en vista dorsal y lateral. A: García-Barriga 15271 (COL); B-E: Robles 48 (FMB); F, G, L, M, P: Gentry 24575 (COL); H, I, J, K, N, O, Q, R: Uribe 6481 (COL). 
arriba de la base de la lámina; inflorescencia $10-18 \mathrm{~cm}$ de largo, sésil o pedunculada, eje con 3-5 nudos de ramificación, entre 20 y 65 flores; paracladios basales $2-9 \mathrm{~cm}$ de largo, con 1-2 niveles de ramificación; ápice de las ramillas atrofiados por lo que rematan en puntos glomerulares con más de 3 flores; flor pedicelada, 5-6-mera; pedicelo 4-13 $\mathrm{mm}$ de largo; hipanto 5-7.4 mm de largo, campanulado, costillado, externamente glabrescente o con indumento denso a laxo de tricomas subulados de base rizada; cáliz subcaliptrado, abre en lóbulos irregulares o regulares (en igual número que pétalos); lóbulos $3-3.3 \mathrm{~mm}$ de largo, gruesos; dientes dorsales inexistentes o levemente desarrollados, raras veces sobresaliendo de los lóbulos; corola cuculada; pétalos 9-19 × 9-17 mm, obovados, de ápice truncado emarginado o redondeado, rojo púrpura, glabros; estambres levemente dimorfos, estambre opositipétalo mayor, filamento 7.5-11 mm de largo; codo 1.5-2.6 mm de largo, subulado, de superficie rugosa; apéndice conectival dorsal 0.4-1.2 mm de largo, a manera de una protuberancia o dentiforme, raras veces inexistente; pedoconectivo 1-3 mm de largo; antera 8-11 mm de largo, sigmoidea, poro dorsal o raras veces apical, estambre opositisépalo, filamento 7.6-11.5 mm de largo; codo 0.5-3 mm de largo, subulado, de superficie rugosa; apéndice conectival dorsal 0.4-0.6 mm de largo, a manera de protuberancia o dentiforme, algunas veces inexistente; pedoconectivo $1.7-4.1 \mathrm{~mm}$ de largo; antera 5-5.8 $\mathrm{mm}$ de largo, sigmoidea, poro dorsal o apical; ovario 3.4-5.2 mm de largo, 5-6-locular, oblongo a ovado, parcialmente fusionado en la base al hipanto en aristas 1-3 mm; ápice con lóbulos redondeados; placentas 1.8-3 mm de largo, obovadas, rudimentos seminales en todas las superficies; estilo 1.2-1.9 mm de largo, cilíndrico o levemente engrosado en el ápice, inserto en botones; estigma puntiforme o levemente dilatado; cápsula 7-9 mm de largo, con el hipanto costillado; semillas 0.5-0.9 mm de largo, cuneiformes con ápice corto, rafe no visible.

Notas taxonómicas: los caracteres diagnósticos de esta especie son el cáliz subcaliptrado, el hipanto costiIlado, la corola tubulosa de pétalos rojos, el estilo que no excede la longitud de la corola y los estambres levemente dimorfos. Dentro del grupo de corolas tubulosa es afín a especies de cáliz subcaliptrado como son $M$. arborea,
M. dimorphanthera y M. colombiana. Las cuatro especies perfectamente podrían considerarse variantes de un solo taxón, pues solo difieren en caracteres bastante plásticos como los indumentos, la longitud de los dientes dorsales del cáliz y algunas características de los estambres. La especie más afín es $M$. dimorphanthera en la que difiere en el color de los indumentos (blancuzcas vs. rojizas o rufas en esta última) y la longitud del estilo (muy largo en esta última). De $M$. arborea difiere en los dientes del cáliz cortos y el indumento blancuzco ralo y no rojizo o marrón. De $M$. colombiana difiere en el color del indumento (rojizo en esta última), la longitud de los dientes calicinos y la forma de los estambres (isomorfos en esta última). Del resto de especies asignadas al "grupo Tomentosa" difiere en el cáliz subcaliptrado (vs. cáliz caliptrado). Meriania quintuplinervis y $M$. tuberculata solo varían en la densidad del indumento y el grado de desarrollo del apéndice conectival dorsal; existen ejemplares con estados intermedios entre las muestras tipo por lo que es muy difícil establecer un límite entre estas dos especies. Por esto, se propone a M. tuberculata como una sinonimia y variante glabrescente de $M$. quintuplinervis.

Distribución y hábitat: especie endémica a Colombia en las tres cordilleras en los departamentos Antioquia, Caldas, Cundinamarca, Quindío y Risaralda, entre 1700 y 2900 $m$ de elevación (Fig. 46). Crece en zonas de bosque andino y subandino.

Etimología: en alusión al número y disposición de las venas principales de la hoja.

Estado de conservación: categorizada como "Preocupación Menor" (LC) en la Lista Roja de la IUCN (2020). Esta especie tiene una EOO de ca. 24,000 km², AOO de ca. 20 $\mathrm{km}^{2}$ y se conoce de cerca de 20 localidades; no obstante, el hábitat del área de distribución está bastante fragmentado. Según lineamientos de la IUCN (2017), cumple los criterios B2ab(ii), por lo que se sugiere su recategorización como "Vulnerable" (VU).

Material examinado: COLOMBIA. Departamento Antioquia, municipio Argelia, km 17 of road Sonsón - Argelia, $2 \mathrm{~km}$ past fork in road to Nariño, 2160 m, 3.X.1987, 
fl, J. L. Zarucchi 6169 (COL). Municipio Medellín, cerca de Santa Elena, camino entre Medellín y Rionegro, 2300-2500 m, 13.V.1946, fl, G. Gutiérrez 1074 (COL, FMB). Municipio Rionegro, 2000 ft, l-1948, fl, C. Sandeman 5721 (COL). Municipio Salgar, acenso a Cerro Plateado, 2200-2240 m, 3.XI.1985, fr, P. Franco-Rosselli 2294 (COL); trail from Encarnación to Parque Nacional Las Orquídeas, 1600-1800 m, 27.I.1979, fl, A. Gentry 24575 (COL). Departamento Caldas, municipio Pensilvania, carretera desde Puerto Suarez, 2450-2600 m, 6.XI.1994, fl, C. Barbosa 10094(89) (FMB). Municipio Samaná, Berlín, cuenca alta del río La Miel, 2750 $\mathrm{m}, 23 . V I I .2004, \mathrm{fl}$, A. Robles 48 (FMB). Departamento Chocó, municipio El Carmen de Atrato, carretera a Urrao, $15 \mathrm{~km}$ al NO de la cabecera municipal, 2400-2700 m, 7.XI.1985, fl, G. Galeano 849 (COL). Departamento Cundinamarca, municipio Albán, Granjas del Padre Luna, Reserva El Gran Ciudadano, 1970, fr, G. Mahecha s.n. (COL, UDBC). Municipio Fusagasugá, Sabaneta, bosques relictuales al noroccidente de Bogotá, 7.VI.1981, fl, C. Barbosa 1533 (FMB); provincia Gualiva, Facatativá a Sasaima, 2300-2900 m, 1.IX.1954, fl, H. García-Barriga 15271 (COL). Municipio San Francisco, vereda Sabaneta, 2550 m, 12.VI.1990, fr, R. Sánchez 1548 (COL); Granjas del Padre Luna, 2100 m, 16.XI.1970, fl, L. Uribe 6481 (COL). Departamento Quindío, municipio Salento, vereda El Roble, 2260 m, 15.III.1993, fl, M. C. Vélez 3149 (COL). Departamento Risaralda, municipio Mistrató, vereda Serna, 2000 m, 19.IX.1980, fr, L. A. Camargo 7395 (COL). Municipio Pueblo Rico, vereda Providencia, a Pavadero, 2620-2680 m, 21.VIII.2004, fl, fr, A. Prieto 2316 (FMB), 2356 (FMB). Municipio Santuario, Parque Nacional Natural Tatamá, Planes de San Rafael, 2450 m, 7.I.2013, fr, M. Alvear 1519 (CAS, COL); Santuario - Apía, orillas del río San Rafael, hacienda de Molina de CARDER, Parque Nacional Natural Tatamá, 6.XII.1989, fr, C. Barbosa 14020 (FMB); vereda San Rafael, Parque Nacional Natural Tatamá, 10.III.2006, fr, J. Betancur 12144 (COL).

Meriania ramosii Humberto Mend., sp. nov. Figs. 44I-K, 50, 51.

TIPO: COLOMBIA. Departamento Chocó, municipio San José del Palmar, escuela antigua de Galápagos, trocha que conduce de la escuela a la quebrada, 1300-1500 m,
13.X.2008, fl, H. Mendoza 17338 (holotipo: FMB!; isotipos: COL!, CUVC!).

Calyptrate flowers, isomorphic stamens, magenta petals and ovary apex 9-15.5 mm long. Related to Meriania silverstonei but differs in the longer ovary apex and glabrescent branches and leaves.

Árboles 15-30 m de altura; entrenudos jóvenes subcuadrangulares, 1.8-4 cm de largo; línea interpeciolar conspicua; ramas y pecíolos glabrescentes; ejes de la inflorescencia, hipanto y caliptra con indumento de tricomas rufos esponjosos irregulares con ramas cortas, diminutos (tipo $30)$, tricomas glandulares sésiles (tipo 4); hojas con pecíolo 2.7-4.3 cm de largo, terete; lámina 9.5-16 ×6-9.3 cm, ovada u ovado-elíptica, textura rígida, quebradiza; base obtusa a redondeada; ápice corto acuminado; margen entero; haz glabro; envés glabrescente, indumento sobre la nervadura de tricomas rufos similares a los de la inflorescencia, tricomas glandulares sésiles (tipo 4); nervadura con 2 pares de venas basales acompañando a la vena media; inflorescencia 8-12 cm de largo, panícula abierta, 20 a 30 flores; eje central con 2-3 nudos de ramificación, primer internodo terete, 8-11 cm de largo; ramillas aplanadas; paracladios basales 10-12 cm de largo, con 2 niveles de ramificación; ramificaciones de ápices trifloros; bráctea en las ramificaciones basales semejantes a las hojas pero pequeñas; flor pedicelada, 5-mera; pedicelo 8-9 mm de largo; hipanto 10-14 $\mathrm{mm}$ de largo, cilíndrico a campanulado, internamente liso; paredes 1-2.8 mm de grosor; torus 2.2-3.1 mm de grosor; cáliz caliptrado; caliptra 8-10 mm de largo antes de la antesis, apicalmente oblonga a obtusa, abre por fisuras irregulares; corola patente; pétalos 32-48 × 30-37 mm, obovados, ápice truncado emarginado, glabros, fucsia oscuro; estambres isomorfos, dispuesto a un lado de la flor después de la antesis, filamento $10-14 \mathrm{~mm}$ de largo; codo $2.9-5 \mathrm{~mm}$ de largo, subulado; apéndice conectival dorsal 1.6-2.5 mm de largo, subulado, blanco; antera 10-13 mm de largo, subulado sigmoidea, poro orientado dorsalmente; ovario 15 $16 \mathrm{~mm}$ de largo, 5-6 mm de diámetro en la base, 5-locular, fusionado en la base al hipanto 1-1.9 mm; ápice muy desarrollado, 9-15.5 $\mathrm{mm}$ de largo, aristado, dientes apicales 2-2.5 mm de largo; placentas $2.9 \mathrm{~mm}$ de largo, oblongo- 


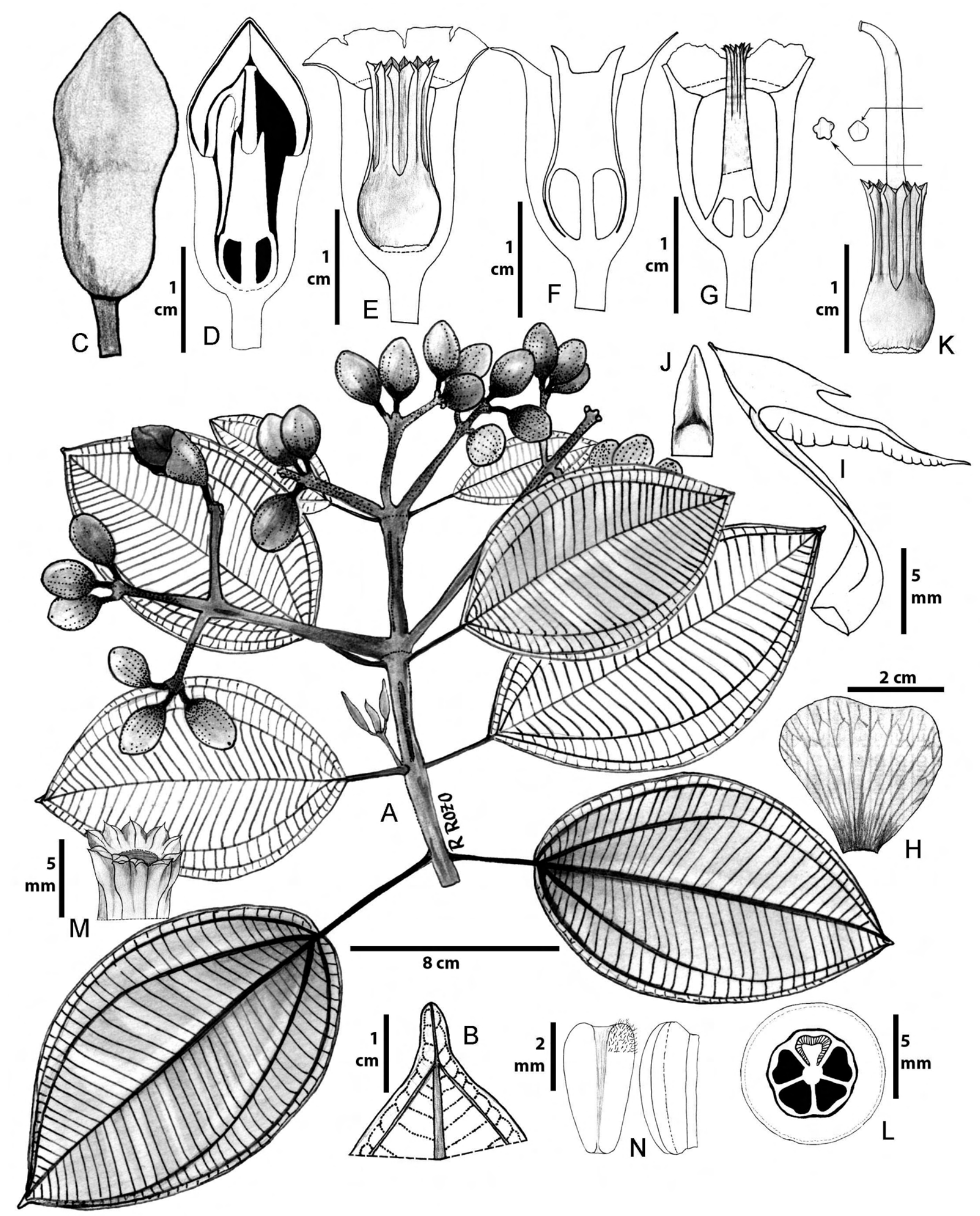

Figura 50: Meriania ramosii Humberto Mend. A. rama florífera; B. ápice lámina foliar; C. botón floral; D. corte longitudinal del botón floral; E. corte longitudinal del hipanto y vista lateral del ovario; F, G. cortes longitudinales del hipanto y ovario; H. pétalo; I. estambre; J. vista ventral del codo; K. vista lateral del ovario y estilo; L. corte transversal del hipanto-ovario; M. ápice del ovario; N. vista frontal y lateral de la placenta. A-N: Mendoza 17338 (FMB). 

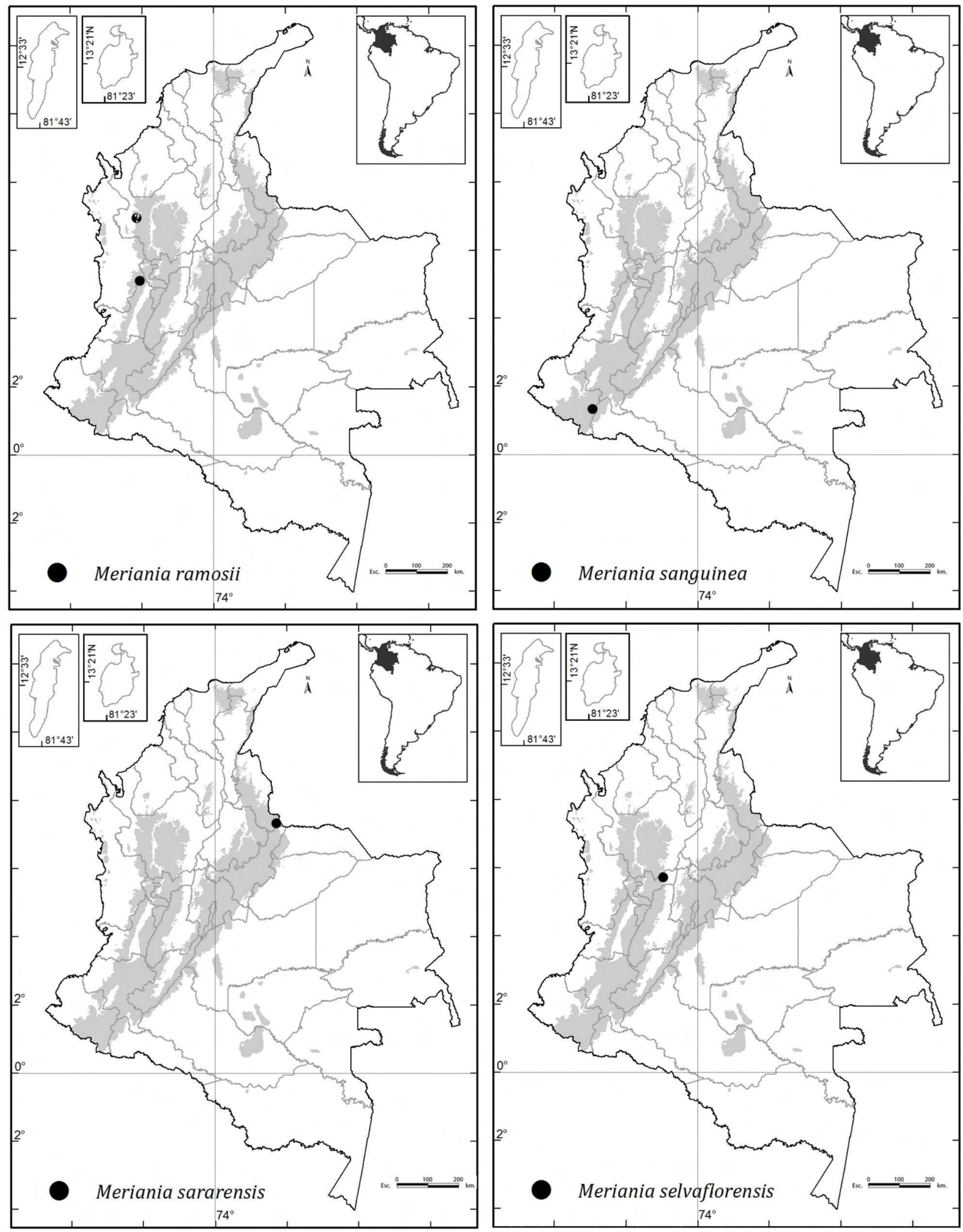

Figura 51: Distribución geográfica de Meriania ramosii Humberto Mend., M. sanguinea Wurdack, M. sararensis Humberto Mend. \& Fern. Alonso y M. selvaflorensis Humberto Mend. 
obovadas, superficie ciliolada, rudimentos seminales en todas las superficies; estilo $14-16 \mathrm{~cm}$ de largo, columnar, curvo hacia el ápice; estigma 1.3-1.5 mm de diámetro, puntiforme o levemente expandido, papiloso; cápsula no vista; semillas no vistas.

Notas taxonómicas: la presencia de caliptra con indumento ferrugíneo, los estambres isomorfos, el tamaño y color de los pétalos y la forma de los estambres, permite asociar esta especie con el grupo Brachycera, documentado por Mendoza-Cifuentes y Fernández-Alonso (2012). Dentro de este grupo, Meriania silverstonei es la especie más afín a $M$. ramosii y que adicionalmente crece en la Cordillera Occidental. Las dos especies son muy similares vegetativamente y su principal diferencia radica en la forma del ovario, ya que en $M$. ramosii el ápice del ovario es mucho más largo al igual que el tálamo del hipanto (Fig. 52). Otra diferencia se encuentra en el indumento del hipantocáliz, ya que $M$. ramosii es glabrescente, mientras que en $M$. silverstonei es denso. Las placentas de $M$. ramosii son cilioladas, caracter ausente en el resto de especie del grupo Brachycera.

Distribución y hábitat: conocida hasta el momento solo de la localidad tipo en el flanco occidental de la Cordillera Occidental en el departamento Chocó, en zonas con vegetación de bosque subandino de acuerdo con la clasificación propuesta por Van der Hammen y Rangel-Ch. (1997) (Fig. 51). Existe una colección proveniente del departamento Antioquia (A. Cogollo s.n. (JAUM)) atribuible a esta especie, pero se revisó someramente y demanda de mayor evaluación.

Etimología: el epíteto específico hace alusión a Jorge Ramos, profesor de botánica jubilado del departamento de Biología de la Universidad del Valle, en agradecimiento a su inmensa labor de formación de botánicos en el Valle del Cauca.

Estado de conservación: esta especie solo se conoce del ejemplar tipo, por lo que su EOO y AOO son mínimos. Posiblemente se encuentra en todo el flanco occidental del norte de la Cordillera Occidental, zona en donde aún se conserva una amplia franja de bosque subandino. En esta zona existen algunos parques nacionales, como el de Tatamá, donde posiblemente se encuentre. Considerando lo anterior, se sugiere su categorización como "Datos Insuficientes" (DD).

Meriania sanguinea Wurdack, Mem. New York Bot. Gard. 16: 4-5. 1967. Figs. 44L-N, 53. TIPO: ECUADOR. Provincia Azuay, the Eastern Cordillera, 1-8 km north of the villaje of Sevilla de Oro, 8000-9000 ft, 27.VII.1945, fl, W. H. Camp E-4620 (holotipo: US!; isotipos: COL!, GH!, NY!, $\mathrm{U} !)$.

Arbustos 2-3 m de altura; entrenudos cuadrangulares de aristas redondeadas, en las ramas jóvenes regularmente canaliculados; línea interpeciolar 3-8 mm de alto, laminar; ramas, pecíolo e inflorescencia con indumento laxo de tricomas pinoides diminutos (tipo 25), las partes más viejas tienden a ser glabras; hojas con pecíolo $3-8 \mathrm{~cm}$ de largo, apicalmente engrosado; lámina $11-22 \times 6-13 \mathrm{~cm}$, ovada; base cordada; ápice agudo; margen dentado; haz bullado-ampollado (con tricomas setosos ampollados tipo $15)$; envés reticulado faveolado, nervadura con indumento denso de tricomas pinoides marrón claro $0.2-1 \mathrm{~mm}$ de largo; nervadura con 3 pares de venas secundarias acompañando a la vena media, solo 2 pares llegan al ápice, basales; inflorescencia $18-57 \mathrm{~cm}$ de largo, pedúnculo $15-23$ cm de largo; eje central con 3-5 nudos de ramificación; paracladios $6-10 \mathrm{~cm}$ de largo, hasta 3 niveles de ramificación; ramillas con entrenudos muy cortos, rematando en 2-3 flores; 30 a 130 flores por inflorescencia; flor pedicelada, 5-mera; pedicelo 8-14 mm de largo; hipanto 2.7-4.4 mm de largo, anchamente campanulado, externamente glabro o con escasos tricomas pinoides diminutos; cáliz truncado, tubo 1.2-1.6 mm de largo; dientes dorsales inexistente o a manera de protuberancias; corola cuculada; pétalos 11-19 × 9-16 mm, obovados, apicalmente redondeados, glabros, rojos; estambres isomorfos, filamento $6-9 \mathrm{~mm}$ de largo; codo 3.6-4.1 mm de largo, espatulado, apicalmente engrosado, rugoso; conectivo dorsal sin apéndices o con un diente $0.5 \mathrm{~mm}$ de largo; antera 6.2-7.7 $\mathrm{mm}$ de largo, levemente curva hacia el dorso, poro dorsal; ovario 3-4.5 mm de largo, 4-5-locular, oblongo, costillado externamente, parcialmente fusionado al hipanto en la base $1 \mathrm{~mm}$; ápice con lóbulos 


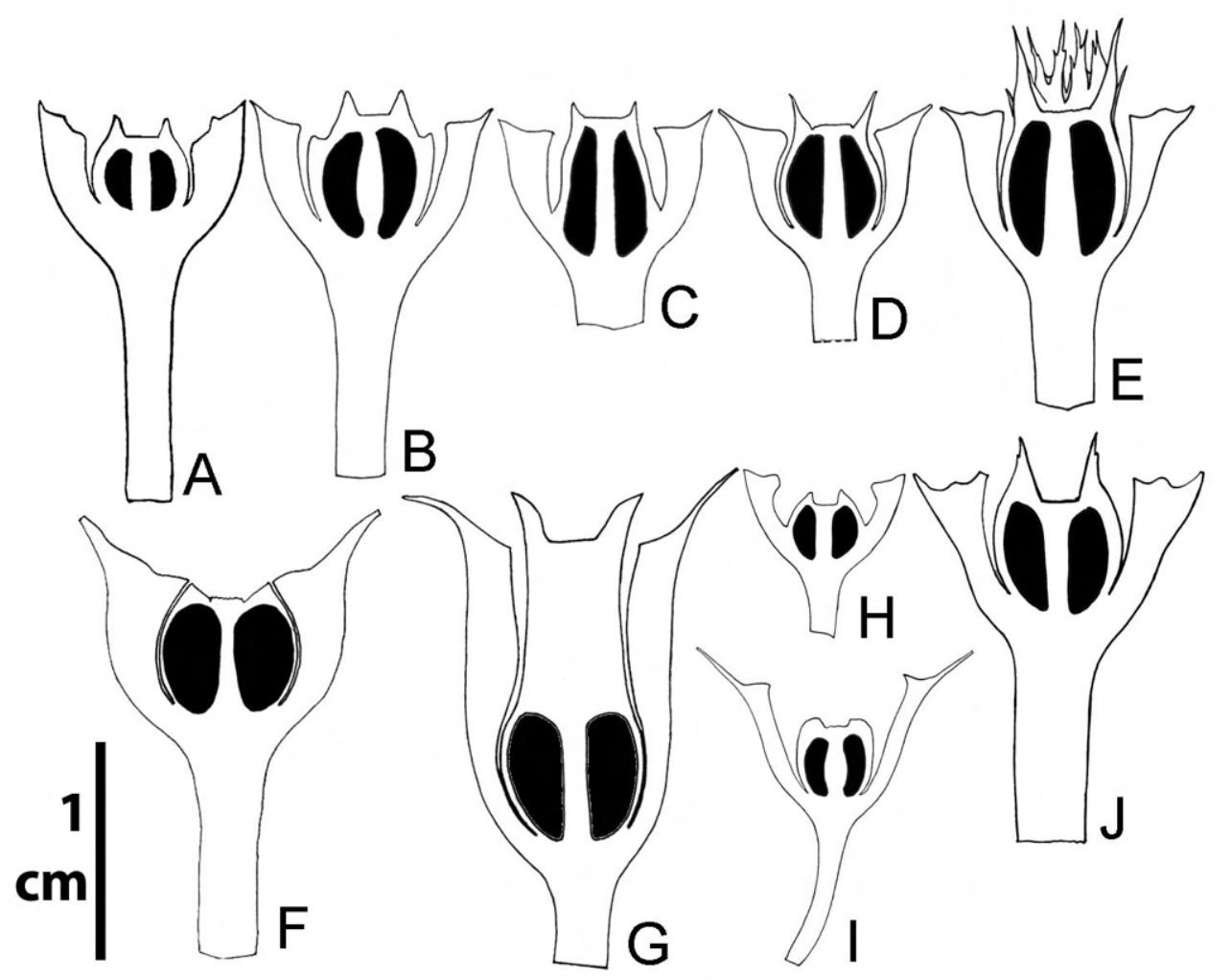

Figura 52: Comparación de la forma del hipanto-ovario en corte longitudinal entre especies del grupo Brachycera y M. ramosii Humberto Mend. A. M. aguaditensis Humberto Mend. \& Fern. Alonso; B. M. brachycera (Naudin) Humberto Mend. \& Fern. Alonso; C. M. haemantha subsp. virolinensis Humberto Mend. \& Fern. Alonso; D. M. mutabilis (Gleason) Humberto Mend. \& Fern. Alonso; E. M. mutisii (Bonpl.) Humberto Mend. \& Fern. Alonso; F. M. silverstonei Humberto Mend. \& Fern. Alonso; G. M. ramosii; H. M. sararensis Humberto Mend. \& Fern. Alonso; I. M. arizae Humberto Mend. \& Fern. Alonso; J. M. yalconensis Humberto Mend. \& Fern. Alonso.

redondeados que encierran la base del estilo 1-1.5 mm; placentas 1.5-1.9 mm de largo, obovadas, rudimentos seminales en todas las superficies; estilo $10-15 \mathrm{~mm}$ de largo, levemente cónico; estigma $1.5 \mathrm{~mm}$ de diámetro, levemente expandido; cápsula 10-11 mm de largo sin incluir el pedicelo, el hipanto cubre solo hasta la mitad del ovario; semillas no vistas.

Notas taxonómicas: se reconoce por la línea interpeciolar laminar, lámina cordada, haz bullado-setoso, cáliz truncado y sin dientes dorsales, corola cuculada de pétalos rojos y estambres isomorfos. Hay tres especies parecidas $y$, aunque no se encuentran en Colombia, es importante aclarar sus diferencias: Meriania almedae Wurdack tiene indumento denso por el envés sobre la nervadura, cáliz con dientes dorsales lineares y sobresaliendo conspicuamen- te de los lóbulos y no tiene línea interpeciolar laminar; $M$. radula Wurdack no tiene línea interpeciolar laminar y $M$. tetragona (Cogn.) Wurdack es completamente glabra con el tallo cuadrangular aristado.

Hábitat y distribución: crece desde el sur de Colombia hasta el sur de Ecuador en zonas de páramo y subpáramo, entre 3000 y 3600 m de elevación. Para Colombia solo se conoce del Páramo de Bordoncillo, en los límites de los departamentos Nariño y Putumayo (Fig. 51).

Etimología: en alusión al color rojo de los pétalos.

Estado de conservación: para Colombia solo se conoce de un registro, pero está distribuida a lo largo de la Cordillera Oriental en Ecuador y en norte de Perú, dentro 

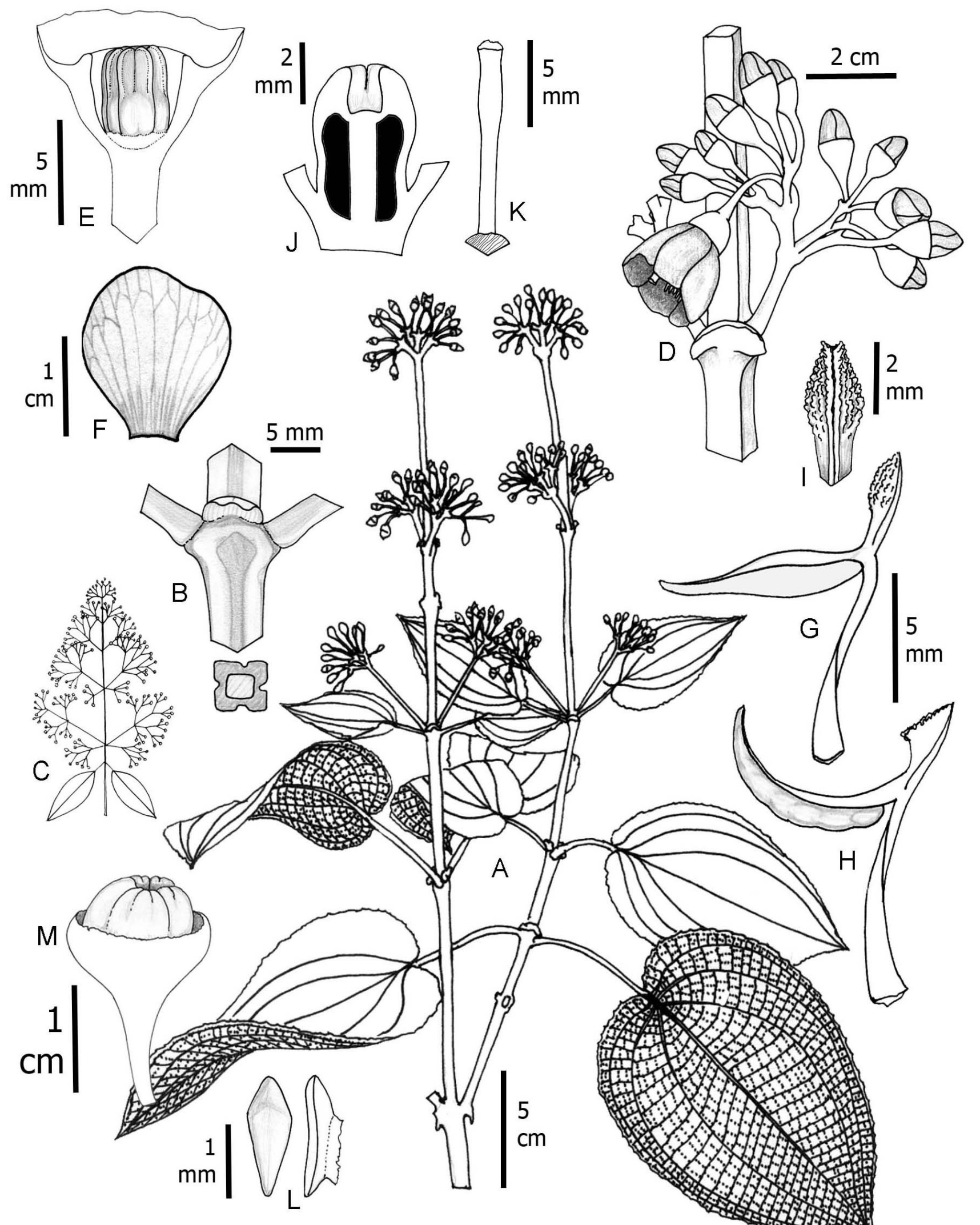
de áreas de conservación. Existen más de 40 colecciones de esta especie en diferentes herbarios y puede crecer en zonas abiertas con algún grado de intervención antrópica. Su categorización solo para Colombia no reflejaría mayor información, por lo que no se categoriza en este trabajo.

Material examinado: COLOMBIA. Departamento Putumayo, municipio Santiago, vereda San Antonio de Bellavista, páramo de Bordoncillo, 30.I.1993, fr, A. Muñoz 181 (COL).

Meriania sararensis Humberto Mend. \& Fern. Alonso, Anales. Jard. Bot. Madrid 69(2): 285. 2012. Fig. 54. TIPO: COLOMBIA. Departamento Norte de Santander, municipio Toledo, Cordillera Oriental, sector del Sarare, hoya del río Margüa, bosque en la quebrada del Río Negro, 1200 1300 m, 9.XI.1941, fl, fr, J. Cuatrecasas 12949 (holotipo: COL!; isotipos: $\mathrm{F}$ !, US!).

Arbusto de ramas bejucosas; entrenudos teretes; ramas, pecíolos e inflorescencia con indumento rufo semidenso de tricomas piramidales cortos (tipo 27); hojas con pecíolo 2.7-3.8 cm de largo; lámina 14.5-21 × 11-17 $\mathrm{cm}$, suborbicular a oblonga u ovoide; base cordada; ápice agudo a obtuso; margen denticulado; haz glabro; envés con indumento sobre la nervadura de tricomas similares a las ramas; nervadura con 3 pares de venas basales acompañando a la vena media, solo 2 pares llegan al ápice; inflorescencia $25-35 \mathrm{~cm}$ de largo, péndula, con 4-6 nudos de ramificación, cerca de 50 a 90 flores; paracladios basales 15-18 cm de largo; los ápices de las ramificaciones de último orden son trifloros pero tienden a mostrar una flor, las otras no se desarrollan; flor pedicelada, 5-mera; pedicelo 7-10 mm de largo; hipanto 4.6-7 $\mathrm{mm}$ de largo, ciatiforme, externamente con indumento denso de tricomas piramidales; pared 1-1.1 mm grosor en la parte media; cáliz caliptrado, caliptra 15-16 mm de largo, ápice agudo, externamente con indumento denso de tricomas filiformes ligeramente rugosos de hasta $1 \mathrm{~mm}$ de largo (tipo 16); corola patente; pétalos 16.7-26.3 × 13-23.2 mm; estambres isomorfos, filamento 6.3-6.9 mm de largo; codo 1.8-2.5 mm de largo, subulado; apéndice conectival dorsal 1.6-2.8 mm de largo, subulado; antera 5.8-7.4 cm de largo, levemente sigmoidea o curva hacia el dorso, poro dorsal; ovario 4-4.5 mm de largo, 5-locular, ovado, fusionado en la base con el hipanto 1.3-1.6 $\mathrm{mm}$, en corte transversal en su parte media con 5 costillas levemente alzadas, de lomo levemente aplanado; ápice con apéndices dentiformes muy pequeños; placentas 2-2.2 mm de largo, ovoides, rudimentos seminales en todas las superficies; estilo $9.5-12 \mathrm{~mm}$ de largo, columnar o levemente cónico; estigma puntiforme; cápsula 8-9 mm de largo sin incluir el pedicelo, hipanto leñoso hemisférico 8-10.5 mm de largo, cubriendo casi por completo el fruto; fruto propiamente 6-7 mm de diámetro, oblongo; semillas 0.63-0.70 mm de largo, cuneiformes con ápice corto.

Notas taxonómicas: Meriania sararensis es una especie muy parecida a $M$. haemantha. No obstante, se diferencian porque $M$. sararensis tiene inflorescencia péndula, tres pares de venas acompañando a la vena media y caliptra con indumento de tricomas filiformes ligeramente barbelados de hasta $1 \mathrm{~mm}$ de largo. También se diferencia por la forma de la base foliar, estambres y pétalos más pequeños, el apéndice conectival dorsal mucho más largo.

Distribución y hábitat: conocida solo de la localidad tipo en el departamento Norte de Santander (Fig. 51). EI hábitat no es conocido.

Etimología: en alusión a la localidad tipo.

Estado de conservación: categorizada como "Peligro Crítico" (CR) (Mendoza-Cifuentes y Fernández-Alonso, 2011). Esta especie fue categorizada en su momento porque la región de donde procede (norte de la Cordillera Oriental) está bastante poblada e intervenida y solo se ha colectado dos veces en un periodo de 80 años. Es muy probable que su distribución reducida sea un factor natural agravado por las condiciones antrópicas actuales.

Material examinado: COLOMBIA. Departamento Norte de Santander, municipio Toledo, corregimiento de San Bernardo de Bata, Santa Inés, quebrada Honda, 1800 m, 7.IV.2008, fr, R. Sánchez 12926 (HECASA). 


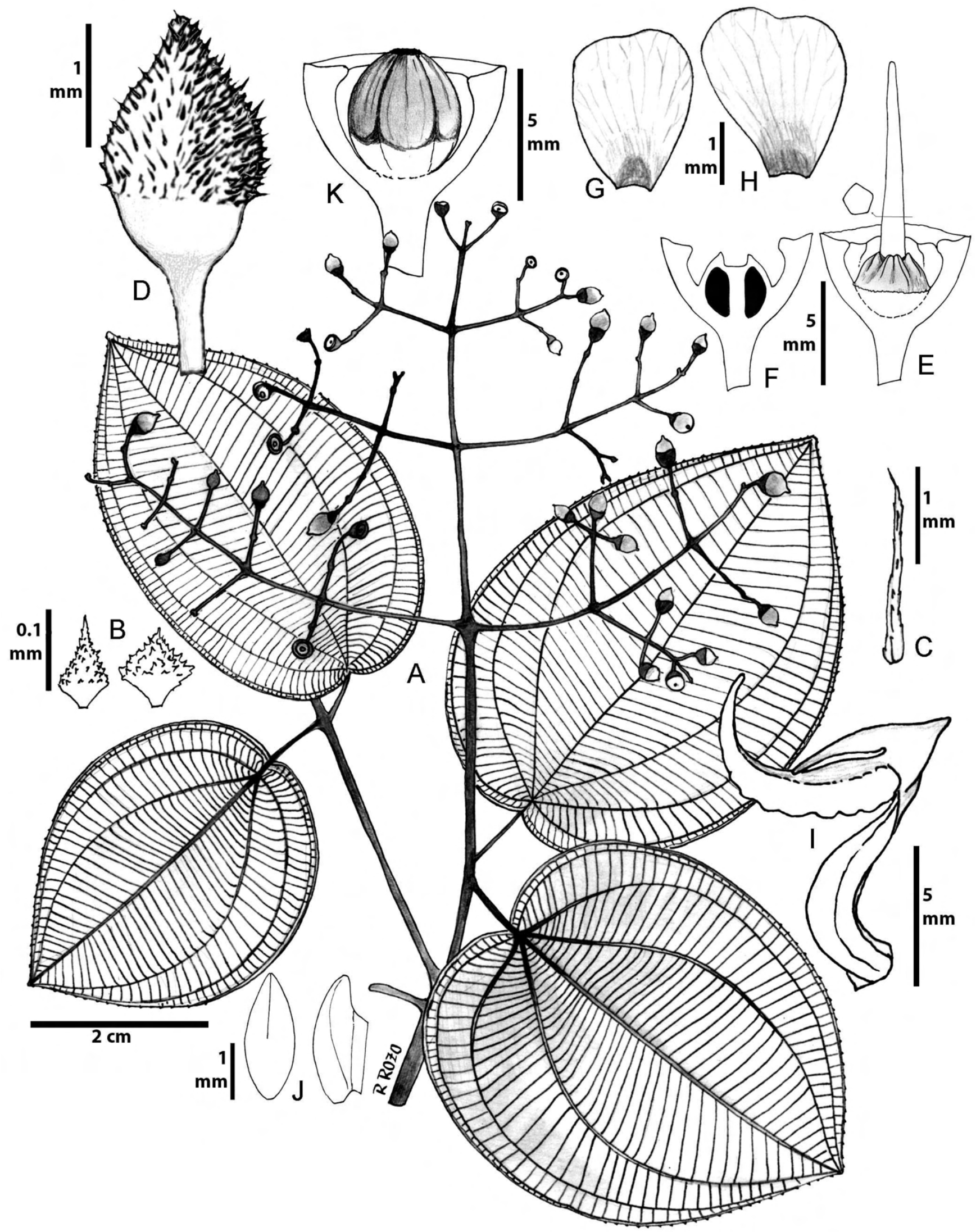

Figura 54: Meriania sararensis Humberto Mend. \& Fern. Alonso. A. rama florífera; B. tricomas de los entrenudos y ejes de la inflorescencia; C. tricoma de la caliptra; D. botón floral; E. corte longitudinal del hipanto y vista lateral del ovario y estilo; $F$. corte longitudinal del hipanto y del ovario; $G$, $H$. pétalos; I. estambre; J. vista frontal y lateral de la placenta; K. fruto con corte longitudinal del hipanto. A-K: Cuatrecasas 12949 (COL); tomada de Mendoza-Cifuentes y Fernández-Alonso (2012). 
Meriania selvaflorensis Humberto Mend., Anales Jard. Bot. Madrid 68(2): 249-252. 2011. Figs. 55, 56A-D. TIPO: COLOMBIA. Departamento Caldas, municipio Florencia, dirección este, quebrada Las Mercedes, $5^{\circ} 31^{\prime} 36^{\prime \prime} \mathrm{N}$, 7502'26'W, 1500-1600 m; 13.X.1992, fl, C. Barbosa 7876 (106) (holotipo: HUQ!, isotipos: COL!, FMB!).

Lianas o arbustos de ramas péndulas y apoyantes; entrenudos teretes; ramas y pecíolos glabros; ejes de la inflorescencia glabros o con ralos tricomas rufos esponjosos irregulares diminutos (tipo 30); pedicelo e hipanto con indumento semidenso con igual tipo de tricomas; caliptra con el mismo indumento del hipanto, pero muy ralo; hojas levemente desiguales en tamaño en el mismo nudo; pecíolo 0.9-2.5 cm de largo; lámina 8-21 ×6.5-11.7 cm, oblongoelíptica u oblongo-ovada; base redondeada a subcordada; ápice fuertemente acuminado, acumen $1-3.5 \mathrm{~cm}$ de largo; margen entero; haz glabro; envés con indumento laxo, tricomas sobre la nervadura similares a los de las ramas, tricomas glandular cortamente pedunculado (tipo 6) en toda la superficie; nervadura con 2 pares de venas basales acompañando a la vena media; inflorescencia $15-44 \mathrm{~cm}$ de largo, 18 a 80 flores; eje central con 4-5 nudos de ramificación; paracladios basales $12-28 \mathrm{~cm}$ de largo, con 2-3 niveles de ramificación; ramificaciones de ápices trifloros o unifloros; bráctea en las ramificaciones semejantes a las hojas, pero pequeñas; flor pedicelada, 5-mera; pedicelo 4-8 $\mathrm{mm}$ de largo; hipanto 6-9 mm de largo, hemisférico a campanulado; paredes 0.9-1.1 mm grosor; cáliz caliptrado, caliptra 15-20 $\mathrm{mm}$ de largo antes de la antesis, circuncísil, apiculada; dientes calicinos dorsales 0.6-0.8 mm de largo, en la base de la caliptra, triangulares o dentiformes; corola patente; pétalos 37-45 × 24-33 mm; estambres levemente dimorfos, los opositipétalos más pequeños, estambres opositipétalos, filamento 1.3-2.1 mm de largo; codo 5-6.6 mm de largo, subulado; apéndice conectival dorsal 1.3-2.4 mm de largo, subulados; pedoconectivo 1-1.4 mm de largo; antera 10.8$11 \mathrm{~mm}$ de largo, sigmoidea, subulada, de paredes rugosas, poro dorsal; estambres opositisépalos, filamento 14-19 $\mathrm{mm}$ de largo; codo 5-5.6 mm de largo, lateralmente expandido de forma triangular, un ribete en el centro; apéndice conectival dorsal 0.8-1.2 mm de largo, lingüiforme a levemente romo; antera 9.1-10.6 mm de largo, subulada sig- moidea, de paredes rugosas, poro dorsal; sin pedoconectivo, o si presente $0.3 \mathrm{~mm}$ de largo; ovario $3.7-4.5 \mathrm{~mm}$ de largo, 5-locular, oblongo a oblongo-ovoide, completamente súpero, en corte transversal en su parte media tiene 5 costiIlas levemente alzadas, de lomo levemente aplanado; ápice con dientes anchos, romos poco sobresalientes; placentas 2.1-2.2 mm de largo, ovoides, rudimentos seminales en todas las superficies; estilo 17.5-19.8 mm de largo, columnar a levemente cónico, curvo hacia el ápice; estigma puntiforme; cápsula cerca de $10 \mathrm{~mm}$ de largo sin incluir el pedicelo, hipanto delgado, se desprende tempranamente de las paredes del ovario dejándolo desnudo; semillas 3.4-4 mm de largo, estrechamente triangulares, de ápice alargado (apariencia filiforme); el ápice 1.4-1.7 mm de largo; rafe no visible; la zona del embrión es más oscura que el resto de la semilla.

Notas taxonómicas: esta especie al parecer varía en su hábito de crecimiento de acuerdo con su hábitat, pues en zonas de bordes puede crecer de forma arbustiva y en el interior de bosque como liana. Se reconoce por las hojas anisofilas, las ramas péndulas bejucosas, caliptra circuncísil con indumento ferrugíneo y los estambres dimorfos. Es cercana al grupo Brachycera, documentado por MendozaCifuentes y Fernández-Alonso (2012); no obstante, difiere de este grupo en los estambres dimorfos, el hábito de crecimiento y las semillas de ápice o lado chalazal alargado. Considerando lo anterior aun no es posible establecer el grupo de especies cercanas a $M$. selvaflorensis.

Distribución y hábitat: conocida hasta el momento solo de la localidad tipo en el Parque Nacional Natural Selva de Florencia, Caldas, en la vertiente de la Cordillera Central que drena hacia el río Magdalena, entre los 1500 y 1800 m, en zonas con vegetación de bosque subandino de acuerdo con la clasificación propuesta por Van der Hammen y Rangel-Ch. (1997) (Fig. 51).

Etimología: en alusión a la localidad tipo, Parque Nacional Selva de Florencia.

Estado de conservación: categorizada como "Peligro Crítico" (CR) (Mendoza, 2011). 

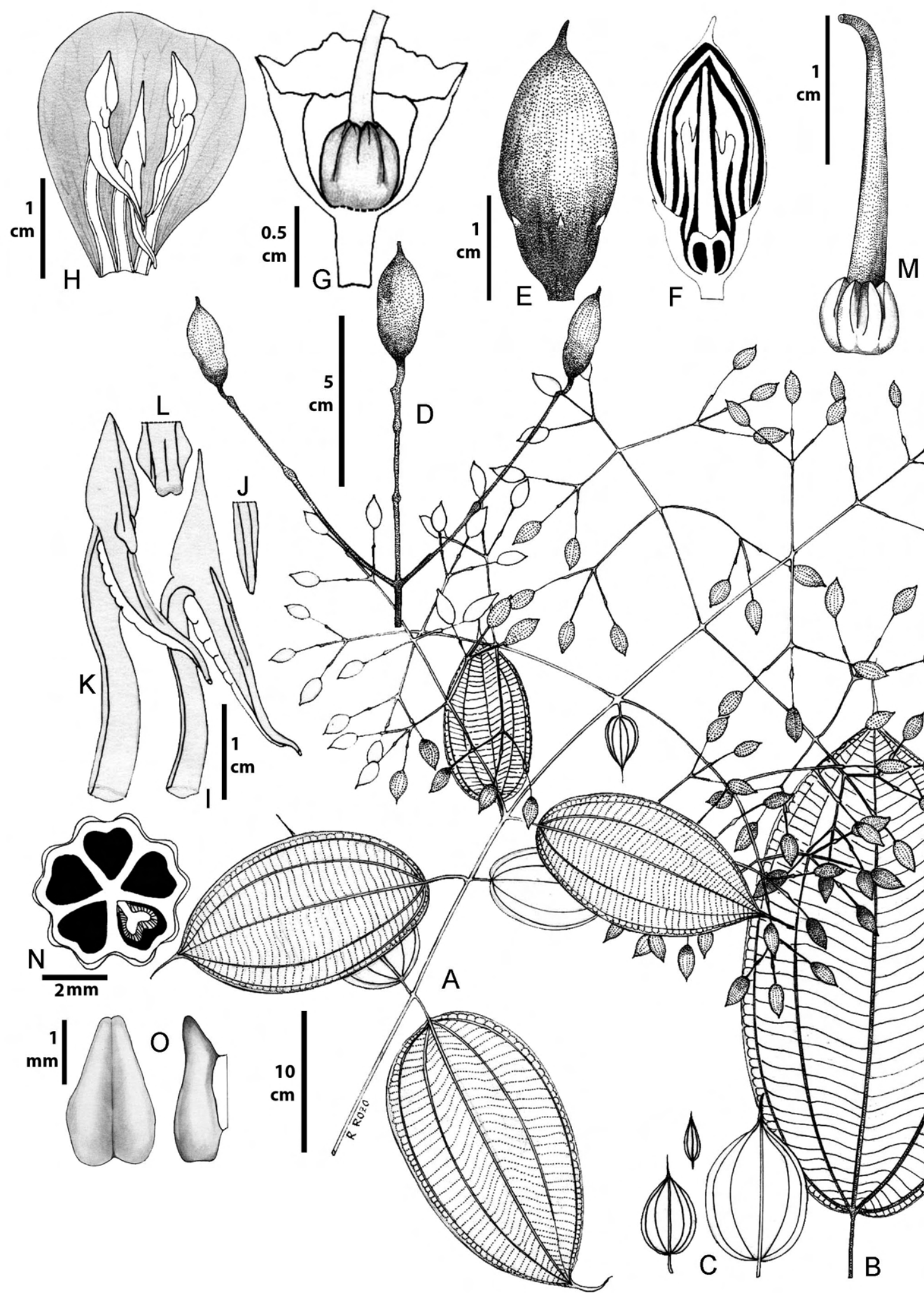

$M$

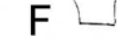




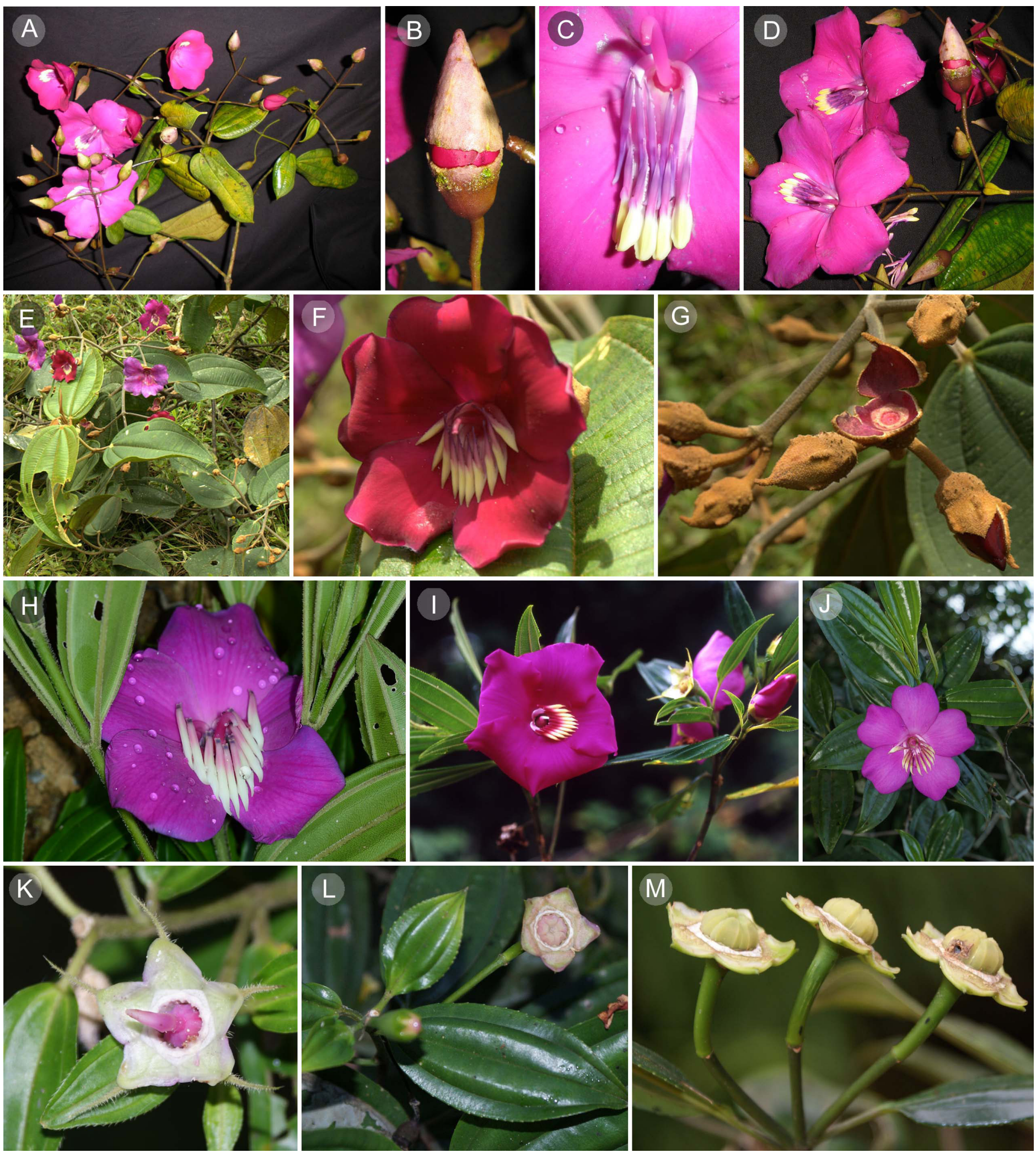

Figura 56: Fotografías de Meriania Sw. de Colombia. A-D. M. selvaflorensis Humberto Mend.; E-G. M. silverstonei Humberto Mend. \& Fern. Alonso; H-M. M. speciosa (Bonpl.) Naudin. Créditos: M. Alvear (A, B, C, D); H. Mendoza (E, F, G, H, J, L, M); F. Nieto (I); W. Ariza (K). 
Material examinado: COLOMBIA. Departamento Caldas, municipio Samaná, corregimiento de Florencia, Parque Nacional Natural Selva de Florencia, 1732 m, 2.III.2011, fl, fr, M. Alvear 1465 (CAS).

Meriania silverstonei Humberto Mend. \& Fern. Alonso, Anales Jard. Bot. Madrid 69(2): 285-289. 2012. Figs. 56EG, 57. TIPO: COLOMBIA. Departamento Valle del Cauca, municipio El Cairo, Reserva Natural La Fontana, trocha de la Quebrada Amarilla, 2100-2400 m, 26-31.V.2008, fl, H. Mendoza 17302 (holotipo: FMB!; isotipos: COL!, CUVC!, FMB!, HUA!).

Árboles 8-30 m de altura; entrenudos subcuadrangulares; ramas, pecíolos y ejes de la inflorescencia con indumento denso a laxo de tricomas esponjosos irregulares diminutos, rufos (tipo 30); hojas con pecíolo 2.2-6.6 cm de largo; lámina 9.7-23 × 6.2-11.3 cm, elíptica, anchamente elíptica u ovado elíptica; base obtusa o redondeada, raras veces levemente peltada; ápice acuminado; margen entero; haz glabro; envés con indumento laxo de tricomas similares a las ramas, en especial sobre la nervadura; nervadura con 2 pares de venas basales acompañando a la vena media; inflorescencia 9-18 cm de largo, con 2-4 nudos de ramificación, 10 a 50 flores; paracladios basales $8-16 \mathrm{~cm}$ de largo; ápice de las ramillas trifloros; flor pedicelada, 5-mera; pedicelo 6-18 mm de largo; hipanto 6.1-9 $\mathrm{mm}$ de largo, hemisférico, externamente con indumento denso de tricomas esponjosos irregulares $0.2-0.4 \mathrm{~mm}$ de largo, con cuerpos verrugosos; pared 1.2-2.5 mm de grosor en la parte media; cáliz caliptrado, caliptra $12-15 \mathrm{~mm}$ de largo, apicalmente obtusa o apiculada, externamente con indumento denso similar al del hipanto; regularmente con dientes dorsales a manera de protuberancias; abre por fisuras irregulares; corola patente; pétalos 17-48 × 15-37 mm; estambres isomorfos, filamento 6.3-13.3 mm de largo; codo 2-4.7 mm de largo, subulado; apéndice conectival 2-3.6 mm de largo, subulado; antera 7-12 mm de largo, subulada sigmoidea, poro dorsal; ovario 6.4-7.1 mm de largo, 5-locular, suborbicular, fusionado en la base con el hipanto 0.5-0.8 mm; ápice con apéndices muy pequeños, levemente dentiformes, $0.5 \mathrm{~mm}$ de largo aproximadamente; placentas 3.7-3.8 mm de largo, obovadas, dorsalmente acanaladas, fibras gelatinosas hiali- nas en medio de los rudimentos seminales, rudimentos en todas las superficies; estilo $15-17 \mathrm{~mm}$ de largo, levemente cónico; estigma puntiforme; cápsula 9-12 mm de largo sin incluir el pedicelo, hipanto leñoso hemisférico de $11-13 \mathrm{~cm}$ de diámetro, cubriendo casi por completo el fruto; fruto propiamente 8-9 mm de diámetro, oblongo; semillas 2-2.6 $\mathrm{mm}$ de largo, cuneiformes, ápice alargado; hilum notorio, un poco más oscuro que la testa.

Notas taxonómicas: la forma alargada del ápice de la semilla en $M$. silverstonei difiere del resto de especies del grupo Brachycera. La forma del ápice de la semilla es un carácter variable en el género Meriania (Mendoza-Cifuentes y Fernández-Alonso, 2011). Las protuberancias (dientes dorsales) en la base de la caliptra pueden variar en esta especie ya que algunos ejemplares del departamento del Valle del Cauca no las presentan. La especie más afín es $M$. ramosii, de la cual difiere notablemente en la forma del ápice del ovario (Fig. 52). Vegetativamente estas dos especies son muy similares, pero $M$. silverstonei tiene pubescencia ferrugínea mientras que $M$. ramosii es glabrescente.

Distribución y hábitat: especie restringida a las cordilleras Occidental y Central de Colombia, en los departamentos Valle del Cauca, Risaralda, Chocó y Antioquia, entre 1400 y 2300 m de elevación en zonas de bosque andino y subandino (Fig. 58). Es más frecuente en la Cordillera Occidental, vertiente Pacífica. Crece en interior de bosque en buen estado de conservación.

Etimología: nombre dedicado al botánico Philip Silverstone Sopkin (1939-2018), profesor quien trabajó en la Universidad del Valle, Cali.

Estado de conservación: categorizada como "Vulnerable" (VU) (Mendoza-Cifuentes y Fernández-Alonso, 2012) y posteriormente recategorizada como "Preocupación Menor" (LC) en la Lista Roja de la IUCN (2020). No obstante, algunos de los registros para esta última propuesta del departamento de Cauca y Antioquia, Colombia, demandan revisión. Es una especie con especificidad de hábitat y los bosques donde se encuentra en los flancos que drenan al río Cauca de las cordilleras Occidental y Central están fuer- 


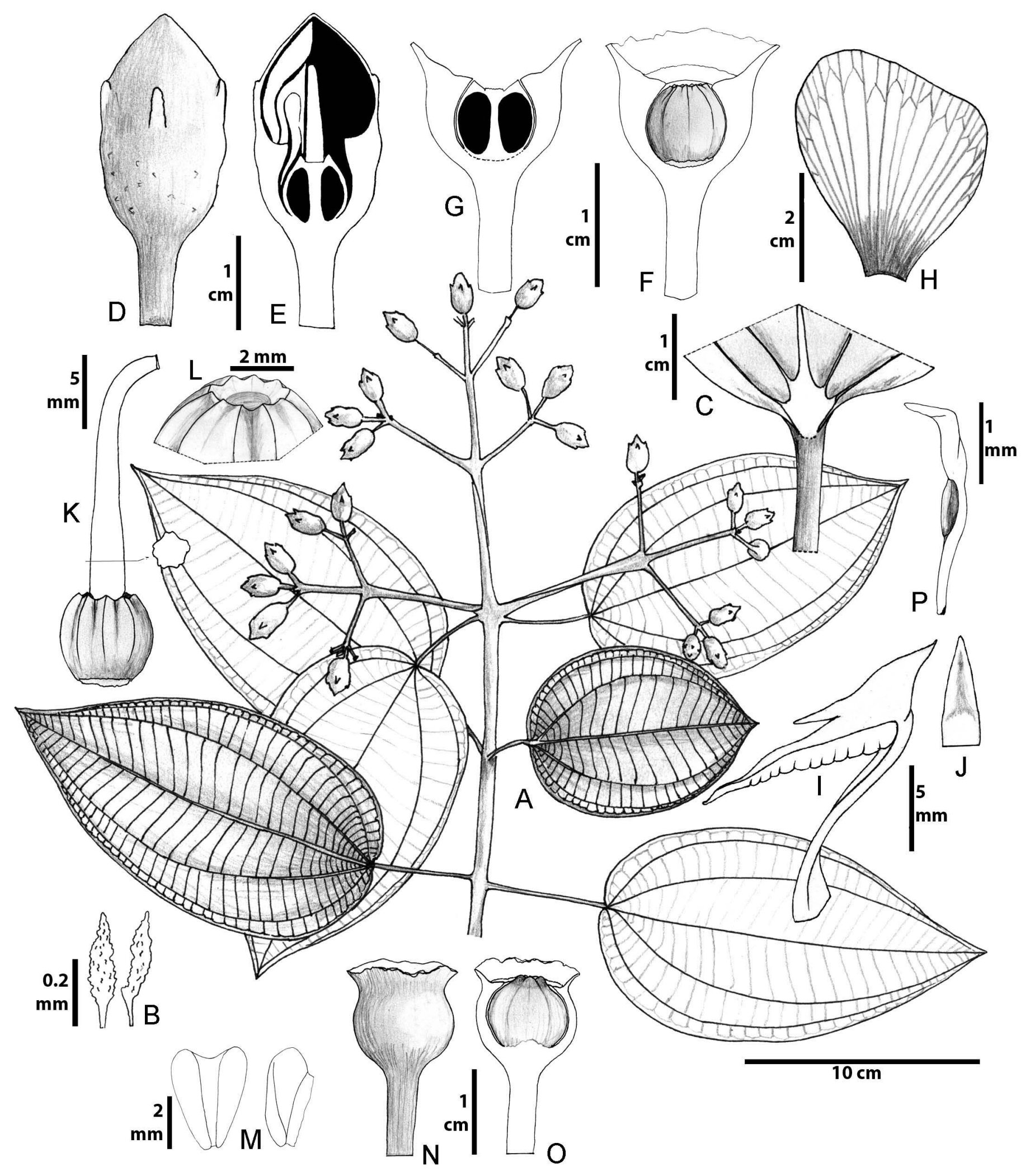

Figura 57: Meriania silverstonei Humberto Mend. \& Fern. Alonso. A. rama florífera; B. tricomas del hipanto; C. base de la lámina foliar por el haz; D. botón floral; E. corte longitudinal del botón floral; F. corte longitudinal del hipanto y vista lateral del ovario; G. corte longitudinal del hipanto y ovario; H. pétalo; I. estambre; J. vista ventral del codo; K. ovario y estilo; L. ápice del ovario; M. vista frontal y lateral de la placenta; N. fruto; O. fruto con corte transversal del hipanto; P. semilla. N, O: Mendoza 14937 (FMB); A-M, P: Mendoza 17302 (FMB); tomada de Mendoza-Cifuentes y FernándezAlonso (2012). 

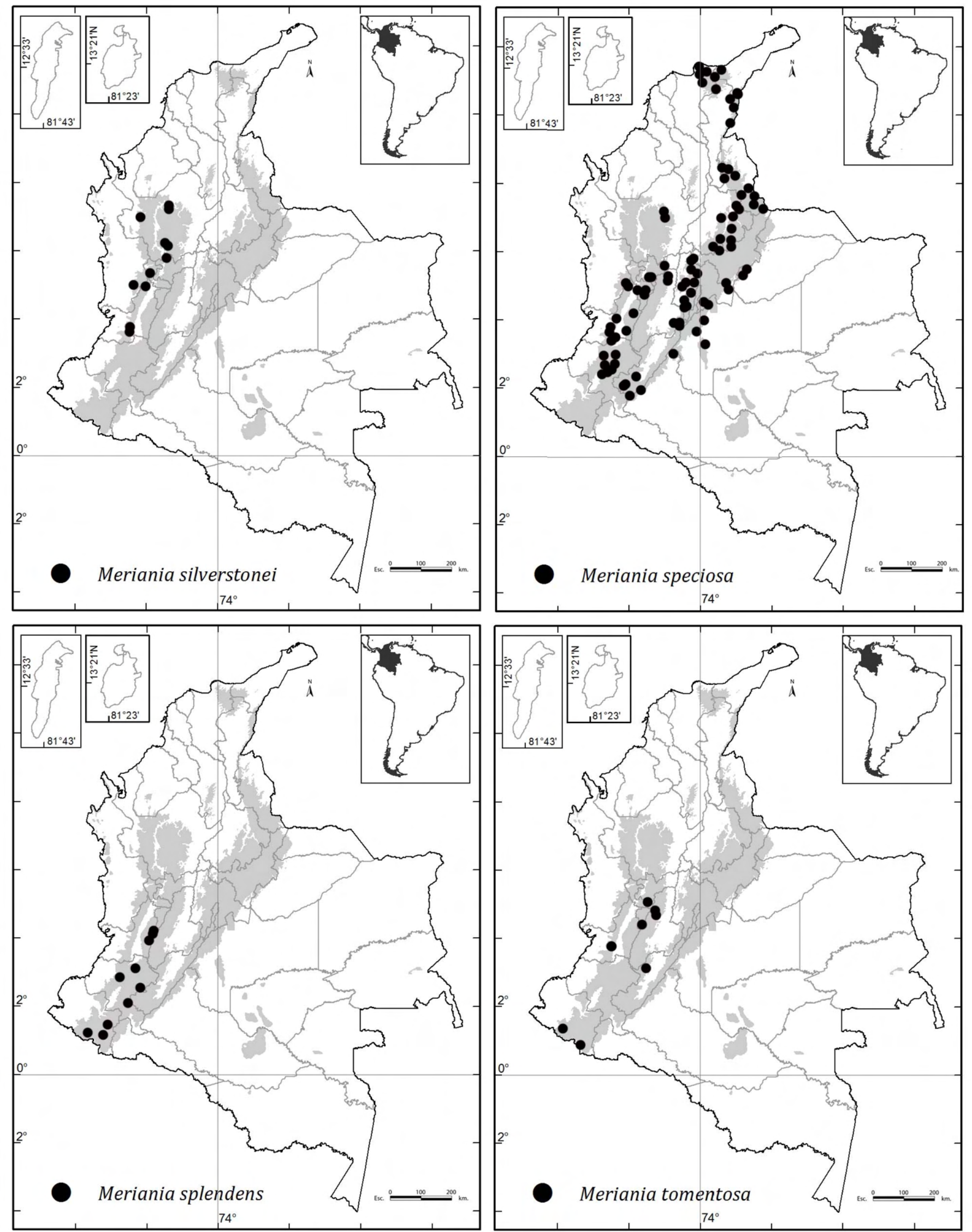

Figura 58: Distribución geográfica de Meriania silverstonei Humberto Mend. \& Fern. Alonso, M. speciosa (Bonpl.) Naudin, M. splendens Triana y M. tomentosa (Cogn.) Wurdack. 
temente fragmentados. Se sugiere considerar la categoría como "Vulnerable" (VU).

Material examinado: COLOMBIA. Departamento Antioquia, municipio Caldas, vereda La Clara, Alto de San Miguel, fl, H. David 2848 (MEDEL). Municipio Frontino, corregimiento de Nutibara, vereda Alto de Cuevas, quebrada del Oso, 1900-2100 m, fl, R. Fonnegra 3554 (HUA); quebrada La Hondita, camino del Retiro a Montebello, 1700 m, 1.III.1975, fl, S. Restrepo s.n. (COL). Municipio Nariño, selvas del municipio, 2000 m, 4.I.1948, fl, L. Uribe 1634 (US). Municipio Valdivia, carretera hacia Briceño, Sector San Fermín, 1900-2100 m, fl, H. David 2247 (HUA). Municipio Yarumal, vereda Corcovado, sector Ventanas, finca Villa Nueva, H. David 2221 (HUA). Departamento Chocó, municipio San José del Palmar, Cerro del Torrá, 1860 m, 4.I.1984, fl, P. A. Silverstone 1508 (CUVC). Departamento Risaralda, municipio Apia, Parque Nacional Natural Tatamá, 2200-2360 m, 26.VIII.2004, st, A. Prieto 2482 (FMB), 2555 (FMB). Departamento Valle del Cauca, municipio Cali, Cordillera Occidental, hoya del río Cali, río Pichindé, entre Quebrada de Juntas y El Recreo, 2070-2260 m, 8.VII.1946, fl, J. Cuatrecasas 22000 (COL, F, NY, US); Cordillera Occidental, entre Las Brisas y La Marina, 1730-1850 m, 27.X.1946, fl, J. Cuatrecasas 22666 (COL, F, NY, US); finca Zíngara, km 18 vía a Buenaventura, 1900 m, 31.I.1994, fl, J. Giraldo 163 (US). Municipio La Cumbre, corregimiento de Bitaco, vereda Chicoral, 2093 m, 23.VII.2003, fl, H. Mendoza 14937 (FMB, HUQ); corregimiento de Bitaco, vereda Chicoral, detrás de Dapa, $1800 \mathrm{~m}$, 24.XI.1990, fl, J. Ramos 3047 (US).

Meriania speciosa (Bonpl.) Naudin, Ann. Sci. Nat., Bot., ser. 3, 18(2): 128, 1852. Figs. 56H-M, 59.

三 Rhexia speciosa Bonpl., Monogr. Melast. 2: 9; t. 4.1823. TIPO: COLOMBIA. Departamento Cauca, municipio Popayán, fl, A. Bonpland 2027 (lectotipo: P 136460!, aquí designado; isolectipos: F!, P 136461!, P136462!, US!).

三 Chaetogastra speciosa (Bonpl.) DC., Prodr. 3: 131, 1828.

= Meriania majalis Benth., PI. Hartw.: 180. 1845. TIPO: COLOMBIA. "Prope Popayán ab incolis Flor de Mayo dicta", fl, K. T. Hartweg 1002 (lectotipo: K!, aquí designado; isolectotipos: BR!, LD!).
= Chastenaea longifolia Naudin, Ann. Sci. Nat., Bot., ser. 3, 4: 55. 1845. TIPO: VENEZUELA. Provincia Caracas, fr, J. Linden 35 (tipo: P!).

= Schwerinia superba Karst., Auswahl Gew. Venez. 1: 12, 1848. TIPO: VENEZUELA. Provincia de Caracas, fl, Moritz 938 (tipo: K!).

= Schwerinia barbinervis Klotzsch ex $\mathrm{H}$. Karst., Auswahl Gew. Venez. 1: 13. 1848. TIPO: VENEZUELA. In montibus Truxillo, fl, Karsten s.n. (tipo: Berlín, desaparecido; lectotipo: $\mathrm{F}$ foto!, aquí designado).

= Meriania barbinervis (Klotzsch ex H. Karst.) Naudin, Ann. Sci. Nat., Bot., ser. 3, 18: 129, 1852.

= Meriania karstenii Naudin, Ann. Sci. Nat., Bot., ser. 3, 18: 128. 1852. TIPO: VENEZUELA. In provincia Americae aequinoctialis dicta Caracas, fl, Linden 1509; Funk (tipo: GENT!). = Meriania macrantha Linden ex Planch., FI. Serres 8; PI. 767, 1852. TIPO: VENEZUELA. (lectotipo: Ilustración PI. 767 !, aquí designado).

इSchwerinia speciosa (Bonpl.) Karst., Fl. Columb. 1: 36, 1859.

= Schwerinia trianae H. Karst., Fl. Columb. 1: 35; t. 18a, 1859. TIPO: Habit ad margines silvarum declivitatis andium Popayanensium circa pagum Insa, 2000-2500 m (lectotipo: ilustración Taf. XIII A., 1, 2 3, 4,5!, aquí designado).

= Meriania umbellata H. Karst., Fl. Columb. 1: 49: t. 24, 1860. TIPO: COLOMBIA. Provincia Bogotá, Ubalá y Gachalá, fl, J. J. Triana 3487 (lectotipo; COL!, aquí designado; isolectotipo: GDC!), syn. nov.

= Meriania grandidens Triana, Trans. Linn. Soc. London 28(1): 65, 1872. TIPO: COLOMBIA. Ocaña, 1846-1852, L. Schlim 666, 776 (sintipo: P 2274670; isosintipos: BR (4) pliegos!, P 2274671!/2274672!, G (2) pliegos!), syn. nov.

$=$ Meriania trianae (H. Karst.) Cogn., Bot. Jahrb. Syst. 8: 19, 1888 , syn. nov.

$=$ Meriania longifolia (Naudin) Cogn., Monogr. Phan. (A. DC. \& C. DC.) 7: 426. 1891, syn. nov.

$=$ Meriania candollei Cogn., in A. DC. \& C. DC., Monogr. Phan. 7: 425, 1891. TIPO: COLOMBIA. In Nova Granate prov. Ocaña ad Pueblo Nuevo, 1800 m, 1846-1852, fl, L. Schlim 253 (lectotipo: $\mathrm{K}$ !, aquí designado; isolectotipos: $\mathrm{BM}, \mathrm{BR}$ tres pliegos!, FI!, G!, MPU dos pliegos, P!), syn. nov.

$=$ Meriania lindenii Cogn., in A. DC. \& C. DC., Monogr. Phan. 7: 427, 1891. TIPO: COLOMBIA. Pamplona ad Chinácota, 


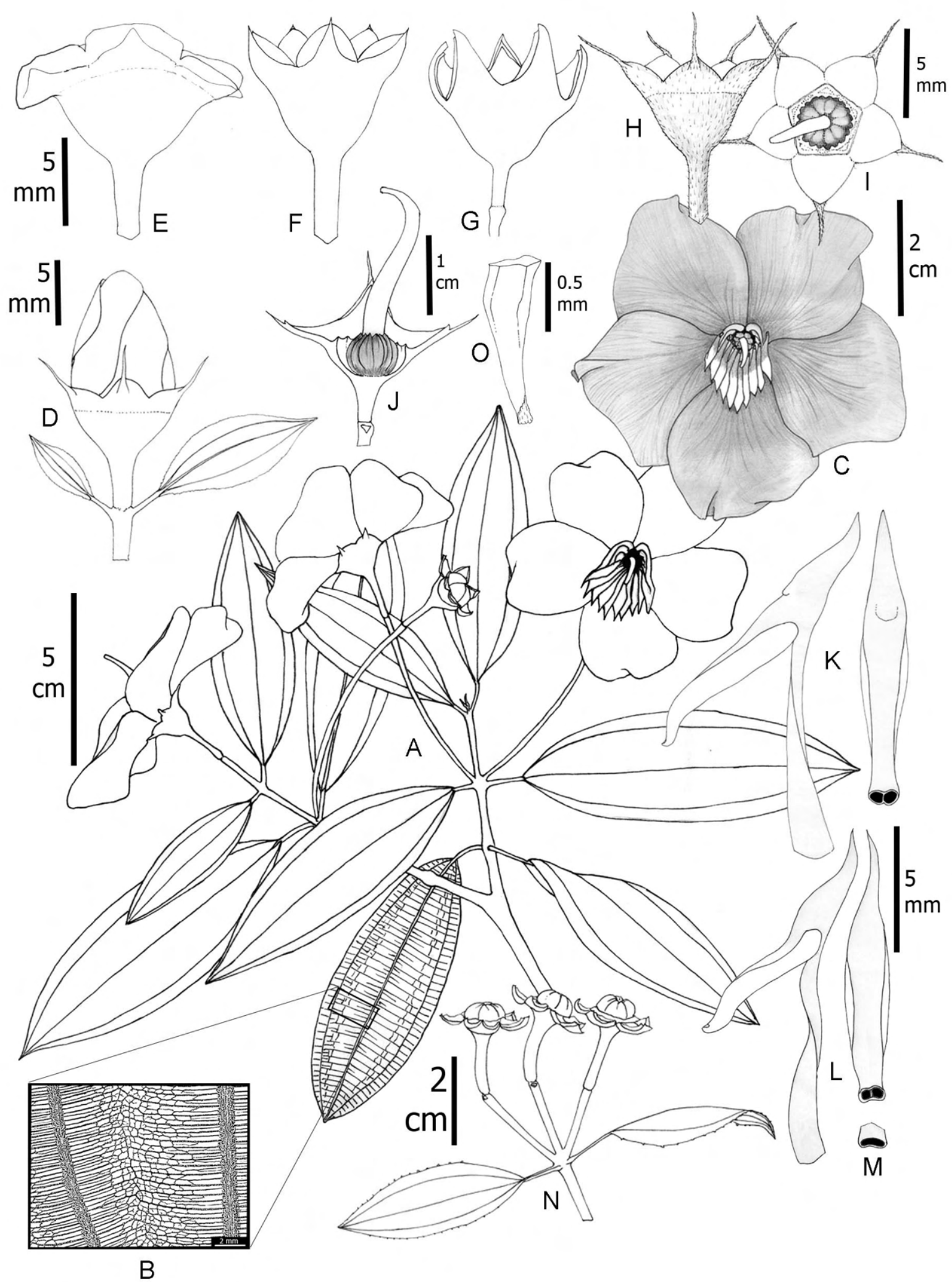

Figura 59: Meriania speciosa (Bonpl.) Naudin. A. rama florífera; B. detalle de la nervadura eritroxiloide por el envés; C. flor; D. botón floral; E, F, G, H. vista lateral del hipanto-cáliz; I. vista superior del hipanto-cáliz; J. corte longitudinal del hipanto y vista lateral del ovario y estilo; K, L. vista lateral y superior del estambre; M. ápice de la antera en vista dorsal; N. rama con frutos; O. semilla. A, B: fotos Sierra Nevada de Santa Marta; C: foto de campo; D, H, I: Yépes 197 (COL); E: Berrit 1435 (CAS); F: Uribe 3790 (COL); G: Cuatrecasas 12370 (COL); J: Mendoza 4097 (FMB); K: Teran 3114 (CAS); L: Sneidern 4815 (CAS, US); M: Betancur 6186 (FMB); N: Uribe 6338 (COL); O: Mendoza 15017 (FMB). 
1000 m, fl, J. Linden 761 (lectotipo: K!, aquí designado; isolectotipo: MPU!), syn. nov.

= Meriania spruceana Cogn., in A. DC. \& C. DC., Monogr. Phan. 7: 426. 1891. TIPO: PERÚ. Municipio Tarapoto, in monte Campana, 1856, fl, R. Spruce 4204 (holotipo: K; isotipos: BR (2) pliegos!, C!, E!, F foto!, G!, GH!, LD!, P!, NY!, TCD!).

= Meriania longifolia var. spruceana (Cogn. ex DC.) Cuatr., Trab. del Mus. Nac. de Cienc. Nat. de Madrid 33: 93. 1936, syn. nov.

= Meriania longifolia var. spruceana (Cogn.) J.F. Macbr., Field Mus. Nat. Hist., Bot. Ser. 13 (4): 309. 1941, comb. superfl.

Arbustos o árboles 2-20 m de altura; entrenudos teretes a subcuadrangulares; plantas glabras o con indumento denso a ralo sobre las ramas, pecíolo, envés, inflorescencia e hipanto; tricomas filiformes de superficie alveolada (tipo 12), retorcidos o levemente rígidos, $0.5-2 \mathrm{~mm}$ de largo; hojas con pecíolo $0.5-1.5 \mathrm{~cm}$ de largo; lámina 4-16 × 1.5-7 cm, elíptica, estrechamente elíptica, oblongo-elíptica u ovada, textura delgado coriácea; ápice obtuso, agudo o levemente acuminado; base aguda, obtusa o raras veces redondeada; margen denticulado, serrado o setuloso; haz glabro o con indumento ralo de tricomas similares a los de las ramas; envés glabro o con indumento de tricomas filiformes retorcidos sobre la nervadura similares a los de las ramas; nervadura con un par de venas acompañando a la vena media, basales; nervadura terciaria no prominente, a manera de líneas, abundantes, las que se encuentran entre la vena media, las secundarias se reticulan en la parte media generando una área semejante a una línea de prefoliación; inflorescencia uniflora o triflora, con proliferación vegetativa; brácteas y bractéolas semejantes a hojas, pero más pequeñas; flor pedicelada, 5-mera; pedicelo 2.5-11 $\mathrm{mm}$ de largo; hipanto 4-8 mm de largo, ciatiforme, internamente con ribetes, externamente glabro o con indumento de tricomas filamentosos o subulados, de textura cartácea, en ocasiones puede ser leñoso; torus levemente ondulado hasta dentado; cáliz con tubo 1.1-2.5 mm de largo; lóbulos 1-14.5 mm de largo, anchamente triangulares, acrescentes en el fruto; diente dorsal inexistente, anchamente triangular o filiforme-subulado, sobresaliendo 1-7 mm del lóbulo; corola patente; pétalos $25-47 \times 17-53 \mathrm{~mm}$, obovados, apicalmente truncado emarginados, glabros, fucsia oscuro; estambres isomorfos, filamento $6.8-14 \mathrm{~mm}$ de largo; codo 3-7 mm de largo, triangular, algunas veces bífido en la punta; conectivo dorsal sin apéndices, abultado o en ocasiones con un apéndice dentiforme hasta $0.5 \mathrm{~mm}$ de largo; antera 6-11 mm de largo, sigmoidea, 1-2 poros dorsales; ovario 5.5-6 mm de largo, 5-locular, ovoide a globoso, completamente súpero; ápice con dientes truncados o algunas veces largamente fimbriados, rodea la base del estilo $0.5-1 \mathrm{~mm}$ de largo; placentas $2 \mathrm{~mm}$ de largo, obovadas, con rudimentos seminales en todas las superficies; estilo $10-19 \mathrm{~mm}$ de largo, cilíndrico, curvo en el ápice; estigma puntiforme o levemente expandido, papiloso; cápsula globosa encerrada holgadamente por el cáliz acrescente; semillas 0.7-2 mm de largo, cuneiformes con ápice corto; rafe no visible.

Notas taxonómicas: para Meriania speciosa se han establecido 22 nombres que ahora son sinonimias. Es una especie de amplia distribución descrita múltiples veces donde han estado involucrados 11 taxónomos: Naudin, de Candolle, Klotzsch, Karsten, Triana, Cogniaux, Linden, Bonpland, Bentham, Macbride y Cuatrecasas.

Esta especie es la de mayor área de distribución de todo el género junto con $M$. macrophylla. El conjunto de caracteres que la sustenta comprende las inflorescencias unifloras o trifloras y con proliferación vegetativa (con proliferación de hojas en las yemas apicales del vástago dando la apariencia de flores axilares), corola patente con pétalos fucsia, los estambres isomorfos y la forma de la nervadura terciaria aledañas a la vena media que es muy reticulada en su parte media (eritroxiloide). Este último caracter solo lo presentan algunas especies antillanas que no se encuentran en Suramérica.

Las especies sinonimizadas $M$. grandidens y $M$. longifolia difieren de $M$. speciosa en la ausencia de indumento de tricomas filamentosos en la mayoría de las estructuras y el desarrollo de lóbulos y dientes dorsales del cáliz. En el caso de las colecciones asignadas a M. grandidens, los lóbulos del cáliz son anchamente triangulares y el diente dorsal es tan grande como el lóbulo. En el caso de $M$. longifolia, los lóbulos son desarrollados, el diente dorsal subulado pero corto y regularmente no excede conspicua- 
mente la longitud del lóbulo. Los caracteres de ápice del cáliz y los tipos de indumentos son variables y tienen una gradación continua en los ejemplares estudiados en Colombia y Venezuela, por lo que son caracteres poco robustos para mantener las tres especies separadas. Hay un buen número de ejemplares, especialmente en los Andes centrales de Colombia al igual que en la Sierra Nevada de Santa Marta, con estados intermedios en el caso de los indumentos, el desarrollo de lóbulos y dientes dorsales del cáliz, que hace muy difícil definir a cuál de las tres especies pertenece. Esta ambigüedad es un claro ejemplo de lo poco práctico que son los conceptos que circunscriben a este grupo de especies, por lo que no es útil mantenerlas separadas.

Por otro lado, la definición de subespecies es una alternativa, pero igualmente hay muchos ejemplares de caracteres intermedios que no permiten una correspondencia geográfica definida, por lo que lo mejor es mantener solo una especie ampliamente variable.

Distribución y hábitat: especie de amplia distribución en las tres Cordilleras en Colombia, Sierra Nevada de Santa Marta y Serranía de La Macarena, entre 420 y 2800 m de elevación (Fig. 58). También se encuentra en Venezuela, Ecuador y norte de Perú. Crece en zonas de bosque subandino y andino, en interior de bosque en regeneración, bordes de caminos y zonas abiertas.

Etimología: en alusión a la vistosidad de sus flores (speciosus=esplendido).

Estado de conservación: esta es la especie de Meriania más abundante en Colombia y prácticamente se encuentra en todo el norte de los Andes, con una EOO de ca. $280,000 \mathrm{~km}^{2}$ y AOO de $4000 \mathrm{~km}^{2}$. Es frecuente en bordes de caminos y zonas intervenidas. Con base en su amplia distribución y abundancia se sugiere su categoría como "Preocupación Menor" (LC).

Material examinado: COLOMBIA. Departamento Antioquia, municipio Amalfi, quebrada Guayabito, $1600 \mathrm{~m}$, 14.II.1993, fl, D. Tuberquia 131 (COL). Municipio Anorí, Porce II, limites Reserva El Arriero de Proaves, 1740 m, 21. XI.2010, C. Vargas 1867 (COL). Departamento Arauca, mu- nicipio Arauca, carretera entre Saravena y Toledo, $1300 \mathrm{~m}$, 7.X.2011, fl, S. Hoyos 1309 (COL). Departamento Boyacá, municipio Arcabuco, Cañón del Río Pómeca, 2400 m, 15. IV.1997, st, H. Mendoza 3145 (FMB). Municipio Duitama, corregimiento El Carmen, carretera El Carmen - Virolín, 2300-2500 m, 4.VI.1995, fl, J. Betancur 6186 (COL, FMB). Municipio Pajarito, carretera de Sogamoso a Casanare, km 96, 1500 m, 12.XII.1969, fl, L. Uribe 6338 (COL). Municipio Puerto Boyacá, El Humbo, 3000 ft, 24.IX.1932, fl, A. E. Lawrance 467 (MO, US). Municipio Santa María, Carretera Santa María - Bogotá, cercanías del embalse de Chivor, sector Cascada setenta, 1200-1300 m, 26.IV.2005, fr, J. Betancur 11629 (COL, FMB). Departamento Caldas, municipio Pensilvania, vereda La India, 2000 m, 22.II.1990, fl, M. Álvarez 1358 (COL); entre Manizales y Chinchiná, 1800 m, II.1946, fl, M. Duque-Jaramillo 2645 (COL). Departamento Caquetá, municipio desconocido, $41 \mathrm{~km} \mathrm{~N}$ of Florencia, 1060 m, 12.I.1974, fl, A. Gentry 9171 (COL, MO, US). Municipio San Vicente del Caguán, Parque Nacional Natural Los Picachos, cuenca alta del Río Pato, 1700 m, 15.XI.1997, fl, H. Mendoza 4076 (FMB); Parque Nacional Natural Los Picachos, Cuenca alta del Río Pato,1600 m, 15.XI.1997, fl, $H$. Mendoza 4097 (FMB). Departamento Casanare, municipio Tauramena, Cordillera Oriental, vertiente oriental, Alto de La Cruz, 1600 m, 5.XII.1961, fl, L. Uribe 3932 (COL). Departamento Cauca, municipio Caldono, vereda El Cidral, microcuenca del río Cabuyal, 1665 m, 20.IV.1995, fl, M. Diago 58 (COL). Municipio El Tambo, Parque Nacional Natural Munchique, bajada al refugio de La Gallera, km 81, $1700 \mathrm{~m}$, 19.VII.1993, st, G. Lozano 6487 (FMB, PSO). Municipio Popayán, 1700 m, 3.IX.1944, fl, K. Von Sneidern 4845 (COL, PSO, VALLE). Municipio Timbio, cuenca Wëtüu, Jardín Botánico de Popayán, 1850 m, 8.VI.1999, fl, F. Güetio 154 (COL). Municipio Tunía, 1850 m, 7.IV.1970, st, L. S. Espinal 3885 (CUVC); El Guayabo, finca La primavera, quebrada Bermejal, Cordillera Central, flanco occidental, 1650 m, 13.V.1964, fl, López-Figueras 8516 (VALLE). Departamento Cesar, municipio Agustín Codazii, Serranía de Perijá, vereda Rancho Bejuco, 1380 m, 4.VI.1994, fl, O. Rangel 12878 (COL). Municipio Chimichagüa, El Carmen, 1450-1500 m, fl, J. M. Campo-Kurmen 1610 (FMB). Municipio La Paz, vereda Altos de Perijá, 2600 m, 18.VII.2006, fl, C. Barbosa 16285 (UTMG); Municipio Río de Oro, vereda Garaguya, 1800 m, 30.III.2008, 
fl, C. Estupiñán 170 (COL). Departamento Chocó, municipio San José del Palmar, vereda El Tabor, 1450-1550 m, 17.I.1983, fl, S. Díaz-Piedrahita 3678 (COL). Departamento Cundinamarca, municipio Albán, Vereda Las Marías, granja El Gran Ciudadano, 1800-2100 m, 28.IV.2003, fl, C. Castellanos 11 (COL). Municipio Medina, Farallones de Medina, 2000 m, 25.II.1997, fl, H. Mendoza 2648 (FMB). Municipio Nilo, inspección de Pueblo Nuevo, finca La Tauramena, 1200-1560 m, fl, J. H. Tórres 710 (COL). Municipio Quetame, al occidente de la población, 1600 m, 28.XI.1963, fl, L. Uribe 4620 (COL). Municipio Sasaima, San Bernardo, vereda Portones, 1650 m, 28.VII.1981, fr, S. Díaz-Piedrahita 3270 (COL). Departamento Huila, municipio Icononzo, 1000-1200 m, 1.XII.1917, fl, F. W. Pennell 2798 (NY, US). Municipio La Argentina, Serranía de Minas, quebrada Negra, $2550 \mathrm{~m}$, 16.XII.2005, fl, J. Contreras 266 (COL); from Acevedo to Alejandría, km 20 S, 4800 ft, 16.VIII.1944, fl, E. L. Little Jr. 8492 (US). Municipio Palestina, vereda Santa Bárbara, finca La Esperanza, 1550 m, 26.X.2005, fl, A. Silva 397 (COL, CUVC, FMB). Muicipio San Agustín, parque arqueológico, 16001700 m, 7.XII.1957, fl, fr, R. Romero-Castañeda 6701 (COL). Departamento La Guajira, municipio Manaure, Serranía de Perijá, El Cinco, 2648 m, 16.XI.1993, st, M. Pardo 385 (COL), O. Rangel 11378-A (COL); Serranía de Perijá, corregimiento de Manaure, Sabana Rubia, 2500 m, 5.III.1959, fr, R. Romero-Castañeda 7444 (COL). Municipio Pueblo Viejo, Sierra Nevada de Santa Marta, Sierra de San Antonio, 2000 m, 11.II.193, fl, H. Cuadros 1459 (MO); Sierra Nevada de Santa Marta, entre Riohacha y Pueblo Viejo, 1000 m, 6.Il.1959, fl, fr, H. G. Barclay 6861 (CAS, COL, MO, US); Sierra Nevada de Santa Marta, vertiente río Cañas, 700-1000 m, 19.VIII.1986, fl, fr, H. Cuadros 2933 (MO); Sierra Nevada de Santa Marta, 4000 ft, II-1898-1901, fl, H. Smith 382 (COL, MO, US). Departamento Magdalena, municipio Ciénaga, La Reserva, 1400 m, 22.VII.1992, fl, E. Carbonó 2655 (UTMG); San Pedro de la Sierra, vereda Palmichal, 1600m, 21.IX.1992, fl, E. Carbonó 2810 (UTMG). Municipio Santa Marta, Corregimiento de Minca, Sierra Nevada de Santa Marta, Cuchilla San Lorenzo, Reserva Natural de Aves El Dorado, 1985-2060 m, 23.I.2011, fl, F. Almeda 10169 (CAS); Bonda, 16.XI.1995, fl, E. Carbonó s.n. (UTMG). Departamento Meta, municipio Cubarral, vereda Aguas Claras, alrededores de la escuela Aguas Claras, 855 m, 19.XI.1995, fl, E. Morales 599 (COL).
Municipio Macarena, Monte Macarena, 3900-4000 ft, 21.I.1942, fl, T. Gilliard s.n. (NY); Sierra de La Macarena, extremo nordeste, Macizo Rengifo, 600-1300 m, 30.XII.1950, fl, J. M. Idrobo 889 (COL), 897 (COL); loc. cit., 1300-1900 m, 6.I.1951, fl, J. M. Idrobo 1081 (COL); Sierra de La Macarena, central mountains, entrada ridge, $1000 \mathrm{~m}, 25.1 .1950, \mathrm{fl}, \mathrm{W}$. R. Philipson 2242 (COL). Departamento Norte de Santander, municipio Cucutilla, Vereda Carrizal, Parque Natural Regional Sisavita, 2400 m, 28.II.2012, fl, F. Almeda 10568 (CAS, COL). Municipio Herrán, Parque Nacional Natural Tamá, sector Orocué, 2400 m, 20.VI.1999, fl, H. Mendoza 7187 (FMB). Municipio La Playa de Belén, Santuario de Flora y Fauna Los Estoraques, 1650 m, 5.IV.2001, fl, R. Galindo 397 (COL, HECASA); carretera de Abrego a Sardinata, río Tarra, 1100-1400 m, 27.V.1969, fl, H. García-Barriga 19954 (CAS, COL, US). Municipio Ocaña, pozo Alto Dinde, $10000 \mathrm{ft}$, VI1948, fl, C. Sandeman 6104 (COL). Departamento Quindío, municipio Armenia, vereda Tigreros, 1450 m, 18.V.1998, fl, D. Macías 854 (COL); loc. cit., I.1956, fl, E. Pérez- Arbeláez 10331 (COL). Municipio Circasia, La Balastrera, 1610 m, 30.V.1981, fl, J. Osorio 7 (COL). Municipio Filandia, vereda Las Cruces, finca El Palacio, 1828 m, 18.VI.2002, st, J. Mendoza 877 (FMB). Departamento Santander, municipio Encino, RN Cachalú, 2000 m, 15.III.1999, st, H. Mendoza 7119 (FMB). Municipio Mesa de Los Santos, 1500 m, 11.XII.1926, fl, E. P. Killip 15284 (US). Municipio San Vicente de Chucurí, Parque Nacional Natural Yariguíes, 1984, fl, R. Ardila 172 (FMB), 177 (FMB). Municipio Suaita, Inspección de San José de Suaita, 1600 m, 11.XI.1998, fl, G. Galeano 6163 (COL). Municipio Tona, vereda Guamales, 2096 m, 30.X.2003, fl, B. Quirós 143 (COL). Deapartamento Tolima, municipio Falán, región de Calamonte 1120 m, 7.XII.1939, st, H. García-Barriga 8298 (COL). Municipio Ibagué, monte Escuela de Agricultura de San Jorge, 20.V.1963, fl, R. Echeverry 723 (COL); between San Agustín to Prado, near Río Negro, $3500 \mathrm{fl}$, ft, 26.II.1944, fl, E. L. Little Jr. 7355 (COL); El Convenio, west of San Lorenzo, 1000-1200 m, 20.XII.1917, fl, fr, F. W. Pennell 3470 (MO, US); Provincia de Mariquita, 2000 m, I-1853, fl, J. J. Triana 3853 (COL). Departamento Valle del Cauca, municipio Cali, corregimiento La Elvira, finca Los Sauces km 4 on the road to Dapa, 1875 m, 2.II.2011, fl, F. Almeda 10219 (CAS); Cordillera Occidental, Farallones de Cali, 2-4 km abajo del pueblo de Pance a lo largo del río Pance, 1500 m, 
4.XI.1975, fl, Dan Hartman 32 (CUVC); veredera Pico de Águila, 1600 m, 16.IV.1992, fr, M. Gamboa 84 (CUVC); km 23 vía al mar, 2100 m, 8.VIII.1978, fl, L. Naranjo 1 (CUVC). Municipio El Cairo, vereda El Madroño, Reserva Natural El Pital, Serranía Los Paraguas, 24.I.2007, D. MontoyaDossman 79 (CUVC). Municipio La Cumbre, Bitaco, eastern slope above the Bitaco river, Bitaco Valley $1 \mathrm{~km}$ above and east of Bitaco, 4500 ft, 16.XI.1963, fl, P. C. Hutchison 3001 (COL). PERÚ. Departamento San Martín, municipio Jepelacio, near Moyobamba, 1100 m, V.1934, fl, G. Klug 3642 (MO). VENEZUELA. Estado Falcon, Sierra de San Luis, montaña de Paraguariba, en la vecindad del salto afluente al Río Seco, entre Hotel Parador y Curimagua, aprox. $5 \mathrm{~km}$ al este del Hotel Parador, 1300 m, 21.VII.1967, st, J. Steyermark 99346 (COL). Estado Táchira, $12 \mathrm{~km} \mathrm{~N}$ of Cordero, $1540 \mathrm{~m}$, 31.III.1974, fl, A. Gentry 11092 (COL); hwy 9, 23 km S of Rubio, Matamulas area, $1750 \mathrm{~m}, 28.1 .1978$, fl, J. Luteyn 5292 (COL). Estado Trujillo, Sierra Trujillo, 4-5 km along old Boconó - Trujillo road, 2200 m, 5.IX.1973, fl, S. S. Tillett 739578 (COL).

Meriania splendens Triana, Trans. Linn. Soc. London 28(1): 65. 1872. Figs. 60, 61A-D. TIPO: COLOMBIA. Provincia de Popayán, Quilcasé, 2000 m, 1851-1857, fl, J. J. Triana s.n. (3858) (lectotipo: K!, aquí designado; isolectotipos: $\mathrm{BM}$ !, COL!, GDC!, P!).

Árboles 3-15 m de altura; entrenudos de ramas jóvenes cuadrangular sulcados con aristas anguladas; nudos triangularmente anchos, línea interpeciolar laminar 3-6 mm de ancho; ramas, pecíolos e inflorescencia con indumento furfuráceo ralo o denso de tricomas esponjosos irregulares con ramas delgadas 0.4-0.5 mm de largo (tipo 30); ramas basales tienden a ser glabras; hojas con pecíolo $2.2-9 \mathrm{~cm}$ de largo; lámina 12.5-26 × 8-18.5 cm, anchamente ovada; ápice agudo a obtuso; base cordada o menos frecuente redondeada; margen entero a fuertemente dentado; haz glabro; envés pubérulo o pubescente furfuráceo sobre las venas, tricomas similares a los de las ramas; nervadura con 3 (raras veces 2 ) pares de venas que acompañan a la vena media más un par submarginal que no alcanza el ápice, basales o levemente plinervias; inflorescencia $23-35 \mathrm{~cm}$ de largo, 30 a 70 flores; pedúnculo 8-10 cm de largo; eje central con 3-4 nudos de ramificación; paracladios $8-10 \mathrm{~cm}$ de largo, con 2-3 niveles de ramificación; ramillas con ápices trifloros o con múltiples flores apicales por la reducción de ejes; flor pedicelada, 5-mera; pedicelos 10-15 mm de largo; hipanto 7-13 mm de largo, campanulado o cilíndrico, externamente glabro a pubérulo con tricomas similares a los de las ramas; torus 2-2.4 mm grosor; cáliz truncado o raras veces con anchos lóbulos de máximo $3 \mathrm{~mm}$ de largo; tubo 3-5.3 $\mathrm{mm}$ de largo; dientes dorsales inexistentes o a manera de protuberancias; corola patente; pétalos 37-70 × 35-50 mm, obovados, con ápice truncado emarginado, glabros, fucsia oscuro; estambres isomorfos, filamento $10.8-23 \mathrm{~mm}$ de largo; codo 2.3-5 mm de largo, triangular subulado; apéndice conectival dorsal 2-4 mm de largo, subulado; antera 7.8$13 \mathrm{~mm}$ de largo, sigmoidea, poro dorsal; ovario 6.5-7.5 mm de largo, 5-locular, ovoide, fusionado al hipanto en la base 1-1.3 mm; ápice con leves lóbulos dentiformes rodeando la base del estilo 0.5-0.8 mm; placentas $3.5 \mathrm{~mm}$ de largo, ovoides, rudimentos seminales en todas las superficies; estilo $13.8-21 \mathrm{~mm}$ de largo, columnar; estigma puntiforme; cápsula $15-25 \mathrm{~mm}$ de largo sin incluir el pedicelo, urceolada; semillas 2.4-2.8 mm de largo, cuneiformes con ápice corto; parte del embrión notoria, más oscura que la testa.

Notas taxonómicas: esta especie se reconoce por los nudos engrosados triangularmente y con línea interpeciolar laminar, el indumento furfuráceo en ramas y envés, las grandes inflorescencias paniculadas, cáliz truncado y sin dientes dorsales, pétalos entre 3.5-4.5 cm de largo y estambres isomorfos. La especie más semejante es M. maxima, que puede encontrarse en la misma zona de los Andes, pero en altitudes inferiores. Para las diferencias de estas dos especies vea los comentarios de M. maxima.

Distribución y hábitat: especie endémica a Colombia en los departamentos Nariño, Cauca y Valle del Cauca, en zonas de bosque andino y altoandino entre 2000 y 3300 m de elevación (Fig. 58). Crece en bosque en buen estado de conservación.

Nombres vernáculos: Triana documenta el nombre "tulipán" en el ejemplar tipo (Cauca). En el departamento Cauca es conocida como "maya", "sietecueros" y "mortiño 


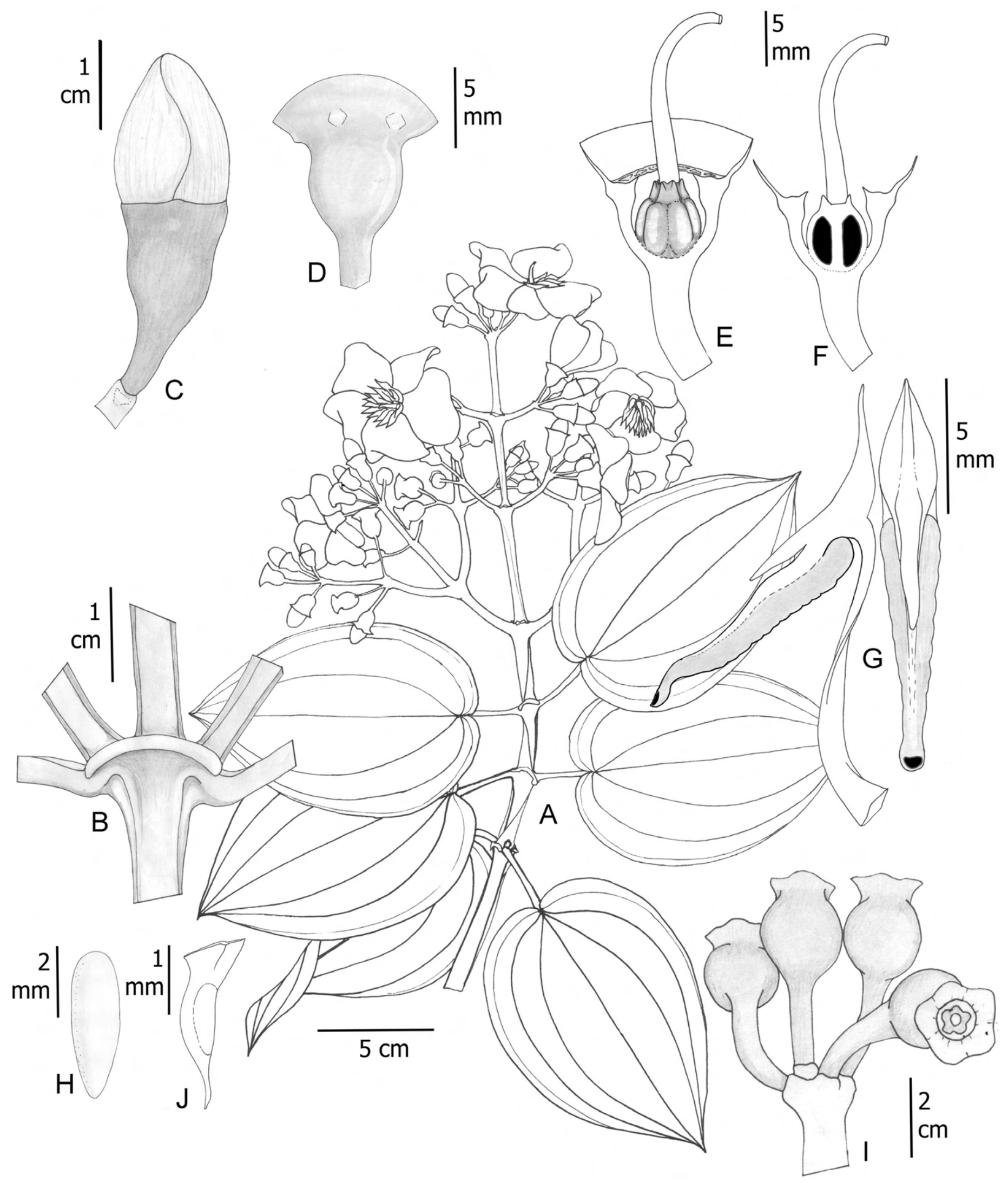

Figura 60: Meriania splendens Triana. A. rama florífera; B. detalle de un nudo mostrando línea interpeciolar laminar; C. botón floral; D. hipantocáliz; E. corte longitudinal del hipanto y de la vista lateral del ovario-estilo; F. corte longitudinal del hipanto y ovario; G. estambres en vista lateral y superior; H. placenta en vista dorsal; I. frutos; J. semilla. A: Ramírez 17215 (CAUP); B, C: Hernández 132 (COL); D, E, F, H: Ewans 16545 (CAS); G, J: Idrobo 3977 (COL); I: Plowman 5311 (COL). 

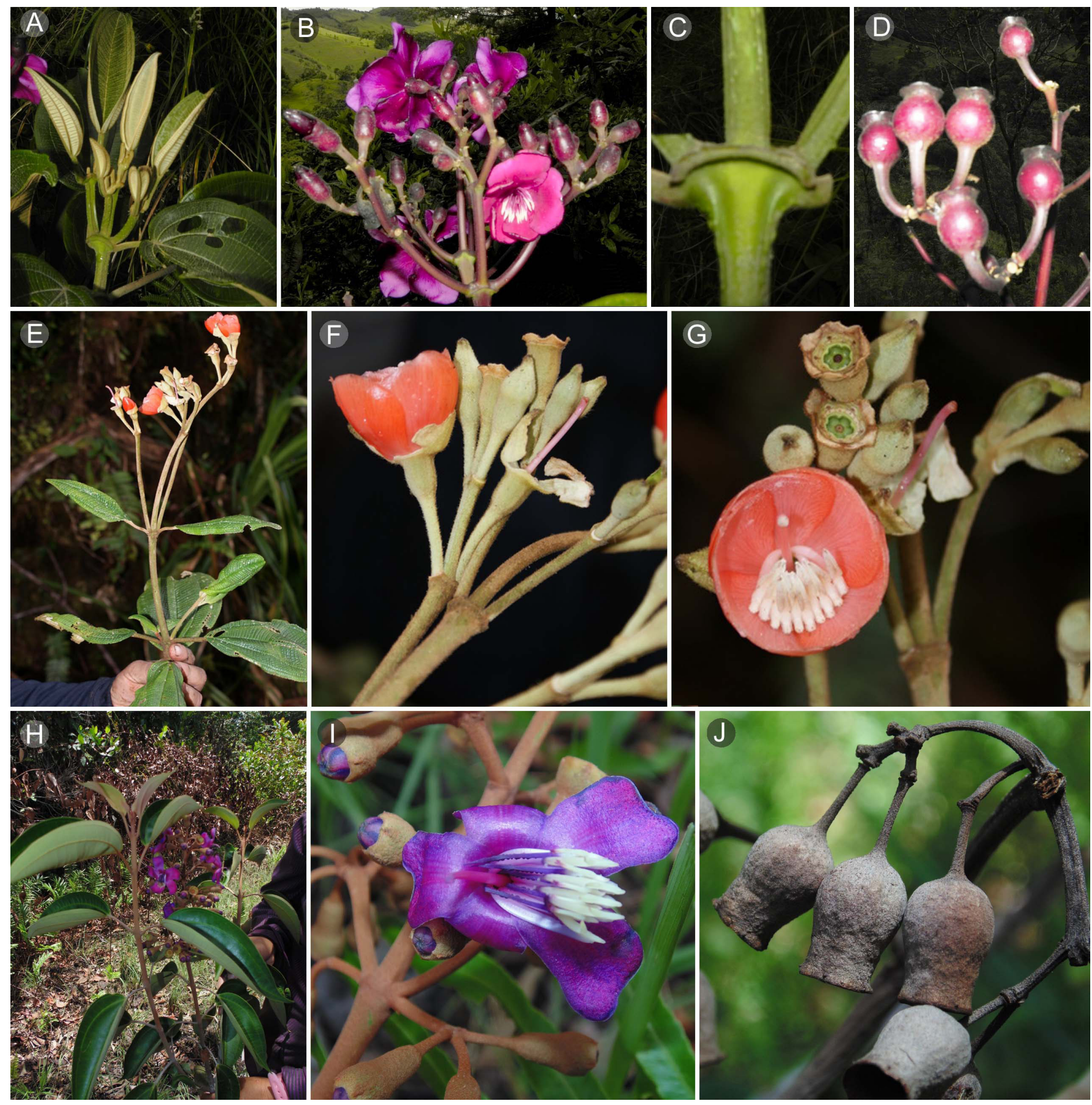

Figura 61: Fotografías de Meriania Sw. de Colombia. A-D. M. splendens Triana; E-G. M. tomentosa (Cogn.) Wurdack; H, I, J. M. urceolata Triana. Créditos: M. Alvear (A, B, C, D); H. Mendoza (E, F, G, H, I, J). 
gigante". En Nariño la llaman "carbunquillo" y utilizan sus flores en infusión para tratar la caspa.

Etimología: en alusión a su hermosura o magnificencia en floración.

Estado de conservación: categorizada como "Preocupación Menor" (LC) en la Lista Roja de la IUCN (2020). Tiene un EEO de ca. 24,000 km², AOO de ca. $20 \mathrm{~km}^{2}$ y se conoce de 10 localidades; además, en el área de distribución han operado fuertes procesos de deforestación que han reducido la franja de vegetación de bosque Andino. Cumple los criterios para su categorización como "Vulnerable" (VU) bajo los criterios B2ab(ii).

Material examinado: COLOMBIA. Departamento Cauca, municipio Almaguer, vereda Riñonada, alrededores de La Cuchilla, 2750-2850 m, 27.VIII.2003, fl, B. Ramírez 17215 (CAUP, COL). Municipio El Tambo, Cordillera Occidental, Charco Azul, VI.1971, fl, L. Uribe 6555 (COL, NY, US). Municipio Popayán, corregimiento de Quintana, 2750-2940 m, 16.II.2003, fl, H. Navia 95 (CAUP); Canaan, Mt. Puracé, 3100-3300 m, 11.VI.1922, fl, E. P. Killip 6708 (NY, US). Municipio Valencia, Macizo Colombiano, Páramo de Las Papas, alrededores de Valencia, 2910 m, 20.IX.1958, fl, J. M. Idrobo 3977 (COL, MO, NY). Departamento Nariño, municipio Cumbal, Caserío de Miraflores, $3000 \mathrm{~m}$, fl, $P$. Ortíz-Valdivieso D-2 (COL). Municipio Gualmatán, La Gorgonia, 2700 m, 9.IV.1979, fl, O. Salazar de Benavides 1995 (PSO). Municipio La Cruz del Mayo, La Cruz, carretera Pasto - La Cruz, entre Plazuelas y La Cruz, 2500 m, 28.X.1962, fl, L. E. Mora-Osejo 2419A (PSO). Municipio Pasto, Bosque de Daza, 2800-2900 m, 28.II.1963, fl, L. S. Espinal 957 (PSO, US); Río de Potreros to Soledad, upper Téllez drainage 2.XII.1944, fl, J. Ewans 16545 (CAS, NY, US). Departamento Valle del Cauca, municipio Bugalagrande, Cordillera Central, hoya del Río Bugalagrande, loma de Barragán, sobre la quebrada Los Osos, 3000 m, 21.IV.1946, fl, J. Cuatrecasas 20961 (VALLE). Municipio Palmira, corregimiento de El Cerrito, vereda Tenerife, monte La Cumbre, 2800-3000 m, III-2003, fl, F. Estrada 35 (VALLE). Municipio Tuluá, Corregimiento Santa Lucía, finca San Luís, 2800 m, 22.IX.1984, fl, W. Devia 731 (MO, US).
Meriania tomentosa (Cogn.) Wurdack, Phytologia 35(1): 4. 1976. Figs. 61E-G, 62.

= Rhexia excelsa Bonpl., Monogr. Melast. 2: 90; t. 34. 1813. TIPO: ECUADOR. Loxa, 1852, fl, A. Bonpland 3335 (lectotipo: P 136435!, aquí designado; isolectotipo: P 136436!).

= Osbeckia excelsa (Bonpl.) Sprengler, Syst. Veg. 2: 312. 1825.

= Graffenrieda excelsa (Bonpl.) DC., Prodr. 3: 106. 1828.

= Brachycentrum excelsum (Bonpl.) Meissn., PI. Vasc. Gen.: 81. 1838.

= Centronia excelsa (Bonpl.) Triana, Trans. Linn. Soc. London 28(1): 72, t. 5. 1872.

三 Centronia tomentosa Cogn., Bull. Acad. Roy. Sci. Belgique, ser., 3 14: 943. 1887. TIPO: ECUADOR. Ad marginus sylv. Primaev. in Andibus Central aequatoriensibus, 3000 m, 1876, fl, E. F. Andre 4475 (lectotipo: K 329483!, aquí designado; isolectotipos: BR!, CAS!, K!, NY!).

= Centronia tunguraguae S.F. Blake, Proc. Biol. Soc. Wash. 35: 118. 1922. TIPO: ECUADOR. Provincia Tungurahua, cantón Ambato, Pondoa, on slopes of Mt. Tungurahua, 2745 m, 10.III.1921, fl, W. Popenoe 1296 (holotipo: US!).

$=$ Centronia peruviana J.F. Macbr. Field. Mus. Nat. Hist., Bot. Ser. 134(4/1): 327-328. 1941. TIPO: PERÚ. Departamento Huánuco, Carpish, bank of mountain stream, $2850 \mathrm{~m}$, 9.XI.1938, fl., H. E. Stork 9928 (holotipo: F!), syn. nov.

= Meriania pichinchensis Wurdack, Phytologia 50(5): 298. 1982. TIPO: ECUADOR. Provincia Pichincha, cantón Mejia, wet forest $6 \mathrm{~km}$ east of Tandapi on new road from Santo Domingo de Los Colorados, 1740 m, 23.I.1981, fl, S. E. Clemant 1698 (holotipo: NY!; isotipos: NY!, QCA!, US!), syn. nov.

Arbusto o árboles pequeños 3-12 m de altura; entrenudos subcuadrangulares en las partes jóvenes, tienden a ser teretes en las partes basales; ramas, pecíolos, lámina por el envés, inflorescencias y flores (hipanto y cáliz) con indumento denso rufo-viloso; tricomas subulados de base ensanchada, barbelada 2-3.5 mm de largo, con menor frecuencia tricomas de base barbelada 0.1-0.3 mm de largo; hojas con pecíolo 1.3-5.7 cm de largo; lámina 9-23 $\times$ 4-12 cm, elíptica, ovado elíptica u oblongo-elíptica; margen espaciadamente dentado o denticulado; base obtusa a 


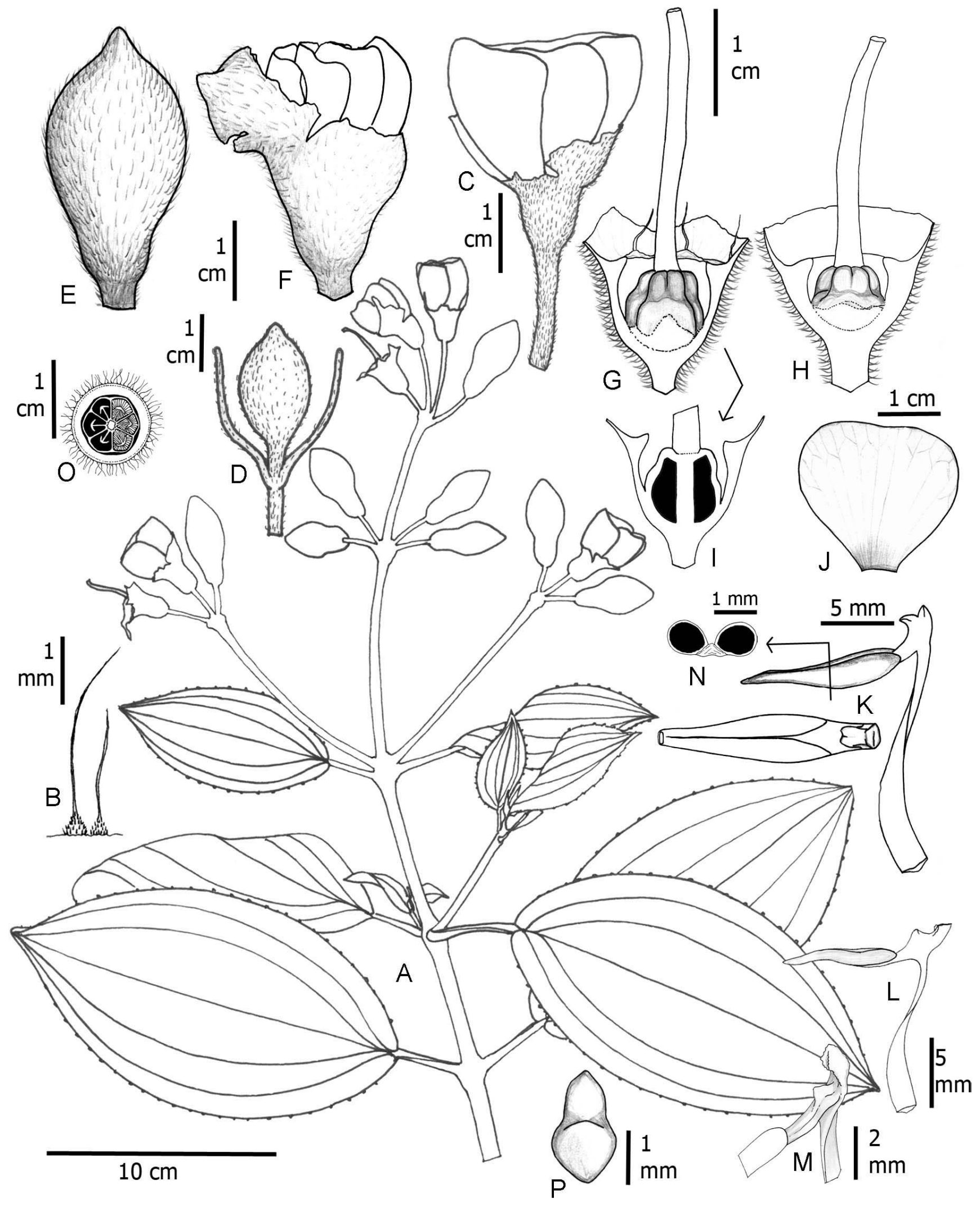

Figura 62: Meriania tomentosa (Cogn.) Wurdack. A. rama florífera; B. tricomas de envés foliar; C. flor abierta; D. botón floral con bractéolas; E. botón floral; F. botón floral en antesis; G, H. corte longitudinal del hipanto y vista lateral del ovario-estilo; l. corte longitudinal del hipanto y ovario; J. pétalo; K. estambre en vista lateral y superior; L. estambre en vista lateral; $\mathrm{M}$. vista lateral del codo y apéndice conectival; $\mathrm{N}$. corte transversal de la antera; O. corte horizontal de hipanto-ovario; P. placenta en vista dorsal. A, C, D: Mendoza 8502 (FMB); B, E, F, G, I, J, K, N, O: Maguirre 44452 (COL); H, M, P: Penneys 1899 (CAS); L: Holm-Nielsen 27069 (CAS). 
redondeada; ápice agudo a corto acuminado, acumen 5-8 $\mathrm{mm}$ de largo; haz glabro, liso o reticulado-bullado (retículo de la nervadura pronunciado); envés blancuzco o marrón rojizo; toda la superficie con indumento denso rufo-viloso, tricomas como en las ramas, rara veces tricomas cortos 0.1-0.3 mm de largo; nervadura con 2-3 pares de venas secundarias que acompañan a la vena media, regularmente la tercera no llega hasta el ápice, basales o plinervias 3-15 $\mathrm{mm}$ arriba de la base; inflorescencia $13-29 \mathrm{~cm}$ de largo, laxa, con 10 a 30 flores; eje central con 2-4 nudos de ramificación; paracladios 4-10 cm de largo, con un nivel de ramificación; ramillas rematando en 2 o 3 flores; flores sustentadas por bractéolas lineares; base de los paracladios con brácteas lineares o como hojas pequeñas; flor pedicelada, 5-8-mera; pedicelo 7-19 mm de largo; hipanto 7.2-10 mm de largo, ciatiforme, liso o levemente costillado, externamente densamente cubierto con tricomas similares a los de las ramas; cáliz caliptrado; caliptra $10-15 \mathrm{~mm}$ de largo, apicalmente aguda o un apículo 1-3 mm de largo, se desgarra irregularmente por un lado, luego se desprende en la base dejando un cáliz truncado; corola cuculada; pétalos 18-24 $\times$ 17-26 mm, anchamente obovados, ápice truncado, anaranjados, glabros; estambres levemente dimorfos por diferente longitud del conectivo basal, forma de codo, ambas series similares en longitud, color blanco; ambas series con una parte del conectivo basal libre de las tecas (pedoconectivo), conectivo uniendo las tecas en su parte ventral (tecas pseudoresupinadas); estambres opositipétalos, filamento 11-15 mm de largo; codo 1.3-3 mm de largo, truncado, rugoso; pedoconectivo 1.2-2.9 mm de largo; apéndice conectival dorsal 0.3-0.7 mm de largo, tuberculado o dentiforme; antera 8-10 $\mathrm{mm}$ de largo, oblongo-subulada, poro dorsal; estambres opositisépalos, filamento $13-15 \mathrm{~mm}$ de largo; pedoconectivo 1.2-1.9 mm de largo; codo 1.5-2.6 mm de largo, a manera de diente o truncado; apéndice conectival dorsal 0.5-1.3 mm de largo, dentiforme; antera 12-14 mm de largo, oblongo-subulada, poro dorsal; ovario 4.6-6.7 $\mathrm{mm}$ de largo, 5-7-locular, ovado, levemente fusionado en la base al hipanto en aristas; ápice con 5-7 lóbulos redondeados a dentiformes; placentas $3.1 \mathrm{~mm}$ de largo, oblongas, rudimentos seminales en todas las superficies; estilo 20-24 $\mathrm{mm}$ de largo, cilíndrico; estigma puntiforme; cápsula 11$14 \mathrm{~mm}$ de diámetro, acopada, hipanto costillado; semillas
0.5-1.1 mm de largo, cuneiformes, ápice corto; rafe de igual color que la testa.

Notas taxonómicas: Meriania tomentosa es el taxón de mayor área de distribución del grupo de cerca de 14 especies de corolas cuculadas, estambres con el conectivo de forma compleja y anteras con diferentes grados de resupinación. Estas especies están adaptadas a la polinización por colibríes y/o murciélagos y al parecer todas producen néctar a partir de tejidos de los estambres como lo documentan Varassin et al. (2008).

El conjunto de caracteres que circunscribe a $M$. tomentosa es: indumento denso rufo-viloso en estructuras vegetativas, inflorescencia y hipanto-caliptra, corola cuculada de pétalos anaranjados, estambres con anteras pseudoresupinadas y el cáliz caliptrado. Meriania tomentosa tiende a tener inflorescencias con pedúnculos largos, brácteas como hojas pequeñas en los nudos basales del eje central, brácteas lineares caducas en la base de las flores, ramificaciones basales largas (paracladios) y terminaciones de las ramillas trifloras. No obstante, hay variación amplia en la permanencia de las brácteas foliosas y el desarrollo o presencia de las ramificaciones.

Es muy semejante a las especies $M$. arborea, $M$. dimorphanthera y $M$. quintuplinervis con la que comparte la mayoría de los caracteres mencionados arriba excepto por la forma del cáliz, el cual es subcaliptrado en las últimas especies. También es muy semejante a M. phlomoides (que presenta corola cuculada, anteras pseudoresupinadas y cáliz caliptrado); no obstante, en esta última los pétalos son albos (blancos a rosados).

Wurdack (1976) estableció la combinación de M. tomentosa y descartó el epíteto "excelsa", que es el más antiguo, ya que éste ya existía para una especie de Meriania de Brasil. La especie sinonimizada, Centronia peruviana, comparte el conjunto de caracteres que circunscribe a $M$. tomentosa, por lo que no tiene caracteres que permita considerarlo como un taxón distinto.

El tipo de Meriania pichinchensis comparte el conjunto de caracteres diagnósticos expuestos arriba para M. tomentosa, excepto por el indumento denso rufo por el envés, ramas e inflorescencia. Wurdack (1982) plantea las únicas variaciones de $M$. pichinchensis con respecto a 
M. tomentosa: indumento menos denso en las ramas y envés, la inflorescencia con las ramificaciones atrofiadas y brácteas elípticas. Estos caracteres diagnósticos de $M$. pichinchensis son variables, ya que hay ejemplares con caracteres intermedios entre las dos especies en la misma provincia de Pichincha (como son D. Penneys 1899, CAS y C. Cerón 5906, CAS). Meriania pichinchensis tiene pelos subulados de superficie rizada solo en las venas por el envés y no en toda la superficie, pero hay estados intermedios. Por ejemplo, sus brácteas son como hojas pequeñas y en $M$. tomentosa son caducas y lineares; no obstante, hay ejemplares de Pichincha en donde hay brácteas lineares y hojas basales pequeñas. Meriania pichinchensis es entonces una forma glabrescente de $M$. tomentosa, con los ejes de las ramificaciones de la inflorescencia atrofiados y por ende sin las brácteas lineares y solo sustentados por brácteas a manera de hojas pequeñas.

Distribución y hábitat: especie presente en los Andes de Colombia, Ecuador y norte de Perú, entre 1800 y 2800 $\mathrm{m}$ de elevación. Hay un ejemplar de Bolivia (J. A. Carrasco 261B (CAS, USZ) que al parecer corresponde a esta especie, pero se encuentra en fruto y no hay plena certeza. En Colombia se encuentra en el centro-sur de las cordilleras Central y Occidental y en el Macizo Colombiano, en los departamentos Cauca, Huila, Nariño, Quindío, Risaralda, Tolima y Valle del Cauca (Fig. 58). Se encuentra en la zona de bosque andino y crece en interior y bordes de bosque, pocas veces se encuentra en zonas completamente expuestas.

Etimología: en alusión al indumento denso ferrugíneo de tricomas filamentosos en las estructuras vegetativas, inflorescencia e hipanto-caliptra.

Estado de conservación: esta especie tiene una EOO de ca. $34,500 \mathrm{~km}^{2}$ y AOO de ca. $32 \mathrm{~km}^{2}$, se conoce de más de 15 localidades en el área de su distribución en Colombia, se encuentran áreas de conservación en Quindío y en el Parque Nacional Natural Munchique (Cauca); por ello, no cumple los criterios para su categorización en algún grado de amenaza. No obstante, es poco frecuente en campo y está asociada a zonas de bosque, por lo que se sugiere su categoría como "Preocupación Menor" (LC).
Material examinado: COLOMBIA. Departamento Huila, municipio Santa María, vereda Carmen de Bolívar, 26.VII.2004, fl, J. Calambas V28 (SURCO). Municipio Tóez, vía al Nevado del Huila, 9.XII.1993, fl, C. Barbosa 9668 (378) (FMB). Departamento Nariño, municipio Funes, páramo Orinoco, 27150 m, 28.IV.2006, fl, A. Baca 18 (PSO). Municipio Ipiales, carretera de La Victoria a San Jorge, El Hospital, 2100 m, fl, L. E. Mora-Ocejo 2177 (COL). Municipio Ricaurte, Reserva Natural La Planada, 1820 m, 31.I.1997, st, G. Herrera 9312 (FMB); loc cit., 1900 m, 5.IX.1999, st, H. Mendoza 8633 (FMB); Reserva Natural La Planada, por la trocha entre La Planada y Santa Rosa, 1900 m, 5.IX.1999, fl, fr, H. Mendoza 8502 (FMB). Departamento Quindío, municipio Génova, camino finca Servia - Valle Chiquito, 2400-3900 m, 30.IV.1990, fl, C. Vélez 1522 (COL). Municipio Pijao, road from Pijao to Páramo de Chili, 2700-2300 m, 30.I.1989, fl, A. Gentry 65357 (MO). Departamento Risaralda, municipio Santa Rosa de Cabal, finca La Granja, 2470-2680 m, 2.II.2004, st, A. Prieto 2806 (FMB). Departamento Tolima, municipio Cajamarca, Parque Nacional Natural Los Nevados, finca Llamitos, 22.VI.1985, fl, A. Cavelier 69 (FMB); cuenca del río Combeima, finca El Silencio, 2600 m, 23.VI.1985, fl, J. Hernández 3207 (FMB). Municipio Ibagué, corregimiento de Juntas, El Silencio, 2800 m, 29.VII.1972, fl, M. T. Murillo s.n. (COL). Departamento Valle del Cauca, municipio Cali, CordiIlera Occidental, Los Farallones, vertiente NW, quebrada Las Nieves, abajo de la mina El Diamante, 2900 m, 30.VII.1946, $\mathrm{fl}, \mathrm{J}$. Cuatrecasas 21789 (VALLE). Municipio Florida, Pueblo Nuevo, vereda Las Dantas, 3050 m, 19.II.1990, fl, S. Sarria 915 (CUVC). Municipio La Cumbre, corregimiento de Bitaco, vereda Chicoral, 2093 m, 21.VII.2003, st, H. Mendoza 14982 (FMB); loc. cit., 2000 m, 23.VII.2003, st, H. Mendoza 15095 (FMB), 15124 (FMB), 15157 (FMB), 15330 (FMB). Municipio Miranda, vereda Las Dantas, 1950 m, 20.I.1990, fl, S. Sarria 808 (CUVC). ECUADOR. Provincia Azuay, cantón Gualaceo, carretera Gualaceo - Macas, 2940 m, 14.I.2008, fl, C. Ulloa 1489 (CAS, MO). Provincia Carchi, cantón Espejo, reserva Golondrinas, sendero entre la Estación Santa Rosa y El Corazón, 1700-2230 m, 22.I.2004, fl, H. Vargas 4233 (CAS), 4296, (CAS). Provincia Loja, cantón Loja, carretera Yangana - PN Podocarpus, dentro de la reserva, 2800 m, 2.VIII.1986, fl, N. Betancurt 337 (CAS). Provincia Napo, cantón Archidona, upper slope of Huagra Urcu, 2600 m, 26.IX.1980, fl, 
L. Holm-Nielsen 27069 (CAS). Provincia Pichincha, cantón Quito, Parroquia Calacali, $20 \mathrm{~km}$ de la carretera Calacali Nanegalito, 2000 m, 19.I.1989, fl, C. Cerón 5906 (CAS); on trail to the Reserva Río Guajalito, 1840 m, 4.XII.2005, fl, $D$. Penneys 1899 (CAS); Reserva Biológica Maquipucuna, Nanegal, 1500-1700 m, 12.VIII.1991, fl, C. Quelal 287 (CAS); sin localidad precisa, Chuquribamba, quebrada de Santa Bárbara, 18.XI.1881, Poortmann s.n. (P). PERÚ. Departamento Cajamarca, provincia San Miguel, Bosque de Quellahorco, 2700 m, 14.IX.1981, fl, I. Sánchez 5788 (MO). Departamento Huánuco, entre Piura y Cajamarca, ruta Huancabamba a Tabaconas, 2700 m, 11.VII.1961, fl, C. Friedberg 322 (COL); trail from $\mathrm{S}$ entrance of Carpish tunnel to crest of ridge, $9000 \mathrm{ft}, 27.11 .1978$, fr, J. Luteyn 5477 (NY); west side of Carpish Pass, 9200 ft, 22.X.1959, fl, B. Maguirre 44432 (COL, F, NY); Carpish, X.1945, fl, C. Sandeman 5257 (K).

Meriania urceolata Triana, Trans. Linn. Soc. London 28(1): 67. 1872. Figs. 61H-F, 63. TIPO: PERÚ. Tarapoto Peruviae occidentalis, Uaupés, X.1852-I.1853, fl, R. Spruce 4439 (lectotipo: K!, designado por Chiavegatto y Baumgratz (2011); isolectotipos: BR!, E!, F foto!, GH!, K (2) pliegos!, NY!, P).

= Meriania paraensis Ducke, Arch. Jard. Bot. Rio de Janeiro 3: 224. 1922. TIPO: BRASIL. Estado Pará, Campos do Ariramba, 150 m, 23.X.1913, fl, L. A. Ducke 14854 (holotipo: MG; isotipos: $M B, R B, U S !)$.

Árboles 0 arbustos 2-7 $\mathrm{m}$ de altura; entrenudos oblongos, aplanados; ramas, inflorescencia e hipanto-cáliz densamente cubierto con tricomas estrellados adpresos marrón claro u marrón rojizo (tipo 38); hojas con pecíolo 1.7-4.5 cm de largo, levemente acanalado en la parte superficie adaxial; lámina 6.2-12.7 × 2.6-7 cm, ovada elíptica a elíptica, textura delgado coriácea; ápice cortamente acuminado; base obtusa a redondeada, con o sin aurículas pequeñas reflexas; margen entero; haz glabro; envés con indumento denso de tricomas estrellados adpresos marrón claro; nervadura con 2 pares de venas basales o el superior plinervio $10 \mathrm{~mm}$ arriba de la base, par de venas inferior cerca del margen algunas veces no visible; venas intersecundarias no evidentes o levemente desdibujadas; inflorescencia
4-10.5 cm de largo, 10 a 20 flores, sésil o primer internodo hasta $5 \mathrm{~cm}$ de largo, sin brácteas; paracladios basales 1.5$4 \mathrm{~cm}$ de largo; flor pedicelada, 5-mera; pedicelos 3-6 mm de largo; hipanto 4.7-8 mm de largo, campanulado; pared 0.9-1 mm grosor; cáliz 3-4.3 mm de largo, truncado; dientes dorsales inexistentes o si presente diminutos; corola patente; pétalos 14-20 × 7-12 mm, obovados, ápice truncado emarginado, glabros, fucsia oscuro; estambres fuertemente dimorfos, estambre opositipétalo mayor, filamento 10-12.6 mm de largo; codo con apéndice subulado de 0.6$1.1 \mathrm{~mm}$ de largo; apéndice conectival dorsal 3.1-4.7 mm de largo, cilíndrico, apicalmente bífido; antera 9.7-11.5 mm de largo, sigmoidea, poro dorsal; estambre opositisépalo menor, filamento 9-11 mm de largo; codo 0.1-0.2 mm de largo, subulado; apéndice conectival 1.8-3 mm de largo, cilíndrico, apicalmente redondeado o levemente bífido; antera 6.5-8.2 mm de largo, sigmoidea, poro ventral; ovario 3.5-5 $\mathrm{mm}$ de largo, 3-locular, oblongo, costillado, completamente súpero o levemente fusionado en la base 0.3-0.8 mm; ápice redondeado; placentas $2.1 \mathrm{~mm}$ de largo, ovoides a linear ovoides, rudimentos seminales solo en la superficie dorsal; estilo $15-17 \mathrm{~mm}$ de largo, filiforme; estigma puntiforme; cápsula 11-15 mm de largo, urceolada; semillas 2.6-3 mm de largo, cuneiformes, ápice corto; rafe de igual color que la testa.

Notas taxonómicas: los caracteres de los estambres en esta especie son similares a los encontrados en el género Adelobotrys, al igual que el número de carpelos. Comparte con otras especies de Meriania el tamaño de la flor, el color de los pétalos y el hábito de crecimiento. El indumento denso de tricomas estrellados marrón-claros la hace inconfundible de sus congéneres del Escudo Guayanés.

Distribución y hábitat: especie distribuida a lo largo del Escudo Guayanés en Colombia, Perú, Brasil, Bolivia, Guyana y Venezuela, entre 100-900 m de elevación. En Colombia se encuentra en los departamentos Amazonas, Caquetá, Guainía, Guaviare, Meta, Vaupés y Vichada, en zonas de afloramientos rocosos y suelos de arenas blancas asociadas al Escudo Guayanés, entre 100 y 600 m de elevación (Fig. 64). 


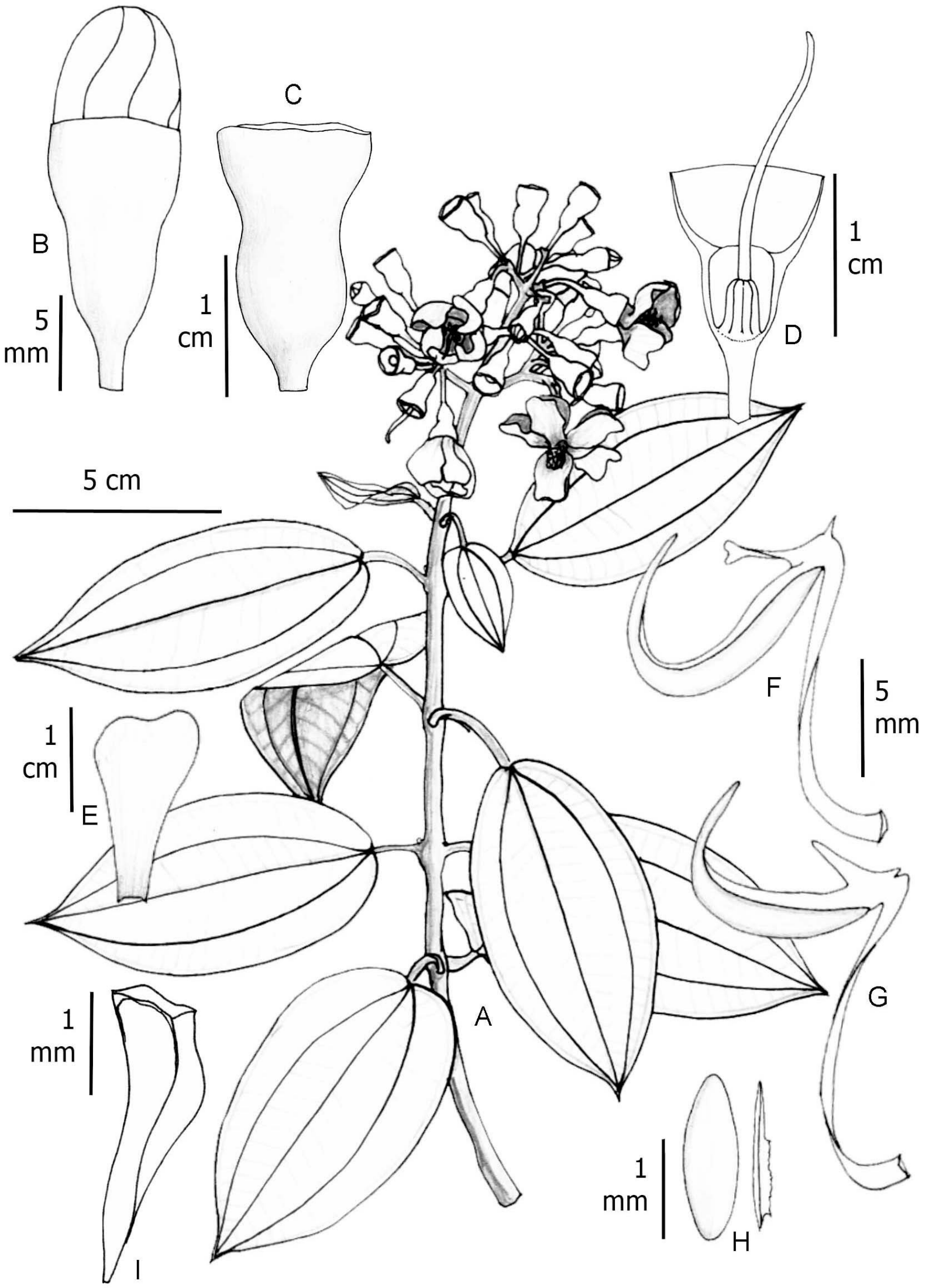

Figura 63: Meriania urceolata Triana. A. rama florífera; B. botón floral; C. vista lateral del hipanto-cáliz; D. corte longitudinal del hipanto-cáliz y vista del ovario-estilo; E. pétalo; F. estambre opositipétalo; G. estambre opositisépalo; H. vista frontal y lateral de la placenta; I. semilla. A, C, D, E, F, G, I: Mendoza 8470 (FMB); B: Córdoba 530 (FMB); H: Prado 693 (FMB). 

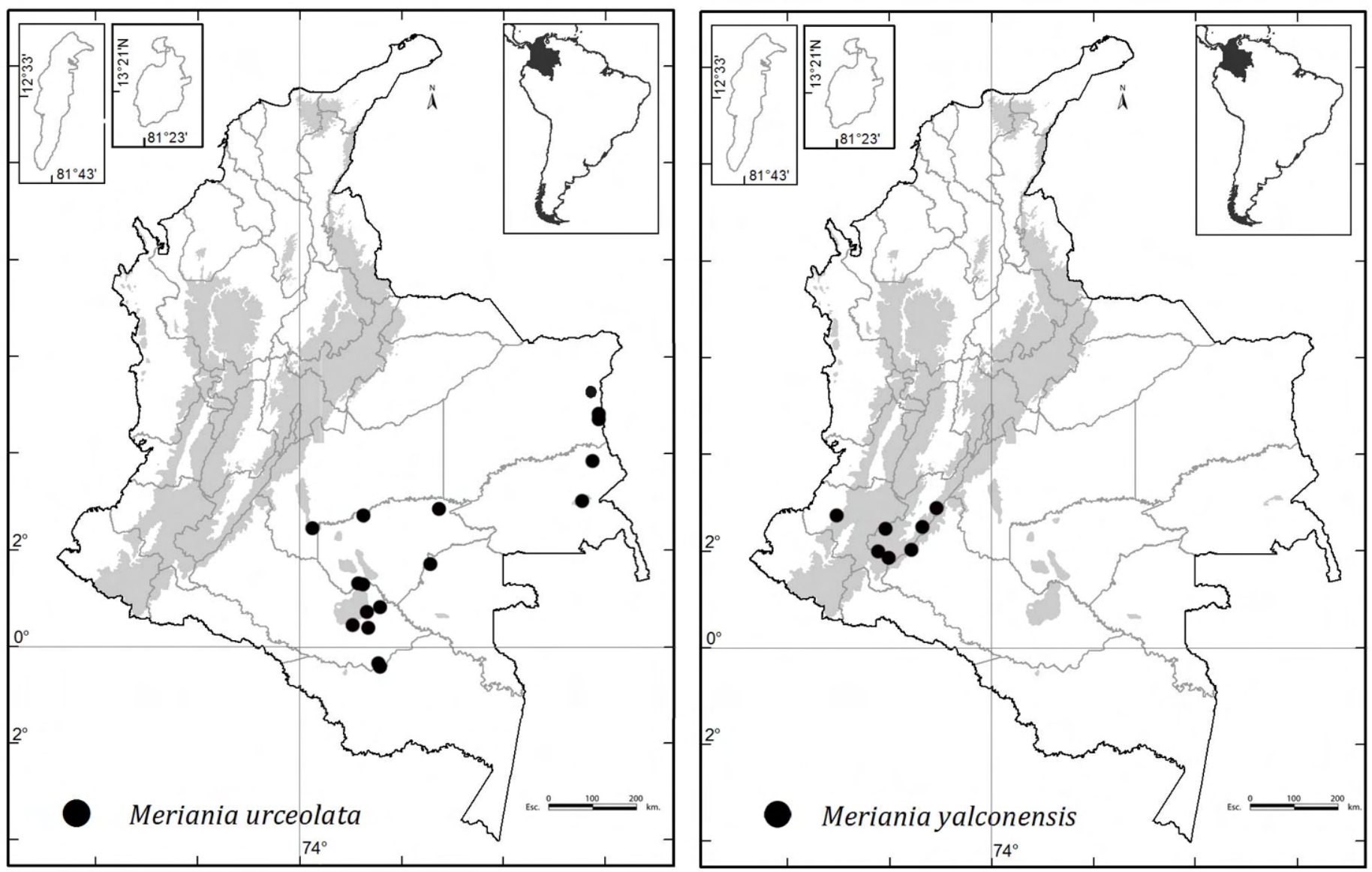

Figura 64: Distribución geográfica de Meriania urceolata Triana y M. yalconensis Humberto Mend. \& Fern. Alonso.

Etimología: en alusión a la forma urceolada del fruto.

Estado de conservación: se sugiere su categoría como "Preocupación Menor" (LC) por su EOO de ca. 147,500 km². Es de amplia distribución a lo largo de Escudo Guayanés en áreas en buen estado de conservación.

Material examinado: COLOMBIA. Departamento Caquetá, municipio Solano, Araracuara, río Caquetá, sabana de Angostura, 400 m, 21.XII.1951, fl, H. GarcíaBarriga 14159 (COL); Araracuara, sabanas del Yarí, 236 m, 014'18.2"N-71²5'43.8"W, 16.Il.2011, fr, D. Caicedo 2792 (COAH); Araracuara, alrededores de Araracuara, 10.XI.1982, fl, J. M. Idrobo 11239, 11488 (COAH, COL); Parque Nacional Natural Chiribiquete, serranía norte, $810 \mathrm{~m}$, 29.XI.1992, fl, C. Barbosa 8124 (COL); Parque Nacional Natural Chiribiquete, campamento sur, 300 m, 6.XII.1990, fl, J. Estrada CHIS 45 (COL); Parque Nacional Natural Chiribiquete, cuenca media del río Cuñaré, 350 m, 15.XI.2000, fl, $H$.
Mendoza 9434 (FMB), 9452 (FMB), 9566 (FMB). Departamento Guaviare, municipio San José del Guaviare, Serranía La Lindosa, quebrada Agua Bonita entre charco La Lindosa hasta La Reserva, 19.III.2008, fr, D. Cárdenas 21398 (COAH); Inspección de Tomachipán, Caño Cocuy, Cerro Cocuy, Parque Nacional Natural Nukak, 350 m, 10.II.1996, fl, M. $P$. Córdoba 2157 (FMB); Puerta de Orión, 168 m, 23.III.1997, st, $R$. Córdoba 2333 (COL); Serranía La Lindosa, vereda Nuevo Tolima, 432 m, 24.IX.2012, fr, A. Gonzáles 128 (COAH). Departamento Guinía, municipio Inírida, resguardo La Ceiba - Caranacoa, sector Huesito, carretera Huesito - Caribe, 100-150 m, 22.IV.2004, fl, D. Cárdenas 14695 (COAH); entre Cerros de Mavicure y Chorro Samuro, 1.I.2007, fl, D. Cárdenas 20333 (COAH); comunidad de Caño Vitina, 13.V.2007, fl, D. Cárdenas 20743 (COAH). Departamento Meta, municipio La Macarena, Serranía La Macarena, Caño Cristales, cercanías de la cabaña de CORMACARENA, 270-320 m, 27.XII.2005, fl, J. Betancur 1195 (COL); río Guayabero, Sabanas de arenisca, 235-700 m, I.III.1959, fl, H. García-Ba- 
rriga 17097 (COL). Departamento Vaupés, municipio Mitú, cabeceras del caño Wacurabá, 200-400 m, 16.V.2006, fr, D. Cárdenas 18742 (COAH); Gran Resguardo Indígena del Vaupés, caño Cuduyarí, 22.VII.2006, fr, D. Cárdenas 19013 (COAH); comunidad de Wacurabá, margen derecho del caño Cuduyarí, sabana de Yapobo, 400 m, 26.IX.2007, fr, D. Cárdenas 21192 (COAH); Río Karurú, Mesa de Yambí, 9501000 ft, 15.IV.1933, fr, R. E. Schultes 19140 (COL). Departamento Vichada, municipio Cumaribio, Selvas de Matavén, Resguardo Unificado Selvas de Matavén, Caño Carajo, 240 m, 16.III.2007, fl, A. Prieto 5438 (FMB); Selvas de Matavén, Resguardo Unificado Selvas de Matavén, sector Caño Zama, 300 m, 6.III.2007, st, A. Prieto 6013 (FMB). Municipio Puerto Carreño, Vereda La Esmeralda, finca El Tomo, confluencia del Caño Terecay con el río Tomo, flanco norte, 85 m, 05³3'48,3"N- 68²7'20,6"O, 04.IV.2017, fl, fr, H. Mendoza 19860 (FMB), 19861 (FMB).

Meriania yalconensis Humberto Mend. \& Fern. Alonso, Anales Jard. Bot. Madrid 69(2): 289-292. 2012. Fig. 65. TIPO: COLOMBIA. Departamento Huila, municipio San Agustín, vereda La Castellana, Reserva Natural Privada Los Yalcones, interfluvio quebradas El Palmar - Río Balseros, sito El Palmar, 2400-2600 m, 15.VIII.2005, fl, H. Mendoza 16439 (holotipo: FMB!; isotipos: COL!, HUA!).

Árboles 10-15 m de altura; entrenudos subcuadrangulares; ramas, pecíolos, inflorescencia con indumento denso de tricomas filiforme de paredes rizadas (tipo 17), ápice de las ramas con tricomas piramidales diminutos (tipo 27); hojas con pecíolo 1.8-3.4 cm de largo; lámina 10-17.5 $\times$ 5.5-8.5 cm, ovado-elíptica a elíptica; base redondeada a levemente cordada (levemente peltada en juveniles), revoluta; ápice agudo a obtuso; margen espaciadamente denticulado; haz glabro; envés con indumento ferrugíneo denso sobre la nervadura de tricomas filiforme de paredes rizadas 0.1-0.3 mm de largo (tipo 17), esponjosos subtriangulares aplanados lateralmente de paredes rizadas (tipo 30), también tricomas setosos hasta $2.5 \mathrm{~mm}$ de largo (tipo 11) en las axilas de las venas secundarias; nervadura con 2 pares de venas principales acompañando a la vena media, levemente plinervias 1-3 mm arriba de la base; inflorescencia 10-16 cm de largo, 15-34 flores, 2-3 nudos de ramificación; para- cladios basales con 1-2 niveles de ramificación; ramillas apicalmente trifloras o con 4-5 flores por los entrenudos muy cortos; flor pedicelada, 7-8-mera; pedicelo 6-13 mm de largo, terete, algunas veces con ralos pelos setosos; hipanto 6-7 mm de largo, ciatiforme; pared 1.5-1.9 mm grosor en su parte media; en la parte interna ribetes gruesos frente a los pétalos 1-13 mm de ancho, 5-5.5 mm de largo, sobresaliendo cerca de $1 \mathrm{~mm}$ arriba el torus; externamente indumento denso de tricomas esponjoso irregular con ramas cortas 0.1-0.2 mm de largo (tipo 30), rufos, también cuerpos globulares esponjosos, suculentos; cáliz caliptrado, caliptra 14-23 mm de largo, ápice agudo o apiculado, externamente con el mismo indumento al del hipanto; corola patente; pétalos 29-42 × 23-34 mm, obovados, de ápice truncado emarginado, glabros, fucsia oscuro; estambres isomorfos, filamento 9-12 mm de largo; codo 3.9-4.2 mm de largo; apéndice conectival dorsal 0.9-1.1 mm de largo, subulado; antera 7.5-10.2 mm de largo, sigmoidea, poro dorsal; polen 10.8-11 $\mu \mathrm{m}$ diámetro; ovario 6.2-8.5 mm de largo, 7-8-locular, ovado, en corte transversal en su parte media tiene 7-8 costillas levemente alzadas, lomo levemente aplanado, fusionado en la base con el hipanto 1.2-2 mm; ápice 2.7-3.4 $\mathrm{mm}$ de largo, apéndices apicalmente dentados; placentas $2.8 \mathrm{~mm}$ de largo, ovoides, rudimentos seminales en todas las superficies; estilo $10.5-15.3 \mathrm{~mm}$ de largo, columnar a levemente cónico, retorcido, levemente curvo en la base; estigma levemente glandiforme; cápsula 9-12 $\mathrm{mm}$ de largo sin el pedicelo, hipanto hemisférico, ovario sobresaliendo 0.4-0.5 mm; pedicelo 0.9-10 mm de largo; semillas cuneiformes, ápice corto (visto en semillas inmaduras).

Notas taxonómicas: el ovario casi súpero y la presencia de los ribetes frente a los pétalos en el interior del hipanto son los caracteres principales de esta especie. Dentro del grupo Brachycera, M. yalconensis es muy similar a M. mutabilis, pero se diferencia en los ribetes internos del hipanto (vs. ausencia de ribetes en $M$. mutabilis), el ápice del ovario con dientes irregulares (vs. con dos dientes por carpelo), el indumento ferrugíneo denso en las hojas y ramas (vs. indumento laxo) y la presencia de tricomas setosos por el envés y los pecíolos (vs. sin setas). Igualmente, es muy semejante a $M$. brachycera, de la que difiere en el indumento farinoso por el envés (vs. aracnoideo en 

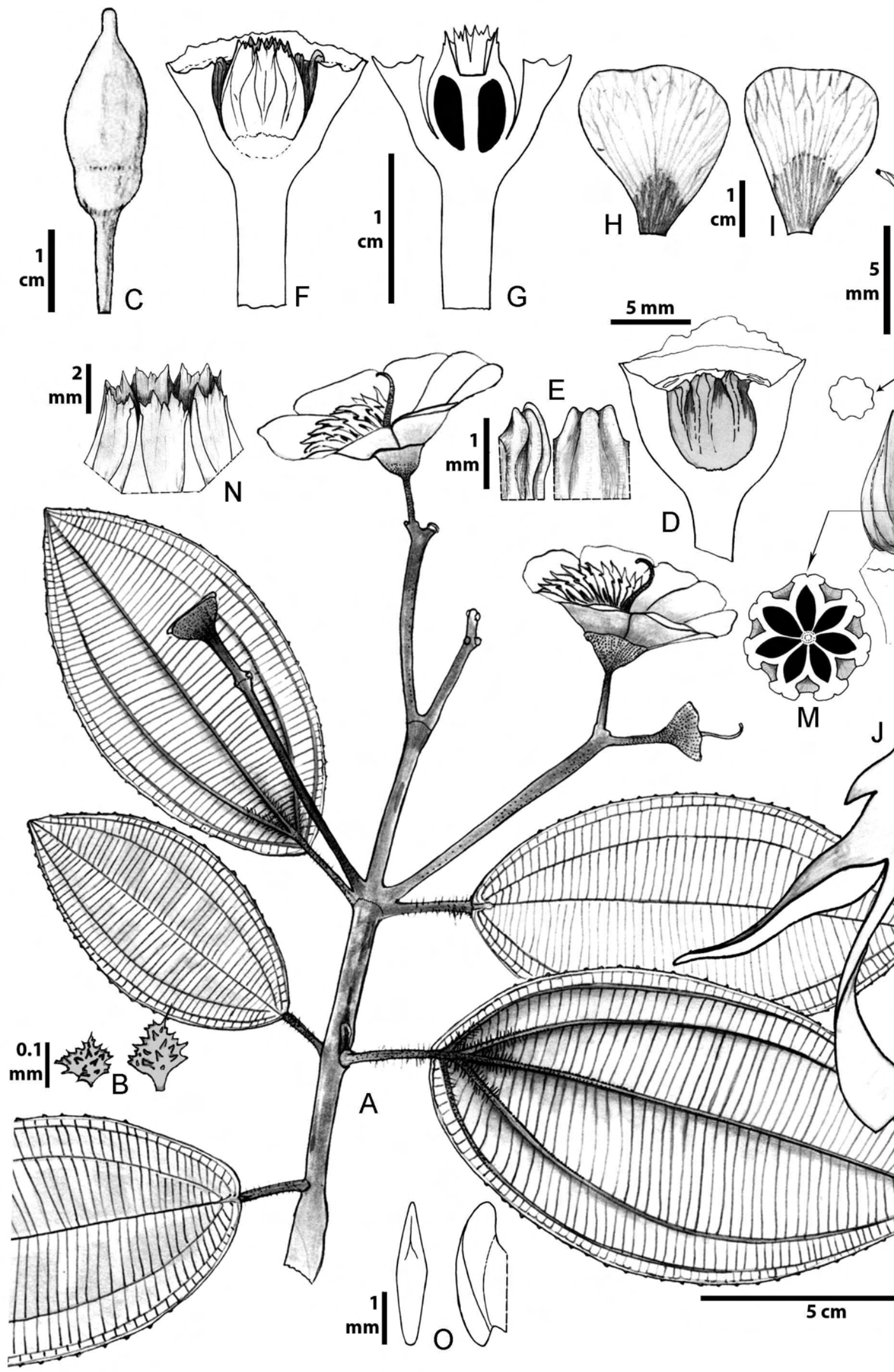

A

A

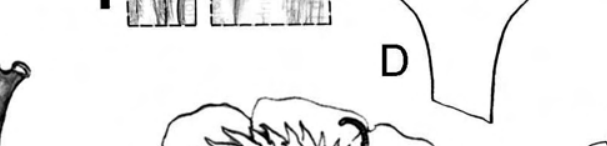


M. brachycera), en la nervadura basal o levemente plinervia (vs. plinervia) y en los ribetes del interior del hipanto y apéndices apicales del ovario. Otra especie con la que se puede confundir es $M$. aguaditensis, pero se diferencia por el indumento de las estructuras vegetativas y por la nervadura basal.

Distribución y hábitat: especie conocida hasta el momento del Macizo Colombiano del norte de los Andes, en los departamentos Huila, Cauca y Putumayo, entre 2200 y $2800 \mathrm{~m}$ de elevación (Fig. 64). Crece en interior de bosque en zonas de bosque andino.

Etimología: en alusión a la localidad tipo.

Estado de conservación: categorizada como Vulnerable (VU) (Mendoza-Cifuentes y Fernández-Alonso, 2012) y posteriormente recategorizada como "Casi Amenazada" (NT) en la lista Roja de la IUCN (2020). Es poco frecuente y tiene especificidad de hábitat, por lo que se ajusta mejor la categorización nueva.

Material examinado: COLOMBIA. Departamento Cauca, municipio Argelia, Cerro Plateado, vertiente hacia la quebrada Soledad, 2600 m, 30.III.1995, fl, M. L. Becking 2515 (CAUP); Cerro Plateado, vertiente hacia la quebrada Soledad, 2600 m, 30.III.1995, fl, M. L. Becking 2514 (COL). Departamento Huila, municipio Palestina, vereda La Guajira, Reserva Natural Comunitaria La Rivera, 1970 m, 28.VIII.2005, st, A. Prieto 4082 (FMB). Municipio Salado Blanco, Parque Nacional Natural Puracé, El Palmar, sector Granates, 2191 m, 23.VI.2003, st, S. Medina 139 (FMB). Municipio San Agustín, vereda La Castellana, Reserva Privada Los Yalcones, Sector Yalcones, 2400-2600 m, 15.VIII.2005, st, H. Mendoza 16344 (FMB), 16361 (FMB). Municipio Suaza, Cordillera Oriental, vertiente occidental, entre Gabinete y Andalucía, 2200-2300 m, 25.III.1940, fl, fr, J. Cuatrecasas 8684 (F 1235803, COL, NY, US); Cordillera Oriental, 1 km NW and W of finca Ventanas, $15 \mathrm{~km} \mathrm{SE}$ of Gigante, 8900 ft, 14.IX.1944, fl, E. L. Little jr. 8654 (NY). Departamento Putumayo, municipio Colón, Reserva Natural La Rejoya, 2650 m, 27.XII.1996, fl, B. Ramírez 10328 (PSO). Municipio Sibundoy, entre San Francisco y Río Blanco, 2300-2800 m,
9.IV.1973, fl, J. J. Hernández 414 (PSO); loc. cit., 2200 m, 2.XI.1979, fl, O. Salazar de Benavides 2072 (PSO).

\section{Discusión}

Para el género Meriania actualmente se consideran 120 especies aceptadas (Wurdack, 1973; Mendoza y Ramírez, 2006; Melastomataceae.Net., 2007-2018; Chiavegatto y Baumgratz, 2009; Mendoza-Cifuentes y Fernández-Alonso, 2010, 2011, 2012); no obstante, con la propuesta actual de sinonimias y especies nuevas, al género lo constituirían 102. Hay dos especies que en un futuro pueden cambiar: Meriania subumbellata Cogn., que debe ser transferida a Adelobotrys - ya que presenta tricomas malpigiáceos- y $M$. brittoniana Wurdack, que es prácticamente similar a $M$. axineoides Gleason. Para Colombia, el Catálogo de Plantas enlista un total de 51 especies de Meriania (Almeda et al., 2016); no obstante, con la presente monografía la lista para el país se establece en 37. Se proponen como especies nuevas a M. neillii y M. ramosii, y 18 sinónimos nuevos.

Bajo esta cifra no se considera a Meriania cordifolia (Karsten) Cogn. (= M. cordata Triana), nombre en desuso y del cual no se conoce la ubicación del ejemplar o ejemplares tipo. Por la descripción de Cogniaux (1891) se asocia a M. speciosa, pero no hay plena seguridad para su sinonimización.

Las especies de Meriania en Colombia se distribuyen en la región Andina (34 spp.), la Sierra Nevada de Santa Marta (2 spp.) y el Escudo Guayanés - Orinoquia (2 spp.), entre 100 y 3700 m de elevación, en zonas húmedas con precipitación anual promedio superior a $2000 \mathrm{~mm}$.

Las especies andinas se asocian al grupo de Meriania s.s., ya que presentan rudimentos seminales en toda la superficie de la placenta y las anteras tienen el haz vascular del conectivo dorsal orientado hacia su base. En este grupo se encuentran $M$. acostae, M. aguaditensis, M. arborea, M. arizae, M. barbosae, M. brachycera, M. colombiana, $M$. dimorphanthera, M. drakei, M. fantastica, M. haemantha, M. heptamera, M. hernandi, M. hexamera, M. macrophylla, M. maxina, M. mexiae, M. mutabilis, M. mutisii, M. nobilis, M. pastazana, M. phlomoides, $M$. quintuplinervis, $M$. ramosii, $M$. sanguinea, $M$. sararensis, $M$. selvaflorensis, $M$. silverstonei, $M$. speciosa, $M$. splendens, $M$. tomentosa y $M$. yalconensis. Las especies asociadas al Escudo Guayanés y 
partes bajas del Magdalena Medio, M. albertiae, M. ornata y M. urceolata, no se ajustan propiamente a la tipología del género; podrían constituir uno distinto con caracteres plenamente diferenciables como son la forma de las anteras esbeltas con el haz vascular de conectivo orientado hacia su ápice, el ovario 3-locular y rudimentos seminales solo en el dorso de la placenta. Finalmente, se encuentra $M$. hoyosii con caracteres similares - pétalos albos, anteras esbeltas con el haz vascular del conectivo orientado hacia el ápice de la antera y rudimentos seminales en todas las superficies de la placenta - a especies de Meriania de la Mata Atlántica de Brasil. De acuerdo con esto, las especies de Meriania en Colombia constituyen tres grupos, dos de ellos que podrían constituir géneros distintos con base en caracteres de las anteras, número de lóculos del ovario y disposición de los rudimentos seminales.

Acorde con la Lista Roja de la IUCN (2020), para Colombia hay categorizadas 18 especies de Meriania, cinco de ellas como Amenazada (EN), tres como Casi Amenazada (NT), tres como Vulnerable (VU) y siete como Preocupación Menor (LC). En este trabajo se sugieren categorías para 31 especies y seis no se categorizan, por tener la mayor proporción de su distribución en otros países. Se presentan algunas discordancias con la Lista Roja y se argumenta que obedecen a registros erróneos o representan ejemplares cultivados.

Finalmente, se recomienda evaluar - a partir de una filogenia robusta, en una revisión integral futura de Meriania-, los caracteres morfológicos expuestos en este trabajo - como la forma de los estambres y la distribución en la placenta de los rudimentos seminales-, para circunscribir al género. Es necesario hacer un estudio anatómico detallado de las anteras y del conectivo dorsal en los principales géneros de la tribu, que permita comprobar la hipótesis propuesta de estambres no geniculados.

\section{Contribución de autores}

HMC concibió la investigación, adquirió los datos, revisó colecciones y escribió el documento.

\section{Financiamiento}

Este estudio fue financiado parcialmente con recursos del propio autor y con el apoyo de la Academia de Ciencias de
California a través de una beca para la revisión de colecciones en el herbario CAS. Se contó con el apoyo personal de Fabián Michelangeli, Marcela Alvear, Frank Almeda, Carmen Ulloa y Robin Foster, para la estancia en diferentes ciudades de EUA para la revisión de las colecciones.

\section{Agradecimientos}

Expreso sinceros agradecimientos al Instituto de Ciencias Naturales de la Universidad Nacional de Colombia y al Instituto de Investigaciones Recursos Biológicos Alexander von Humboldt, Colombia, por la ayuda prestada para el desarrollo de este trabajo. A la Academia de Ciencias de California, por concederme una pasantía que me permitió complementar este trabajo y en especial, por el préstamo de colecciones de herbarios de Europa y Norteamérica. Al Jardín Botánico de Bogotá, por el apoyo a la finalización del artículo. Por facilitar la consulta de sus colecciones a los herbarios CAS, CAUP, COAH, COL, CUVC, F, FAUC, FMB, HECASA, HUA, HUQ, JBB, JAUM, MEDEL, MO, NY, QCA, QCNE, PSO, SURCO, UDBC, UPTC, US y VALLE. A Frank Almeda, Fabián Michelangeli, Marcela Alvear, Daryn Penneys, Gilberto Ocampo, Carlos Parra, Carmen Ulloa, Eduardo Calderón, William Ariza, Álvaro Idárraga, Germán Télles, Mauricio Posada, Robin Foster, Álvaro del Campo, Álvaro Cogollo, Fernando Forero y Sebastián Moreno, quienes contribuyeron de forma variada suministrando imágenes, ejemplares, comentarios o facilitando el apoyo logístico. Al Missouri Botanical Garden, por el permiso de uso de algunas imágenes.

\section{Literatura citada}

Almeda, F. 1993. An evaluation of the Mesoamerican species of Meriania (Melastomataceae: Merianieae). Proceedings of the California Academy of Sciences ser. 4, 48(7): 141-152.

Almeda, F. 2009. Melastomataceae. In: Davidse, G., M. SousaSanchez, S. Knapp y F. Chiang (eds.). Flora Mesoamericana, Vol. 4. Missouri Botanical Garden Press, St. Louis, E.U.A. Pp. 164-338.

Almeda, F., M. Alvear, H. Mendoza-Cifuentes, D. S. Penneys y F. Michelangeli. 2016. Melastomataceae. In: Bernal, R., R. Gradstein y M. Celis (eds.). Catálogo de las Plantas de Colombia. Instituto de Ciencias Naturales, Universidad Nacional de Colombia y University of Göttingen. Bogotá, Colombia. Pp. 1585-1664. 
Bachman, S. y J. Moat. 2012. GeoCAT an open source tool for rapid Red List assessments. http://geocat.kew.org (consultado febrero de 2018).

Baumgratz, J. F. A. 1985. Morfologia dos frutos e sementes de Melastomatáceas brasileiras. Arquivos do Jardim Botânico do Rio de Janeiro 27: 113-155.

Baumgratz, J. F. A., K. Fidanza, R. Bernardo, B. Chiavegatto, R. Goldenberg, P. J. F. Guimaraes, R. Kriebel, A. B. Martins, F. A. Michelangeli, M. Reginato, R. Romero, M. L. D`El Rei Souza y E. Woodgyer. 2010. Melastomataceae. In: Forzza, R. C., J. F. A. Baumgratz, C. E. M. Bicudo, A. A. Carvalho Jr., A. Costa, D. P. Costa, M. Hopkins, P. M. Leitman, L. G. Lohmann, L. C. Maia, G. Martinelli, M. Menezes, M. P. Morim, M. A. N. Coelho, A. L. Peixoto, J. R. Pirani, J. Prado, L. P. Queiroz, V. C. Souza, J. R. Stehmann, L. S. Sylvestre, B. M. T. Walter y D. Zappi (eds.). Catálogo de plantas e fungos do Brasil, Vol. 2. Instituto de Pesquisas Jardim Botanico do Rio de Janeiro. Rio de Janeiro, Brasil. Pp. 1236-1278.

Bentham, G. 1840. Contributions towards a flora of South America: Enumeration of plants collected by Mr. Schomburgk in British Guiana. Journal of Botany 2(14): 286-315.

Bonpland, A. 1823. Monographie des Mélastomacées, Vol. 2 Rhexies. In: Humboldt, A. de y A. Bonpland (eds.). Monographie des Mélastomacées. Paris, Francia. Pp. 1-158, pl. 1-60.

Calderón, E. 2011. Sobre el cultivo de Meriania hernandi en la reserva natural El Refugio. DeJardínes 1(2): 21-24.

Calderón, E. y H. Mendoza. 2000. Melastomatáceas de los géneros Axinaea, Blakea, Castratella, Centronia, Killipia, Meriania, Monochaetum, Ossaea y Tibouchina en Colombia. Biota Colombiana 1(3): 336-357.

Chiavegatto, B. y J. F. A. Baumgratz. 2009. Revisão Taxonômica do gênero Meriania Sw. (Melastomataceae) no Brasil. Tesis de doctorado. Instituto de Pesquisas Jardim Botânico do Rio de Janeiro, Escola Nacional de Botânica Tropical. Río de Janeiro, Brasil. 174 pp.

Chiavegatto, B. y J. F. A. Baumgratz. 2011. Typification and synonymy of Meriania species (MerianieaeMelastomataceae) from Brazil. Kew Bulletin 66: 167-169. DOI: https://doi.org/10.1007/s12225-010-9224-1

Cogniaux, A. 1891. Melastomatacées. In: A. y C. de Candolle (eds.). Monographie Phanerogamarum 7: 1-1256.

Cotton, E., F. Borchsenius y H. Balslev. 2014. A revision of Axinaea (Melastomataceae). Scientia Danica, Series B, Biologica,
Vol. 4. The Royal Danish Academy of Sciencesand Letters. Copenhague, Dinamarca. 120 pp.

De Candolle, A. P. de. 1828. Prodromus Systematis Naturalis Regni Vegetabilis, Pars 3. Sumptibus Sociorum Treuttel et Würtz. Paris, Francia. Pp. 99-102.

De Candolle, A. P. de. 1838. Collection De Mémoire Pour Servir À L'histoire Du Règne Végétal Et Plus Spécialement Pour Servir De Complément À Quelques Parties Du Prodromus Regni Vegetabilis, Pars 4. Treuttel et Würtz. Paris, Francia. pp. 17-19.

Dellinger, A. S., D. Penneys, Y. M. Staedler, L. Fragner, W. Weckwerth y J. Schönenberger. 2014. A specialized bird pollination system with a bellows mechanism for pollen transfer and staminal food body rewards. Current Biology 24(14): 16151619. DOI: https://doi.org/10.1016/j.cub.2014.05.056

Dellinger, A. S., M. Chartier, D. Fernández-Fernández, D. S. Penneys, M. Alvear, F. Almeda, F. A. Michelangeli, Y. Staedler, W. S. Armbruster y J. Schönenberger. 2018. Beyond buzzpollination-departures from an adaptive plateau lead to new pollination syndromes. New Phytologist 221(2): 11361149. DOI: https://doi.org/10.1111/nph.15468

Dellinger, A. S., L. M. Scheer, S. Artuso, D. Fernández-Fernández, F. Sornoza, D. S. Penneys, R. Tenhaken, S. Dötterl y J. Schönenberger. 2019a. Data from: Bimodal pollination systems in Andean Melastomataceae involving birds, bats and rodents. The American Naturalist 194(1): 104-116. DOI: https://doi.org/10.1086/703517

Dellinger, A. S., S. Artuso, S. Pamperl, F. A. Michelangeli, D. S. Penneys, D. M. Fernández-Fernández, M. Alvear, F. Almeda, W. S. Armbruster, Y. Staedler y J. Schönenberger. 2019b. Modularity increases rate of floral evolution and adaptive success for functionally specialized pollination systems. Communications Biology 2: 453. DOI: https://doi. org/10.1038/s42003-019-0697-7

Don, D. 1823. An illustration of the natural family of plants called Melastomataceae. Memoirs of the Wernerian Natural History Society 4: 285.

Don, G. 1832. A general history of the dichlamydeous plantsMelastomataceae, Vol. 2. J. G. and F. Rivington. London, UK. 722-806.

Endlicher, S. F. L. 1840. Genera plantarum secundum ordines naturales disposita-Melastomataceae, Vol. 16. F. Beck. Vindobonae, Austria. pp. 1205-1223. 
Fernández-Fernández, D. M., L. Jost y A. S. Dellinger. 2020. Two new species of Meriania (Melastomataceae) from eastern Ecuador. Phytotaxa 458(1): 1-14. DOI: https://doi. org/10.11646/phytotaxa.458.1.1

Fernández-Hilario, R., R. Goldenberg y F. A. Michelangeli. 2020. A new species of Meriania (Melastomataceae) with remarkably small flowers from northern Peru. Phytotaxa 456(1): 86-94. DOI: https://doi.org/10.11646/ phytotaxa.456.1.6

Gleason, H. A. 1941. Novelities in the Melastomataceae. Bulletin Torrey Botanical Club 68: 245.

Goldenberg, R., F. S. Meyer y F. A. Michelangeli. 2020. Taxonomic notes in Meriania (Melastomataceae) from the Brazilian Atlantic Forest, including a new species, a resurrected one and a new synonym. Phytotaxa 453(3): 218-232. DOI: https://doi.org/10.11646/phytotaxa.453.3.4

IUCN. 2017. Guidelines for using the International Union for Conservation of Nature Red list categories and criteria. Version 13. Prepared by the Standards and Petitions Subcommittee. http://www.iucnredlist.org/documents/ RedListGuidelines.pdf (consultado febrero de 2018).

IUCN. 2020. The International Union for Conservationof Nature Red List of Threatened Species. Version 2020-2. https:// www.iucnredlist.org (consultado julio de 2020).

JSTOR. 2018-presente. Global Plants database JSTOR. https:// plants.jstor.org/ (consultado en diciembre de 2019).

Lozano, G. y M. Alvear. 2001. Novedades en Axinaea y Meriania (Melastomataceae) de Colombia. Caldasia 23(1): 147-152.

Lukana, N. G. y P. E. Berry. 2001. Meriania Sw. (Melastomataceae). In: Berry, P. E., K. Yatskievych y B. K. Holst (eds.). Flora of Venezuelan Guayana, Vol. 6. Missouri Botanical Garden Press, St. Louis. Pp. 384-386.

Macbride, J. F. 1941. Melastomataceae. Field Museum of Natural History, Botanical Series 13, pt. 4: 327.

Martius, C. F. P. 1831. Nova Genera et Species Plantarum qua in intinere per Brasiliam. 3(3): 123-124.

Melastomataceae.Net. 2007-2018. A Site with Information on the Biodiversity of Melastomataceae. www.melastomataceae. net (consultado febrero de 2018).

Mendoza, H. 2011. Meriania selvaflorensis (Melastomataceae), una nueva especie lianescente de Colombia. Anales del Jardín Botánico de Madrid 68(2): 249-252. DOI: https://doi. org/10.3989/ajbm.2279
Mendoza, H. y B. Ramírez. 2006. Guía ilustrada de géneros de Melastomataceae y Memecylaceae de Colombia. Instituto de Investigación de Recursos Biológicos Alexander von Humboldt, Universidad del Cauca. Bogotá D.C., Colombia. 288 pp.

Mendoza-Cifuentes, H. y J. L. Fernández-Alonso. 2010. Evaluación de caracteres del cáliz y de los estambres en la tribu Merianieae (Melastomataceae) y definición de homologías. Revista de la Academia Colombiana de Ciencias Exactas, Físicas y Naturales 34(131): 143-172.

Mendoza-Cifuentes, H. y J. L. Fernández-Alonso. 2011. Análisis cladístico de Centronia (Merianieae/Melastomataceae) con base en caracteres morfológicos. Revista de la Academia Colombiana de Ciencias Exactas, Físicas y Naturales 35(137): 431-450.

Mendoza-Cifuentes, H. y J. L. Fernández-Alonso. 2012. Novedades en Centronia y Meriania (Merianieae, Melastomataceae) y revisión taxonómica de Meriania grupo Brachycera. Anales del Jardín Botánico de Madrid 69(2): 259-294.

Mendoza-Cifuentes, H., F. Almeda y M. Alvear. 2014. Novelties in Meriania (Melastomataceae: Merianieae) from Andean rainforests of Colombia. Phytotaxa 178(1): 23-32. DOI: http://dx.doi.org/10.11646/phytotaxa.178.1.2

Michelangeli, F. y E. Cotton. 2008. Melastomataceae. In: Hokche, O., P. Berry y O. Huber (eds.). Nuevo Catálogo de la Flora Vascular de Venezuela. Fundación Instituto Botánico de Venezuela Dr. Tobías Lasser. Caracas, Venezuela. Pp. 466-484.

Michelangeli, F., W. Camenate Reyes y K. Sosa. 2015. A revision of Meriania (Melastomataceae) in the Greater Antilles with emphasis on the status of the Cuban species. Brittonia 67(2): 118-137. DOI: https://doi.org/10.1007/s12228-0159366-4

Muchhala, N. y P. Jarrin-V. 2002. Flower visitation by bats in cloud forest of western Ecuador. Biotropica 34(3): 387-395. DOI: https://doi.org/10.1111/j.1744-7429.2002.tb00552.x

Naudin, C. V. 1852. Melastomacearum quae in Musaeo Parisiensi Continentur -Monographicae Descriptionis. Annales des Sciences Naturelles; Botanique, sér. 3, 18(2): 124-129.

Nixon, K. C. y Q. D. Wheeler. 1990. An amplification of the phylogenetic species concept. Cladistics 6: 211-224.

Ortíz Valdivieso, P. y R. Medina T. 2012. Algunas especies de Epidendrum (Orchidaceae) poco conocidas del Alto Putumayo. Orquideología 29(1): 15-22. 
Penneys, D. S. 2007. Phylogeny and character evolution in the Blakeeae (Melastomataceae). PhD Thesis. University of Florida. EUA. 176 pp.

Posada-Herrera, J. M., A. Idárraga y F. Alzate. 2020. A new species of Meriania of the Brachycera group (Melastomataceae: Merianieae) with dimorphic stamens. Phytotaxa 44(3): 225231. DOI: https://doi.org/10.11646/phytotaxa.442.3.8

Renner, S. S. 1999. Melastomataceae. In: Jorgensen, P. M. y S. Leon-Yanez (eds.). Catalogue of the Vascular Plants of Ecuador. Monographs in Systematic Botany from the Missouri Botanical Garden 75: 561-585.

Restrepo, H. F. 1994. Algunos aspectos sobre el síndrome de polinización en Meriania nobilis y Tibouchina lepidota (Melastomataceae). Tesis de grado. Departamento de Biología, Universidad de Antioquia. Medellín, Colombia. 80 pp.

Schulman, L. y J. Hyvönen. 2003. A cladistic analysis of Adelobotrys (Melastomataceae) based on morphology, with notes on generic limits whitin the Tribe Merianieae. Systematic Botany 28(4): 738-756.

Spach, E. 1835. L’histoire naturelle des vègètaux, Phanèrogames, Melastomataceae, Vol. 4. Librarie encyclopèdique de Rarete. Paris, Francia. pp. 202-277.

Swartz, O. 1798. Plantae Indiae Occidentalis. Flora Indiae Occidentalis 2: 1-823.

Triana, J. J. 1865. Dispositio Melastomacearum. Bulletin du Congrès International de Botanique et D’horticulture: 457461.

Triana, J. J. 1872(“1871"). Les Mélastomacées. Transactions of the Linnean Society of London 28: 1-188.

Tropicos. 2016. Tropicos.org. Missouri Botanical Garden. Missouri, EUA. https://www.tropicos.org/name/50300500 (consultado mayo de 2020).

Tropicos. 2020. Tropicos.org. Missouri Botanical Garden. Missouri, EUA. http://www.tropicos.org/Name/20304743 (consultado mayo de 2020).

Turland, N. J., J. H. Wiersema, F. R. Barrie, W. Greuter, D. L. Hawksworth, P. S. Herendeen, S. Knapp, W.-H. Kusber, D.-Z. Li, K. Marhold, T. W. May, J. McNeill, A. M. Monro, J. Prado, M. J. Price y G. F. Smith (eds.). 2018. International Code of Nomenclature for algae, fungi, and plants (Shenzhen Code) adopted by the Nineteenth International Botanical Congress Shenzhen, China, July, 2017. Regnum Vegetabile
159. Koeltz Botanical Books. Glashütten, Alemania. DOI: https://doi.org/10.12705/Code.2018

Ulloa Ulloa, C. y J. Homeir. 2008. Meriania franciscana (Melastomataceae), una especie nueva de los Andes de Ecuador. Anales del Jardín Botánico de Madrid 65(2): 383387.

Uribe, L. 1962. Sertula Florae Colombiae V. Caldasia 8(3): 532. Uribe, L. 1965. Sertulae Florae Colombiae, VIII. Caldasia 9: 324. Uribe, L. 1969. Sertula Florae Colombiae XI. Caldasia 10(48): 293.295.

Uribe, L. 1972. Catálogo ilustrado de las plantas de Cundinamarca. Vol. 5. Passifloraceae, Begoniaceae, Melastomataceae. Instituto de Ciencias Naturales, Universidad Nacional de Colombia, Bogotá, Colombia. 165 pp.

Van Der Hammen, T. y J. O. Rangel-Ch. 1997. El estudio de la vegetación en Colombia. In: Rangel, O., P. D. Lowy y M. Aguilar (eds.). Colombia-Diversidad Biótica II-Tipos de vegetación. Instituto de Ciencias Naturales/Universidad Nacional de Colombia; Instituto de Hidrología, Meteorología y de Estudio Ambientales (IDEAM). Bogotá, Colombia. Pp. 17-57.

Varassin, I. G., D. Penneys y F. Michelangeli. 2008. Comparative anatomy and morphology of nectar-producing Melastomataceae. Annals of Botany 102(6): 899-909. DOI: https://doi.org/10.1093/aob/mcn180

Vogel, S. 1997. Remarkable nectaries: structure, ecology, organophyletic perspectives-I, Substitutive nectaries. Flora 192: 305-333.

Walpers, G. G. 1846. Sinopsis Plantarum Escogenearum DialyPetalorum Suplementem Tertium. Lipsiae 5: 676-681.

Wurdack, J. 1957. Certamen Melastomataceis. Brittonia 9(2): 101-109.

Wurdack, J. 1967. Plants collected in Ecuador by W. H. Camp Melastomataceae. Memoirs of the New York Botanical Garden 16: 1-45.

Wurdack, J. 1973. Melastomataceae (Memecylaceae by T. Morley). In: Lasser, T. (ed.). Flora de Venezuela, No. 8. Instituto Botánico, Ministerio de Agricultura y Cría. Caracas, Venezuela. Pp. 1-819.

Wurdack, J. 1976. Certamen Melastomataceis XXV. Phytologia 35(1): 4.

Wurdack, J. 1978. Suplemento a la Melastomataceas de Venezuela. Acta Botánica Venezuelica 13(1-4): 133-134. 
Wurdack, J. 1980. Melastomataceae. In: Harling, G. y B. Sparre (eds.). Flora of Ecuador, No. 13. Universität Göteborg y Riksmuseum. Stockholm, Suecia. Pp. 1-406.

Wurdack, J. 1982. Certamen Melastomataceis XXXIV. Phytologia 50(5): 298.

Wurdack, J. 1984. Certamen Melastomataceis XXXVII. Phytologia 55(3): 132.
Wurdack, J. 1986. Atlas of hairs for Neotropical Melastomataceae. Smithsonian Contributions to Botany 63: 1-80.

Wurdack, J. 1988. Certamen Melastomataceis XXXVIII. Phytologia 64(4): 293-294.

Wurdack, J. 1993. Melastomataceae. Flora of the Guianas, Series A Phanerogams 13: 1-301. 